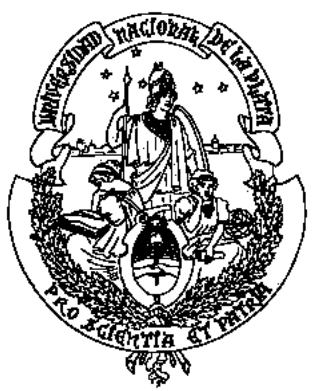

Universidad Nacional de La Plata

Facultad de Humanidades y Ciencias de la Educación

Secretaría de Posgrado

\title{
Con las mejores intenciones...
}

Estudio sobre las prácticas políticas de los jóvenes estudiantes en la actual escuela secundaria obligatoria, en un contexto de fragmentación social

Analía Elisabet Errobidart

\section{TOMO I}

Tesis para optar por el título de Doctora en Ciencias de la Educación

Directora: Dra Graciela Carbone, Universidad Nacional de Luján

Co- Directora: Dra Mónica De la Fare, Universidad Nacional de La Plata

27 de noviembre de 2014. 


\section{Resumen}

Este trabajo de investigación se ha propuesto indagar y comprender las prácticas asociadas con la construcción de una ciudadanía activa y participativa que desarrollan los jóvenes estudiantes en las escuelas secundarias seleccionadas, en la ciudad de Olavarría, durante el período 2009-2011.

Iniciado un proceso de reposicionamiento estatal, la Ley de Educación Nacional № 26.206 deposita en la escuela sus expectativas de formación de una ciudadanía activa, construida sobre la base jurídica de "igualdad de derechos". Las escuelas, como parte de un sistema educativo fragmentado, tienen serias dificultades para instituir normas democráticas e igualitarias en el marco del escenario social contemporáneo. En su interior se desarrollan prácticas sociales que revelan la contingencia de lo social caracterizado por la desigualdad y la fragmentación, situación que genera, para los jóvenes, diversas y desiguales posibilidades de producir acciones orientadas a la convivencia, la participación y la generación de demandas ante situaciones de conflictos irresueltos.

El formato del curriculum escolar, que mantiene en su desarrollo el peso de la historia de la escuela secundaria tradicional, pareciera, por momentos, constituirse en un obstáculo para sostener las nuevas relaciones pedagógicas y sociales necesarias para educar a los jóvenes como sujetos políticos.

Ya sea para comprender las disposiciones de los jóvenes como también la propuesta de la nueva LEN es preciso indicar que -a pesar de los nuevos aires democratizantes que surcan el cono sur del continente- sigue siendo necesario reflexionar sobre las nuevas formas de construcción de hegemonía neoliberal, de acuerdo con los posicionamientos que marcan reconocidos referentes de la Pedagogía Crítica (Apple, Torres, entre otros).

Palabras clave:

Jóvenes estudiantes- escuela secundaria - prácticas políticas- curriculum 


\section{Abstract}

This research work has been proposed to investigate and understand the practices associated with the construction of an active and participative citizenship developed by students in selected high schools, in Olavarría city, during the period 2009-2011.

Initiated the state repositioning process, the National Education Law $N^{\circ} 26206 / 06$ deposited in high school its expectations to develop an active citizenship, constructed on the juridical base of "equal rights". High schools, as part of a fragmented educative system, have serious difficulties to instruct democratic and equal rules in middle to the contemporary social scene. With they develop social practices that reveal the contingency of the social life characterized by the unequal and fragmented situation that produces for the youth, different and unequal possibilities to generate their own actions oriented to coexistence, participation and generation of demands in front of unresolved conflicts situations.

The school curriculum's format, that maintains in its development the weight of traditional high school history, seems, for moments, being built on an obstacle to sustain the new pedagogic and social relationships needed to educate students as politic subjects.

Either to understands the young dispositions so as the new LEN's proposal, it is necessary indicate that -in spite of the new democratizing airs that course across the continent- it's still necessary concern about the new ways of neoliberal hegemony construction, according with the positioning marked by Critical Pedagogy recognized referents (Apple, Torres, between others).

Key words:

Young students- secondary school- politics practices- curriculum 


\section{Dedicatorias y agradecimientos}

Dedico este trabajo -y el esfuerzo y los sueños implicados en él- a quienes de diversos modos están presentes en sus páginas.

De manera especial, a Alejandro (mi marido, mi compañero y mi más paciente sostén) y a mis hijas Eugenia, Nina y Emilia, tres soles que han colaborado conmigo en todo lo que ha estado a su alcance.

A mi mamá Yolanda y a mi papá Dardo (que ya no está, pero que me acompaña siempre), porque me hicieron fuerte y a la vez, sensible. Y a Ketty (mi suegra), que siempre me alienta a seguir adelante con mis proyectos.

A María Elsa porque es mi maestra.

A las compañeras del grupo IFIPRAC-Ed: a Stella, a Gabriela G, Constanza, Ana, Fabiana.

Muy especialmente a los jóvenes becarios y tesistas del GRUPO 5: Gabriela C., Paula, Anabela, Gastón, Marianela, Mariángeles, con quienes no dejo de aprender y de reir!

Mi agradecimiento hacia Graciela Carbone trasciende esta relación académica: ella ha acompañado y orientado mi trayectoria formativa desde 1999, en que aceptó dirigir mi tesis de maestría. A pesar de tantos años no logro aprender de su serenidad, su afectividad, la persistencia de sus convicciones y su firmeza. Es un modelo de ciudadana responsable y solidaria, de docente y de investigadora.

A Mónica de la Fare, de quien recibí las primeras orientaciones al ingresar al Doctorado de Cs. de la Educación de la UNLP, que fueron muy valiosas y significativas.

A los directivos, docentes y estudiantes con quienes compartí dos años de trabajo de campo, mates y asados.

Y a la Facultad de Ciencias Sociales de la UNICEN, donde aprendí a pensar la educación "desde otro lugar". 


\section{Contenido TOMO I:}

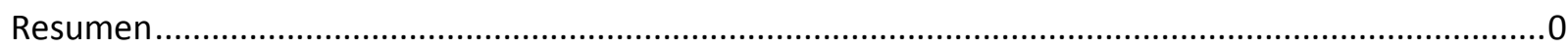

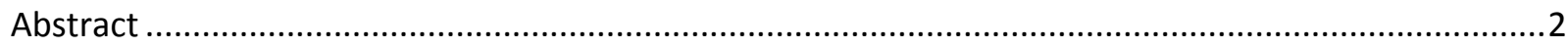

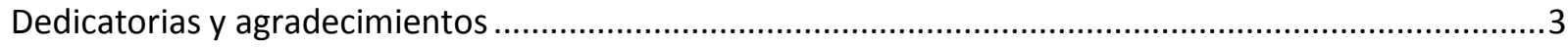

Anexo documental y metodológico (ver TOMO II) .............................................................................

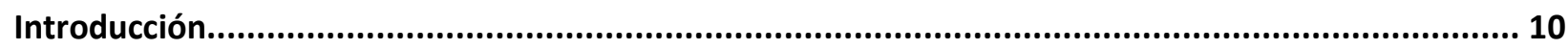

Ciudadanía, democracia y educación en los albores del siglo XXI .....................................................14

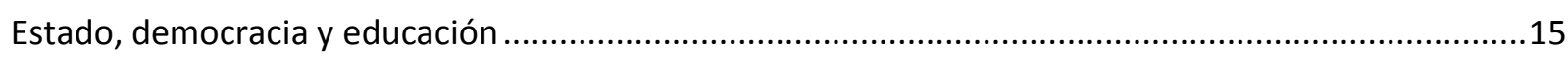

Ampliación de la obligatoriedad escolar para la inclusión social ...........................................................17

Algunas inquietudes acerca de los nuevos aires democratizantes ......................................................19

Un interés persistente por la dimensión política de la educación .........................................................20

Los jóvenes y la ciudadanía en los contextos escolares de la actualidad ............................................22

La trama sociopolítica en la que transcurrió la investigación .................................................................27

Desafíos de investigar las prácticas políticas que nos hablan de nuevas construcciones ciudadanas ...28

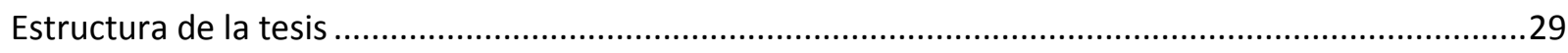

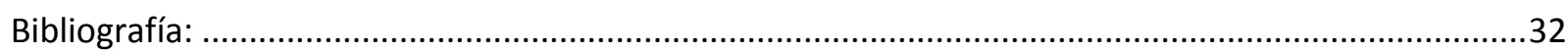

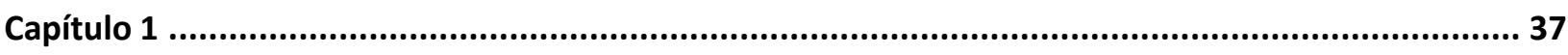

Investigar las prácticas políticas de los jóvenes estudiantes en una ciudad intermedia del centro de la provincia de Buenos Aires. Acerca del diseño de la investigación ............................................... 37

1.1.- Diseño teórico y metodológico de la investigación ............................................................................37

1.1.1. Campos disciplinares para abordar el tratamiento del problema ................................................42





1.1.4. Presentación del tema y formulación del problema de la investigación ......................................48

Preguntas de la investigación...................................................................................................52

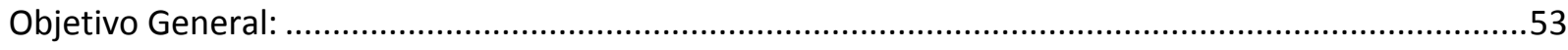

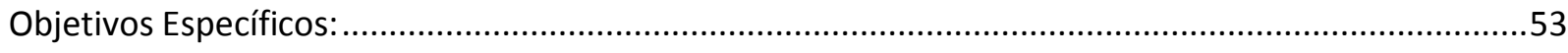

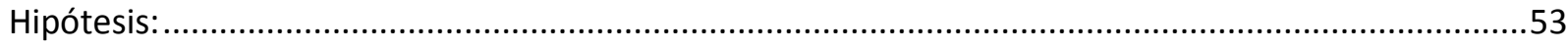



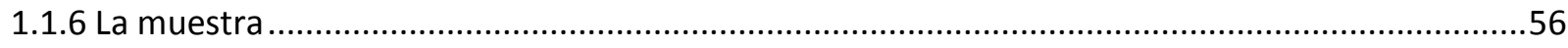

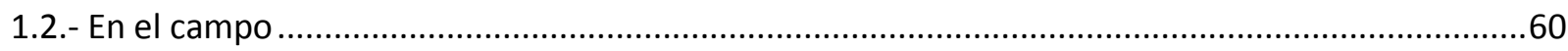

1.2.1 




1.1.3.-Acerca de la escritura de las prácticas para la elaboración del Informe de Investigación ...........74

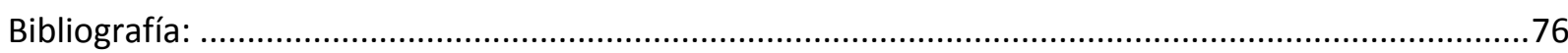



Los dilemas entre sujeto y estructura en la construcción de ciudadanía: interacción entre campos, sujetos en juego -y nuevas reglas del juego- en un contexto social contingente............................... 81

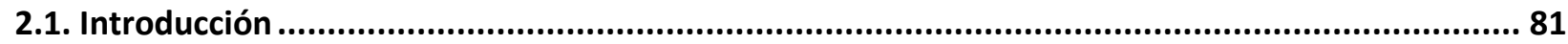

2.2. El campo educativo y sus propiedades en un contexto de cambio epocal..................................84

2.2.1 Transformaciones del Estado que impactan sobre el campo social ........................................86

2.2.2 La relevancia del Estado para el funcionamiento democrático de la sociedad ..........................88

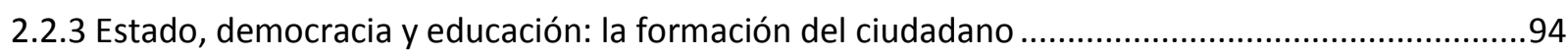

2.3. Los jóvenes en las escuelas secundarias: prácticas y estrategias políticas ..................................99

2.3.1 Acerca de los jóvenes como sujetos sociales contemporáneos..........................................100

2.3.1 1. La visibilización de los jóvenes y los estudios de juventud .............................................100

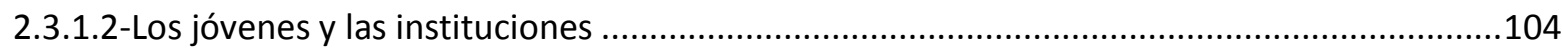

2.3.1.3-La situación actual de los jóvenes en Latinoamérica ...................................................107

2.3.2 Los jóvenes que integran la muestra ...................................................................... 109

2.3.3. Las estrategias políticas desarrolladas por los jóvenes en la escuela secundaria ....................112

2.4. La ciudadanía y su doble problemática, en crisis .......................................................114

2.4.1. Evolución histórica de la ciudadanía .........................................................................116

2.4.2 Los desafíos de la ciudadanía en un contexto social contingente .......................................121

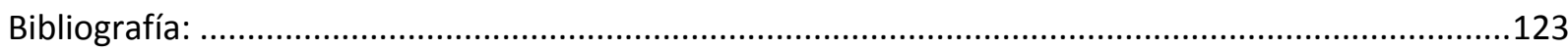

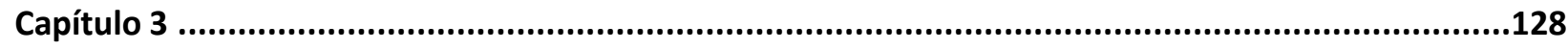

Historia, cultura y curriculum en la construcción de la ciudadanía en la escuela secundaria. 30 años de historia para comprender el presente ......................................................................128

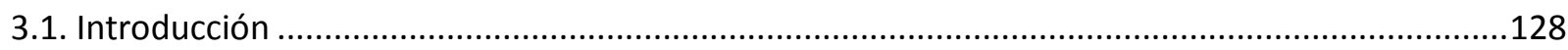

3.2. Historia, cultura escolar y curriculum en la escuela secundaria ............................................129

3.2.1. El desarrollo del curriculum y su práctica: algunas precisiones y delimitaciones.....................133

3.3. La política y a la formación ciudadana en el curriculum de la educación secundaria. Una revisión histórica para comprender el presente .................................................................142

3.3.3.1. Prescripciones curriculares y regulación del sistema provincial de educación......................159

3.3.3.2 Cuadro comparativo de las prácticas políticas formalizadas en las escuelas secundarias

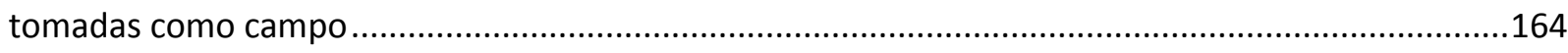


3.4. Nuevo reto a la historia, la cultura y el curriculum escolar 165

Bibliografía:

Capítulo 4:

La convivencia, entre lo legal y lo justo: prácticas que habilita y obtura la dinámica social de la escuela.

4.1. Introducción 171

4.2. Acerca de cómo se construye la vida común en las escuelas en estudio 175

4.2.1. El cambio de nivel como un encuentro/desencuentro con otros diferentes 175

4.2.2. La construcción del mundo común en una sociedad que individualiza 178

4.3. Convivencia y diferencia 182

4.3.1. El tratamiento de la diversidad en la escuela secundaria: cuestiones de sexualidad y género.182

4.3.2. Organizar la vida en común, pero entre iguales 190

4.4. Las implicancias de asumirse como "sujetos de derecho" en la construcción de la convivencia escolar..... 193

4.4.1. El valor de la enseñanza de los derechos y de la historia de la comunidad. 194

4.4.2. Los derechos que se reconocen por fuera de la escuela 197

4.4.3. Tensiones entre el disciplinamiento escolar y el discurso sobre los derechos de los jóvenes ..200

4.5. En búsqueda de reglas que organicen la vida en común .202

4.6. Acerca la convivencia posible que se enseña/se aprende en las escuelas .. 206

Bibliografia: 209

Capítulo 5:

La política y lo político en la participación juvenil en escuela secundaria básica: espacios que se habilitan, prácticas que tensionan las lógicas de la escuela

5.1. Introducción.

5.2. La participación de los jóvenes en los canales instituidos de formación política en la escuela secundaria

5.2.1. Perspectivas para comprender la participación política 214

5.2.2. Las prácticas políticas formales en las escuelas secundarias 217

5.2.2.1. Conquista y abandono de la política formal en la escuela: el caso de los CE 220

5.2.3. Los jóvenes y los espacios de participación que se habilitan desde el campo educativo y el campo de la política: los CE y el CDE.

5.2.4. La política y lo político en la materia Construcción de Ciudadanía.....

5.3. La desigualdad social que se expresa en la participación política en la escuela...... .248

Bibliografía: 
Capítulo 6:

Cuando la acción de los jóvenes desafía lo que la escuela puede procesar: absorción de la protesta juvenil o constitución de la demanda. Su impacto en la subjetividad de los jóvenes........................253

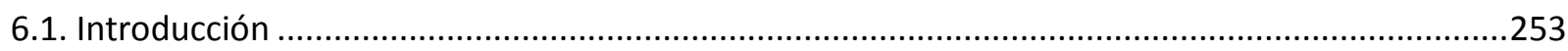

6.2. Acerca de la demanda y los sujetos sociales que participan de ella...........................................255

6.3. Cuando la institución escolar absorbe y cancela los reclamos de los jóvenes estudiantes...........259

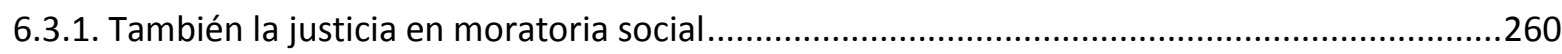

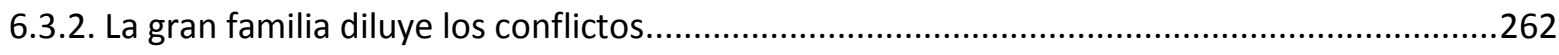

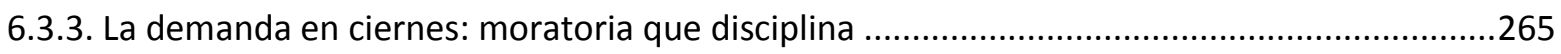

6.4. Fragmentación social que se reproduce en la escuela o ¿dónde está la escuela? .........................268

6.4.1. Una relación fragmentada y sedimentada en la cultura escolar que se construye desde la

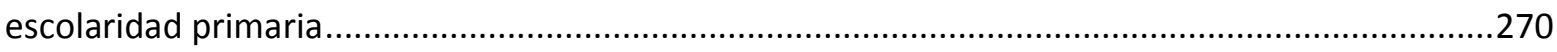

6.4.2. Una protesta espontánea y circunstancial descubre la debilidad de los lazos sociales entre

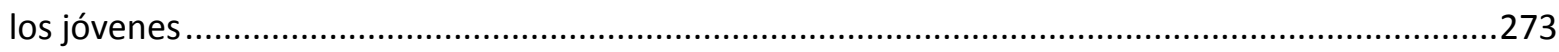

6.5. Reclamos que se constituyen en demanda: análisis de un caso .................................................275

6.5.1. “Queremos seguir estudiando, que por favor nos dejen" ....................................................276



6.6. El pasaje de sujetos sociales a sujetos políticos: la potencialidad de la demanda. .......................282

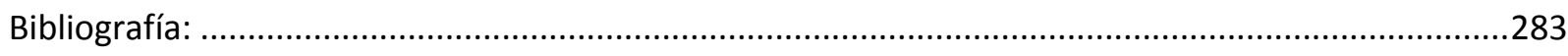



7.1. Primera recapitulación: en la convivencia escolar, los jóvenes redefinen la idea de lo común, lo

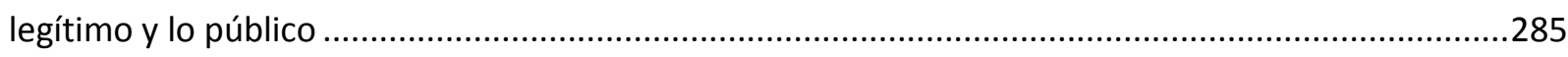

7.2. Segunda recapitulación: ¿participación política en la escuela o simplemente, participación

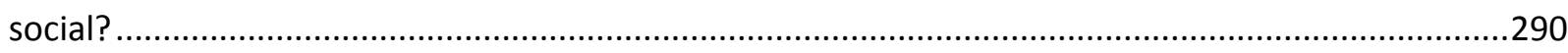

7.3. Tercera recapitulación: la constitución de los jóvenes como sujetos políticos .............................293

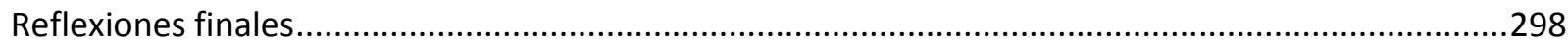




\section{Anexo documental y metodológico (ver TOMO II)}

Introducción

Anexo I: Glosario

\section{Anexo II: Marco Normativo}

Decretos

Leyes consultadas y mencionadas (en orden cronológico):

Ordenanzas y Resoluciones:

Documentos oficiales consultados y mencionados

\section{ANEXO III: Datos estadísticos}

Presentación

Anexo IV: Instrumentos metodológicos utilizados en la investigación

ANEXO V: Sistematización de los datos obtenidos de la aplicación de los instrumentos Presentación.

V.1: Sistematización de datos obtenidos a través de la encuesta

V.2: Sistematización de datos obtenidos a través de entrevistas a jóvenes

Presentación

ESB № 1. Escuela secundaria dependiente de la universidad.

ESB № 5. Escuela secundaria privada religiosa.

ESB № 6. Escuela secundaria centenaria

ESB № 7. Escuela secundaria suburbana.

ESB № 2010. Escuela secundaria rural.

V.3: Sistematización de datos obtenidos a través de la técnica de focus group

Presentación

Registro de temas relevantes para la investigación que surgen de la aplicación de la técnica de focus group

ESB № 1: escuela secundaria universitaria

ESB № 5: escuela secundaria privada confesional

ESN № 6: escuela secundaria centenaria

ESB № 10: escuela pública suburbana

ESB № 2010. Escuela secundaria rural.

V.4: Sistematización de datos obtenidos a través de entrevistas a docentes a cargo de la materia Construcción de Ciudadanía 
Presentación

V.5: Sistematización de datos relevantes obtenidos a través de entrevistas a directivos

V.6: Sistematización de la documentación curricular existente en las escuelas

Presentación

ANEXO VI: Selección de Notas periodísticas de diarios locales

ANEXO VII: Registro fotográfico 


\section{Introducción}

Con las mejores intenciones... estamos haciendo referencia a una reconocida frase de Oscar Wilde, "las peores obras son las que están hechas con las mejores intenciones". Con ella como metáfora, invirtiendo los términos la proposición, pretendemos mostrar los resultados de una investigación acerca de las prácticas políticas que han sido habilitadas por la nueva reforma educativa realizada en Argentina, a la luz de las sugestivas sugerencias de las usinas ideológicas del neoliberalismo para los países en vías de desarrollo que conforman la región sur de América Latina en el proceso de reposición estatal o segunda generación de reformas del Estado.

Las peores obras, refiere a la destrucción de la escuela pública y con ella, a los ideales modernos de igualdad y universalidad, destrucción lograda por el neoliberalismo a partir del cambio del sentido de lo común y lo público en el campo social y la preeminencia de la esfera económica por sobre la social. Las mejores intenciones... refieren a las alternativas que emprenden distintos gobiernos latinoamericanos (entre ellos, algunos gobiernos argentinos) aprovechando las recomendaciones y la retórica del empoderamiento que emanan de la usinas ideológicas del poder y de cuyo éxito nos permitimos desconfiar.

Los treinta años transcurridos desde la recuperación de la democracia en nuestro país hasta la actualidad, han sido el contexto de construcción de significados diversos en la sociedad en cuanto a posibilidades de organización social, fortalecimiento de la democracia como modo de vida, atención a la construcción de una ciudadanía plural y de encontrar un sentido justo y solidario para el futuro común de los argentinos y de los pueblos de la región sur de América Latina. Con ellos se comparten, a lo largo de la historia, modelos de Estado, de sociedades y estilos de asumir la democracia y la ciudadanía, en la búsqueda de estrategias que reparen las exclusiones históricas de esta región del continente. También, desde la década de los 70 del siglo anterior, se compartieron procesos de militarización y cruentas dictaduras que torcieron los caminos que -quizá- hubieran posibilitado otro destino para los pueblos, ahora sometidos por la política hegemónica del neoliberalismo. 
En Argentina, recuperada la vida democrática en 1983 y tras una breve transición jubilosa, asistimos progresivamente a un proceso de inclusión a un proyecto global, cuyas líneas decisorias se plasmaron en el consenso de Washington (1989). A partir de ello, la aplicación de las recomendaciones económicas de allí emanadas ha dejado como consecuencias cambios estructurales a nivel nacional y regional, un escenario social cambiante, diverso y fragmentado (Svampa, 2005), al compás de transformaciones profundas en la vida cotidiana de las personas y de las instituciones.

En ese contexto, la educación, que en nuestro país se caracterizó por su alcance universal e igualitarista a través de un sistema educativo público, gratuito y laico, comenzó a ser percibida -a través de operaciones de construcción de sentidos que bien describe J. Kenway (1994) para el caso australiano- como un bien al que los sujetos acceden individualmente. A partir de esta alteración de sentido fue posible el diseño de la conocida "transformación educativa" de corte neoliberal que se inició en los años '90, como uno de los indicadores de la reducción del gasto público y cambio de funciones del Estado. A partir de entonces, las políticas neoliberales diseñadas por los organismos internacionales que funcionan como usinas ideológicas del modelo político-económico global, orientan -con mayor o menor grado de incidencia- las reformas educativas del continente, que articulan con las particularidades contextuales en cada país.

En el contexto señalado $-y$ que será motivo de desarrollo en páginas subsiguientesasistimos en la actualidad a la puesta en marcha de una segunda reforma del sistema educativo y del sentido de la educación y, es en la trama de este proceso socio-histórico y cultural que tiene anclaje la investigación que se desarrollan en los próximos capítulos.

El propósito final del este estudio puede explicarse atendiendo a dos circunstancias problemáticas: por un lado, la existencia de una sociedad fragmentada y tendiente, progresivamente, a la polarización social, como el canon que marca la época; por otro, la emergencia, luego de la crisis socioeconómica y política del año 2001 , de un proyecto político que promete reivindicaciones sociales para los sectores excluidos, superando la 
versión paradigmática del neoliberalismo que sostiene la inclusión social a partir del "efecto derrame $^{1 \prime \prime}$, contraponiéndole el principio de justicia social. En términos sociológicos ambas circunstancias refieren a posicionamientos opuestos ante la nueva cuestión social ${ }^{2}$ : uno, atendiendo a la fuerza determinante de la estructura y el otro, atendiendo a la fuerza determinante de los sujetos. Esta investigación pretende asomarse a comprender cómo, en la vida cotidiana escolar, se articulan ambas posiciones a través de las prácticas políticas de los sujetos.

Reconocemos, junto a distintos investigadores del campo de las políticas sociales (Hintze (2007), Murillo (2006), Strada Rodriguez (2012)), la existencia de ciertas conexiones entre los discursos provenientes de organismos multilaterales como el Banco Mundial, OCDE (Organización para la Cooperación y el Desarrollo económico), y organizaciones como UNESCO (Naciones Unidas para la Educación, la Ciencia y la Organización Cultural), OEA (Organización de Estados Americanos), OIT (Organización Internacional del Trabajo) destinados a recomendar políticas sociales a los países en desarrollo desde fines del siglo pasado y los discursos contestatarios que componen las agendas políticas de las esferas gubernamentales de algunos países latinoamericanos, como es el caso de Argentina, desde 2003.

Acordamos con los estudios que expresan que, luego del fracaso de las reformas estructurales orientadas hacia el logro de un "Estado mínimo", la reposición del Estado impulsada por los mismos organismos internacionales que condujeron a la crisis anterior, aparece como una nueva oportunidad para los pueblos de América Latina (Calderón 2007). En ese escenario incierto, la segunda reforma del sistema educativo argentino, coloca en la escuela secundaria la responsabilidad superior de formar a los jóvenes como ciudadanos

\footnotetext{
${ }^{1}$ La Teoría del Derrame, en las políticas sociales, se asocia según Bonvecchi y Smulovitz a una visión derivada en su variante reactiva. Esto supone que los frutos del crecimiento económico se distribuyen por derrame desde los sectores económicos de mayores ingresos hacia los de menores ingresos. Para esta variante, la función central de la política social seria, entonces, facilitar el derrame. Y para ello es necesario estimular la actividad económica y preparar a la mano de obra para aprovechar el estímulo (Strada Rodriguez, 2012)

${ }^{2}$ En referencia a la problemática abordada por Pierre Rosanvallón (2007) puntualizamos en dos problemas concretos producto de la desintegración del modelo social industrial: la desintegración de los principios organizadores de la solidaridad y el fracaso de la concepción tradicional de los derechos sociales. Ambos problemas afectan, como señalaremos, a la construcción del sujeto político.
} 
activos, en un modelo político que reasigna al Estado el papel de garante de la inclusión social.

La referencia territorial en esta investigación está centrada en Argentina, en una ciudad intermedia de la provincia de Buenos Aires -tal como se explicita en el Capítulo 1, punto 1.1.5, pero tanto los desarrollos teóricos como los análisis del campo se han realizado observando la necesaria vinculación con los sucesos que se registran en los demás países de América Latina ${ }^{3}$.

Algunas ideas-claves nutridas en la teoría pedagógica crítica y de la resistencia con los estudios y aportes de autores como M. Apple (1979; 1997; 2012) y H. Giroux (1993, 1997 y 2012), han guiado el desarrollo de la investigación:

-abordar algunas vinculaciones entre Estado, democracia y educación nos acerca a la comprensión de los rumbos de las políticas educativas y su incidencia en decisiones a escala micropolítica, que afectan la vida cotidiana de los actores escolares

-la educación constituye un campo de fuerzas capaz de producir y reproducir desigualdad social pero a la vez, posibilita un espacio para la resistencia y la construcción colectiva de formas alternativas de "leer" el mundo y actuar en él

-la educación se presenta como una acción radical en el fortalecimiento de la democracia en la medida que esté sostenida en ideales como la igualdad y la justicia social

-los actores de los procesos educativos, en especial docentes y jóvenes, son concebidos como sujetos políticos no solo capaces de resistir a las imposiciones hegemónicas sino también como sujetos capaces de diseñar alternativas superadoras de la desigualdad y la exclusión

\footnotetext{
${ }^{3}$ Esta articulación se realiza atendiendo de manera especial la producción de conocimiento latinoamericana, sobre temáticas similares, que han sido consultadas.
} 


\section{Ciudadanía, democracia y educación en los albores del siglo XXI}

La relación entre ciudadanía, democracia y educación, constituye el marco interpretativo que, desde una perspectiva de análisis socio-político, se aborda en este trabajo de investigación. En un acercamiento sucesivo a las prácticas de los sujetos, el desarrollo teórico irá adquiriendo especificidades que conectarán, de manera dialógica, a la sociología de la educación, la política educativa y la sociología del curriculum.

Del campo disciplinar conocido como sociología de la educación, se seleccionan en especial los aportes de Pierre Bourdieu en relación a las estrategias de reproducción social que se desarrollan de manera relacional al interior del sistema educativo. El concepto de práctica social, central en nuestro diseño de investigación y en la articulación de las tres dimensiones en que se propone analizar el problema, presenta una doble estructuración: como sentido objetivo (objetivismo) y como sentido vivido (subjetivismo).

Las dimensiones que articula la práctica son: la contingencia del orden social que abre posibilidades a los sujetos y a la emergencia de lo político como diferente de la política; la transición a la educación secundaria obligatoria y los cambios curriculares prescriptos por la política educativa; la condición de "sujetos de derecho" de los jóvenes, que los posiciona, discursivamente, con una renovada condición en la escuela secundaria.

El concepto de práctica articula, a la vez, el campo de la sociología de la educación con el de la sociología del curriculum, en tanto se entiende al curriculum como el desarrollo de contenidos y prácticas (Gimeno Sacristán, [1988], 1994). Las prácticas vinculadas al curriculum comprende tanto a las prácticas explícitas como aquellas que permanecen solapadas y que han sido denominadas como curriculum oculto (Jackson, 1998). Un análisis realizado a partir de la sociología del curriculum permitirá comprender qué hay de nuevo en los discursos políticos y en las prácticas concretas que se desarrollan en las configuraciones escolares, en relación a la construcción de ciudadanía que realizan los jóvenes en el ámbito escolar.

A partir de los análisis realizados desde la perspectiva de la política educativa hemos comparado procesos de cambio de paradigmas educativos reflejados en leyes sancionadas 
en los últimos treinta años en Argentina. Las transformaciones impulsadas desde la política educativa promueven procesos de cambio curricular.

Entendemos, tal como lo plantean algunos estudios consultados (Gimeno Sacristán 1993) que la formación del ciudadano no se reduce a los contenidos ni a las estrategias didácticas que se ponen en práctica en cada asignatura específica, sino que remite al conjunto del curriculum en el que se expresa un proyecto educativo. En esta investigación será entendido así y, más aún, cuando el problema de la construcción de ciudadanía pretende analizarse a través de las prácticas que desarrollan los jóvenes estudiantes en situaciones escolares que son mediadas por la historia y la cultura institucional.

El énfasis puesto en el estudio de las prácticas que desarrollan los jóvenes en la escuela responde a la inquietud de interpretar la acción de los sujetos en las instituciones. Respondiendo a la lógica de la organización social moderna numerosas investigaciones sobre la escuela suelen silenciar las voces de quienes las transitan, como sostiene Duschatzky (1999). Si bien seguiremos los programas escolares, nos interesa especialmente poder penetrar en los sentidos que los jóvenes le imprimen a lo que ellos hacen en la escuela en relación a su construcción como sujetos políticos, cuyo proceso ya se ha iniciado en otros ámbitos como la familia, el barrio o la calle y sobre el que la escuela aporta -o no- a la producción de nuevas significaciones.

\section{Estado, democracia y educación}

Los cambios en las relaciones entre el Estado y las formas de organización social y política, nos instalan frente al desafío de indagar sobre las características de las tareas encomendadas a la educación en la formación de los ciudadanos.

La despolitización asociada a las nuevas democracias que ha instalado el neoliberalismo económico, produce también una forma de ciudadanía no problemática, vacía de política. Estas características han convertido a la ciudadanía en lo que O’Donnell (2004) llamó ciudadanías de baja intensidad.

En distintos países de Latinoamérica y luego de estallidos sociales producidos por la primera etapa de recorte de las funciones estatales en los años `90, se observan tendencias políticas 
que se orientan al reposicionamiento del Estado, asociadas a un discurso de que destaca el lugar de los ciudadanos en la construcción de nuevas alianzas entre el Estado y la sociedad civil. En esta segunda etapa de reforma del Estado capitalista (Oszlak, 1999), los discursos se inclinan a favor de un modelo de ciudadanía activa.

Los cambios en el Estado implican cambios en la democracia y en la educación. El neoliberalismo ha producido "la ruptura del pacto democrático, y se trata de ver qué papel juega hoy la educación en la formación de la ciudadanía, entendiendo que la escuela no es hoy el único espacio en el que se construye la ciudadanía" (Torres, 1994).

Siguiendo los estudios de O'Donnell (2004), hoy nos inclinamos por reconocer que en América Latina existen "democracias delegativas" que se caracterizan por una manera de concebir y ejercer el poder político, un funcionamiento deficitario de las instituciones, al igual que el incumplimiento de los derechos civiles, sociales y políticos de los ciudadanos. En ese escenario parecería dificultosoel pasaje desde una democracia delegativa, que conlleva un ejercicio formal de la ciudadanía, a una democracia participativa, que requiere del ejercicio de una ciudadanía activa, comprometida y solidaria.

A lo largo de las indagaciones teóricas realizadas y de la permanencia en el campo de la investigación, fueron cobrando significatividad algunos temas a través de los cuales se decidió comprender las prácticas políticas de los jóvenes en la vida cotidiana las escuelas secundarias, siguiendo las reflexiones metodológicas de Rockwell (2009). Esos temas -que condujeron a la construcción de las categorías teóricas resultantes del análisis interpretativo de los datos construidos en el trabajo de campo- son: participación, convivencia y demanda. El tipo de práctica ciudadana asociado al ejercicio de las categorías señaladas, se conoce como "ciudadanía sustantiva" (Bottomore, 1992) y alude al proceso por el cual los sujetos, en un proceso reflexivo, se reconocen a sí mismos como constructores de ciudadanía, esto es: activan el desarrollo de prácticas políticas (porque su acción disputa el poder presente en el campo).

Coincidimos con Torres cuando sostiene que los sujetos no nacen dispuestos al ejercicio político de la ciudadanía y que, por lo tanto, hay que educarlos en ello. "Tienen que ser educados en política democrática en una serie de formas, incluidos la fundamentación 
normativa, el comportamiento ético, el conocimiento del proceso democrático y el desempeño técnico" (Torres, C.A., 2001:22).

Esta tarea, que parece desmesurada, le ha sido encomendada a la escuela secundaria actual, ya que el Art. 30 de la Ley de Educación Nacional (LEN) expresa:

“La Educación Secundaria en todas sus modalidades y orientaciones tiene la finalidad de habilitar a los/las adolescentes y jóvenes para el ejercicio pleno de la ciudadanía, para el trabajo y para la continuación de estudios".

\section{Ampliación de la obligatoriedad escolar para la inclusión social}

En los escenarios sociales actuales, caracterizados por la fragmentación, la contradicción, la exclusión, la competencia y la pérdida de ideales que nos lleven a pensar en la plenitud de la humanidad, vamos a considerar el valor de la educación como una acción reconstructiva y, a la vez, performativa de cara al futuro. Paulo Freire ha considerado que la educación verdadera es praxis, reflexión y acción del hombre sobre el mundo para transformarlo (Freire, 1969). Una educación así entendida pone al servicio de la acción transformadora del sujeto la herencia social acumulada, el conocimiento y la técnica producidos a lo largo de la historia.

Cabe preguntarnos cómo es entendida la educación desde la perspectiva neoliberal, en relación a los aspectos económicos, sociales, culturales y, en especial, políticos. Buscamos respuestas realizando una breve reconstrucción del proceso a través del cual, en los últimos veinte años, se han impulsado en Argentina y en la región latinoamericana, reformas educativas en concordancia con los modelos de Estado que la política global ha impulsado.

En el marco de procesos internacionales y regionales orientados a recuperar la paz social tras la aplicación de las recetas del neoliberalismo salvaje, a partir del año 2003 se produce en Argentina-impulsado por el nuevo gobierno encabezado por N. Kirchner- un extenso debate acerca de la educación necesaria para

\footnotetext{
"recuperar la capacidad productiva del país, promoviendo la distribución del ingreso y el consumo interno como principales motores del crecimiento. En ese contexto, el trabajo formal y la educación debían convertirse en las herramientas más importantes de inclusión social plena" (Filmus y Kaplan, 2012: 17).
} 
Ese debate culmina en la sanción de la Ley de Educación Nacional (№ 26 266/2006).

La nueva Ley de Educación Nacional concebida por Filmus (op. cit) como un nuevo modelo educativo para un nuevo modelo socioeconómico, establece como medida distintiva $-\mathrm{y}$, a la vez como línea de continuidad con el proceso de extensión de la obligatoriedad de la educación, impulsada como tendencia mundial desde los ‘80 y `90-, la extensión de la escolaridad básica hasta la educación secundaria completa.

La nueva Ley se promulga bajo el mandato de inclusión social que viene, por un lado, con la intención de hacer cumplir un derecho largamente reconocido y, por otro, a paliar la situación de des-control social donde los jóvenes aparecen frecuentemente etiquetados como "peligrosos"-especialmente los jóvenes pobres o vinculados a situaciones delictivaspara quienes la escuela funcionará como instancia de inclusión social.

Frente a la nueva reforma educativa encontramos diversas posiciones -que si bien reconocen el valor inclusivo y justo del texto normativo- manifiestan su preocupación por las distancias que existen entre el texto prescripto (y los documentos emanados de los organismos intermedios como el Consejo Federal de Educación) y las condiciones contextuales en las que se aplica la LEN.

Autores como Filmus y Kaplan (2012), Kliksberg (2013) sostienen que la LEN ha venido a llenar una ausencia en el proceso histórico argentino, considerando que desde la generación del 80 hasta la fecha ninguna otra Ley Educativa había acompañado un proyecto de país de manera integral, orientándose al crecimiento económico y a la inclusión social.

"El modelo de desarrollo delineado por Kirchner en aquel discurso ${ }^{4}$ exigía que la educación retomara las funciones históricas que jamás debió abandonar: la escuela como herramienta fundamental para la construcción de la Nación y a partir de su capacidad de distribuir valores y conocimientos que cimientan la unidad nacional sobre la base de la identidad cultural de los argentinos; y la educación como factor de unidad y cohesión social sobre la base de la capacidad de favorecer la igualdad de oportunidades y posibilidades de acceso a saberes socialmente necesarios para todos, sin distinción" (Filmus, 2012: 19)

\footnotetext{
${ }^{4}$ Nota de la autora: se refiere al discurso de asunción del presidente N. Kirchner (2003)
} 
La perspectiva ideológica que ha acompañado al modelo político que se define como populismo encuentra correspondencia con algunos nuevos gobiernos del continente latinoamericano. El discurso y las medidas adoptas en los tiempos inmediatos que siguieron a la crisis neoliberal de principio de siglo fueron asociadas a una "refundación" (Svampa, 2008) de la política a través de la política social y las modificaciones de leyes fundamentales como la de educación, abriendo un nuevo lugar para los excluidos, en un nuevo estilo democrático.

\section{Algunas inquietudes acerca de los nuevos aires democratizantes}

Como es posible observar en diferentes ámbitos de acción del gobierno nacional (publicaciones de distinta índole: documentos de política pública, medios de comunicación, propaganda oficial, etc), el discurso político dominante en nuestro país en los últimos diez años destaca la reconfiguración de la política con una marcada participación de los jóvenes como un signo de estos tiempos, en sintonía con otros acontecimientos protagonizados por jóvenes en distintas partes del mundo ${ }^{5}$. Las prácticas políticas de los jóvenes, hasta hace poco tiempo invisibilizados y ellos mismos despreocupados por tales signos de participación, cobran una visibilidad desconocida.

En ese marco, la nueva LEN otorga a los jóvenes un protagonismo inusitado en los procesos educativos formales, a la vez que destaca la inclusión social como la función principal de la escuela secundaria. Se suma a ello, la formación para una ciudadanía activa capaz de sostener la democracia participativa que, de acuerdo con los discursos dominantes, comienza a construirse.

La pregunta por los distintos modos de construir ciudadanía de acuerdo a posiciones y disposiciones (Bourdieu, 2011) de los sujetos -los jóvenes- en el contexto de un sistema educativo fragmentado, ha orientado el desarrollo de esta investigación. Así queda expresado en la formulación de las preguntas y en el Objetivo General que se enuncian en el

\footnotetext{
${ }^{5}$ Una oportuna compilación de experiencias respecto de la "vuelta" de los jóvenes a la política, es realizada por José Natanson (2012) y por F. Saintout (2010), entre otros.
} 
Capítulo 1 (p: 52).Sostendremos que la desigualdad de las posiciones sociales imprime diferentes disposiciones en los sujetos tanto frente a la nueva "oferta" educativa, como a la obligatoriedad de la educación en el nivel secundario.

Ya sea para comprender las disposiciones de los jóvenes y también la propuesta de la nueva Ley de Educación Nacional, es preciso indicar que -a pesar de los nuevos aires democratizantes que surcan el cono sur del continente- sigue siendo necesario reflexionar sobre las nuevas formas de construcción de hegemonía neoliberal (Apple, 2012).

Por un lado, la reforma educativa del año 2006 se produce en un marco de reformas regionales y declaraciones globales que destacan el reconocimiento de derechos (individuales) largamente postergados en los sectores sociales más desfavorecidos. Al mismo tiempo, apelando a operaciones discursivas que articulan con matrices idiosincráticas de justicia social, se afianza el respaldo a la nueva Ley de Educación, que comienza a implementarse sin encarar los problemas sociales estructurales que la educación por sí sola sería incapaz de resolver (pobreza, exclusión, minimización del mercado laboral, entre otros). Del mismo modo, problemas específicos como el salario docente, la formación de los docentes, la creación de escuelas provistas de materiales y mobiliario, entre otros, quedan en una zona de indefinición, abriendo la posibilidad de duda respecto de las posibilidades concretas de materializar el cambio en el sentido que se enuncia.

No escapa a esta consideración -y será tema de debate en los próximos capítulos- la permanente necesidad de estar alerta ante las estrategias educativas y culturales -sobre la base de decisiones políticas y económicas- que instala el poder dominante global, en formas similares para las diferentes regiones del mundo capitalista y que se instalan y naturalizan progresivamente en el sentido común a partir del discurso oficial (Apple, 1979).

\section{Un interés persistente por la dimensión política de la educación}

La dimensión política de la educación es y ha sido uno de los aspectos centrales que han atraído el interés y ha marcado el curso de los diferentes trabajos realizados a lo largo de la trayectoria académica de la autora. También lo son la enseñanza y los jóvenes, destinatarios mayoritarios de los procesos educativos. 
En un trabajo anterior -la tesis de Maestría en Educación realizada en entre los años 20022004 (Errobidart, 2006)-, el objeto de estudio estaba focalizado en las prácticas comunicacionales que se establecen a través de procesos sistemáticos de enseñanza de la comunicación en el nivel secundario. El rango de las prácticas relevadas comprendía la amplitud del acto comunicativo posible de generarse en espacios y grupos de clase escolar donde preponderaban relaciones democráticas, hasta la negación del otro en espacios atravesados por actitudes profundamente autoritarias y verticalistas. Los casi diez años transcurridos, los cambios sociales y políticos acaecidos, inclinan el interés de esta investigación hacia las prácticas políticas constructoras de ciudadanía activa que se generan/producen en la escuela secundaria actual.

En estos días conceptos como: extensión de la obligatoriedad de la educación, formación ciudadana y política en perspectiva de derecho, participación política de los jóvenes, inclusión social en la escuela secundaria, entre otros, han sido instalados por el discurso oficial de la política educativa nacional. Tal discurso, constituido por conceptos entramados en las construcciones discursivas de las perspectivas críticas y emancipadoras, conlleva sin embargo, significaciones muy distantes de su origen crítico (Tamarit, 1998; Apple, 2012).

En tanto conceptos "constructores de sentido", las operaciones discursivas oficiales se constituyen como una referencia y, a la vez, un desafío para comprender cómo opera en las prácticas de los actores, cómo son resignificados por los jóvenes escolarizados, en un análisis que incluye el contexto -en tanto producto de un devenir socio-histórico- y la impronta individual y colectiva.

Considerando los diversos cambios y reestructuraciones del sentido de la vida social, cultural, política y económica que los sujetos se han visto compelidos a afrontar ante el cambio de funciones del Estado y sus instituciones, despiertan un particular interés los análisis realizados sobre "la condición de los jóvenes". Nuestra atención se centra, en particular, en la condición de sujetos políticos de los jóvenes en la escuela secundaria, considerando las apropiaciones que ellos han realizado en los planos político, social y cultural en procesos de socialización previos, constituidos en bagaje con el que ingresan a las 
escuelas secundarias, y las posibilidades de profundización de tales apropiaciones que las acciones educativas escolarizadas pueden realizar.

Este estudio se propone analizar las características que asumen las prácticas políticas y los sentidos acerca de la política que construyen los jóvenes en el contexto que conforma la nueva escuela secundaria, comprendida en el segmento de ampliación de la obligatoriedad escolar que establece la Ley de Educación Nacional № 26206/06. En ese contexto, la construcción de ciudadanía es enunciada por la política educativa como una cuestión de derecho, que sienta las bases para el ejercicio de una ciudadanía activa.

La extensión de la obligatoriedad de la escuela secundaria en Argentina formula como una de sus metas principales la formación de los jóvenes como ciudadanos, con un significado y una proyección hacia el empoderamiento de los sujetos inédita por su fuerza discursiva ${ }^{6}$ y la masividad en la cobertura que pretende.

Un análisis temprano de los derroteros que va siguiendo la formación de la ciudadanía en el marco de un renovado proceso, es una apuesta a la posibilidad de su mejora, porque como ya lo ha expresado Giroux (1993) "por el bien de la democracia, es preciso recuperar la educación ciudadana".

\section{Los jóvenes y la ciudadanía en los contextos escolares de la actualidad}

Estudios sobre jóvenes, sobre las relaciones de los jóvenes con la política y la ciudadanía, sobre la formación/construcción de la política y ciudadanía por parte de los jóvenes, se han constituido en un foco de interés para investigadores de distintos campos y en antecedentes valiosos para este estudio. Ante la amplitud de trabajos encontrados, a los efectos de registrar la literatura producida en el recorte temático vinculado con la investigación que se presenta, se tomaron como referencia los siguientes ejes:

1.- la emergencia de los jóvenes en el espacio público

\footnotetext{
${ }^{6}$ Los documentos oficiales -que se abordarán en el cuerpo de la tesis- refieren al ejercicio, en la escuela, de una ciudadanía activa, reflexiva y crítica.
} 
2.-las particularidades de las prácticas políticas de los jóvenes contemporáneos:

2.1. prácticas políticas ligadas al campo político y a las instituciones tradicionales/modernas

2.2. otras prácticas políticas que desbordan las instituciones modernas

3.-transformaciones en el campo educativo, en el nivel secundario y en el contexto curricular escolar

3.1. transformaciones del sistema educativo: a- diversificación y fragmentación del sistema educativo; $b$ - transición entre niveles del sistema educativo

3.2. transformaciones en el plano curricular y en la formación/construcción ciudadana de los jóvenes: a- investigaciones realizadas en otros países; b.investigaciones realizadas en argentina

Se organiza el estado del arte mencionando los aportes de los trabajos que se han considerado más significativos en relación a los ejes señalados, sin desconocer la amplitud de las discusiones producidas respecto de la reemergencia de los jóvenes en el contexto social, cultural y político, y sus diversas implicaciones. Se ha tomado como criterio, además, mencionar las obras consideradas para este fin como más relevantes y que serán citadas a lo largo del texto de la tesis, aunque sin ofrecer una síntesis o reseña de cada una. El hecho de omitir mencionar otros aportes, no significa desconocerlos, sino que representa ésta una opción metodológica en el armado del texto. De manera similar, se ha privilegiado el análisis de investigaciones producidas en los últimos 10 años $^{7}$, a excepción de algunas obras más antiguas que siguen teniendo vigencia para orientar y esclarecer este trabajo.

Han sido consultadas investigaciones sobre la emergencia de los jóvenes en el espacio público (Cháves y Faur, 2006; Cháves, 2009; Freixa, 1998; Kessler, 2004; Reguillo, 2000 y 2012; Saintout, 2009).Estos estudios permitieron identificar, a partir del período que se inicia después de transcurrida la segunda guerra mundial, ciertos aspectos de la transformación

\footnotetext{
${ }^{7}$ Se estipulan diez años, aunque los límites no son exactos, variando según la significatividad de los casos.
} 
social de principios del siglo XX, que contribuyeron a la emergencia de la juventud (y los estudios sobre la juventud): un mercado abierto al consumo juvenil, la programación de los medios masivos de comunicación -en especial la TV y el cine-, los cambios que se producen en la educación (señalando especialmente la incorporación a los niveles oficiales de la educación secundaria -en Europa y EEUU), aspecto que dio paso al ingreso masivo a los estudios superiores). Todos esos aspectos $-\mathrm{y}$ otros que no son mencionados aquí-, han contribuido a problematizar al reconocimiento de los jóvenes como actores sociales.

En América latina, los jóvenes son visibilizados como fuerza social, varios años más tarde. Las décadas de los 60 y 70 dan cuenta de la existencia y autonomía de este grupo social que al interior de la categoría juventud, se presenta como diverso. Un tema presente en la memoria histórica de los estudios del período 80-90 son las secuelas que las dictaduras militares que recorrieron el continente latinoamericano dejaron sobre las nuevas generaciones.

Transcurridas las décadas de los años 80 y 90, en que los jóvenes se visualizan especialmente por sus prácticas de consumo (culturales y materiales) y una cierta "desaparición" de la escena política. Es por ello que, las tendencias actuales en los estudios sobre jóvenes en un proceso de cambio epocal que torna contingente lo social y lo político, los ubican en un escenario de re-emergencia de los jóvenes en la política.

Ha sido definido otro eje de análisis de los estudios de juventud, recortando y agrupando aquellos estudios que refieren a las particularidades de las prácticas políticas de los jóvenes contemporáneos. Distinguimos dos tendencias: los que adoptan una definición de la política que se circunscribe al concepto clásico que discute y tensiona las relaciones con el poder y sus circuitos institucionalizados, y otros estudios que refieren a las prácticas políticas de los jóvenes que desafían las lógicas instituidas.

En relación a los primeros, frente a las voces que exponen un rechazo y alejamiento de los jóvenes de la política (Beck, 2002), los estudios realizados por Natanson (2012), Rossi (2009), Saintout (2010), entre otros, expresan una "vuelta de los jóvenes a la política", analizando las condiciones de ese reencuentro en el marco de las cuestionadas instituciones de la modernidad. 
Los estudios mencionados en segundo orden, resultan ser de alta significatividad para esta investigación, y son aquellos que problematizan las prácticas políticas de los jóvenes en los contextos escolares del nivel secundario. Dentro de este grupo, se identifican las investigaciones realizadas por Kriger (2010), Mayer (2009), Núñez (2013) quienes relevan prácticas políticas en el contexto de la escuela secundaria, que escapan a los circuitos formales por donde se entiende y encausa la política en la escuela, analizando las nuevas experiencias y su potencial performatividad. La política, como práctica social -y como se ha expresado en los puntos anteriores-, es un componente esencial de la ciudadanía, y es por ello que se mencionan como relevantes los trabajos citados. El trabajo de Núñez, que aborda en el desencuentro entre escuela y culturas juveniles temas como la convivencia y la organización estudiantil, aporta referencias sobre nuevas formas de vivir la política en la escuela.

Finalmente, otro grupo de estudios incorpora en su análisis el tratamiento escolar de la ciudadanía. Se tienen en cuenta diferentes aportes: los que refieren al nivel de las transformaciones del nivel educativo secundario $y$ los que junto con tales transformaciones, analizan las particularidades del desarrollo curricular en torno de la ciudadanía.

Otras investigaciones consultadas analizan los procesos de cambio que experimentan los sistemas educativos a partir de las decisiones políticas de ampliar la extensión de la obligatoriedad educativa, y a partir de ellas se asumieron perspectivas claves para esta investigación. En ese sentido, el concepto de fragmentación del sistema educativo, desarrollado por Tiramonti (2004), a partir de su diferenciación de un estudio pionero realizado por Braslavsky (1985) que daba cuenta de un sistema educativo segmentado, han resultado relevantes tanto para la formulación de las preguntas de la investigación, como también para el análisis de los datos construidos durante el trabajo de campo ${ }^{8}$.

\footnotetext{
${ }^{8}$ Una gran cantidad de trabajos de investigación sobre el sistema educativo y el estallido de la escuela media se registran en los primeros años del nuevo siglo. Si bien no se mencionan especialmente en esta introducción, algunos de ellos serán referidos en el desarrollo del trabajo.
} 
Un estudio de carácter nacional coordinado por Dussel (2007) en los primeros pasos de la "vuelta al secundario", nos informa acerca de la necesidad de democratizar las relaciones al interior de las escuelas, tanto en la voz de los alumnos como de algunos docentes que ofician de "portavoces". Además, la investigación se sitúa en un claro diagnóstico de los problemas que aquejan a la escuela secundaria "estallada", "fragmentada", pero aun así, elegida como ámbito de contención y aprendizajes (variados) por los jóvenes.

Un aporte singular se reconoce en la investigación coordinada por J. Gimeno Sacristán (1999) que analiza la transición entre la Educación Primaria y la Secundaria, considerando diferentes planos: cultural, curricular e institucional. Sus aportes resultan relevantes considerando en especial el impacto que tiene este "pasaje" de nivel, para los niños de los sectores populares que no cuentan con una tradición familiar o comunitaria que acompañe esta nueva situación.

Respecto al análisis curricular (tanto en el análisis de los contenidos como en el proceso de su desarrollo) y de las prácticas de enseñanza-aprendizaje explícitas en torno de la ciudadanía, no se han hallado investigaciones locales. En primer lugar, cabe señalar que a partir de las transformaciones del sistema educativo que produce la LFE, la ampliación de la obligatoriedad se produjo aumentando la cantidad de años en el nivel primario (nueve años en total), incorporando los primeros años que correspondían al nivel secundario. Así, los CBC para la Formación Ética y ciudadana son vinculados a los demás bloques temáticos y su enseñanza queda atrapada en la lógica institucional de la escolaridad primaria. Sin embargo, estudios como los realizados por Caffarelli (2008), Milstein (2009), nos permiten advertir que lo político, como dimensión de la civilidad y sentido de las prácticas de los sujetos miembros de una comunidad educativa en democracia, se manifiesta en la escuela dando cuenta, precisamente, de los cambios operados en el Estado y la democracia, en la primera década del nuevo siglo.

Otro aporte que se recoge de esos estudios sobre las transformaciones del nivel secundario y del curriculum advierte sobre la fragmentación social del sistema educativo pero también sobre el "quiebre" que se hace evidente en el pasaje de un nivel a otro, en tanto pone en evidencia el deterioro de la formación en la educación primaria. 
Sobre la construcción ciudadana orientada por la política curricular, se han relevado valiosos estudios realizados a partir de tesis doctorales en diversas universidades de España (Universidad de Madrid, Universidad de Barcelona, Universidad de Castilla), en el marco de la nueva $\operatorname{LOE}^{9}$. En ellas se abordan distintos problemas que presenta la incorporación casi "mesiánica" (Escudero Rodríguez, 2011) de la formación de la ciudadanía en el contexto escolar, frente al individualismo y consumismo imperantes.

En investigaciones realizadas en los años superiores de la educación primaria, estudios realizados en América Latina (Arango Correa, 2008; Peralta Duque, 2009) señalan la distancia entre las prescripciones curriculares que enuncian nuevas condiciones complejas y contemporáneas de la ciudadanía, y las estructuras institucionales y subjetivas que permanecen ancladas en un modelo anterior.

En síntesis: si como sostiene (R. Reguillo Cruz, 2012:12), los jóvenes son "un importante espejo que permite analizar hacia donde se mueve la sociedad", este estudio pretende capturar las formaciones sociales y políticas que se desarrollan en relación a la construcción de ciudadanía, entramados en el contexto de la escuela secundaria actual.

Los jóvenes no constituyen hoy una categoría unívoca ni son sus prácticas portadoras de significados compartidos por quienes participan en los mismos espacios y expresiones, pero tampoco la escuela, como espacio público, es portadora de ya de mandatos universales e igualitaristas.

\section{La trama sociopolítica en la que transcurrió la investigación}

En relación a la investigación en educación, nos interesa señalar que en la actualidad, la diversidad de puntos de vista y regímenes de significación presentes en el campo disciplinar, colocan a las investigaciones en educación principalmente en dilemas entramados en la relación conocimiento- sociedad - política (Carli, 2006). Y que, a su vez, tales investigaciones requieren considerar los cambios contemporáneos en los planos social, económico, cultural y político.

\footnotetext{
${ }^{9}$ En España, Ley Orgánica de Educación 2/2006
} 
Parece necesario indicar, atendiendo a lo anteriormente señalado, que los momentos en que se definía el problema de la investigación y se realizaban los primeros avances para definir un campo y la existencia del problema en su real complejidad, coincidió con el período de transición entre el gobierno de Néstor y Cristina Kirchner, en el año 2008. El inicio del nuevo gobierno estaba signado por una serie de demandas que se habían gestado en el período que le antecedía: normalidad institucional, atención a demandas insatisfechas producto de la fragmentación social producida en los años '90, concreción de las promesas surgidas por el espacio de crítica al modelo neoliberal que instala el kirchnerismo (Svampa, 2008). El tratamiento de la política y la educación, resultan dos procesos centrales para la construcción discursiva que se construye desde el nuevo gobierno.

Estos aspectos contextuales, relevantes para comprender la trama de las prácticas de los jóvenes en las escuelas, son abordados con profundidad en el Capítulo 2, punto 2.2.

\section{Desafíos de investigar las prácticas políticas que nos hablan de nuevas construcciones ciudadanas}

Un análisis de las prácticas políticas de los jóvenes en el espacio público que es la escuela, nos remite a considerar los aportes que desde el campo de la sociología realizan Bourdieu y Wacquant reflexionando sobre los problemas que se presentan en diferentes momentos de la investigación.

Para su estudio se toman en cuenta las reflexiones de Wacquant (2005:14) cuando, revisando el pensamiento de Bourdieu en relación a la sociología, la política y la democracia, expresa que es necesario realizar una

“...sistemática excavación de las condiciones sociales de la posibilidad de las prácticas democráticas, que requiere de un doble giro en el enfoque. Primero, exige que descendamos del cielo de las ideas abstractas e ideales elevados (...) para explorar el suelo de las realmente existentes conductas, significaciones y organizaciones políticas; y segundo, que no solo localicemos las capacidades políticas inscriptas en las estructuras formales, sino también las diversas inclinaciones y expectativas de actores concretos y cómo estos llegan a estar dotados o no de las categorías, aptitudes y deseos que se exigen para participar del juego democrático". 
En relación al problema de la investigación, el primer giro del enfoque presentado, nos remite a la cuestión de construcción sociológica en la tensión entre sujetos y estructura en contexto socio histórico, proponiéndonos el ejercicio de indagar en las prácticas de los sujetos y las organizaciones.

En el contexto escolarizado, este aspecto podría confrontar con cierta normatividad pedagógico-política, por la cual los agentes del sistema tienden a considerar que si algo ha sido prescripto, se traducirá -sin más- en unas prácticas orientadas a tales fines. Este modus operandis de la tecnocracia educativa hecho discurso en los agentes, podría confundir en la lectura de la realidad si no realizamos un distanciamiento y una vigilancia necesaria para captar la diferencia entre el discurso (de la estructura y de ciertos agentes) y las prácticas de los sujetos que se relacionan en las escuelas singulares. Principalmente, porque una lectura ingenua podría colisionar con las acciones de los jóvenes que presionan por alterar la dinámica del contexto escolar.

El segundo giro de la cita nos invita a relevar no solo las instancias de manifestación y significación de la política que habilita la estructura formal, sino las diferentes concepciones acerca de la política y lo político que expresan los sujetos de acuerdo con las distintas posiciones que detentan en el campo social y político y, a partir de ello, buscar comprender cómo es posible la construcción de habilidades para desempeñarse con una actitud activa, en la vida democrática.

Como se ha expresado anteriormente, las decisiones sobre los cambios en la educación se relacionan dinámicamente con un modelo de Estado, de democracia y de ciudadanía, y no puede desconocerse que los jóvenes, la escuela y la sociedad no pueden definirse prescindiendo de las tramas socio-históricas en que se construyen.

\section{Estructura de la tesis}

La tesis está compuesta por seis capítulos y las conclusiones.

En el Capítulo 1 se presenta el diseño teórico y metodológico de la investigación, además de justificar el ámbito del estudio. Ante las transformaciones producidas en el paradigma social 
sostenido por un Estado organizador y regulador de la vida política y, por lo tanto, de la formación de la ciudadanía a través de instituciones especializadas como la escuela, se plantea la pregunta principal que sintetiza el problema que se va a investigar:

-¿Cómo construyen su condición de ciudadanos los jóvenes que asisten a la Escuela Secundaria Básica -obligatoria- en la ciudad de Olavarría, en tiempos de profunda desigualdad social?

El Capítulo 2 aborda los debates y la perspectiva teórica general que presenta el problema en estudio. En este capítulo se presentan las relaciones entre los principales conceptos con que se define el problema en estudio: las prácticas políticas que expresan cómo los jóvenes se construyen como ciudadanos en el contexto de la escuela secundaria actual. Partimos de suponer que la escuela es una de esas instituciones que han gravitado significativamente en la formación de los ciudadanos, que ve alterada su función y su sentido.

El problema teórico que orienta la investigación se ubica en la dinámica que adquieren los cambios de los campos social, político y educativo, analizada principalmente desde la perspectiva relacional desarrollada por $\mathrm{P}$. Bourdieu.

Respecto del Capítulo 3, en él se desarrolla la formación de la ciudadanía y las prácticas políticas en el desarrollo curricular de la escuela secundaria. Se presenta un análisis de política educativa en su relación con los diseños curriculares producidos en los últimos 30 años, para el grupo de contenidos vinculados a la formación/construcción de ciudadanía. Se analizan por un lado, los documentos curriculares en tanto disposiciones prescriptivas que orientan la acción escolar, los dispositivos propuestos para su desarrollo y concreción, y las prácticas que se producen a partir de ellos, en las cinco escuelas secundarias seleccionadas como campo de la investigación.

En los capítulos 4, 5 y 6 se analizan los datos construidos durante el trabajo de campo, atendiendo a las tres categorías que se construyen y con las que se identifica a la ciudadanía activa, colocando en primer plano las prácticas de los jóvenes. En el capítulo 4 se analiza la convivencia como construcción fundamental de la vida en común, analizando las tensiones, interacciones y conflictos en la vida cotidiana escolar, y las reflexiones de los sujetos. 
En el capítulo 5 se analiza la política y lo político en la participación juvenil en escuela secundaria básica: espacios que se habilitan, prácticas que tensionan las lógicas de la escuela, atendiendo a ¿Cómo y por qué los jóvenes deciden su participación en cuestiones políticas y qué significación adquiere para ellos?. Respecto del Capítulo 6, este capítulo aborda la acción de los jóvenes que desafía aquello que la escuela puede procesar, y emprende acciones para realizar una absorción de la protesta juvenil o constitución de la demanda.

Finalmente, se presentan las conclusiones y proposiciones a las que se arriba luego de haber realizado el proceso de investigación.

Se acompaña este texto con un anexo documental que se presenta en otro tomo. 


\section{Bibliografía:}

APPLE, M. (1979). Ideología y currículo. Akal, Madrid.

- (1997). Teoría crítica y educación. Miño y Dávila, Buenos Aires.

-(2012). Poder, conocimiento y reforma educacional. Apple, Alzamora y

Capagno (edit). Universidad Nacional de La Pampa, Santa Rosa.

ARANGO CORREA, L. (2008). Representaciones y prácticas sobre ciudadanía en estudiantes de octavo grado de educación básica secundaria de tres planteles educativos pertenecientes a estratos sociales diferentes. Tesis de Maestría. Universidad de Antioquía. Colombia. Consultado el día 4 de junio de 2013 en:

http://tesis.udea.edu.co/dspace/bitstream/10495/445/1/RepresentacionesPracticasCiudada nia.pdf

BECK, U. (comp) (2002). Hijos de la libertad. FCE, México.

BOBBIO, N. (1993). Igualdad y libertad. Paidos, Barcelona.

BOTTOMORE, Th. (1992): “Ciudadanía y clase social, cuarenta años después" En: Marshall y Bottomore, Ciudadanía y clase social. Alianza, Madrid

BOURDIEU, P. (2011). Las estrategias de la reproducción social. Siglo XXI, Buenos Aires.

BRASLAVSKY, C. (1985). La discriminación educativa en Argentina. FLACSO_Gel, Buenos Aires.

CAFFARELLI, C. (2008). Condenados al éxito. Inclusión educativa en sectores vulnerables. Dunken, Buenos Aires.

CALDERON, F. (2007). Ciudadanía y desarrollo humano. PNUD- Siglo XXI, Argentina.

CARLI, S. (2006). "La investigación en educación en Argentina" en Cuadernos de Educación Año IV, número 4. Córdoba, Noviembre 2006. (pp. 11 a 21)

CHÁVES, M. (2009). Jóvenes, territorios y complicidades. Una antropología de la juventud urbana. Espacio editorial, Buenos Aires.

CHAVES, M. Y FAUR, E. (2006). Informe: investigaciones sobre juventudes en Argentina: estado del arte en ciencias sociales. IDAES- USAM, Argentina.

DUSCHATZKY, S. (1999). La escuela como frontera. Reflexiones sobre la experiencia escolar de jóvenes de sectores populares. Paidós, Buenos Aires. 
DUSSELL, I; BRITO, A. y NUÑEZ, P (2007). Más allá de la crisis. Visión de alumnos y profesores de la escuela secundaria argentina. Santillana, Buenos Aires.

ERROBIDART, A. (2006). “...de los conocimientos a las prácticas. Configuraciones sociales y didácticas la enseñanza de la Comunicación Social. Estudio realizado con practicantes del Profesorado de Comunicación Social de Olavarría". Tesis de Maestría. Inédita.

ESCUDERO RODRÍGUEZ, A. (2011). Ciudadanía y educación para la ciudadanía. Universidad de Castilla. España. Tesis doctoral. Consultada 4 de junio de 2013 en:

https://ruidera.uclm.es/xmlui/bitstream/handle/10578/2956/TESIS\%20Escudero\%20Rodr\% C3\%ADguez.pdf?sequence $=1$

FILMUS, D. (1997). La descentralización educativa en Argentina: elementos para el análisis de un proceso abierto. Coloquio Regional sobre Descentralización de la Educación en América Central, Cuba y República Dominicana (1997 Nov. 3-5: San José).-CLAD; Países Bajos. Gobierno Nacional; Costa Rica. Ministerio de Planificación Nacional y Política Económica; Costa Rica. Ministerio de Educación Pública.

FILMUS, D. y KAPLAN, C. (2012). Educar para una sociedad más justa. Debates y desafíos de la Ley de Educación Nacional. Aguilar, Buenos Aires.

FREIRE, P. (1969). La educación como práctica de la libertad. Siglo XXI, Buenos Aires.

FEIXA, C. (1998). De jóvenes, bandas y tribus. Ariel, Barcelona.

GIMENO SACRISTÁN, J. [1988](1994). El curriculum: una reflexión sobre la práctica. Morata, Barcelona.

GIMENO SACRISTAN, J. y PEREZ GOMEZ; A. (1993): Comprender y transformar la enseñanza. Morata: Madrid.

GIMENO SACRISTÁN, J. (1999). La transición a la educación secundaria. Morata, Madrid.

GIROUX, H. (1993). La escuela y la lucha por la ciudadanía. Siglo XXI, México.

(1997). Cruzando límites. Trabajadores culturales y políticas educativas. Paidós,

Buenos Aires

- (2012). La educación y la crisis del valor de lo público. Desafiando la agresión a los docentes, los estudiantes y la educación pública. Criatura editora, Montevideo.

HINTZE, S.(2007).Políticas Sociales argentinas en el cambio de siglo. Conjeturas sobre lo posible. Espacio Editorial, Buenos Aires.

JACKSON, Ph. (1998). La vida en las aulas. Morata, Madrid. 
KENWAY, J. (1994). "La educación y el discurso político de la Nueva Derecha" En Ball, S (comp): Foucault y la educación. Disciplinas y saber. Morata, Madrid.

KESSLER, G. (2004). Sociología del delito amateur. Paidós. Buenos Aires.

KLIKSBERG, B. (2013): Conferencia de apertura en el XV World Congress on Comparative Education, Facultad de Ciencias Económicas, Buenos Aires 2013.

KRIGER, M. (2010). Jóvenes de escarapelas tomar. Escolaridad, comprensión histórica y formación política en la Argentina contemporánea. Facultad de Periodismo y Comunicación Social. Observatorio de Jóvenes, Comunicación y Medios. UNLP. La Plata.

LEWKOWICZ, I. (2004). “Escuela y ciudadanía” En: Corea, C. y Lewkowicz, I. Pedagogía del Aburrido. Escuelas destituidas, familias perplejas. Paidós, Buenos Aires.

MARTíN BARBERO, J. (2012). Culturas, tecnicidades, comunicación. En OEl: www.oei.es/cultura2/barbero.htm

MAYER, L. (2009). Hijos de la democracia ¿Cómo piensan y viven los jóvenes hoy? Paidós, Buenos Aires.

MILSTEIN, D. (2009). La Nación en la escuela. Viejas y nuevas tensiones políticas. Miño y Dávila, Buenos Aires.

MURILLO, S. (coord.).(2006).Banco Mundial. Estado, mercado y sujetos en las nuevas estrategias frente a la cuestión social. Ediciones del CCC, Buenos Aires.

NATANSON, J. (2012). ¿Por qué los jóvenes están volviendo a la política? De los Indignados a La Cámpora. Debate, Buenos Aires.

NúÑEZ, P. (2013). La política en la escuela. La Crujía, Buenos Aires.

O’DONNELL, G. (1993). Estado, democratización y ciudadanía. En Revista NUEVA SOCIEDAD NRO. 128 NOVIEMBRE- DICIEMBRE 1993, PP. 62-87

\section{-(2004). Contrapuntos. Paidós, Buenos Aires}

OSZLAK, O. (1999). “De menor a mejor: el desafío de la segunda reforma del Estado". Revista Nueva Sociedad, № 160, Venezuela.

PERALTA DUQUE, B. (1999).La formación ciudadana en el sistema educativo de Colombia: ¿una mirada reactiva o transformadora?. Rev. Eleuthera. Vol. 3, enero - diciembre 2009, págs. 165-178. Consultado en http://eleuthera.ucaldas.edu.co/downloads/Eleuthera3 6.pdf 
REGUILLO CRUZ, R. (2000). Emergencia de culturas juveniles. Estrategias del desencanto. Tesis Norma, Buenos Aires.

-- (2012). Culturas juveniles. Formas políticas del desencanto. Siglo XXI, Buenos Aires.

ROCKWELL, E. (2009). La experiencia etnográfica. Historia y cultura en los procesos educativos. Paidós, Buenos Aires.

ROSANVALLON, P. (2007). La nueva cuestión social. Repensar el Estado providencia. Manantial, Buenos Aires.

ROSSI, F (2009). La participación de las juventudes hoy. La condición juvenil y la redefinición de involucramiento político y social. Prometeo. Buenos Aires.

SAINTOUT, F. (2009). Jóvenes: el futuro llegó hace rato. Percepciones de un tiempo de cambios: familia, escuela, trabajo y política. Prometeo, Buenos Aires.

(2010). “Jóvenes y política. Los límites de la aparente aporía” En Saintout F (comp.): Jóvenes argentinos: pensar lo político. Prometeo, Buenos Aires.

STRADA RODRIGUEZ, J. (2012). Debates al interior de la economía social: la reconfiguración neoliberal y la visión regeneradora de las políticas sociales. Papeles de trabajo. Centro de Estudios Interdisciplinarios Etnolingüística y de Antropología Sociocultural, Rosario, n. 24, dic. 2012. Disponible en http://www.scielo.org.ar/scielo.php?script=sci arttext\&pid=S185245082012000200004\&lng=es\&nrm=iso>. Accedido en 26 jun. 2014.

SVAMPA, M. (Editora) (2000). Desde abajo. La transformación de las identidades sociales. UNGS/ Biblos, Buenos Aires

-(2005). La sociedad excluyente. La Argentina bajo el signo del neoliberalismo. Taurus, Buenos Aires

-(2008). Cambio de época. Movimientos sociales y poder político. Siglo XXI- CLACSO, Buenos Aires.

TAMARIT, J. (1998). Educar al soberano. Críticas al iluminismo pedagógico de ayer y de hoy. Miño y Dávila, Buenos Aires.

TIRAMONTI, G. (2004). "La fragmentación educativa y los cambios en los factores de estratificación". En Tiramonti, G. (comp). La trama de la desigualdad educativa. Mutaciones recientes en la escuela media. Manantial, Buenos Aires.

TORRES, C.A. (1994). Las secretas aventuras del orden. Miño y Dávila, Buenos Aires. 
-(2001) Democracia, educación y multiculturalismo. Siglo XXI, México.

WACQUANT, L (2005). El misterio del ministerio. Pierre Bourdieu y la política democrática. Gedisa, Barcelona. 


\section{Capítulo 1}

\section{Investigar las prácticas políticas de los jóvenes estudiantes en una ciudad intermedia del centro de la provincia de Buenos Aires. Acerca del diseño de la investigación}

En este capítulo, se presenta un desarrollo organizado de la estructura o diseño de la investigación.

Distinguiremos proyecto de investigación y diseño de la investigación a efectos de comprender las relaciones entre ambos en el proceso de la investigación. El proyecto abarca el plan total de la investigación y en el marco del doctorado que se ha realizado, y fue oportunamente aprobado ${ }^{10}$. El diseño desarrolla las principales acciones implicadas en el trabajo de investigación, su fundamentación y justificación metodológica y la selección de instrumentos y técnicas en relación a las características del problema.

En el trabajo de campo y la construcción de los datos se podrá advertir han producido algunas modificaciones en el "Anteproyecto de tesis" presentado en el año 2008 tanto en su soporte conceptual como en el aspecto metodológico. Todos los cambios fueron orientados por la dialéctica relación que se estableció con las situaciones producidas en el terreno, en el campo, atendiendo a sus particularidades.

\section{1.- Diseño teórico y metodológico de la investigación}

Esta investigación educativa se ubica en el campo de conocimiento de las ciencias sociales, entendiendo que "la producción de conocimientos sobre educación es conceptualizada como una práctica social con historias y tradiciones específicas, que se desarrolla en contextos sociales y marcos institucionales que la condicionan y le otorgan orientaciones particulares" (Palamidessi, 2007: 27).

En el ámbito de las investigaciones socioeducativas se reconocen -de acuerdo con las formulaciones que Vasilachis de Gialdino $(1992,2007)$ señala para las ciencias sociales en

\footnotetext{
${ }^{10}$ Anteproyecto: “Jóvenes estudiantes de la escuela secundaria y construcción de ciudadanía" (aprobado por despacho de comisión de posgrado, expediente № 0500-000234/09-000)
} 
general- tres paradigmas dominantes: el positivista, el materialista e interpretativista. Entenderemos por paradigma las ideas acerca del conocimiento mismo y cómo producirlo válidamente (Sautu, 2005), asumiendo que estas ideas constituyen un conjunto de creencias básicas con que el/la investigador/a define y acota su problema de investigación, implícita o explícitamente.

Los principales paradigmas dominantes asumen, a grandes rasgos, las características que Vasilachis de Gialdino (2007) desarrolla y que presentamos a continuación.

El paradigma positivista se caracteriza por la observación exterior de los fenómenos, la formulación de leyes como expresión de la regularidad de dichos fenómenos, las explicaciones causales y la verificación o rectificación de los cuerpos teóricos. El paradigma materialista, representado en su inicio por $\mathrm{K}$. Marx ${ }^{11}$ tiene una gran relevancia en el desarrollo de las ciencias sociales. Encuentra en el materialismo histórico (Feuerbach) y en el idealismo (Hegel) los fundamentos de su metodología; pero la ciencia real comienza, para Marx, en la vida real, sin especulación. Se reconoce en el carácter real de sus objetos de estudio, en la acción práctica del hombre y desde allí el conocimiento se produce desde lo más simple y concreto hacia lo más complejo y abstracto: la acción de los individuos en sus relaciones sociales y políticas ponen de relieve la relación existente entre ésta forma de acción y la organización social y política. La organización social y política y el Estado "brotan" -según Vasilachis- constantemente del proceso de la vida de los individuos.

El paradigma interpretativo -aún en vías de consolidación, de acuerdo a la perspectiva que desarrolla Vasilachis-, presenta como fundamento "la comprensión del/los sentidos de la acción social en el mundo de la vida y desde la perspectiva de los participantes" (2007:48). Se reconocen cuatro elementos particulares de este paradigma: la negativa a "naturalizar" el mundo social, la relevancia del contexto donde se produce la acción, la comprensión de los procesos sociales por sobre la observación, destacando la perspectiva de los actores, la apelación a la doble hermenéutica, es decir, la re-interpretación de las situaciones realizada por parte de los sujetos intervinientes.

\footnotetext{
${ }^{11}$ Este paradigma se consolida en dos vertientes: la neomarxista representada por Lefebre y Goldman; y la crítica, representada por Marcuse, Adorno y Horkheimer. Ambas desarrollan sus producciones más importantes en las décadas de 1960 y 1970.
} 
Esta investigación se ubica en éste último paradigma y desde esos fundamentos se ha realizado la construcción del marco teórico de la investigación. Éste se construyó atendiendo, desde una perspectiva sociológica general, a las tensiones siempre vigentes entre la posibilidad de agencia del sujeto y las constricciones que imprime la estructura. Hemos realizado aproximaciones al problema apelando a las teorías disponibles y accesibles tanto en relación a la comprensión del problema como a la perspectiva metodológica y la selección de estrategias de relevamiento utilizadas en el campo, buscando la correspondencia entre los dos tipos de acciones implicadas. Siguiendo a Sautu (2005:23) sostendremos que:

\footnotetext{
"La idea de teoría o de qué es la teoría cuando se la define en el contexto de una investigación, impregna la totalidad del diseño, incluyendo obviamente la construcción del marco teórico y los supuestos teóricos que sostienen la utilización de modelos estadísticos o una estrategia cualitativa de análisis"
}

En ese sentido se aborda la teoría sociológica general implicada y se definen los campos disciplinares que mejor contribuyen a la comprensión del problema y posteriormente, a la argumentación conceptual con que se especifican las conjeturas implicadas.

Resultan de interés para este estudio las perspectivas sociológicas desarrolladas por N. Elías (1989, 1998), P. Bourdieu (1997; 2007) y actualmente, por B. Lahire (2003), considerando los aportes realizados a la superación de la relación dicotómica entre el sujeto y la estructura social, destacando la relacionalidad entre ambos. Los estudios mencionados que se realizan en el campo de la sociología, aportan conceptos y categorías de análisis para comprender las actuales relaciones sociales al interior de las escuelas.

En el caso de los aportes de N. Elías (1989), se selecciona el concepto de configuración social para explicar y comprender las relaciones de interdependencia entre los sujetos y las estructuras. Se reconocen fundamentalmente las nociones de "sujetos en interacción" que se mueven en "configuraciones sociales" que les preexisten pero que son -lentamentecambiantes.

En “Mozart, sociología de un genio" (1998), Elías da cuenta -a través del análisis de la vida de un sujeto descollante en la transición de la edad media a la modernidad como fue Mozart-, 
de cómo un sujeto, a la vez producto de un contexto y de una historia familiar particular, desarrolla estrategias para posicionarse en nuevos escenarios y, a la vez, para reducir el dolor psicológico y el conflicto, mientras intentaba subsistir económicamente y seguir desarrollando su música. La configuración social, política y económica ${ }^{12}$ estaba cambiando quizá tan drásticamente como en la actualidad- pero el sujeto también modifica sus esquemas. Los cambios en las configuraciones, dirá Elías, son mucho más lentos que la vida de los sujetos que interactúan en ellas, pero están constituidos por las actuaciones de los sujetos.

La práctica se aborda a partir de la teoría relacional de P. Bourdieu. Como justifica el propio Bourdieu (1997: 7-8) su teoría, se trata más bien de

“...una filosofía de la ciencia que cabe llamar relacional, en tanto que otorga supremacía a las relaciones (...) una filosofía de la acción designada a veces como disposicional, que toma en consideración las potencialidades inscriptas en el cuerpo de los agentes y en la estructura de las situaciones en las que éstos actúan, o con mayor exactitud, en su relación. Esta filosofía, que se condensa en un reducido número de conceptos fundamentales, habitus, campo, capital, juego y cuya piedra angular es el doble sentido de las estructuras objetivas (la de los campos sociales) y de las estructuras incorporadas (los habitus) se opone radicalmente a los presupuestos antropológicos inscriptos en los lenguajes en los que los sujetos sociales, y muy especialmente los intelectuales, por lo general suelen confiar para rendir cuenta de la práctica (particularmente cuando, en nombre de un racionalismo estrecho, consideran como irracional toda acción o representación que no esté engendrada por las razones explícitamente planteadas de un individuos autónomo, plenamente consciente de sus motivaciones)."

Las críticas que suscitaron las publicaciones de los resultados de sus investigaciones, por parte de algunos académicos, se centraron en su aparente tendencia a hacer predominar el peso de la estructura por sobre la posibilidad de acción de los sujetos. A lo largo de sus

\footnotetext{
${ }^{12}$ “El concepto de "configuración” puede ser utilizado para interacciones sociales contextualizadas de distinta magnitud. Se puede aplicar tanto a grupos pequeños como a sociedades integradas por miles o millones de individuos interdependientes. El profesor y sus alumnos en una clase, el médico y sus pacientes en un grupo de terapia, clientes de un café reunidos en torno a la mesa de tertulia, los niños en un jardín de infancia, todos ellos constituyen entre sí figuraciones abarcables, pero también forman figuraciones los habitantes de un pueblo, de una gran ciudad o de una nación, aun cuando e $n$ estos casos la figuración no sea directamente perceptible porque las cadenas de interdependencia que vinculan entre sí a las personas, son en estos casos muchos más largas y diferenciadas" (Elías, 1999:158)
} 
investigaciones Bourdieu se ocupó de revisar y reforzar sus argumentos analíticos en el estudio de las relaciones sociales. El elemento articulador entre ambos componentes de la tensión individuo - sociedad ha sido el concepto de habitus.

En su debate con el estructuralismo y el concepto de reglas, sostiene que los sujetos, en su condición de agentes sociales, construyen sentidos que los independizan de su acción de meros ejecutantes de normas, otorgándole de este modo un sentido a sus prácticas, en una complicidad entre "el habitus y el mundo social" (Bourdieu, 1997). Bourdieu (2007:86) define al habitus ${ }^{13}$ como un

“...sistema de disposiciones duraderas y transferibles, estructuras estructuradas, predispuestas a funcionar como estructuras estructurantes, es decir como principios generadores y organizadores de prácticas y de representaciones que pueden ser objetivamente adaptadas a su meta sin suponer el propósito consciente de ciertos fines ni el dominio expreso de las operaciones necesarias para alcanzarlos, objetivamente "reguladas" y "regulares" sin ser para nada el producto de la obediencia a determinadas reglas $\mathrm{y}$, por todo ello, colectivamente orquestadas sin ser el producto de la acción organizadora de un director de orquesta"

Esta teoría social relacional nos brinda herramientas para indagar, a partir de sus principales conceptos, la relación entre la práctica de los sujetos y el campo. El campo educativo es entendido como un espacio de luchas simbólicas con autonomía relativa, en un macrocosmos social, que comparte características estructurales con otros campos (como el político, el de las artes, la economía, entre otros) pero a la vez, presenta propiedades que lo diferencian de los demás. El campo educativo se caracteriza por la transmisión de la cultura, por el tratamiento y distribución de los bienes simbólicos que producen y acumulan los sujetos sociales en su devenir histórico.

Lahire (2003) inscribe su producción en la perspectiva desarrollada por Bourdieu otorgando nuevas significaciones a conceptos centrales como campo, habitus y práctica. Se define como heterodoxo al momento de posicionar su producción, pues reconoce diversos aportes

\footnotetext{
${ }^{13}$ Gutiérrez (1994) explica la evolución que el concepto habitus ha experimentado a lo largo de la obra de Bourdieu: pasó por un inicio determinista (en La Reproducción), a construcciones más abiertas "que toman en cuenta el problema de la invención" (Gutiérrez, 1994: 45).
} 
de la tradición sociológica al interpretar las condiciones sociales contemporáneas, distintas de las condiciones de la sociedad sobre /para la que escribió Bourdieu.

Discute el concepto de campo, entendiendo por éste un espacio o universo de acción que funciona de distinto modo a los grandes campos de significación definidos por el autor de referencia. Sostiene que es necesario reconocer "los diferentes universos en los que los agentes se inscriben y que no funcionan de la misma manera" (Gessaghi y Sendón, 2008: 73) para poder entender que los habitus no constituyen un sistema homogéneo de disposiciones duraderas en los sujetos sino que, en virtud de los distintos campos por los que transita un sujeto, activa habitus heterogéneos. La revisión y redefinición de estos dos conceptos resultan de interés en esta investigación, pues afectan directamente a la categoría prácticas sociales (en este caso, políticas) que constituyen el objeto de la investigación. Para Lahire, la práctica es el entrecruzamiento del habitus y el campo y, a través de la práctica puede reconocerse la existencia de un "hombre plural", heterogéneo y contradictorio.

Los aportes que realizan los tres autores mencionados a la sociología de la educación nos permiten poner en tensión sus posiciones con los discursos dominantes en el actual escenario de la política educativa, que conlleva las intenciones ideológicas de esta etapa del capitalismo y las actuaciones de los sujetos que se acomodan y resisten a esos marcos de acción desde sus posiciones sociales cargadas de historicidad.

\subsubsection{Campos disciplinares para abordar el tratamiento del problema}

El campo disciplinar al que refiere el problema se inscribe en el campo de la sociología de la educación y la sociología del curriculum.

En el marco de la sociología de la educación, se destacan los aportes que realiza la llamada "nueva sociología de la educación" que se inicia en Inglaterra en la década de los '70 y que denuncia la reproducción del sistema capitalista a través de las instituciones educativas. Posteriormente, la teoría de la resistencia se pronuncia diciendo que los mecanismos de reproducción social y cultural nunca son completos y siempre se encuentran con elementos de oposición por parte de los destinatarios de las políticas que emanan desde el centro de poder. Uno de sus principales representantes explica la perspectiva crítica de la nueva sociología de la educación: 


\begin{abstract}
“En la perspectiva radical, las escuelas como instituciones sólo podrían ser comprendidas a través de un análisis de su relación con el Estado y con la economía. En esta visión, la estructura profunda, el significado subyacente de la escolarización podrían revelarse a través del análisis de cómo las escuelas funcionan como agencias de la reproducción social y cultural; esto es, cómo legitiman la racionalidad capitalista y sostienen las prácticas sociales dominantes" (Giroux, 1983, p. 1-2)
\end{abstract}

Este enfoque de los procesos educativos desnuda rápidamente la no neutralidad del conocimiento escolar y, así, la sociología del curriculum se pregunta por los modos "en que una cultura selecciona, clasifica, distribuye, transmite y evalúa el conocimiento curricular" (Goodson, 2000:10). En este trabajo se señalan como dimensiones insoslayables del contexto, la historicidad del curriculum de la escuela secundaria -focalizando en los contenidos explícitos que vinculan la educación con la política-, las relaciones de poder en las instituciones educativas y el valor del conocimiento en las relaciones escolares.

Las prácticas políticas que orientan la construcción de ciudadanía constituyen una producción de sentido cuyo contenido se relevará a partir de la acción de los actores en contexto. Para ello, será necesario comprender las lógicas que organizan -y los sentidos que producen- las diferentes configuraciones escolares, producto de su propia historicidad implicada en las estructuras objetivas y en las estructuras internalizadas de los sujetos, que se manifiestan en las acciones explícitas y ocultas del curriculum en acción (Jackson, 1998; Torres Santomé, 1996).

Cada escuela, como configuraciones sociales que comparten procesos históricos comunes y a la vez diferenciales, ha delineado sus propias culturas institucionales que componen marcos de acción para los jóvenes. Estos a su vez, no representan al alumno socializado por la institución familia sino a jóvenes que muestran distintos grados de sujeción a las reglas institucionales, y que en interacción con otros jóvenes y con la mediación de la tecnología, especialmente las que producen las redes sociales, disputan saberes y posiciones ante escuelas, a veces, perplejas (Corea y Lewkowicz 2004; Reguillo Cruz 2007; entre otros autores consultados cuyas perspectivas se desarrollan en el capítulo 2). 


\subsubsection{La estrategia teórico-metodológica}

La explicitación de las decisiones metodológicas se corresponde, también, con el paradigma en que se ubica la investigación y que fue presentado con anterioridad.

Todo el proceso metodológico de la investigación se ha realizado acompañado de una reflexión epistemológica ${ }^{14}$ (Vasilachis de Gialdino, 1993) que ha orientado las decisiones durante el diseño preliminar, la estadía en el campo, la escritura de registros e interpretación de los mismos, aspecto que ha imprimido confianza en las decisiones tomadas al calor de los interrogantes y dudas que planteaba el campo y para preservar -en ciertas ocasiones- la habilitación a permanecer en las situaciones sociales en estudio.

La inscripción de la investigación en el paradigma interpretativo se ha orientado hacia un enfoque socio-antropológico para comprender la dinámica de la vida cotidiana escolar, de modo de definir estancias prolongadas en el campo y establecer relaciones sociales cara a cara, específicas, con los sujetos de la investigación. Esta perspectiva permite capturar la lógica de la dinámica de la vida cotidiana (Rockwell, 1995) y, a la vez, penetrar en la negatividad del dato, esto es, develar aquello que el dato oculta.

Se advierte que la reciente incorporación en los diseños del curriculum escolar de contenidos y procedimientos de formación política y ciudadana desde el primer año de la escuela secundaria, expresa un interés oficial por establecer un "retorno a la política" por parte de los jóvenes. La tarea de adentrarse a la vida de las escuelas seleccionadas permitirá indagar en los retículos sedimentados de la cultura escolar, favoreciendo la construcción de los datos que orienten a la comprensión de los procesos que allí ocurren.

Otro aspecto que resulta relevante por sus implicancias teóricas y metodológicas es la perspectiva historiográfica ${ }^{15}$ (Viñao Frago, 2008) con que se han abordado los procesos, las

\footnotetext{
${ }^{14}$ La reflexión epistemológica se representa como un proceso que acompaña la acción investigativa, articulando los conceptos y las estrategias a los efectos de hacer nuestra investigación más comprensible y sostenida en criterios de validez, de nuestra investigación. Se distancia de la idea de "vigilancia epistemológica" de Bachelard, retomada por Bourdieu, en tanto no es entendida como una mirada que ejerce un control externo, sino que es inherente al proceso metodológico en sí. Sobre esta cuestión, profundizan los alcances de esta posición, Samaja (1995) y Vasilachis de Gialdino (1993), entre otros.

${ }^{15}$ El abordaje desde esta perspectiva puede observarse especialmente en el capítulo 3 pero también sostiene la trama del desarrollo de los capítulos 4,5 y 6 .
} 
situaciones y las prácticas analizadas. Así, se han vinculado las prácticas relevadas comprendiéndolas como el emergente de un proceso histórico, aspecto que favoreció la comprensión de la compleja trama social que las prácticas representan en los escenarios actuales.

La permanencia en el campo permitió comprender el sentido de los procesos que tienen lugar en el transcurrir de la vida cotidiana escolar $y$, de este modo, se favoreció el relevamiento e interpretación del significado político de ciertas prácticas que los jóvenes realizan en la escuela.

La trama experiencial construida, el conocimiento, las emociones e intereses del investigador no quedan en la puerta de la escuela, sino que pasan a formar parte de la investigación. A decir de Guber (2008:86): "el bagaje teórico y el sentido común del investigador [...] lo acompaña pudiendo guiar, obstaculizar, distorsionar o abrir su mirada". La permanencia en el campo permite una comprensión "desde adentro", con los sujetos y las situaciones. En el campo, no es el investigador el único que diseña estrategias de comportamiento y acción, sino que los otros, los sujetos de la investigación, también desarrollan las propias. Como explica Guber (2008: 87):

\footnotetext{
"Si caracterizamos al conocimiento como un proceso llevado a cabo desde un sujeto y en relación con el de otros sujetos cuyo mundo social se intenta explicar, la reflexividad en el trabajo de campo es el proceso de interacción, diferenciación y reciprocidad entre la reflexividad del sujeto cognoscente sentido común, teoría, modelo explicativo de conexiones tendenciales- y la de los actores o sujetos/objetos de investigación".
}

\subsubsection{Propósito de la investigación}

Esta investigación -como se adelantó en la Introducción ( $p: 20)$ - tiene como propósito relevar las características que adoptan las prácticas políticas de los jóvenes en el nivel básico de la escuela secundaria (ESB), considerando a éstas como prácticas sociales complejas que construyen ciudadanía. 
Puesto que desde la política educativa vigente el reconocimiento de los jóvenes como sujetos de derecho se realiza bajo el "mito" de la igualdad jurídica ${ }^{16}$, las condiciones contextuales en las que se implementa la obligatoriedad de la educación secundaria y la relevancia otorgada a la construcción de ciudadanía, se espera que permitan identificar las características de las prácticas políticas desarrolladas por los jóvenes incluidos en las escuelas secundarias en un contexto que presenta una fragmentación social ostensible.

Las prácticas sociales dan cuenta de sujetos en interacción que se encuentran inmersos en determinadas configuraciones: la familia, la escuela, programas sociales, clubes, iglesias. Si se considera, además, la particularidad de que se producen en una institución, ello significa que son prácticas con historia, que guardan algún tipo de relación con patrones de comportamiento que los sujetos que anteceden a estas situaciones han ido perfilando. Pero, además, estas prácticas se producen en un proceso sociopolítico excluyente que es necesario advertir y considerar en la profundización de las categorías conceptuales que se construyen para esta investigación.

Resulta de interés presentar sucintamente el contexto sociopolítico y económico del problema. Cabe observar, entonces, que la sanción de la Ley de Educación Nacional (LEN) del año 2006 se produce en un contexto de creciente exclusión social en el que, paradógicamente, "mientras que la economía y el mercado de trabajo excluyen y desintegran, la escuela escolariza a proporciones cada vez más elevadas de niños y jóvenes" (Tenti Fanfani, 2010: 19). Vale destacar que, como señala el autor, la escolarización no va acompañada, en todos los casos, de procesos construcción de conocimiento, con lo cual la escuela ve alterada su función tradicional.

Considerando el renovado interés por la construcción de una ciudadanía activa y participativa que presenta la LEN, este estudio puede constituirse en un documento de consulta para orientar las prácticas pedagógicas o, al menos, favorecer una lectura compleja de la situación en que transcurre la vida cotidiana escolar.

\footnotetext{
${ }^{16}$ Se dice "mito" de igualdad jurídica en tanto, si bien todos los sujetos somos iguales ante la ley, en la realidad, las prácticas sociales no lo expresan de ese modo (Buis, E., 2011)
} 
El contexto político (nacional e internacional) caracterizado por lo que Oszlak (1999) llama segunda generación de reformas del Estado, conduce a los gobiernos a producir un grupo de políticas públicas orientadas a "rescatar" e incluir a los sujetos expulsados del sistema productivo por la dinámica del modelo neoliberal actual. Esto es, luego de la crudeza de las primeras reformas ${ }^{17}$ estructurales impulsadas por el neoliberalismo dominante, que producen crisis sociales que amenazan la gobernabilidad, se re-posiciona un Estado que debe "afrontar desafíos mucho más arduos: "fortalecer" lo que queda e incorporar nuevas funciones que procuren restablecer los equilibrios políticos y sociales perdidos"(op cit: 4). Como señala el autor, el desafío principal es conseguir la gobernabilidad del sistema, para lo cual se hace necesario promover la equidad entre los ciudadanos, ante sociedades fragmentadas.

La fragmentación social existente en el país se manifiesta también en el sistema educativo (Tiramonti, 2004; Tiramonti y Montes, 2009) y así las escuelas desarrollan su tarea de manera articulada con el contexto social específico en el que están situadas, constituyéndose en segmentos que operan con sus propias lógicas, en el marco general del sistema educativo.

Parece evidente "que la red de relaciones que caracterizó a la sociedad moderna está cambiando y que esto cambia los marcos estructurantes de la acción y el terreno en que se mueven las instituciones educativas" (Tiramonti 2004, p.19). Estos aspectos, como ya se ha indicado en la Introducción, se desarrollan con mayor profundidad en el Capítulo 2.

\footnotetext{
17 "Las reformas de primera generación tuvieron como objetivo central encoger al Estado, no necesariamente mejorarlo. Menos Estado no significaba comprimir su estructura y dotación por un simple afán racionalizador, sino porque ese aparato desarrollaba funciones y actividades que en el nuevo contexto ideológico pasaron a ser consideradas ilegítimas. De hecho, la cuestión de la racionalidad organizativa y funcional del Estado fue postergada para una segunda etapa. El objetivo era desprenderse de segmentos institucionales completos, a través de su eliminación lisa y llana o su transferencia a otros actores e instancias jurisdiccionales". (Oszlak, 1999:3)

"Se apeló así a la descentralización, que trasladó responsabilidades de gestión a los gobiernos subnacionales; a la privatización, que puso en manos de empresas privadas (y a menudo, de empresas estatales transnacionales) la provisión de los principales servicios públicos; a la desregulación, que implicó el vaciamiento o supresión de organismos que cumplían funciones reguladoras de la actividad socioeconómica, las que pasaron a ser consideradas superfluas o negativas para su desenvolvimiento; y a la tercerización de servicios, que llevó a numeras instituciones públicas a procurarse en el mercado, ciertos insumos y servicios antes suministrados por unidades operativas propias". (Oszlak, 1999: 4)
} 


\subsubsection{Presentación del tema y formulación del problema de la investigación}

La ciudadanía, entendida desde diversas perspectivas teóricas como pertenencia a una determinada comunidad política (García Delgado y Nosetto, 2004; Marshall, 1949; Kymlicka y Norman, 1997), se construye en distintas etapas no lineales que permiten comprender cómo se entretejen las relaciones de los sujetos con el Estado. En esa construcción, coexisten dos aspectos o dimensiones relativos a la ciudadanía: una dimensión externa, mediante la cual se reconoce a un sujeto como miembro de una comunidad y una condición interna, subjetiva, por la que el sujeto se reconoce a sí mismo como miembro de una comunidad y activa -o no- mecanismos para producir prácticas que trascendiendo la pura individualidad, contribuyan al bien común.

Analizar la ciudadanía como una construcción histórica y social, que sufre transformaciones a lo largo del tiempo y de las formaciones sociales en las que es analizada, constituye un tema de interés en estos tiempos en que las categorías modernas resultan insuficientes para comprender las prácticas y los sentidos que se manifiestan en la vida cotidiana de los sujetos.

Las transformaciones operadas por el nuevo orden neoliberal vigente han producido una fuerte erosión en el modelo de ciudadanía asociada al Estado de Bienestar, caracterizada por -una cierta- consolidación de los tipos de ciudadanía descriptos por Marshall (1949): ciudadanía civil, ciudadanía política y ciudadanía social. La redefinición en las funciones del Estado y el declive de las instituciones asociadas al estado moderno, en su desestructuración, habilitan nuevos escenarios en los que los sujetos -liberados o expulsados de las estructuras modernas- desarrollan prácticas que van configurando diferentes procesos de subjetivación en su relación con la política.

Los jóvenes, en especial, parecen estar inmersos en una cosmovisión epocal que otorga supremacía a las acciones del sujeto individualizado por sobre las acciones orientadas a la vida en común, o a la construcción de proyectos comunitarios, encontrándose imbuidos de un profundo descreimiento del sistema político y de los políticos en su conjunto. Abordan este tema, entre otros, Reguillo Cruz (2000; 2012), Giroux (2003), Chaves (2010). 
En Argentina, el escenario neoliberal que se instala a partir de la década de los `90, evidencia el pasaje a una ciudadanía fragmentada y en la que se destaca el reconocimiento de la figura del ciudadano consumidor como ícono de la época. La crisis del año 2001 y las políticas de reposicionamiento del Estado iniciadas a partir de 2003 realizan una producción discursiva que re-instala la idea de Estado garantista, que propone un reconocimiento de derechos cuyo propósito es la inclusión social y la ampliación de la ciudadanía, para lo cual la escuela debe desarrollar una tarea relevante. El énfasis puesto en el reconocimiento y ejercicio de derechos individuales por parte de la política global choca con la necesidad humanitaria y social de construir la vida en común.

La pérdida de capacidad de las instituciones modernas para producir subjetividades orientadas a la vida en común y la ruptura de la secuencia institucional (Estado-familiaescuela- iglesia- hospitales- clubes- fábrica), favorece la emergencia de nuevos/otros espacios sociales donde los jóvenes se construyen como sujetos sociales. La escuela, debilitada en su capacidad instituyente y aislada de la familia que le "entregaba" sujetos dispuestos a cumplir la función de alumnos, debe confrontar con la persistente y creciente influencia de los MMC y las NTIyC que redefinen la trasmisión de la herencia cultural y la relación de la escuela con la sociedad (Martín Barbero, 2008).

Por otro lado -y a pesar de lo inacabado de sus propósitos, de las confrontaciones entre las pautas escolares instituidas y las culturas juveniles-, la escuela es un espacio valorado por los distintos grupos sociales que han tenido en ella experiencias exitosas o quienes la perciben aún como posibilidad de mejoramiento de sus posiciones sociales, el ejercicio de la vida política, la formación ciudadana y la transmisión de la cultura. La escuela continúa siendo un lugar donde se vive el espacio público, progresivamente desestructurado por la hegemonía neoliberal.

Diversas experiencias que se difunde por los MMC y las redes sociales, construidas en situaciones novedosas y, a la vez, indicativas de la gestación de un nuevo canon social, permiten observar que los jóvenes experimentan y definen en la escuela acciones orientadas a la profundización de la vida política asociadas a la ciudadanía activa, a través de acciones 
de participación, convivencialidad y demanda, aunque estas acciones no sean reconocidas como tales por los agentes del sistema ni "soportadas" por la cultura institucional.

Por su parte, la nueva ley, en su versión provincial y el diseño curricular de la Provincia de Buenos Aires, hacen especial referencia al fortalecimiento de la formación ciudadana de los jóvenes y definen un nuevo modo de concebir la gestión escolar, con mayor participación estudiantil a partir de la creación de los Centros de Estudiantes, la reglamentación para establecer Acuerdos Institucionales de Convivencia y la creación de un nuevo espacio curricular, la materia Construcción de Ciudadanía, en el trayecto de la Escuela Secundaria Básica (ESB).

Como contraparte, pareciera que al mismo tiempo que aumenta la visibilidad social de las culturas juveniles, se debilitan las posibilidades de la escuela de concretar la misión que le es asignada. Se asume que la educación ha desbordado al sistema y hoy nos encontramos ante una sociedad que emprende diversos procesos educativos por fuera del sistema formal.

Según diferentes fuentes consultadas (Calderón, 2007; Fundamentos del Diseño Curricular de la provincia de Buenos Aires, 2006) las definiciones en torno de la formación ciudadana de la escuela secundaria básica, se orientan a fortalecer las posibilidades de los sujetos jóvenes de percibirse a sí mismos como sujetos de derecho a partir de los aprendizajes necesarios para desenvolverse como ciudadanos activos en los actuales escenarios sociales. Coincidimos con Kessler (1996:165) en considerar que al poner de relieve la construcción y ejercicio de la ciudadanía

“...aparta al individuo de un rol pasivo, asimétrico, de receptor de ayuda en virtud de la compasión pública o privada. Lo reubica -al menos en el terreno simbólico- como sujeto de derechos, y si se encuentra privado de la provisión de los mismos, como sujeto de demandas".

El problema en relación al cual se desarrolla la investigación, se formula de la siguiente manera: la noción de ciudadanía asociada al modelo Estado de Bienestar ${ }^{18}$ sufre una fuerte erosión por la relevancia que progresivamente ha adquirido un nuevo modelo social,

\footnotetext{
${ }^{18}$ Se considera al Estado de Bienestar como el momento de realización de la utopía de consecución de derechos ciudadanos, durante la modernidad.
} 
político, económico y cultural cuyo centro es el mercado. La sociedad como construcción integrada se fragmenta en diversos segmentos, apoyados en la lógica del individualismo. A partir de ello, se abren nuevos discursos y prácticas sociales inciertas, espontáneas y alternativas al modelo construido por la modernidad.

A partir de la última década del siglo pasado (1990) las transformaciones asociadas con el ingreso de los países periféricos a un nuevo modelo global producen profundos cambios en la función del Estado y sus instituciones. Desde una perspectiva crítica, se cuestiona la exclusión social y la reproducción de las desigualdades que el nuevo modelo produce. En Argentina, las críticas a la aplicación del primer momento de reformas al Estado, aún siguen expresándose por la secuela de desintegración social que produjo.

Iniciado un proceso de reposicionamiento estatal, junto a otras leyes de relevancia para el reconocimiento y ampliación de derechos ${ }^{19}$ se sanciona la Ley de Educación Nacional № 26206, que establece, entre otras importantes medidas, la obligatoriedad de la educación secundaria completa (6 años). Esta ley deposita en la escuela secundaria sus expectativas de formación de una ciudadanía activa, como lo expresa en sus objetivos.

La puesta en marcha de la nueva ley se realiza sobre la existencia de un sistema educativo fragmentado, en el que las escuelas muestran dificultades para transmitir saberes y también para instituir normas democráticas e igualitarias en el marco del escenario social contemporáneo. El formato del curriculum escolar, que mantiene en su desarrollo el peso de la historia de la escuela secundaria tradicional, pareciera, por momentos, constituirse en un obstáculo para sostener las nuevas relaciones pedagógicas y sociales necesarias para educar a los jóvenes.

Es necesario advertir que los jóvenes transitan, a la vez, por diversos espacios (diferenciados según las posiciones sociales de los sujetos) en los que exploran otras formas de

\footnotetext{
${ }^{19}$ Nos referimos a la Ley de Promoción y Protección Integral de los Derechos de los Niños, Niñas y Adolescentes (en Provincia de Buenos Aires, Ley № 13.298/04) y al Fuero Familiar y Penal Juvenil (Ley 13634/05 de La Provincia de Buenos Aires).
} 
relacionarse y de practicar la política que impactan en el proceso de construcción de ciudadanía que sostiene la escuela.

\section{Preguntas de la investigación}

Las preguntas de la investigación plantean los interrogantes que quedan pendientes luego de dialogar con la literatura producida y la realidad que se analiza, mostrando los interrogantes acerca de lo que queremos conocer.

Ante la ruptura del paradigma social sostenido por un Estado organizador y regulador de la vida política y por lo tanto, de la formación de la ciudadanía a través de instituciones especializadas como la escuela, se plantea la pregunta principal que sintetiza el problema que se va a investigar:

-¿Cómo construyen su condición de ciudadanos los jóvenes que asisten a la Escuela Secundaria Básica -obligatoria- en la ciudad de Olavarría, en tiempos de profunda desigualdad social?

Las recomendaciones metodológicas consideradas en el armado de este diseño, como las realizadas por Sautu (2005), aconsejan que la formulación de las preguntas de la investigación derive de las construcciones teóricas sobre un tema o problema, y que a la vez se "traduzcan" en los objetivos de la investigación. Atendiendo a esas consideraciones, se formularon las siguientes preguntas que orientan la investigación:

-¿Qué sentidos conlleva para los jóvenes que concurren a las distintas escuelas seleccionadas, las nociones de política, derechos y ciudadanía?

- ¿Qué prácticas políticas desarrollan los jóvenes en el contexto escolar?

- ¿Qué formas y contenidos curriculares respecto de la ciudadanía circulan en el contexto de la escuela secundaria básica, obligatoria?

-¿Cómo contribuye u obstaculiza la escuela a la promoción de prácticas ciudadanas que articulen lo individual y lo comunitario? 


\section{Objetivo General:}

Indagar e interpretar cómo construyen su condición de ciudadanos los jóvenes que asisten a la escuela secundaria básica de la ciudad de Olavarría, provincia de Buenos Aires, en el período 2009-2011.

\section{Objetivos Específicos:}

- Analizar los sentidos que los jóvenes le otorgan a la política y a la ciudadanía.

-Explorar qué lugar tiene la escuela secundaria básica en la construcción de ciudadanía en los actuales escenarios sociales.

-Identificar los diferentes tipos de ciudadanía que contribuye a formar la escuela y las prácticas curriculares asociadas a ellos.

\section{Hipótesis:}

Iniciado en Argentina un proceso de reposicionamiento estatal, La Ley de Educación Nacional № 26206/06 demanda a la escuela la formación de una ciudadanía activa, construida sobre la base jurídica de "igualdad de derechos". Desde el discurso de la política educativa se observa una tendencia a valorar las capacidades de los sujetos, en especial la de los jóvenes y a sus prácticas, que se manifiestan como portadoras de una politicidad capaz de conmover la inercia reproductiva de la escuela.

Como parte de un sistema educativo fragmentado las escuelas tienen serias dificultades para instituir normas democráticas e igualitarias en el marco del escenario social contemporáneo caracterizado por un lado, por la contingencia de lo social y por otro, por la desigualdad y la fragmentación, situaciones que generan diversas y desiguales posibilidades de participación para los jóvenes.

Por lo tanto, la construcción de ciudadanía que se produce en las escuelas secundarias estará entretejida en la fuerza que imponen la historia y la cultura escolar y la resistencia que ejercen las nuevas prácticas políticas que instalan en ella los jóvenes. 


\subsubsection{Localización de la investigación}

Otro aspecto a ser considerado en este primer capítulo, es la localización de la investigación. ¿Por qué Olavarría? ¿Qué aporta al conocimiento del campo de la educación, finalmente, una investigación en cinco escuelas de Olavarría, una ciudad intermedia ${ }^{20}$ (Gravano, 2005) ubicada en el centro de la provincia de Buenos Aires?

Olavarría ${ }^{21}$ es una ciudad del interior bonaerense con 111.708 habitantes (según datos del INDEC correspondientes al Censo 2010) que ha sufrido en los últimos 20 años una profunda transformación productiva y social.

La ubicación geográfica de la ciudad prometió, en las décadas de los 60 y 70, otro destino que el actual en los aspectos económico, social y político, tanto para ella como para la región centro (El Popular, 1999: 222). Olavarría era en ese momento "la ciudad del trabajo", con pleno empleo y una proyección de crecimiento. Las transformaciones productivas impulsadas por el gobierno de Menem (1989- 1999) desmantelaron la industria local (principalmente las fábricas cementeras y la producción satélite que generaban), dejando tras su quiebra, decenas de miles de desempleados con indemnizaciones volátiles y nuevos trabajos cuentapropistas de corto alcance (quioscos, remiseras, videoclubes, entre otros) ${ }^{22}$.

${ }^{20}$ El autor construye la categoría de ciudad intermedia a partir de indicadores estructurales y de funcionalidad, en un rango poblacional que abarca desde los 50000 a los 500000 habitantes. Contempla, además, la inclusión las dinámicas simbólicas que constituyen la especificidad de los centros urbanos de rango medio.

${ }^{21}$ Olavarría es una ciudad intermedia de la Provincia de Buenos Aires. Fue fundada en el año 1867 por el Coronel Álvaro Barros, como estrategia de avanzada contra los indios mapuches pampeanos, en los albores de la trágica "Campaña del desierto". Está ubicada en el centro de la provincia, comunicada con todos los puntos económicos y culturales neurálgicos del país, a través de la Ruta Nacional № 3, ferrocarril y vías aéreas.

En la década del ' 90 sufrió la crisis social más importante de su historia tras el cierre de la fábrica de cemento Loma Negra, que dejó a 6000 familias en emergencia laboral, incorporándose a las filas de desocupados que marcaron una nueva etapa en la historia de nuestro país. Este hito cambió el escenario socioeconómico y cultural de la ciudad.

Actualmente su actividad económica es mixta, conformada principalmente por la actividad minera, agropecuaria e industrial.

Desde 2003 ha sido denominada "Capital de la Región" en función de ser una de las primeras ciudades de la provincia en posicionarse para el diseño y puesta en marcha del Plan Nacional de Ordenamiento Territorial (2005) encarado por el gobierno del Dr N Kirchner. En la actualidad, sus actividades políticas, económicas y culturales se enmarcan en el Plan de Regionalización de la provincia de Buenos Aires (2011)

${ }^{22}$ Diversas tesis de la carrera de Antropología Social de la FACSO-UNICEN dan cuenta de este proceso: Bassa, A. "Cooperativas: ¿una alternativa posible?; Hiese, A. (1996) "Trabajo gerencial en tiempos posfordistas"; Paz, C. (1999): "Nuevos modelos de gestión y cambio cultural ¿hacia una resignificación del trabajo humano?" .También se encuentran investigaciones locales como las dirigidas y compiladas por Villafañe (2002); Gravano (2005). 
El escenario social sufrió una fuerte alteración en los 90, pero tras la crisis del 2001, se produjo una alteración más rotunda, aunque la información nunca fue reconocida oficialmente por las autoridades municipales. "Se sabe" ${ }^{23}$ que fueron trasladados a los barrios suburbanos construidos por la gobernación Provincial y municipal, habitantes de las villas del Conurbano Bonaerense, quienes con su presencia imprimen otra lógica a la dinámica de la ciudad.

De manera coincidente con la persistencia de la crisis social, comienzan a producirse delitos graves, fatales, asesinatos por encargue y, en los últimos años, ataques y homicidios entre jóvenes, que han colocado a la ciudad entre las más peligrosas del país ${ }^{24}$. Olavarría comparte con otras ciudades intermedias abatidas por la desintegración de la responsabilidad social estatal y su consecuente polarización económica, educativa, cultural-, altos índices de hechos delictivos, circuitos comerciales de drogas, trata de personas, entre otras miserias que afectan la condición humana.

Este escenario, sucintamente presentado, nos permitiría inferir que la ciudad puede ser homologada, en las reconfiguraciones de su escenario social, con otros territorios del país. Se enumeran algunas de las características que identifican tal reconfiguración, como son señaladas por Kessler, Svampa y González Bombal (2010) para identificar al Conourbano Bonaerense: como lugar de residencia de las clases populares pauperizadas; como espacio de desarrollo de movimientos de desocupados; como foco de la inseguridad y homicidios (en Olavarría, especialmente juveniles). Y, a la vez, se crean nuevos barrios privados, crece la producción agropecuaria y minera y desde el gobierno local se pretende constituir a la zona como un polo turístico.

Desde la perspectiva metodológica con que se aborda el problema en estudio, se pretende resolver la supuesta dicotomía de niveles "micro" y "macro" utilizando el concepto de escala. Este concepto remite a un equilibrio entre lo particular y lo general que es señalado por Rockwell como un problema central de la investigación etnográfica, en tanto no pueden

\footnotetext{
${ }^{23}$ Diversos informes de investigación publicados por investigadores de la UNICEN, dan cuenta de este fenómeno, recuperando la voz de los actores barriales: Gravano (2005); Chapato y Errobidart (2013).

${ }^{24}$ Informe de la Agencia de Noticias de la FACSO-UNICEN, junio de 2012 (www.facso.unicen.edu.ar)
} 
eliminarse ninguno de los dos polos. Ello se resuelve, de acuerdo con la autora, de la siguiente manera:

\footnotetext{
"Dentro del trabajo etnográfico existe un marco particular, el del ámbito cotidiano, que de hecho presupone un recorte de escala. El trabajo empírico se realiza en el marco de un "pequeño mundo", accesible temporal y espacialmente mediante la experiencia directa del investigador. Este marco es punto de partida necesario en ambas direcciones (Rockwell, 2007:77)"
}

La desigualdad económica y social se profundiza en relación a los años 90. Todas estas particularidades señaladas impactan también en el campo de la educación, en esta ciudad media que ve reconfigurada su dinámica.

\subsubsection{La muestra}

La muestra definida para la concreción de la investigación está constituida por cinco escuelas del nivel secundario del partido de Olavarría. Sin intención de constituir una muestra representativa -que no tendría caso, vistos los propósitos mencionados-, los primeros pasos se orientan a conocer el universo de escuelas secundarias del partido. Para ello fue consultada la página web oficial de la Dirección General de Cultura y Educación, Portal $A B C^{25}$, para tener acceso a los datos sobre el mapa de escuelas de la provincia $y$, en particular, de las escuelas secundarias (de gestión pública y privada) de la ciudad de Olavarría ${ }^{26}$.

La consulta de la reglamentación existente se realizó con el asesoramiento y acompañamiento de los agentes que se desempeñan en el Centro de Investigación Educativa (CIE) que depende de la Dirección de Educación Superior, área de Capacitación, de la DCyE, con sede en Olavarría. Se constató en diversas oportunidades, que los actores escolares no habían tomado conocimiento de la nueva normativa (las leyes promulgadas y los

\footnotetext{
${ }^{25}$ www.abc.gov.ar

${ }^{26}$ Los datos obtenidos en el año 2009, se presentan en el Anexo Documental y Metodológico, Anexo I, cuadros 1 y 2.
} 
documentos oficiales que transmiten una nueva concepción de educación formal y de escuela secundaria)

Consultada la Resolución № 01/07 de la DGCyE, se observa que en el año 2009 coexisten en la Provincia de Buenos Aires, tres tipos de escuelas secundarias: escuelas de fusión, escuelas de crecimiento y escuelas de creación ${ }^{27}$, cuyas características se desarrollan en el Capítulo 3. La cantidad de escuelas secundarias (considerando los distintos tipos mencionados con anterioridad) en la ciudad de Olavarría, asciende en 2009 a 24 escuelas de Secundaria Básica (SB) de gestión estatal y 11 escuelas de gestión privada. Dadas las características de la investigación, se decide la construcción de una muestra intencional para realizar el trabajo de campo.

Los criterios para seleccionar las escuelas son los siguientes:

-por su tipología: de fusión y de complementariedad

-por la localización de la población que atiende: se seleccionan escuelas urbanas, suburbanas y rurales

-por el tipo de gestión: públicas y privadas

-por las características socioeconómicas y culturales de la población que reciben: media alta, media-media, media baja y baja

- accesibilidad para la investigadora

Las primeras exploraciones en el terreno se realizaron en 9 escuelas: 2 rurales, 2 suburbanas, 2 privadas urbanas, 2 urbanas y una universitaria ${ }^{28}$.

Finalmente, se decide comenzar el trabajo de campo en cuatro escuelas de gestión estatal: ESB (urbana), ESB (rural), ESN (suburbana) y la Escuela Nacional dependiente de la UNICEN.

\footnotetext{
${ }^{27}$ Estos tipos de escuelas se organizan en función de dar albergue a nuevos públicos que no habían sido considerados por las leyes anteriores, y que bajo el mandato de obligatoriedad de la actual ley, deben ingresar al sistema.

${ }^{28}$ Una vez realizado el trabajo correspondiente al momento de exploración documental y en el campo, considerando los resultados de la encuesta aplicada a los alumnos y los relevamientos correspondientes a las categorías en estudio en la perspectiva sociología del curriculum, se observa una saturación en los resultados obtenidos que no aportan diferencias sustantivas entre las 2 escuelas rurales, urbanas y las 2 privadas, con lo cual se simplifica la muestra quedando reducida a 5 escuelas.
} 
De gestión privada se selecciona una escuela: la escuela católica parroquial. Suman en total 5 escuelas de Educación Secundaria Básica.

Parece importante aclarar que -excepto la escuela dependiente de la universidad- las restantes escuelas secundarias seleccionadas fueron inicialmente escuelas primarias y luego, en el marco de distintos proyectos políticos fueron incluyendo el nivel secundario ${ }^{29}$.

El universo de la investigación estará compuesto por los $570^{30}$ jóvenes que concurren a las 9 escuelas secundarias seleccionadas inicialmente.

Las unidades de análisis de la investigación son las prácticas políticas de los jóvenes. En principio, las prácticas se relevan en distintos ámbitos de desarrollo curricular establecidos por la DGCyE como espacios privilegiados para la construcción de ciudadanía y el ejercicio político en la escuela: la materia Construcción de Ciudadanía, los Centros de Estudiantes, los Acuerdos Institucionales de Convivencia.

\begin{tabular}{llllll}
\hline Unidad de & Prácticas & Prácticas & Prácticas & Prácticas & Prácticas \\
análisis & políticas de los & políticas de los & políticas de los & políticas de los & políticas de los \\
jóvenes & jóvenes & jóvenes & jóvenes & jóvenes \\
estudiantes de & estudiantes de & estudiantes de & estudiantes de estudiantes de \\
la & ESB & la & ESB la & ESB la ESB & la ESB rural \\
universitaria & confesional & centenaria & suburbana & \\
\hline
\end{tabular}

convivencia

participación

\section{demanda}

\footnotetext{
${ }^{29}$ Este aspecto se desarrolla en el Capítulo 3 “Historia, cultura y curriculum en la construcción de la ciudadanía en la escuela secundaria. 30 años de historia para comprender el presente".

${ }^{30}$ Este número corresponde a la cantidad de jóvenes que respondieron a la primera encuesta exploratoria que se a realizó al inicio de la investigación, y no a la cantidad de estudiantes "reales" que concurren a las escuelas seleccionadas.
} 
Las categorías con que se define la ciudadanía, son convivencia, participación y demanda, cuyos alcances conceptuales se abordan en el capítulo 2.

Todo lo anteriormente expuesto, incide en la selección de las técnicas o herramientas metodológicas para la recolección de información y construcción de los datos, que no pueden pensarse de manera independiente de las características del problema y objeto de estudio. Se trabajó, principalmente, con entrevistas semiestructuradas y en profundidad, pautadas y casuales, y también con registros de observaciones.

Se construyeron datos apelando a diversas fuentes e instrumentos, y como señala Van der Maren (1999), por las características contextualizadas de su origen pueden agruparse en: datos invocados, datos provocados y datos suscitados. Los datos invocados son aquellos a los que acude el investigador, orientado por los intereses de la indagación, en el vasto y heterogéneo territorio de la información preexistente, cuya construcción fue ajena a sus propósitos, pero atrayente para la lectura hermenéutica. Los datos invocados fueron los datos obtenidos a través del "archivo" (documentos oficiales, libros de texto escolar, resoluciones, invitaciones a eventos, cuaderno de comunicaciones, actas, etc) y aquellos que se obtuvieron por observación directa sin alterar el curso "normal" de las actividades. Los datos provocados fueron construidos a través de instrumentos específicos de la investigación, como las entrevistas y el focus group; su formato y las condiciones de aplicación dependen exclusivamente del investigador. $Y$ finalmente, los datos suscitados refieren a los que se construyeron en situaciones similares a las corrientes, pero con la presencia de la investigadora. En nuestro caso incluimos en esta categoría a las conversaciones y cualquier otro tipo de interacciones que proporcionaran información relevante, una intencionalidad consustancial con sus intereses.

Cabe aún señalar que esta investigación que se ubica en el grupo de investigaciones de tipo cualitativo, se define como socio-antropológica por las razones que se exponen a continuación: si bien se realiza una prolongada inmersión en el campo para desentrañar los sentidos construidos por los jóvenes en torno de la ciudadanía en contextos escolares, no se ha centralizado, como lo hacen la mayoría de los estudios antropológicos, en el concepto de cultura. Las perspectivas etnográficas educativas tienen esa tradición, referenciadas 
especialmente en los estudios de Elsie Rockwell y Justa Ezpeleta, entre otras que así lo manifiestan.

Esta investigación presenta, a su vez, un fuerte componente de tradición interpretativa en el campo de la sociología de la educación, por lo que se ha preferido ubicarla en la denominación de estudio socio-antropológico.

\section{2.- En el campo}

Se identifican tres momentos en el desarrollo de la investigación. Los tres momentos que se desarrollan a continuación no deberían interpretarse como experiencias secuenciadas o fragmentadas entre sí y tampoco separadas en el tiempo por algún hecho puntual. En especial, en el caso de los momentos 2 y 3 , puede advertirse en la descripción que se realiza en el Capítulo 3 una especie de superposición ${ }^{31}$ puesto que la permanencia en el campo que implica el segundo momento, habilita para la comprensión y el registro de prácticas juveniles, entrevistas espontáneas y los sentidos atribuidos a tales acciones, que se han ubicado en el tercer momento.

\subsubsection{Se describe un primer momento de exploración en escuelas secundarias}

seleccionadas, en el que se realizaron relevamientos de información estadística proveniente de la DGCyE (2009) y DINIESE (2010) que aportó a la caracterización general de la implementación de la "nueva escuela secundaria". Esto permitió identificar cantidad de escuelas, estudiantes que asisten a este tramo de la ES, ubicación, etc.

También se realizaron acciones orientadas al conocimiento específico de los jóvenes alumnos que concurren a las escuelas, participando en diferentes eventos que los reunían o realizando seguimientos de sus acciones por medios gráficos.

Esta fase exploratoria de la investigación amplió la comprensión del campo empírico en que se manifiestan las prácticas políticas de los jóvenes, permitiendo la anticipación no solo de

\footnotetext{
${ }^{31}$ Como imagen, cabe considerar el juego de muñecas rusas -Mamushkas o Matrioshkas-, que contienen nuevas figuras en su interior, iguales o diferentes en su forma y expresión, pero que remiten a la idea de concepción, albergue, con-cavidad.
} 
aspectos metodológicos sino también la realización de ajustes a la formulación del problema.

El interés original de la investigación orienta las acciones exploratorias hacia los jóvenes, a partir de la necesidad de comprender a estos niños-jóvenes entre 11 y 18 años que aparecen como destinatarios de distintos intereses políticos, sociales, culturales, en los primeros años de este joven milenio.

En la última década, la presencia de la juventud en distintos ámbitos de la vida social ha adquirido una notoria relevancia. A diferencia de la década de los ` 90 donde a los jóvenes se los visualizaba principalmente como nuevos sujetos de consumo y como portadores de peligrosidad social (Reguillo Cruz, 2000), en la primera década del siglo se observa un resurgimiento de los jóvenes en el campo social, político, cultural, pero en este caso, como sujetos portadores de derechos, cuestión que ha producido nutridos debates y una profusa producción de conocimiento en el campo académico.

Una de las primeras aproximaciones a los jóvenes se realiza en un club, en una práctica deportiva de un equipo de softball. El equipo olavarriense perteneciente a una escuela secundaria pública de la ciudad (EB urbana, en la muestra), logró el primer puesto en los Torneos Deportivos Juveniles Bonaerenses (2008) y, a su regreso de la ciudad de Mar del Plata (sede de los juegos), ningún representante escolar asistió a recibirlos. Esa situación reveló un conflicto entre escuela- alumnos- club- padres, que motivó la inclusión de la escuela urbana involucrada en la muestra definitiva. Las expresiones de los jóvenes, padres y profesores participantes del evento, exponían niveles de divergencia respecto de la relación de las autoridades escolares con los estudiantes, que ponían en descubierto pujas y supuestas disputas de poder en la escuela.

Otro evento del cual se participó fue organizado por la Facultad de Ciencias Sociales de UNICEN y consistió en las Jornadas "Sociales en acción" con la participación de estudiantes de 3er año de la ESB y estudiantes que cursan la etapa superior de la escolaridad secundaria. En esas Jornadas se realizaron talleres sobre temas de interés de los jóvenes, desde el abordaje conceptual y metodológico de las ciencias sociales. Las voces de los jóvenes fueron las protagonistas de todo el encuentro, en el que señalaron especialmente las 
contradicciones que se presentan cuando son reconocidos como sujetos de derechos, pero en la práctica esos mismos derechos les son cercenados.

Con un abundante bagaje de conocimientos producto de esta primera exploración ${ }^{32}$, junto al análisis documental en la dimensión técnico-política (sanción e implementación de nuevas leyes sobre la situación de los jóvenes en Argentina), la inquietud dominante se concentraba en la pregunta ¿Quiénes son éstos jóvenes? ¿Cómo piensan y viven las prácticas políticas? ¿a qué escuelas van, qué hacen en la escuela en relación a su construcción como sujetos políticos?. Se decide, entonces, la elaboración y aplicación de una encuesta, considerando que de este modo, podría obtener información de interés en relación a los objetivos y a la hipótesis planteada, desde la perspectiva de los actores implicados.

Se seleccionaron 9 escuelas para la aplicación de la encuesta. En una de las escuelas suburbanas no pudo realizarse en todos los cursos de la ESB por conflictos internos que derivaron en el funcionamiento de la escuela con control policial ${ }^{33}$. Este hecho contribuyó al abandono de esta escuela suburbana para la integración en la muestra definitiva.

Acerca de los propósitos de la encuesta aplicada. La primera parte de la encuesta releva datos referidos a: composición del grupo familiar, trabajo del padre y de la madre, nivel educativo alcanzado y otras actividades que cada uno realiza por fuera de la actividad doméstica o laboral. La información obtenida en esta primera parte de la encuesta, permitirán obtener una visión de las posiciones sociales de los jóvenes que integran el universo de estudio.

\footnotetext{
${ }^{32}$ Diversos relatos referidos a situaciones extraescolares relevados en esta etapa serán analizados en los capítulos subsiguientes. En este punto, solo se han mencionado dos de modo ilustrativo.

${ }^{33}$ Una riña armada entre estudiantes de ESB que finalizó con detenidos y un preceptor hospitalizado, hizo que las autoridades educativas pidieran control policial. Este asunto produjo un debate mediático denso en el que comenzaron a ponerse en evidencia las dificultades que encontraba la nueva escuela media de sectores excluidos para empezar a funcionar. La directora de la escuela solicitó que pospusiera por un tiempo mi concurrencia, por lo que se perdió la posibilidad de aplicación de la encuesta.

La situación no se resolvió en esa comunidad educativa. Finalmente los estudiantes fueron destinados a otras escuelas definidas por la UEGD (unidad educativa de gestión distrital), hasta tanto se finalizara la construcción de una nueva escuela en ese barrio (cabe aclarar que será ésta la única escuela que se construyó en la ciudad para atender a las nuevas poblaciones de estudiantes secundarios)
} 
Las preguntas $1^{34}, 2^{35}, 3^{36}$ y $4^{37}$ brindan información sobre cómo piensan la ciudadanía los jóvenes (positivamente, entendida como acción, participación en diferentes situaciones de las que son protagonistas; negativamente, como ficción, o como acción ritual) y si se traduce en prácticas políticas en la escuela. La pregunta 4 permite conocer además, las posiciones que ocupan en los espacios habilitados por el sistema educativo para el ejercicio de la política en la escuela.

La consigna $5^{38}$ pretende rastrear otros espacios, por fuera de la escuela, donde los jóvenes producen prácticas políticas orientadas a la convivencia, demanda y decisión-acción, jerarquizando las actividades en función del tiempo dedicado.

La pregunta $6^{39}$ se orienta a detectar jóvenes con potenciales actitudes positivas hacia las prácticas políticas pero que aún no han encontrado la oportunidad de participar.

El criterio de selección de los cursos se definió fundamentalmente por su existencia concreta $^{40}$. En los primeros meses de 2010 se cargaron los datos de las encuestas en el programa SPSS 13 Base (Pardo Merino y Ruiz Díaz, 2005). Así se comenzaron a obtener los primeros datos generales, de tipo cuantitativo, que permitieron una aproximación más precisa sobre los jóvenes, las escuelas y los contextos sociales en que éstas funcionan.

Mientras tanto, se realizó una exploración en las escuelas que permitió relevar acciones o programas que vinculan a los estudiantes de 1ㅇ, 2으 y 3er año ESB con actividades socioculturales, de participación política, de prácticas solidarias, campañas preventivas, etc. Se solicitó para su análisis la programación de los espacios curriculares "Construcción de ciudadanía" y se obtuvo la autorización para la observación de clases.

\footnotetext{
${ }^{34}$ ¿Qué es para vos la ciudadanía?

${ }^{35}$ ¿Con qué la relacionás?

${ }^{36}$ ¿Qué prácticas vinculadas con la ciudadanía realizás en la escuela?

${ }^{37}$ Has participado o participás de laguna actividad solidaria, preventiva, en defensa de algo o de alguien, puesta en valor de derechos, espacio político -como centro de estudiantes, etc? ¿Cuál?

${ }^{38}$ La consigna dice: "Cuando no estás en la escuela, ¿̇en qué actividades participás?. Coloca un número a la de mayor tiempo dedicado, comenzando por 1". Se enumeran las siguientes actividades: ayudas a tu familia; integras un grupo de voluntariado; participás en instituciones del barrio (cuáles?); participás en el centro de estudiantes; ¿Vas a un club?, ¿practicás algún deporte? ¿Cuál?; participás en un movimiento ecológico?; sos miembro de una iglesia?; tenés una banda?; mirás tele?; chateas?; formás parte de una red virtual?, cuál?; estás en la calle (plaza, centro, ciber, etc); otros...

${ }^{39}$ ¿En qué otras actividades - que no realizá-s te gustaría participar?

${ }^{40}$ Algunas escuelas de reciente creación como ESB 2, Escuela Secundaria Universitaria y el pluriaño rural, no cuentan con todos los cursos en marcha al momento de la realización de la encuesta (año 2009).
} 
Se realizaron 570 encuestas, distribuidas del siguiente modo $^{41}$ :

\begin{tabular}{|c|c|c|}
\hline Escuelas ESB & Cantidad de alumnos & Porcentaje \\
\hline ESB 1 & 118 & 20,7 \\
ESB 5 & 120 & 21,1 \\
ESB 6 & 242 & 42,5 \\
ESB 7 & 15 & 2,6 \\
ESB 10 & 54 & 9,5 \\
ESB 2011 & 13 & 2,3 \\
ESB 2010 & 8 & 1,4 \\
Total & 570 & 100,0 \\
\hline
\end{tabular}

La escuela pública urbana (identificada con el № 6) es la que provee a la investigación de la mayor cantidad de estudiantes para ser encuestados (42.5\%). La encuesta se aplica en primero y segundo de la ESB, que funcionan en el turno de la mañana, junto a toda la estructura del nivel secundario que históricamente (desde su creación en el año 1910) ha desarrollado sus actividades pedagógicas y administrativas en ésta franja horaria ${ }^{42}$. Algunos cursos de primer año (que se corresponde con el ex 70 grado) continúan en el turno en que funciona el nivel de Educación Primaria, en el horario de la tarde.

Luego, la escuela privada parroquial (identificada con el № 5) presenta una cantidad de estudiantes (21.7\%) que la posiciona en segundo lugar por su tamaño; le sigue la escuela secundaria universitaria (identificada con el № 1, con un 20.7\%) y, con cantidades muy

\footnotetext{
${ }^{41}$ Cuadro № 1, Anexo Metodológico V. Como se especifica en la "Grilla de codificación de encuestas a alumnos de ESB de escuelas públicas y privadas del partido de Olavarría" (Anexo Metodológico V), las escuelas se identifican con un número asignado a los efectos de mantener a resguardo su identidad y la de sus actores:

1. Escuela secundaria universitaria

10. Escuela suburbana pública, de reciente creación

2010. Escuela secundaria rural (seleccionada)

2011. Escuela secundaria rural (luego, sale de la muestra)

5. Escuela privada religiosa

6. Escuela urbana pública, centenaria

7. Escuela privada (luego, sale de la muestra)

${ }^{42}$ Esta breve referencia permite inferir la tendencia conservadora y la valoración de la tradición que empapa a la cultura institucional de esta escuela
} 
inferiores de estudiantes, la escuela suburbana (identificada con el №7, que aporta el 9.5\%) y las escuelas privada (identificada con el № 4, que aporta el $2.6 \%$ de estudiantes) y rurales (identificadas con los № 2010, que aporta el 1.4\%, y 2011, con el 2.3\%).

Mientras que las entrevistas a los equipos directivos permitieron identificar elementos relevantes para comprender la organización y el desarrollo curricular implementados desde el año 2007, ésta información -junto a la que fue recogida a través de la observación-, hizo posible tomar conocimiento de la existencia -con cierta regularidad en todas las escuelas- de las siguientes acciones vinculadas con la política y la ciudadanía, previstas por la política curricular oficial:

-la creación de Centros de Estudiantes

-el desarrollo de la materia Construcción de Ciudadanía

-la creación de los Acuerdos Institucionales de Convivencia

-proyectos extracurriculares de vinculación con la comunidad

\subsubsection{Un segundo momento, de permanencia en el campo y comprensión de las tramas}

socioculturales que organizan la vida en la escuela y en las que se producen las prácticas políticas que desarrollan los jóvenes. Se realiza una permanencia prolongada en las escuelas seleccionadas, apelando a una elaborada disposición para comprender lo que allí sucede. Esto significa intensificar la capacidad de percepción de la realidad agudizando el análisis y la reflexión (Goetz y Le Compte, 1988; Ameigeiras, 2007; Guber, 2008). La principal estrategia metodológica utilizada es la observación participante.

De acuerdo a las expresiones de Guber (2011):

"La observación participante, entonces, abandona el ámbito de las "técnicas" concebidas unilateralmente desde el medio académico, para constituir una expresión en que los lugareños y sus investigadores negocian los términos de su relación y, al hacerlo, producen (mutuos) comprensión y conocimiento".

Se relevaron los espacios formales creados por la política educativa para fortalecer la práctica política de los estudiantes, orientados a la construcción de ciudadanía: materia Construcción de Ciudadanía, Centro de Estudiantes, Concejos de Convivencia Institucional. Ya 
en el campo, se registra una nueva (o al menos no prevista en la documentación del curriculum escolar) estrategia de formación política de los jóvenes, que ingresa a las escuelas (solo a tres de las escuelas seleccionadas), desde la noosfera del sistema político: los Concejos Deliberantes Estudiantiles.

Cabe aclarar que la indagación no se circunscribe exclusivamente a las prácticas que se producen en los espacios mencionados sino que, a partir de la presencia en estos espacios, se abren nuevas posibilidades de capturar situaciones y episodios críticos en los que se pudieron profundizar categorías como cultura escolar, cultura juvenil, dislocación de las relaciones entre culturas, emergencia de nuevas prácticas políticas en la escuela. El propósito del trabajo en esta etapa fue participar en la vida cotidiana escolar, de modo tal que esa participación condujera a aquellos ámbitos donde las prácticas políticas estudiantiles se manifestaran.

Resulta consistente con lo anterior, una expresión de Diana Milstein (Errobidart, 2012):

"Quisiera hacer una reflexión sobre esto: el campo no es el territorio (o no es sólo el territorio), como podría pensarse, en este caso, la escuela, el barrio, la Salita. El campo lo constituyen las relaciones sociales sobre las que estoy problematizando, no se reducen a la localidad. Es más: cuanto más variedad de espacios encuentro, más se enriquece el trabajo".

El estilo de indagación descripto por Milstein (2009) aportó orientaciones significativas a esta investigación para el relevamiento de acciones fuera del ámbito escolar, en tanto que, cuando las circunstancias lo ameritaron, salimos del ámbito escolar para seguirlas acciones de los sujetos en otros espacios.

El posicionamiento teórico- metodológico de la investigación implica una integración y puesta en tensión permanente entre los datos recogidos y la teoría, por lo cual el proceso se torna intenso. Las construcciones e intuiciones que acompañan al investigador reorientan las decisiones metodológicas y orientan la búsqueda de nuevas referencias teóricas, o su producción (Guber, 2008).

En el caso que nos ocupa, cada escuela es una realidad en sí misma y las particularidades de su dinámica han sido desarrolladas en el Capítulo 3. Este trabajo no es una etnografía en sentido estricto, pero se nutre de su perspectiva epistemológica y de muchas de sus 
estrategias metodológicas para poder penetrar lo que es visible, lo que subyace debajo de lo que parece evidente y así, construir o reconstruir los sentidos de las prácticas políticas juveniles, enlazados en la trama de la vida cotidiana de la escuela secundaria.

En relación a esta perspectiva, dice Willis (1977: 17):

"Para responder alguna de aquellas cuestiones y contradicciones debemos traspasar la superficie de la etnografía con un análisis más interpretativo. Sugiero que podemos acercarnos a una comprensión más profunda de la cultura que hemos estudiado por medio de las nociones de penetración y limitación".

La primera noción refiere al reconocimiento dentro de una cultura institucional, de las condiciones de existencia de sus miembros y de las posiciones sociales de los sujetos. La segunda, refiere a obstáculos y desviaciones que confunden. Es la articulación entre ambos conceptos lo que favorece la interpretación ${ }^{43}$.

La diversidad de situaciones que cada escuela presenta y las posibilidades-obstáculos que cada una presenta para que los estudiantes desarrollen prácticas políticas, ha sido uno de los ejes o esquemas que orientaron en cada caso, las preguntas que condujeron a la formulación del problema ${ }^{44}$. "En la práctica, entonces, el campo no servía para ratificar hipótesis, sino para generarlas, y más radicalmente aún, para producir un conocimiento inesperado y nuevo" (Guber, 2008: 47).

En esta etapa de la indagación, se redefinió ${ }^{45}$ la muestra, haciendo un recorte de la muestra inicial, que quedó constituida del siguiente modo:

\footnotetext{
${ }^{43}$ Es interesante aclarar que $\mathrm{P}$. Willis escribe su reconocida etnografía en una escuela secundaria marginal de Inglaterra en la década de 1970, conviviendo durante dos años con los jóvenes de la escuela, dentro y fuera de ella.

${ }^{44}$ En el punto 2.2 "Los jóvenes en las escuelas secundarias: prácticas y estrategias políticas", del Capítulo 2, se tomará como categoría sociológica principal para comprender la interacción de sujetos en una estructura, la noción de configuración social de Norbert Elías.

Para cada configuración se analizará la historia y el ideario institucional en tensión con las particularidades de los grupos de jóvenes que la integran en la actualidad. En ella, las distintas actividades previstas -que son enunciadas desde la política educativa como actividades comunes a todas las escuelas- acerca de la política y lo político, como ámbitos de expresión cotidiana, permiten recoger información que luego se elabora como dato en su interpretación teórica.

${ }^{45}$ Esta redefinición se produce atendiendo al criterio de accesibilidad y economía de la investigación: en el caso de las dos escuelas rurales, las poblaciones y problemas estructurales presentaban características similares, pero una de ellas, la que quedó integrando la muestra, generó mayores condiciones de trabajo: rapport, rápida incorporación en el tratamiento de las problemáticas que se generaban. En el caso de la escuela de DIPREGEP que se quita de la muestra, esta decisión expone los siguientes argumentos: la escuela (donde se realizan las primeras encuestas) quiebra económicamente en el año 2009 y en el año 2010 reabre con otro nombre y convertida en una Cooperativa de Docentes. Los problemas de índole legal y
} 
- estudiantes de primero y segundo año de ESB № 2, escuela secundaria universitaria, que a partir del año 2008 inicia el ciclo de ESB. Es de gestión pública

-estudiantes de primero, segundo y tercer año de ESB № 7, de gestión pública -estudiantes del pluriaño (años integrados) de ESB № 5, escuela rural de gestión pública

-estudiantes de primer y segundo año de ESB №4 de la escuela secundaria de gestión privada

-estudiantes de primer y segundo año de la ESB № 1, de gestión pública

Si bien la Educación Secundaria Básica incluye 1ำ,ํㅜ y 3o años, en las escuelas con matrícula alta la encuesta se tomó únicamente en los primeros y segundos años, por dos razones: porque el trabajo de campo prolongado hacía que, si se encuestaban los 3ros años, al año siguiente ya no se pudo encontrar a los estudiantes encuestados y porque en la prueba del instrumento en tres escuelas (tomadas como caso- piloto) la saturación de las respuestas no aportaba nuevos datos que justificaran un aumento tan importante del volumen trabajo.

En esta etapa, las ideas directrices fueron dos: continuar y profundizar la indagación con los jóvenes alumnos de la ESB y orientar el análisis hacia algunos puntos de la práctica curricular dedicados a la gestión de las actividades políticas de representación estudiantil y a las de construcción de la vida en común. La acción de los sujetos y las especificaciones curriculares institucionales se presentan separadas a los fines analíticos, pero deben ser comprendidas en la trama de la vida cotidiana en la que se concretan: determinadas prácticas se producen porque existe la posibilidad de que se produzcan, porque se ha generado esa disposición en la configuración escolar, porque la cultura, la historia, la circunstancia actual permite que se produzcan. 
El abordaje metodológico del curriculum se realizó a través de un análisis documental consultando para ello los documentos oficiales y analizando luego su interpretación en el contexto escolar. Para esta última instancia se seleccionaron los programas de la materia Construcción de Ciudadanía.

Se realizó el análisis del contenido curricular definido para la materia Construcción de Ciudadanía, con el propósito de hacer un análisis temático que "consiste en señalar los "nudos de sentido" que componen la comunicación y cuya presencia o frecuencia de aparición podría significar algo para el objeto analítico señalado" (Bardin, citado por Furlán; 1997: 154)

Se trabajó también registrando diversas situaciones escolares, tanto en el desarrollo de las prácticas de enseñanza-aprendizaje, como la observación de recreos, reuniones, funcionamiento de proyectos extracurriculares, actividades desarrolladas por preceptores en horas libres, entre otras.

Durante esta etapa se focalizó en dos grandes categorías de prácticas políticas escolares: las prácticas vinculadas a la "política" y las prácticas vinculadas a "lo político" ${ }^{46}$ de la vida escolar. Las primeras, refieren a las organizaciones formales previstas por la legislación y reglamentación vigente en las escuelas de enseñanza secundaria de la Provincia de Buenos Aires: Centros de Estudiantes ${ }^{47}$ y Concejo Deliberante Estudiantil ${ }^{48}$, donde se reproducen formas de participación similares, en su dinámica, a los procesos de gobierno democrático: presentación de propuestas, elecciones, mandatos, gestión.

La segunda, adopta dos tipos de formatos prescriptos: la incorporación, desde el año 2007, de la materia Construcción de Ciudadanía en la ESB $^{49}$, la construcción de Acuerdos de Convivencia Institucional ${ }^{50}$ y la articulación con nuevos programas sociales extracurriculares, que desde la DGC y E son sugeridos como posibilidad de trabajo conjunto, orientados a la

\footnotetext{
${ }^{46}$ Estas dos categorías (cuyo origen puede rastrearse en teóricos del posfundacionalismo político como Marchard y Lefort) operan con fuerza en el análisis de las prácticas políticas juveniles que se registraron.

${ }^{47}$ Res $4900 / 05$ de la DGE y C., Provincia de Buenos Aires

${ }^{48}$ Ordenanza 3180/08 del Honorable Concejo Deliberante de la ciudad de Olavarría

${ }^{49}$ Documento curricular para la ESB: Construcción de Ciudadanía. DGCyE Provincia de Buenos Aires

${ }^{50}$ RES 1709/09 de la DGCyE Provincia de Buenos Aires
} 
participación de los estudiantes en problemáticas contextuales. Esta última modalidad es más permeable a los acontecimientos de la vida cotidiana, presenta modificaciones y cambia de acuerdo a la dinámica escolar, propiciando la emergencia de prácticas políticas situacionales por parte de los jóvenes.

Tomando en cuenta las prescripciones curriculares y normativas -por un lado- y las prácticas que se desarrollan en el entramado de la cultura institucional y las adecuaciones a los actuales requerimientos de la educación secundaria, por otro, se identificaron los siguientes espacios orientados al desarrollo de prácticas políticas juveniles:

- Espacios de representación política estudiantil: Centro de Estudiantes y Concejo Deliberante Estudiantil (la política)

- Orientaciones para organizar la vida en común: Acuerdos Institucionales de Convivencia, materia transversal: Construcción de Ciudadanía y espacio institucional de trabajo comunitario o prácticas socioeducativas extracurriculares ${ }^{51}$ (lo político)

\subsubsection{El tercer momento de la investigación implicó la selección de situaciones o episodios (Milstein, 2009) que permitieran una profundización del sentido o significado que los jóvenes atribuyen a sus prácticas, para comprender mejor las tensiones entre la cultura escolar y la cultura juvenil, en las que se construye ciudadanía.}

Se realizaron encuentros intencionales con los jóvenes a efectos de generar debates en torno de las situaciones o episodios relevados en la permanencia en el campo durante la etapa anterior (cuyos datos generales se fueron almacenando).

Se realizó una devolución de los datos de la encuesta inicial, en busca de una reflexividad compartida con los estudiantes (Guber, 2008) y se problematizaron las situaciones más significativas. En torno de ellas se realizaron, posteriormente, sesiones de focus group, entrevistas en profundidad de manera individual o grupal., con el propósito de capturar los sentidos o significados que subyacen, en muchas oportunidades, a aquello que es naturalizado por el entorno escolar.

\footnotetext{
${ }^{51}$ Inspirado en el art. 32, Cap. IV de la Ley Nacional de Educación № 26206
} 
El trabajo con focus group, de acuerdo con las consideraciones de Sautu (2005: 47):“...no es solamente una técnica para recoger datos o producir información exploratoria...sino que es un método para lograr acceder a lo que Schultz (1972) denomina "la intersubjetividad o descripciones ordinarias de la realidad compartidas por la gente"”'

En el desarrollo de los focus group con los jóvenes, la investigadora debió mediar en algunos grupos muy enfrentados o generar nuevas preguntas para incentivar los debates, en otros, para que emergiera esa intersubjetividad mencionada.

Las entrevistas en profundidad, tal como sostienen Taylor y Bogdan (1992: 100), consisten en encuentros presenciales intensivos entre el investigador y el entrevistado, con los siguientes propósitos:

“...encuentros éstos dirigidos hacia la comprensión de las perspectivas que tienen los informantes respectos de sus vidas, experiencias o situaciones, tal como las expresan con sus propias palabras. Las entrevistas en profundidad siguen el modelo de una conversación entre iguales, y no de un intercambio formal de preguntas y respuestas."

En el caso que se presenta, estuvieron orientadas a profundizar en aquellos aspectos que se relevaron de manera previa en el campo a través de técnicas de recolección de información, apelando a la interacción y la confianza establecida a lo largo de la permanencia en el campo con el propósito de comprender más profundamente algunos aspectos o situaciones identificados como significativos por la investigadora.

El tercer momento de la investigación se inició con el ingreso y la permanencia en el campo de la etapa anterior, a efectos de comprender su dinámica. Involucrarse en la vida cotidiana de las instituciones, sus problemas, sus modos de relación y significación, implicó un modo de avanzar en el reconocimiento del campo, a través de un doble proceso. Por un lado, una actitud vigilante y alerta, atenta, que permitiera capturar las significaciones ocultas a las escenas cotidianas; esto es, relevar aquello que no es evidente de las situaciones sociales (Rockwell, 1995), lo que subyace a ellas y que no se hace explícito "de primera mano". Por otro lado, las situaciones relevadas condujeron a realizar una permanente búsqueda y consulta de autores de referencia en la elaboración del marco teórico con que se comprende el campo. 
Para relevar ambas significaciones prácticas de la política (esto es, como la política y lo político), se desarrollan dos estrategias metodológicas consecutivas con los jóvenes: un trabajo en pequeños grupos por el que se analizan las diferentes formas de participación política habilitadas por cada escuela y luego, una etapa de socialización y debate que busca poner en evidencia el sentido del tipo de participación relevado.

Un segundo momento de trabajo adoptó la dinámica de focus group y se construyó sobre el análisis del debate anterior. Esta estrategia pone en tensión los dichos y principios sostenidos en la socialización anterior, contraponiéndolos con hechos o sucesos de la vida cotidiana, que se tensionan la dinámica escolar: actitudes deshonestas en el transcurso de las elecciones de estudiantes, robo de celulares y otros objetos en el interior de los salones de clases, agresiones entre los mismos jóvenes dentro o a la salida de la escuela, peleas cotidianas en los grupos áulicos con distintos grados de violencia, relaciones conflictivas con adultos, entre otras, que no parecen canalizarse por ninguno de los dispositivos analizados en la primera parte del trabajo.

Se realizaron también entrevistas en profundidad a algunos de los estudiantes que hubieran expresado o realizado alguna práctica relevante para el caso en estudio, dando indicios de actitudes propositivas o positivas hacia algún tipo de práctica política o por la negatividad ante las mismas.

Esta estrategia de relevamiento permaneció abierta durante la etapa de escritura, considerando la posibilidad de que fuera necesario volver al campo y relevar aspectos puntuales que requieren aclaración o profundización.

La aplicación de los instrumentos de relevamiento utilizados en esta etapa. El contacto directo e intencional con los jóvenes estudiantes se intensificó en el año 2010-2011 con la excusa de realizar una devolución de los datos de la encuesta y conversar sobre algunas cuestiones que se desprenden de ella. Para ello, se acordó con los equipos directivos un encuentro en algún espacio escolar. Cada escuela particular interpretó el modo de proveer ese espacio. Mayoritariamente, realizaron un contacto con profesores que mantienen buen vínculo con cada grupo (curso), ya sean profesores tutores o profesores responsables de 
programas institucionales extracurriculares o profesores con buen rapport con los estudiantes.

La nueva reglamentación provincial acerca del "Régimen académico para la educación secundaria" ${ }^{52}$, generó una enorme preocupación en los equipos directivos ante el requerimiento específico de la normativa respecto de que los estudiantes no podrán retirarse de los establecimientos educativos durante las horas libres. En algunos casos se hizo el intento de "ubicar" en esos tiempos (las horas libres) las intervenciones solicitadas para esta investigación, requerimiento que fue aceptado siempre que algún responsable institucional (preceptor, bibliotecario, integrante del equipo directivo) se hiciera cargo de la disciplina y cuidado general del grupo.

La dinámica de trabajo presentó variaciones en cada escuela. Los instrumentos que se utilizan tienen el mismo formato y contenido, pero el modo de uso fue variando de acuerdo a las particularidades de cada escuela y de cada grupo de estudiantes, buscando en todos los casos un mayor aprovechamiento de los encuentros, en tanto cada instrumento permite un acercamiento más profundo en alguno de los aspectos incluidos en los mismos.

Devolución de los datos de la encuesta. Se utilizó inicialmente la información derivada de las encuestas (en el Anexo que acompaña a este capítulo, Instrumento №3), para retomar el contacto temático específico con los estudiantes. No se presentaron la totalidad de los datos sino aquellos que daban cuenta de la constitución del grupo (edad, sexo), de la trayectoria educativa familiar, de las actividades que los alumnos realizan cuando no están en la escuela y de las actividades que quisieran realizar. Luego, se presentaron las respuestas que dan a las preguntas orientadas a la significación de la ciudadanía y la participación política, organizadas en tres categorías conceptuales que son expuestas ante el grupo: "la política" como las actividades de la dimensión formal del concepto, asociadas a prácticas de gobierno y representación; "lo político", como la dimensión de la participación orientada a la

\footnotetext{
${ }^{52}$ Resolución 587/11: Régimen Académico para la Educación Secundaria de la provincia de Buenos Aires.
} 
convivencia y la construcción de la vida en común y una tercera categoría que emerge de las respuestas que se articulan o mixturan, las dos anteriores ${ }^{53}$.

El análisis de las respuestas y los cuestionamientos que las acompañan dieron lugar a la segunda parte del trabajo para la que se utilizó la técnica de focus group ${ }^{54}$. El desarrollo de esta técnica adoptó una modalidad creativa, adecuada a las posibilidades que brinda el contexto escolar. Los focus group se organizaron para 6-8 integrantes, mientras que los grupos escolares son -en general- mucho más numerosos. Se establecieron acuerdos de trabajo en los distintos cursos y se organizó el aula en un gran círculo de alumnos y en el centro, funcionó el grupo focal, que respondía a las preguntas del coordinador (investigador). Cuando las respuestas no eran compartidas por los estudiantes del círculo externo -los que no integraban el focus group- pedían la palabra para introducir nuevas perspectivas. Esta dinámica adquirió características especiales en cada escuela.

Estos encuentros fueron grabados y, en algunos casos, los docentes o preceptores tomaron notas de lo que sucedía en el aula. Cada informe o registro fue ampliado posteriormente por la investigadora.

El proceso de elaboración analítica de los registros (Guber, 2004; Achilli, 2003; Rockwell, 1995; Willis, 1998) resultó indicativo de la necesidad de administración de entrevistas en profundidad con alguno de los integrantes de los grupos (en el Anexo que acompaña este capítulo, Instrumento № 5). Las entrevistas, aunque pautadas y realizadas en contextos adecuados para ese fin, siguieron la premisa de "no directividad", favoreciendo la fluidez de la comunicación, haciéndola más distendida y profunda.

\subsection{3.-Acerca de la escritura de las prácticas para la elaboración del Informe de Investigación}

\footnotetext{
${ }^{53}$ Por ejemplo, cuando en el marco de actividades políticas formales se generan fisuras que permiten que fluyan intereses o demandas genuinas no contempladas en ese formato (Centro de Estudiantes, AIC)

${ }^{54}$ El instrumento propiamente diseñado, forma parte del Anexo Documental y metodológico, Anexo IV, Instrumento № 4.
} 
A partir de la reconstrucción de las prácticas relevadas en las diferentes configuraciones educativas, y a través de un trabajo interpretativo de los distintos tipos de registros (registros de campo, producciones de los jóvenes, registros de audio), se presentarán tres capítulos analíticos que constituyen los aportes principales de la investigación. Su escritura revela la interpretación de ciertas prácticas desarrolladas por los jóvenes, en configuraciones sociales que actúan a la vez como una sedimentación generada a través de la experiencia histórica, y como campos de posibilidades y espacios de interlocución inteligibles para quienes interactúan (Elías, 1998).

Las interacciones de los sujetos, el conocimiento de la psicogénesis y sociogénesis de las prácticas políticas que se realizan en las distintas escuelas, permiten aportar conocimiento local acerca de la construcción de ciudadanía, tomando como ejes las categorías con que se releva la acción política de los jóvenes: participación, convivencia y demanda en la vida escolar. El análisis interpretativo de las prácticas de los jóvenes en relación con cada una de ellas se constituye en un capítulo del informe de la investigación, con la intención de analizar cómo cada una de las categorías, consideradas constitutivas de la subjetividad política orientada a producir una ciudadanía activa, cobra particularidades y ciertos rasgos comunes, en el desarrollo de los procesos educativos relevados.

La escritura de esta investigación se corresponde con la que Almegeiras (2007) denomina "escritura temática", combinando las expresiones que dan lugar a la primera persona (los actores) con el análisis y la interpretación de la investigadora. 


\section{Bibliografía:}

ACHILLI, E. (2005). Investigar en Antropología Social. Laborde Editor, Rosario.

AMEIGEIRAS, A. (2007). El abordaje etnográfico en la investigación social. En Vasilachis de Gialdino (comp): Estrategias de investigación cualitativa. Gedisa, Buenos Aires.

BOURDIEU, P. (1997): Razones prácticas. Sobre la teoría de la acción. Anagrama, Barcelona. (2007): El sentido práctico. Siglo XXI. Argentina.

BUIS, E. (2011). "Sobre gnomos y gigantes: los tratados grecorromanos y la igualdad soberana de los Estados como ficción histórico-jurídica". Revista Lecciones y Ensayos, Nro. 89, 2011, Facultad de Derecho. UBA. Pp 73.117

CALDERON, F. (2007). Ciudadanía y desarrollo humano. PNUD- Siglo XXI, Argentina.

CHAPATO, M.E. y ERROBIDART, A. (comp.)(2013). La educación como práctica sociopolítica. Los sentidos de educar que se construyen desde abajo. Aportes para la comprensión de la educación bajo el imperativo de inclusión social. Miño y Dávila, Buenos Aires.

CHAVES, M. (2010). Jóvenes, territorios y complicidades. Una antropología de la juventud urbana. Espacio editorial, Buenos Aires.

COREA, C. y LEWKOWICKZ, I. (2004). Pedagogía del aburrido. Escuelas destituidas, familias perplejas. Paidos, Buenos Aires

ELÍAS, N (1989): El proceso de la civilización. Investigaciones sociogenéticas y psicogenéticas. FCE, México.

-(1998): Mozart, sociología de un genio. FCE, México.

(1999). Sociología fundamental. Gedisa, Barcelona.

ERROBIDART, A. (2006): “...de los conocimientos a las prácticas. Configuraciones sociales y didácticas en la enseñanza de la Comunicación Social. Estudio realizado con practicantes del Profesorado de Comunicación Social, FACSO. UNICEN." Inédita.

(2012): “Entrevista con Diana Milstein: Conversaciones sobre el compromiso militante con la investigación social". Revista INTERSECCIONES EN COMUNICACION. Año 6/№6/ciclo 2012.FACSO- UNICEN, pp.191-208

FURLÁN, A. (1997): La ideología del discurso escolar. ENEPI- UNAM. México DF. 
GARCÍA DELGADO, D. y NOSETTO, L. (2004). “La Ciudadanía en una etapa de reconstrucción: imaginarios y desafíos". Boletín Virtual TOP (Tecnología para la organización pública) № 10. http://www.top.org.ar/boletin/boletinn10.htm

GESSAGHI Y SENDÓN (2008): Socializaciones y disposiciones heterogéneas: sus vínculos con la escolarización. Entrevista a Bernard Lahire. Dossier Revista Na 30 Propuesta educativa. FLACSO.

GIROUX, H. (1983): Teorías de la reproducción y la resistencia en la nueva sociología de la educación: un análisis crítico. Publicado originalmente en Harvard Education Review No. 3, 1983. Traducción de Graciela Morzade. Buenos Aires. Disponible en:

www.pedagogica.edu.co/storage/rce/articulos/17 07pole.pdf (visitado el 20 de noviembre de 2012)

-(1993). La escuela y la lucha por la ciudadanía. Siglo XXI, Buenos Aires

-(2010). La educación y la crisis del valor de lo público. Desafiando la agresión a los docentes, los estudiantes y la educación pública. Criatura editora, Montevideo.

GOETZ, J. y Le COMPTE, M (1988) Etnografía y diseño cualitativo en investigación educativa. Morata, Barcelona.

GOODSON, I. (2000). El cambio en el curriculum. Octaedro, España.

GRAVANO, A. (2005). Imaginarios sociales de una ciudad media. Emblemas, fragmentos y otredades urbanas. Estudios de Antropología Urbana. REUN, FACSO- Publicación de la Universidad Nacional del Centro de la Provincia de Buenos Aires, Tandil.

GUBER, R. (2008). El salvaje metropolitano. Reconstrucción del conocimiento social en el trabajo de campo. Paidós, Buenos Aires.

GUBER, R. (2011). La observación participante como sistema de contextualización de los métodos etnográficos. La investigación de campo de Esther Hermitte en los Altos de Chiapas, 1960-1961. Revista Latinoamericana de Metodología de las Ciencias Sociales. Publicación electrónica de la FCH y S. UNLP. [S.I.], v. 1, n. 2, p. 60-90, nov. 2010. ISSN 1853-7863.

Disponible en: http://www.relmecs.fahce.unlp.edu.ar/article/view/v01n02a04/11.

GUTIÉRREZ, A. (1994). Pierre Bourdieu: las prácticas sociales. CEAL, Buenos Aires. JACKSON, Ph. (1998). La vida en las aulas. Madrid, Morata. 
KESSLER, G. (1996). Adolescencia, pobreza, ciudadanía y exclusión. En KONTERLLNIK I. y JACINTO C. Adolescencia, pobreza, educación y trabajo. Losada, Bs. As.

KESSLER, G.; SVAMPA, M. Y GONZALEZ BOMBAL, P. (2010) (coord.). Reconfiguraciones del mundo popular. El Conurbano Bonaerense en la postconvertibilidad. UNGS-Prometeo, Buenos Aires.

KYMLICKA, W. y NORMAN, O. (1997). El retorno del ciudadano. Una revisión de la producción reciente en teoría de la ciudadanía. ÁgorA núm. 7/invierno de 1997, p: 5-42. Fundación CEPS, España.

LAHIRE, B. (2003). El trabajo sociológico de Pierre Bourdieu. Deudas y críticas. Siglo XXI, Buenos Aires.

----------(2004). El hombre plural. Los resortes de la acción. Bellaterra, Barcelona. (2008). Reconfiguraciones de la comunicación entre escuela y sociedad. En TENTI FANFANI (comp): Nuevos temas en la agenda de la política educativa. Siglo XXI, Buenos Aires.

MARSHALL, Th. (1949). Ciudadanía y clase social. FCE, México.

MILSTEIN, D. (2009). La Nación en la escuela. Viejas y nuevas tensiones políticas. IDES- Miño y Dávila, Buenos Aires.

OSZLAK, O. (1999). "De menor a mejor: el desafío de la segunda reforma del Estado". Revista Nueva Sociedad, № 160, Venezuela.

PALAMIDESSI, M. (2007) Introducción. En Palamidessi, M.; Suasnabar, C. y Galarza, D. (comp): Educación, conocimiento y política, Argentina, 1983-2003. FLACSO/Manantial, Buenos Aires.

PARDO MERINO, A. y RUIZ DÍAZ, M. (2005). Análisis de datos con SPSS 13 Base. Mc Graw Hill, Madrid.

ROCKWELL, E. (1995) (coord.). La escuela cotidiana. Fondo de Cultura Económica, México. (2007). La experiencia etnográfica. Historia y cultura en los procesos educativos. Paidós, Buenos Aires

REGUILLO CRUZ, R. (2000). Emergencia de las culturas juveniles. Estrategias del desencanto. Tesis Norma, Buenos Aires.

-(2012). Culturas juveniles. Formas políticas del desencanto. Siglo XXI, Buenos Aires. 
SAMAJA, J. (1995). Epistemología y metodología. Elementos de una teoría de la investigación científica. Eudeba, Buenos Aires.

SAUTÚ, R. (2005). Todo es teoría: objetivos y métodos de investigación. Lumiere, Buenos Aires.

TAYLOR, S. y BOGDAN, R. (1993). Introducción a los métodos cualitativos de Investigación. Paidós, Buenos Aires.

TENTI FANFANI, E. (2010). La escuela y la cuestión social. Ensayos de sociología de la educación. Siglo XXI, Buenos Aires.

TIRAMONTI, G. (2004)(comp.). La trama de la desigualdad educativa. Mutaciones recientes de la escuela media. Manantial, Buenos Aires.

TIRAMONTI, G. y MONTES, N. (2009)(comps). La escuela media en debate. Problemas actúales y perspectivas desde la investigación. Manantial/Flacso, Buenos Aires.

TORRES SANTOME, J. (1996). El curriculum oculto. Madrid, Morata.

VAN DER MAREN, J. (1999). La búsqueda de informaciones contextualizadas. De Boech Université. París Bruxelles. Selección y traducción: Graciela M. carbone.

VASILACHIS DE GIALDINO, I. (2007). La investigación cualitativa. En: Vasilachis de Gialdino, (comp): Estrategias de investigación cualitativa. Gedisa, Buenos Aires.

(1992). Métodos cualitativos I. Los problemas teórico-

epistemológicos. Centro Editor de América Latina, Buenos Aires.

VILLAFAÑE, A. (2002) (comp). Construyendo lo local. Al Margen, La Plata.

VIÑAO FRAGO, A. (2008): "La escuela y la escolaridad como objetos históricos. Facetas y problemas de la historia de la educación". En MAINER J (coord.)(2008). Pensar críticamente la educación escolar: perspectivas y controversias historiográficas. Prensa Universitaria de Zaragoza, Zaragoza.

WILLIS, P. (1977). Aprendiendo a trabajar. Cómo los chicos de clase obrera consiguen trabajos de clase obrera. AKAL, Madrid.

-(1980). Notas sobre método. En Hall et al. (eds) "Culture, Media, Language", Hutchinson, London, 1980, págs 105-121 -Traducción del original de Gabriela López. 


\section{Otras fuentes:}

DGCyE (2009): Dependencias oficiales y de gestión privada en Olavarría. Escuela Secundaria Básica. Portal abc.gov.ar

DINIESE (2010): La educación argentina en cifras. Ministerio de Educación de la Nación

EL POPULAR [EP] (1999): Cien años junto a la ciudad. Talleres gráficos de El Popular. Olavarría. 


\section{Capítulo 2}

\section{Los dilemas entre sujeto y estructura en la construcción de ciudadanía: interacción entre campos, sujetos en juego -y nuevas reglas del juego- en un contexto social contingente}

\subsection{Introducción}

El problema teórico que orienta la investigación se ubica en la dinámica que adquieren los cambios de los campos social, político y educativo, analizada principalmente desde la perspectiva relacional desarrollada por P. Bourdieu. El mencionado proceso de cambio y su impacto en la construcción ciudadana, se analiza atendiendo a los debates actuales en el campo de la ciencia política, de los cuales se analizan las implicancias que éste adquiere para la existencia del Estado y la democracia.

En ese entramado relacional, ubicamos las transformaciones que se operan en los sujetos, tanto en el plano subjetivo como en las estructuras por donde transitan y que los contienen, colocando especial atención en la escuela, reconocida como una de las instituciones que gravita significativamente en la construcción de ciudadanía.

Un punto de partida para este análisis se construye partir del seguimiento de algunos debates contemporáneos de la Ciencia Política y la Sociología, que plantean que estamos en presencia de un nuevo orden que no logra suturar o clausurar lo social y en el que, por lo tanto, la construcción de ciudadanía que ofrece producir el curriculum escolar también es una construcción inestable y relacional. Lo social es entendido, siguiendo a Castoriadis (1986, citado por Retamozo, 2009) como el trasfondo sedimentado donde opera el acto de institución y la sociedad como el producto inestable y contingente de una operación que pretende ser hegemónica.

En ese mismo sentido y siguiendo a Castoriadis, Laclau (1990: 104) considera que

\footnotetext{
“...hoy día tendemos a aceptar la infinitud de lo social, es decir, el hecho de que todo sistema estructural es limitado, que está siempre rodeado por un exceso de sentido que él es incapaz de dominar, y que, en consecuencia la "sociedad" como objeto unitario e inteligible que funda los procesos parciales, es una imposibilidad".
} 
En el marco de la teoría filosófico-política posfundacionalista se comprende la idea de la noexistencia de la sociedad como fundamento último que atiende a los fundamentos contingentes como constitutivos de lo social. El objeto de su trabajo -dirá Marchart (2009)consistirá en indagar los fundamentos contingentes, la indeterminación, el antagonismo, los intentos de sutura y los procesos de apertura.

Estos elementos se encuentran, también, presentes en la escuela como institución que es parte de la estructura del sistema social, como en los habitus de algunos sujetos (tanto docentes como estudiantes) que la constituyen. Algunos otros sujetos, al mismo tiempo, operan con lógicas heredadas del proyecto moderno.

La modernidad, a través del Estado, se preocupó por la construcción de un orden social capaz de estructurar el caos y prevenir el conflicto, a partir de instituciones que se constituyeron como legítimas. En la actualidad, la realidad se presenta impulsada por procesos de cambio vertiginosos, y las acciones estratégicas del Estado parecen difusas e inconducentes para producir clausuras necesarias para la convivencia social y la orientación de la vida de los sujetos.

Atendiendo a la contingencia del nuevo orden social, ubicamos el problema pedagógico de constitución del sujeto político, del ciudadano. En esa trama se produce la acción de la escuela que, como institución privilegiada de "producción del ciudadano" de acuerdo con el legado moderno, hoy es compelida a desarrollar su acción sin el respaldo ni la protección que el Estado le aseguraba. Pero, a la vez, se advierte que la acción de los jóvenes ha desbordado las instituciones modernas que ordenaban "la sociedad", desarrollando otras prácticas y estrategias a través de las cuales expresan sus intereses y disputas.

Como ha sido señalado en la Introducción han operado cambios en la estructura del sistema capitalista que afectan al modelo de Estado y, con ello, la definición de democracia que sustenta la vida social. La redefinición de las funciones del Estado, en relación a la organización social de los sujetos y la demanda de iniciativas para que desarrollen actividades autónomas y participativas, implica cambios en las disposiciones internas que requieren de renovados procesos de "inculcación". Se propone, entonces, analizar cómo influyen los cambios en las posiciones y disposiciones de los jóvenes en relación al campo 
educativo y político, pero también los cambios en la estructura del sistema, en el curriculum, y qué sentidos adquieren las prácticas que articulan el mundo objetivo y el mundo subjetivo.

Analizar la función de la educación en la formación de ciudadanos y las prácticas políticas de los sujetos en la nueva escuela secundaria, posibilitará la construcción de indicios que nos permitan divisar qué sentidos de ciudadanía y, por lo tanto de democracia, contribuye a formar la escuela.

La ciudadanía es definida como una condición social que se construye subjetivamente con otros y que, a su vez, construye políticamente la vida democrática (Fleury, S, 2005). La práctica política es una condición ineludible de la construcción ciudadana, y lo político (que diferenciamos de la política vinculada con el poder, el gobierno, la estructura) se presenta como la relación que surge entre los sujetos al compartir el espacio público y se interesan en resolver problemas que hacen al bien común (Arendt, 2008). Estas prácticas no están exentas de interés por disputar el poder que sostiene el orden social contingente contemporáneo.

La formación de los jóvenes como sujetos políticos se realiza en el campo social de manera relacional a través de diversas prácticas - dentro y fuera de las instituciones tradicionalesque le otorgan algún sentido a lo político.

En esta investigación, la referida construcción de ciudadanía se relevará a través del análisis de prácticas contextualizadas en configuraciones sociales (es decir, que se desarrollan en un campo, las escuelas secundarias), atendiendo especialmente a las acciones que en este capítulo se definen como estrategias políticas desarrolladas por los jóvenes. Se pretende comprender cómo se articulan las condiciones objetivas externas (campo) y las estructuras objetivas internalizadas (habitus), en el proceso de construcción de ciudadanía en la escuela secundaria. Respecto de la función del habitus en la teoría relacional de Bourdieu, Alicia Gutiérrez señala que

\footnotetext{
"Al rescatar las estructuras sociales internas y al considerar al habitus como principio de estructuración de prácticas (además de la posición que se ocupa en los diferentes campos) y con ello la trayectoria del agente social, esta perspectiva teórica supone análisis diferentes de aquellos que se sustentan más bien
} 
en la libre iniciativa de un actor social cuyas estrategias estarían sometidas esencialmente a las coerciones de las estructuras externas" (Gutiérrez, 1994: 69-70).

Para Lahire (2009: 14) el habitus refiere a las maneras de hacer que están incorporadas y que expresan lo que el mundo social ha hecho con nosotros. Y destaca, en su obra, la pluralidad de situaciones que afectan los modos de hacer las cosas por las que transita un sujeto. A partir de analizar las ideas con que Durkheim y Bourdieu definen el habitus, esclarece su postura al pensar que no estaríamos en presencia de un modo rígido de actuar en función de un tipo de habitus adquirido, sino que éste es flexible y que se adapta a los distintos campos y situaciones. Y se pregunta, considerando la pluralidad de comportamientos que se observan, si lo que ha cambiado hoy es la mirada del investigador o lo que efectivamente ha cambiado es el mundo, para concluir que, en realidad, son las dos cosas.

Las herramientas analíticas que permiten definir aspectos fundamentales de la investigación, desde la perspectiva de la acción, son:

- El abordaje del campo educativo en su relación dinámica con el campo social y el campo político. Se describirán sus propiedades en un contexto de cambio epocal, considerando las operaciones más significativas en relación al problema en estudio.

-las prácticas a las que los jóvenes estudiantes de las escuelas secundarias les atribuyen sentido político, entendidas también como relacionales e históricas.

\subsection{El campo educativo y sus propiedades en un contexto de cambio epocal}

El campo educativo, como un espacio de luchas simbólicas, es un microcosmos con autonomía relativa, en un macrocosmos social que comparte características estructurales con otros campos (como el político, el de las artes, la economía, entre otros) pero, a la vez, presenta propiedades que lo diferencian de los demás. El campo educativo se caracteriza por la transmisión de la cultura, por el tratamiento y distribución de los bienes simbólicos que producen y acumulan los sujetos sociales en su devenir histórico.

La noción de campo en la teoría de Bourdieu es definida como "espacio de juego históricamente construido con sus instituciones específicas y sus leyes de funcionamiento propias" (citado por A. Gutiérrez, 1994:31). 
De acuerdo a las características generales de los campos, éstos se definen principalmente por lo que está en juego y por los intereses específicos que lo diferencian de otros campos. El campo está dominado por especialistas autorizados que conocen las características del juego (enjeu) e interés (illusio) puestos en él. Una interpretación posible de las disputas actuales en el campo educativo está dada por una apertura (producto de la extensión de la obligatoriedad) que amenaza la propiedad de distribución desigual de los bienes simbólicos. En el análisis propuesto, existiría una lucha ideológica entre los "especialistas", en la que unos luchan por conservar un orden y otros que pretenden subvertir ese orden. Pero, al mismo tiempo, en las arenas de la lucha que son las escuelas, los jóvenes son considerados por los especialistas como espectadores (o profanos) del juego que se desarrolla en él (Bourdieu, 2001:16) -tanto en el campo educativo como en el político-. Los jóvenes disputan el estado del capital cultural que circula en el campo educativo, como también los contenidos derivados desde el campo político para ser enseñados en las escuelas.

Según Gutiérrez, el campo es un estado -en el sentido de momento histórico-, un sistema temporal y espacial de posiciones que no pueden analizarse con independencia de las características de quienes las ocupan, considerando en ellas el capital que está en juego, “que orienta las estrategias de los que están comprometidos en el campo" (Gutierréz, 2010; 12). Esta referencia permite exponer que, en relación a las posiciones sociohistóricas que ocupan los jóvenes en el campo educativo, las estrategias y las prácticas políticas de disputa y de acción resultarían diferentes en función de las trayectorias familiares en el campo educativo y en el campo político, que confieren volumen específico al capital en juego.

El campo social, convulsionado por los cambios epocales, produce cambios contundentes en las instituciones y en las leyes de su funcionamiento. Al analizar el origen de los cambios se observa que la dinámica del capitalismo requiere de una nueva configuración que demanda desde el campo económico al político, para establecer un nuevo orden que favorezca flujos e intercambios globales. En la dinámica de las relaciones se observa, de acuerdo con autores reconocidos de diversas disciplinas como, Oszlak (1999), Touraine (2001), Bauman (2007b) una primacía del campo económico sobre el político; y del campo político, sobre el social y educativo. 
Ciertas transformaciones del campo social son señaladas como transformadoras, a su vez, del campo educativo. Como consecuencia de las modificaciones del campo social que devienen de las transformaciones del Estado, las instituciones educativas también han resultado modificadas, y en ese proceso de apertura, desgarro o de mayor permeabilidad, la educación "ha desbordado al sistema" (Martín Barbero, J. 2003:12). En consecuencia, sería posible considerar que la eficiencia del sistema educativo en la formación y disciplinamiento de los ciudadanos -función ampliamente reconocida por la sociología de la educación-, estaría perdiendo efectividad ante los cambios.

Esa situación -que será objeto de indagación- podría favorecer a los jóvenes para abrirse paso $^{55}$ en el campo educativo, no ya desde el lugar del alumno (los espectadores o profanos del campo) sino como sujetos portadores de derechos, de saberes, de cultura.

En los párrafos que siguen se abordarán problemas contemporáneos del campo social y del campo político que impactan sobre el campo educativo.

\subsubsection{Transformaciones del Estado que impactan sobre el campo social}

"Un Estado que no es capaz de hacer valer su legalidad sustenta una democracia con baja intensidad de ciudadanía".

(O’Donnell, 1993)

Para comprender las transformaciones que operan en el campo social resulta necesario analizar las transformaciones que han sufrido las nociones de Estado y democracia en una nueva etapa del capitalismo, denominada neoliberalismo (Borón, 2003). Para este breve análisis se hará referencia a estudios de autores reconocidos del campo de la ciencia política.

N. Bobbio (1989: 129-130) expresa:

"Desde el punto de vista de una definición formal e instrumental la condición necesaria y suficiente para que exista un Estado es que en un territorio determinado haya un poder capaz de tomar decisiones y

\footnotetext{
${ }^{55}$ Esta idea de abrirse paso, es similar al planteo de Reguillo Cruz de "emergencia de las culturas juveniles", donde emergencia da cuenta de un renacer, brotar, dar lugar (otro lugar) a alguien que por el peso de la estructura (en este caso, de la institución escuela)
} 
emitir los mandatos correspondientes, obligatorios para todos los que habitan en ese territorio, y obedecidos efectivamente por la gran mayoría de los destinatarios en la mayor parte de los casos en los que se requiere la obediencia; cualesquiera que sean las decisiones."

En su análisis de la evolución de los estudios sobre el Estado realiza una distinción entre las teorías sociológicas del Estado y la doctrina jurídica del Estado. Según el autor, "Esta distinción se volvió necesaria luego de la tecnificación del derecho público y de la consideración del Estado como persona jurídica que había derivado de tal tecnificación" (1989:74). Sostiene Bobbio que la concepción del Estado como ordenamiento jurídico no negaba la existencia del Estado como organización social, que cobra vigencia con el advenimiento de la sociología como ciencia, en la que se destaca la obra de Max Weber (1908, citado por Bobbio), que distingue "la diferenciación entre validez ideal, de la que se ocupan los juristas, y validez empírica de las normas de la que se ocupan los sociólogos" (Bobbio, 1989:74)

Entre las teorías sociológicas del Estado, reconoce dos con mayor influencia en la actualidad: la teoría funcionalista y el marxismo. La principal diferencia entre ambas, sostiene Bobbio, radica en el lugar que se le otorga al Estado en el sistema social. Para el funcionalismo, el Estado y las instituciones que lo constituyen desempeñan las funciones políticas fundamentales de todo sistema social. Para el marxismo, existe una distinción fundamental: la base económica (estructura), condiciona el desarrollo del sistema político en la que ubica al Estado (superestructura).

La diferencia principal entre las dos radicaría en que la primera se organiza en tono al orden y la segunda, en torno a la ruptura de ese orden que permite pasar de un estado "del Estado" a otro. "Mientras la primera se preocupa esencialmente del problema de la conservación social, la segunda se preocupa fundamentalmente del cambio social" (Bobbio, 1989: 77).

Siguiendo los razonamientos del autor mencionado, al funcionalismo le interesan los cambios que tiene capacidad de controlar, dentro del mismo sistema (capitalista); y, la teoría marxista, se interesa por los cambios que ponen en crisis al sistema capitalista dominante. Mientras que la primera teoría respalda la cohesión social, la segunda busca la construcción 
de antagonismos. Difícilmente, sostendrá Bobbio, se encontrarán en la historia del pensamiento sociológico y político, dos prototipos más puros de esta gran división.

En el apartado que sigue nos interesa analizar la relación del Estado con las formas de gobierno, especialmente con la democracia, en un contexto de experimentaciones capitalistas donde los países de América latina son, a decir de Atilio Borón, "bancos de prueba".

Esta breve introducción para comprender las teorías sobre el Estado que se debaten en la actualidad en el campo de la política, facilitará el análisis del funcionamiento de la democracia, y luego, la ciudadanía que se propone construir en relación con ella.

\subsubsection{La relevancia del Estado para el funcionamiento democrático de la sociedad}

En un análisis filosófico-político sobre la democracia, Bobbio (1986) señala la diferencia entre los ideales democráticos y "la democracia real", entre lo que la democracia promete ser en el plano teórico y lo que puede ser en la realidad; es decir, lo que los sujetos hacen en nombre de esos ideales democráticos. Señala el carácter siempre dinámico de la vida democrática, aspecto que la diferencia del despotismo y advierte:

\footnotetext{
"que la única manera de entenderse cuando se habla de democracia, en cuanto contrapuesta a todas las formas de gobierno' autocrático, es considerarla caracterizada por un conjunto de reglas (primarias o fundamentales) que establecen quién está autorizado para tomar las decisiones colectivas y bajo qué procedimientos" (1986: 14)
}

La definición descriptiva de democracia que realiza Bobbio, la presenta como una forma específica de gobierno en la que el poder político está en manos de muchos, en contraposición a otras formas de gobierno en las que el poder es de unos o de pocos. Como bien aclara, "muchos" es un concepto ambiguo, pero remite a la idea de que si bien no son todos, son la mayoría. La ampliación de la participación democrática, generalmente remite a esta idea de "mayor número de personas habilitadas para participar", sin hacer mención a otro aspecto fundamental de la vida democrática, que es el procedimental. 
Algunas condiciones necesarias para su funcionamiento -mencionadas por el autor- son: los llamados derechos de libertad de opinión, de expresión de la propia opinión, de reunión, de asociación, etc., que resultan ser los derechos a partir de los cuales nació el Estado liberal. En una democracia, el Estado no sólo ejerce el poder "sometido a la ley" sino que lo hace dentro de los límites del reconocimiento constitucional de los derechos inviolables de los individuos.

En un análisis de las democracias orientadas por el liberalismo o el socialismo (derivadas del análisis inicial entre funcionalismo y marxismo como teorías de Estado en que se inscribe la vida democrática), realiza reflexiones relevantes respecto a los gobiernos democráticos actuales, preguntándose si estamos viviendo en un "gobierno de los hombres o de las reglas". Si bien deja abierta la cuestión, se posiciona a favor del gobierno de las reglas, como opción única para garantizar el bien común.

A lo largo de este trabajo, sostendremos que la democracia es más que un conjunto de procedimientos y condiciones para elegir y ser electo, ya que se considera a esa dimensión de la democracia como una democracia electoral. La democracia es, fundamentalmente, una manera de organizar la sociedad con el objeto de asegurar y expandir los derechos, de los cuales son portadores y ejecutores los individuos. Estos aspectos son los que definen a la democracia de ciudadanía.

Guillermo O’Donnell (1993) realiza valiosos aportes sobre la relación Estado, democracia y ciudadanía, sobre la base de estudios en los que analiza las democracias "poliárquicas" que encuentra en la historia de los países latinoamericanos (en especial, sudamericanos).

Una primera distinción realizada por él nos lleva a considerar que existen varios contrastes "entre democracias representativas y consolidadas y las formas democráticas - es decir, poliarquías- emergentes en muchos países recientemente democratizados".

En el artículo de referencia sostiene que la mayor parte de los países que han recuperado la democracia de manera reciente "no se están encaminando hacia regímenes democráticos representativos, institucionalizados, ni parece probable que lo vayan a hacer en el futuro previsible" (O’Donnell, 1993:62). Por el contrario, los países de Latinoamérica comparten una vida democrática que puede caracterizarse de este modo porque sus gobiernos accedieron por elecciones limpias y sostienen algunos de los principios que la definen como 
tal, como son las libertades políticas fundamentales: opinión, expresión, asociación, movimiento y acceso a medios de comunicación plurales y afirman la supremacía de los poderes constitucionales por sobre los poderes fácticos.

Resulta de especial interés el análisis que realiza el autor respecto del lugar que la historia y la sociedad le asignan al Estado, y cómo éste se articula para adoptar la configuración actual:

"los Estados están entrelazados con sus sociedades respectivas de complejas y variadas maneras; esa inserción conduce a que los rasgos de cada uno de ellos y de cada sociedad tengan un enorme influjo sobre el tipo de democracia posible de consolidarse (si es que se consolida), o sobre la consolidación o fracaso de la democracia a largo plazo" (O’Donnell, 1993: 65).

En su perspectiva, el Estado no solo debe asociarse a la noción de poder público, sino que principalmente el Estado es un organizador social sobre una base legal.

\begin{abstract}
“El sistema legal es una dimensión constitutiva del Estado y del orden que éste establece y garantiza en el territorio dado. No se trata de un orden igualitario, socialmente imparcial; tanto bajo el capitalismo como bajo el socialismo burocrático ese orden respalda y ayuda a reproducir relaciones de poder que son sistemáticamente asimétricas. Pero es un orden, en el sentido en que compromete múltiples relaciones sociales en base a normas y expectativas estables (si bien no necesariamente aprobadas) (O’Donnell, 1993: 65-66)
\end{abstract}

La ley es la parte constitutiva del Estado, es la urdimbre que sostiene la trama social.

Otra dimensión del Estado señalada por O’Donnell es la ideológica, y que lo asocia, en la historia inmediata, con el Estado-Nación. En ella se asientan, entre otros, los ideales de igualdad $y$, aunque no se extienda y concrete en otros planos, es fundamental para garantizar el funcionamiento de la ciudadanía política que sostiene al régimen democrático. Pero la ciudadanía no podría reducirse al ejercicio de ese acto político.

Los países estudiados por O’Donnell a principios del siglo XXI-en especial Argentina, Brasil y Perú- presentan, además de una crisis social y económica, una crisis en sus Estados. La crisis se extiende, según expresa, a tres dimensiones:

"la dimensión del Estado como un conjunto de burocracias capaces de cumplir con sus obligaciones con una eficiencia razonable; la dimensión de la eficacia de la ley; y la dimensión de la credibilidad del 
alegato de que los organismos estatales normalmente orientan sus decisiones por una cierta concepción del bien común." (O’Donnell, 1993: 69)

En las situaciones enunciadas los Estados se vuelven ineficaces para regular la vida social a lo largo de su territorio.

“El aumento de la criminalidad, las intervenciones ilícitas de la policía en los vecindarios pobres, la práctica habitual de la tortura e incluso ejecuciones sumarias de sospechosos de crímenes que provienen de sectores pobres o estigmatizados, la negación de derechos de la mujer y de diversas minorías, la impunidad del tráfico de drogas y el gran número de niños abandonados en las calles (todo lo cual denota escaso progreso en relación con el anterior período autoritario), no reflejan únicamente un grave proceso de decadencia urbana. También expresan la ineptitud creciente del Estado para poner en vigor sus propias regulaciones" (O’Donnell, op.cit., 70)

A la vez, y como producto de lo expresado anteriormente, se observa un retroceso significativo del espacio público. Algunos espacios son invadidos ante el crecimiento de la pobreza -plazas, paseos, edificios públicos abandonados- y otros, por el miedo creciente a la violencia y la inseguridad. También se observa un avance de contextos privados -como los barrios, los espacios de esparcimiento, las escuelas- que vienen a remarcar y fortalecer la brecha social que se observa en los modos de ejercer el derecho privado. Allí, los circuitos privados funcionan con reglas propias que debilitan de manera ostensible la democracia y su sistema legal. A menudo, sostiene O’Donnell "la presencia de esos circuitos de poder se repite en el centro de la vida política nacional, comenzando con el Congreso, la institución que supuestamente es la fuente de la legalidad existente y que abarca el territorio nacional" (1993:72).

Las democracias resultantes se basan en un Estado esquizofrénico, que combina funcional y territorialmente características democráticas y autoritarias. La democracia tiene una existencia formal, donde los sujetos pueden votar, las elecciones son mayoritariamente transparentes y se cumplen ciertos derechos indispensables. Pero cuando existen áreas de restricciones de garantías individuales, se cercena el componente liberal de la democracia y por lo tanto, las condiciones de la ciudadanía. O'Donnel vincula la existencia de un Estado de baja legalidad con una democracia y ciudadanía de baja intensidad.

Nuevas investigaciones realizadas por O’Donnell y su equipo (2009) le permiten construir el concepto de democracias delegativas, para definir un tipo específico de funcionamiento democrático, registrado en los países de la región, en América Latina. Este concepto busca 
señalar cómo la falta de control sobre el Poder Ejecutivo afecta el buen funcionamiento de la democracia (Peruzzotti, 2011).

Para caracterizar brevemente este tipo de democracia, identifica algunas características que agrupa en dos aspectos: estáticos y dinámicos.

Como aspectos estáticos de la democracia delegativa (DD) enuncia los siguientes:

-representa una manera de concebir y ejercer el poder político

-es democrática por su legitimidad de origen (su surgimiento de elecciones limpias y competitivas) y porque en ella se mantienen vigentes ciertas libertades política básicas, tales como las de expresión, reunión, prensa, asociación y movimiento

-sin ser ajena a la tradición democrática, es menos liberal y republicana que la democracia representativa

-la concepción básica es que la elección da al/la presidente el derecho y la obligación de tomar las decisiones que mejor le parecen para el país, sin considerar la existencia de las instituciones que ejercen diversos aspectos de control sobre el poder ejecutivo

- esta concepción lleva a que la manera típica de adopción de políticas públicas sea abrupta e inconsulta

- esta auto-concepción expresa la idea de que la/el presidente es el más autorizado intérprete de los grandes intereses de la nación.

- los partidos políticos son vistos como una expresión parcial de esos intereses.

“De ahí que el/la presidente DD sea movimentista: lo que dirige no es un partido o una facción sino un movimiento que contiene o expresan uno o más partidos y diversas organizaciones sociales y/o paraestatales, pero no reducible a ellos" (O’Donnell, 2010: 3).

-puede expresar diversas orientaciones ideológicas. La mayor parte de los casos pertenece, más o menos vagamente, a la izquierda.

Entre los aspectos dinámicos enuncia:

-los líderes -generalmente surgidos de profundas crisis- encarnan una gran causa. Una vez resuelta o controlada la crisis, y respaldados por sus éxitos la acumulación de poder requiere de control o neutralización de las instituciones 
-otra particularidad es lo que el autor llama "el lenguaje de la crisis", y su recurrente presencia, que mantiene unido al líder con la imagen del salvador

-la referencia a la crisis sirve a la vez, para conectar con los responsables de la crisis, a quienes convierte en "enemigos" de la causa que representa, dicotomizando el espacio político y social, a través de la creación de antagonismos.

Este tipo de democracia tiene "parecidos de familia" con otros regímenes políticos: la democracia representativa y el populismo. La primera, es otra forma de democracia que se diferencia de la democracia delegativa precisamente, por las diferencias entre la "representación" y la "delegación plena" que implica la DD, en la que "en principio no quedan los componentes de accountability y de interrelación institucional implicados por la representación democrática” (O`Donnell op.cit. 3).

El populismo, por su parte, ha presentado -aunque en muchos casos temporariamente, señala el autor- formas democráticas; la gran mayoría se ha instaurado de manera autoritaria, como resultado de algún golpe de estado o por "basarse en elecciones que no fueron limpias ni competitivas".

Laclau argumenta otra postura sobre el populismo como estilo de gobierno presente en la región latinoamericana, vista como opción representativa de las mayorías en los actuales escenarios creados por el neoliberalismo. En su libro "La razón populista” (2005), el autor entiende que el populismo es una opción "para una profundización de la democracia de manera radical".

Esta opción política que invierte la relación a favor de lo popular, específicamente de los excluidos por el modelo neoliberal, debe ser atendida en el marco de análisis más complejos del pensamiento político del autor que entiende que, dada la contingencia de estos tiempos (como se considera al inicio del capítulo), el populismo es la opción democrática capaz de articular la demanda de los grupos excluidos.

Hasta aquí han sido expuestas distintas concepciones referidas tanto al análisis teórico como empírico de la democracia, que será entendida como el contexto, la trama en la que 
funcionan las diversas organizaciones e instituciones sociales en las que se construye ciudadanía.

\subsubsection{Estado, democracia y educación: la formación del ciudadano}

La crisis del Estado moderno amenaza la conservación de ciertas leyes generales del campo educativo, pero se manifiestan con firmeza algunos de sus principios fundantes: como expuso Bourdieu (1997: 35) el campo educativo "mantiene el orden preexistente, es decir la separación entre los alumnos dotados de cantidades desiguales de capital cultural".

Aun cuando lo social es contingente la escuela, como institución social, continúa siendo un espacio de instauración e inculcación de "diferencias durables" (Bourdieu, 1993). En este estudio, será preciso indagar qué intersticios encuentran los jóvenes para instalar su interés en el campo educativo y la construcción de ciudadanía, y cómo (con qué estrategias) participan de ese juego.

Es necesario comprender la tensión entre los viejos modelos instituidos y los nuevos que pugnan por establecer un nuevo orden, reconociendo el proceso histórico y relacional que dio origen y existencia a los campos social y educativo. Ambos campos han sido construidos a partir de intereses e instituciones específicas que se constituyeron como hegemónicas durante la modernidad, en relación a un proyecto de Estado -Nación y que como dijimos, desde la segunda mitad del siglo XX, está en crisis. La crisis y las negociaciones entre el Estado y la sociedad civil para articular las relaciones sociales (de Sousa Santos, 2002) muestran que aquello que resultara entonces instituyente, hoy no lo es con la misma intensidad.

El campo educativo se constituye bajo el imperativo moderno de igualdad y uniformidad y está representado por el sistema educativo -y su red burocrática estatal-, las instituciones (escuelas) y sus agentes socializadores (directivos y docentes). La homogeneización de la cultura y la formación de la ciudadanía que sostuviese al Estado Nacional fue en 1880 la principal razón de la promulgación de la Ley de Educación № 1420 en Argentina. Desde la década de los `90, ese interés que sienta las bases constitutivas del sistema educativo argentino sobre igualdad y universalidad y el capital -cultural y simbólico- que detentaran la 
escuela y sus agentes, están en crisis ante los cambios que sufre el modelo de EstadoNación y con él, la noción de democracia que sustenta.

Tamarit señala que no debemos olvidar que a lo largo de la historia se le ha atribuido a la educación una "potencialidad democratizante que la historia sistemáticamente se ha negado a confirmar"; esto es, aceptar que, si bien la escuela puede contribuir "...a la formación de ciudadanos democráticos, esto no implica que la mera transmisión obrará de milagro para construir conciencias críticas" (Tamarit 1994: 100). Pero además, es el propio Estado democrático quién fija los límites "tolerables" de libertad y de conciencia de los ciudadanos que, finalmente, deben resultar funcionales con la existencia del propio régimen -lo que en términos de Foucault sería asegurar la "gobernabilidad del sistema"-.

En Argentina, la Ley 1420 (1884) de educación común, gratuita y obligatoria para la educación primaria expresaba su vocación de educar a los ciudadanos para que conformaran el Estado-Nación del joven país.

La escuela secundaria creada unos años antes por Mitre (1863), en cambio, tenía como fin formar a las élites dirigentes. En 1870 Sarmiento creó la primera Escuela Normal en Paraná, cuyo propósito consistió en poner en marcha una formación de docentes modélica basada en una filosofía humanística que sostuviera los ideales de orden y progreso. Con éste espíritu de época fue creada en el año 1910 la escuela centenaria (escuela normal, con niveles primario y secundario) que forma parte de las escuelas seleccionadas para relevar las prácticas políticas de los jóvenes.

Las primeras décadas del siglo XX estuvieron atravesadas por las disputas entre sectores socialistas y liberales (apoyados por la iglesia) en torno a temas como el ingreso a las escuelas de las mujeres y los hijos de los trabajadores, por el dominio sobre los fines y las definiciones del contenido de la educación (Puiggrós, 1998). El gobierno progresista de H. Irigoyen (1928-1930) que produjo importantes adelantos para el sector obrero en términos educativos, fue depuesto por el primer golpe militar a un gobierno democrático, que llevó como presidente a Uriburu. 
Luego de distintos focos de tensión en la sucesión democrática legal y las interrupciones militares, en 1945 llegó al poder Juan D. Perón. Durante los períodos de su gestión se registra el primer ingreso masivo a la educación secundaria de los hijos de trabajadores (Southwell, 2011). Fue a partir del gobierno de Frondizi, en los inicios del desarrollismo en 1959, que se crea el CONET, a efectos de unificar las escuelas técnicas existentes e impulsar el desarrollo educativo del nivel secundario hacia el sector industrial.

En ese mismo período se crean la escuela primaria parroquial, la escuela suburbana y la escuela primaria rural (todas en el año 1960) que conforman también la muestra de esta investigación y que cinco décadas después incorporarán el nivel secundario.

El clima político de esa época (1960) estaba dominado por debates entre socialistas, populistas y los grupos conservadores que pugnaban por mantener "el orden". La revolución cubana había radicalizado las tendencias políticas e ideológicas en toda Latinoamérica. "Una sociedad crispada, movilizada, dividida entre la apuesta revolucionaria y las salidas conservadoras, van a sumergirse en el peor de los horrores, cristalizado en los años del Proceso" (Terán, 2008: 281).

Hasta 1976, cuando comienza la última dictadura militar, se registran experiencias cortas (Southwell, 2011) de modificaciones en el funcionamiento del nivel medio de educación formal. Con la llegada de la dictadura, por ocho largos años se estableció un férreo control de la vida (y de la vida política) del país. Si bien en este período (1976-1982) no se producen modificaciones de las leyes existentes, se suprimieron las libertades de expresión y se inició una cruel persecución a todos aquellos que defendieron las libertades democráticas.

En su cometido de control ideológico, el gobierno dictatorial elimina de la educación secundaria la materia Estudio de la Realidad Social Argentina (ERSA), de fecundo contenido político, incluida durante el breve gobierno peronista de Héctor Cámpora (1973) y la reemplaza por Educación Moral y Cívica, apoyada en dos conceptos estructurantes de familia y religión. Como expresa Carbone (2011: 22)

\footnotetext{
“El perfil ideológico de este documento irradia hacia todos los niveles de la gestión del curriculum y se expande desde el organismo nacional hacia las jurisdicciones. En este caso particular, se puede observar el intento de compatibilización entre la afirmación excluyente de una pertenencia religiosa y de una
} 
concepción de familia con ciertos rasgos de fundamentación psicológica que daba el tono de actualización de la época".

La autora señala, además, que es en este período cuando se inicia la descentralización de los servicios educativos en el nivel de gestión y de financiamiento ${ }^{56}$

El retorno a la democracia con el gobierno de Alfonsín (1983-1989) recuperó gran parte de los debates críticos al interior del sistema educativo, especialmente con el desarrollo del II Congreso Pedagógico Nacional (que fue celebrado a los cien años de la realización del primero, llevado a cabo durante el gobierno de D. Sarmiento). Se considera oportuno señalar a este gobierno como el último intento de resituar a la educación y la escuela pública bajo un mandato de distribución social e igualitaria de conocimiento y la formación de una ciudadanía activa y crítica $^{57}$, para pasar luego, con el gobierno de Menem, a un modelo social fragmentado y desigual.

En la primera década del siglo XXI se crea la escuela polimodal dependiente de la universidad (la quinta escuela seleccionada). Si bien se trata de un proyecto preexistente en el seno de la comunidad universitaria, parte de su impulso radica en reposicionar un proyecto educativo público de calidad, ante el deterioro evidente de la educación pública en general y el desmembramiento del nivel secundario en particular.

La educación, en consecuencia, está sujeta a las decisiones de política educativa que definen los modelos de democracia posibles bajo el Estado neoliberal. La escuela (y la escolaridad), como también la educación no formal, son arena de disputa en la constitución de un nuevo orden social y político, que incluye definiciones acerca de un nuevo sentido de la democracia.

La nueva Ley de Educación Nacional habilita a partir de la extensión de la escolaridad obligatoria, la conformación de una ciudadanía “...comprometida con los valores éticos y

\footnotetext{
${ }^{56}$ Estos procesos serían completados más adelante, durante el gobierno del Dr. Menem (1989-1999)

${ }^{57} \mathrm{Al} \mathrm{mismo} \mathrm{tiempo,} \mathrm{se} \mathrm{entiende} \mathrm{que} \mathrm{la} \mathrm{resistencia} \mathrm{a} \mathrm{cambiar} \mathrm{el} \mathrm{eje} \mathrm{de} \mathrm{la} \mathrm{educación} \mathrm{pública} \mathrm{ante} \mathrm{el} \mathrm{embate}$ neoliberal, contribuyeron a que durante este período no haya sido posible concretar las reformas educativas consustanciales con las conclusiones del II Congreso Pedagógico Nacional.
} 
democráticos de participación, libertad, solidaridad, resolución pacífica de conflictos, respeto a los derechos humanos, responsabilidad, honestidad, valoración y preservación del patrimonio natural y cultural"' (LEN, 2006. Cap. 1., Art. 11, punto C)

En ese sentido, se producen cambios en el sistema educativo y en los diseños curriculares. Una modificación fundamental se observa en la extensión de la obligatoriedad de la educación secundaria pero, en relación al tema que nos ocupa las modificaciones incluyen: la incorporación en el diseño curricular de materias específicas, una serie de acciones formativas que se corresponden con estructuras y formatos del campo político (como la existencia obligatoria de Centros de Estudiantes, delegados por cursos) y recomendaciones de articulación con experiencias que se proponen por fuera de la escuela, como el Concejo Deliberante Estudiantil, el Parlamento Juvenil, entre otros. Estas iniciativas hablan de un renovado espíritu de construcción política desde el campo social y político, para ser impulsadas desde la escuela.

Por su parte, la construcción social e histórica del curriculum escolar, sus relaciones con el poder y el conocimiento, las formas de construcción de significado (Goodson, 2000) y no únicamente su desarrollo técnico, se encuentran arraigados en las estructuras y en los sujetos (sistema educativo -con especial referencia a las escuelas- y agentes escolares, respectivamente). El discurso renovador que acompaña la segunda reforma estructural de la educación argentina, parece no encontrar aún correlato con las acciones que se desarrollan en la arena de juego de los tres campos en interacción.

A partir de las reflexiones inspiradas en la pedagogía crítica, consideramos que en la actualidad, en medio de la hegemonía neoliberal,

\footnotetext{
"la retórica de la libertad e igualdad puede haberse intensificado pero existen pruebas irrefutables de que existe cada vez mayor explotación, dominación y desigualdad y que las conquistas anteriores en materia educativa, seguridad económica, derechos civiles y demás, o bien están desdibujados o bien se encuentran bajo una grave amenaza" (Apple, 2012:73)
}

En concordancia con la visión sociológica que venimos desarrollando, entendemos que la lectura del campo y de las diferentes posiciones de los actores, el conocimiento de las leyes de la dinámica del campo y de las reglas del juego, de las posibilidad de acción y de los 
posibles cambios de posición de los sujetos al interior del campo, habilitan al jugador al desarrollo de estrategias para imponer o al menos instalar sus intereses. Se tienen en cuenta en este análisis las dos dimensiones en que se estructura lo social: la de los sujetos (con sus hábitus, historias, posiciones y disposiciones) y la del sistema (la estructura y el campo) con sus procesos históricos de conformación, sus reglas, sus leyes y requerimientos de volúmenes diferenciales de capital en juego.

El capital es un concepto asociado al concepto de campo, que junto con el de juego e interés contribuyen a una más acabada comprensión de la dinámica relacional del campo; es aquello que está en juego en el campo y que contribuye a darle identidad. Puede definírselo como "un conjunto de bienes acumulados que se producen, se distribuyen, se consumen, se invierten, se pierden" (Gutiérrez, 1994: 24). Como señala la autora, este concepto es liberado -por Bourdieu- de la lógica económica al que lo sujeta el marxismo y se extiende a "cualquier tipo de bien susceptible de acumulación". Se reconocen en la obra de Bourdieu diferentes tipos de capital: social, cultural, simbólico.

En el campo de la educación el capital cultural resulta el más significativo en la medida que permite comprender la inversión más estratégica del Estado en educación: la transmisión de la cultura. La disponibilidad y el volumen del capital cultural serán analizados como variables gravitantes en el desempeño de los jóvenes en la escuela secundaria obligatoria.

\subsection{Los jóvenes en las escuelas secundarias: prácticas y estrategias políticas}

Los jóvenes construyen su condición de ciudadanos desarrollando un conjunto de prácticas a veces novedosas para la escuela-, en un contexto signado por la fragmentación social, el consumismo, el uso de las NTlyC, la individualización y un profundo malestar en las instituciones modernas. A partir de sus expresiones algunos jóvenes muestran un profundo desprecio por las formas de "hacer política" de "los políticos", sin que esto signifique que ellos se excusen de hacer política, solo que algunos lo hacen "de otro modo".

Sostiene Bourdieu que la participación en un campo de juego implica el conocimiento de las leyes de funcionamiento, de sus códigos, lenguajes, un interés y un capital que habilite a los 
sujetos a participar legítimamente de él. Estas condiciones de participación son susceptibles de ser problematizadas en tanto que, en el caso que nos ocupa, algunos jóvenes son compelidos a ser parte de las interacciones que se producen en el campo educativo sin que medie un interés por participar de la lucha por la transmisión simbólica.

En relación a las prácticas políticas que desarrollan los jóvenes en el campo educativo, serán consideradas en este trabajo, tanto aquellas prácticas que el sistema educativo espera producir a través de sus leyes de funcionamiento, como aquellas en la que los jóvenes manifiestan una actitud activa y creativa y que dan cuenta de la capacidad de invención del sujeto. La noción de habitus permitirá comprender el capital históricamente acumulado por los sujetos, condición necesaria para conocer el campo, conocer el juego y disponer de estrategias de disputa. Analizar, desde la perspectiva mencionada, las prácticas políticas de los jóvenes en las diferentes escuelas seleccionadas en la muestra, nos presentará un abanico de posibilidades para aproximarnos a los sentidos que adquiere la ciudadanía que la escuela contribuye a construir.

\subsubsection{Acerca de los jóvenes como sujetos sociales contemporáneos}

Mencionaremos inicialmente las perspectivas con que se realizan estudios de juventud en Argentina y en América Latina, destacando en este abordaje las principales características que identifican a los jóvenes que componen la población de estudio en este trabajo. La franja de edad de los jóvenes que integran esta investigación oscila entre los 11 y 18 años ${ }^{58}$, situación que nos llevaría a indicar que como grupo etario, podrían denominarse "niñosjóvenes"; pero optaremos por la denominación de jóvenes.

\subsubsection{La visibilización de los jóvenes y los estudios de juventud}

Abordar teóricamente cuestiones sobre juventud requiere de ciertas precisiones y delimitaciones que nos permitan tomar distancia de significados y connotaciones acuñadas en otro momento histórico y social, para poder así aproximarnos a una definición de los conceptos que esté anclada en la significación de los cambios que esta época conlleva.

\footnotetext{
${ }^{58}$ Ver en Anexo Metodológico V, Cuadro N³ “Distribución de la población total según edad"
} 
Compartimos con diversos autores que la idea de juventud es definida por el canon de cada época $\mathrm{y}$, en relación a ello, P. Bourdieu sostendrá que la juventud "no es más que una palabra" (1990:163) $)^{59}$ dando cuenta de una clasificación que, a su vez, resulta una forma de poner límites en la disputa social por el poder. Entendemos, además, que la juventud "hecha cuerpo" dispone a la realización de prácticas concretas que se manifiestan efectivamente en el contexto social, como lo han destacado diversos autores.

La palabra juventud remite a una construcción simbólica cuya significación se juega en las relaciones sociales y en el "espíritu" de la época en que se la analice. Agrega Bourdieu que "solo con un abuso tremendo del lenguaje se puede colocar bajo un mismo concepto universos sociales que no tienen casi nada en común", haciendo referencia a un concepto que envuelve en su denominación a sujetos con situaciones y posiciones sociales diversas, difícilmente reconocidas como de la misma condición.

Se considera actualmente oportuno reemplazar el universal "juventud" por la idea de "juventudes", como modo de tomar distancia de las ideas homogeneizantes y abstractas sobre los jóvenes y poder pensarlas en su carácter relacional y posicional, enmarcada en tiempo y espacio (Pérez Islas (1998); Cháves (2006); Bomvillani, Palermo, Vázquez y Vommaro (2008).

Tampoco debe soslayarse la idea de que, como propone Reguillo Cruz (2000: 29) "las categorías no son neutras, ni aluden a esencias; son productivas, hacen cosas, dan cuenta de la manera en que diversas sociedades perciben y valoran el mundo, y con ello, a ciertos actores sociales". Pero esto no significa que el grupo social al que se está haciendo referencia pueda pensarse de manera uniforme y ahistórica, sino que se hace necesario pensarlo en su carácter diferencial, dinámico y discontinuo.

\footnotetext{
${ }^{59} \mathrm{Si}$ bien el artículo La juventud no es más que una palabra es breve, no lo es la obra de Bourdieu, en la que se destaca, entre otros, el concepto de habitus como articulador del sentido objetivo (material) y del sentido subjetivo de las prácticas, dando cuenta de lo social (y cultural) hecho cuerpo y que por lo tanto, no se agota en la descripción externa.
} 
Distintos estudios (entre ellos, los realizados por Reguillo (ruz) acuerdan con que es en la segunda posguerra cuando emerge la industria cultural que tiene a los jóvenes como destinatarios, al mismo tiempo que se realiza una "producción" de costumbres para disponer (y consumir) durante el tiempo de ocio.

Reguillo Cruz reconoce que la modernidad industrial construye un estadio entre la niñez y la adultez denominado juventud, que es signada principalmente por la moratoria social cuyas características principales son la subordinación al poder adulto y la correspondencia con un relato hegemónico acerca de lo que es "ser joven" (Reguillo Cruz, 2000). Luego, los desmanes de la posguerra les reconocerían derechos específicos y, en la segunda mitad del siglo XX, la industria cultural creó para los jóvenes circuitos de consumo que los han interpelado con gran éxito, impactando, incluso, en la construcción de identidades, alianzas y reconocimientos.

Desde una perspectiva antropológica, Mariana Chaves (2010: 76-81) realiza una caracterización de la juventud a través de representaciones de los adultos que implica "perder de vista el carácter de construcción social de la condición juvenil". Las representaciones encontradas por la investigadora son: joven como ser inseguro de sí mismo, joven como ser en transición, joven como ser no productivo, joven como ser incompleto, joven como ser desinteresado y/o sin deseo, joven como ser desviado, joven como ser peligroso, joven como ser victimizado, rebelde o revolucionario, joven como ser de futuro. Esta caracterización de los jóvenes por parte de los adultos, resulta de interés para comprender los patrones con que la escuela "juzga” a los jóvenes.

La mirada escolar también construyó conceptos acabados acerca de los jóvenes. La escuela como institución disciplinadora ha construido, a lo largo de su performance moderna, al "alumno" por sobre el joven, del mismo modo que el hospital recibió "enfermos", la cárcel "delincuentes", el ejército "soldados". El sujeto quedaba así subsumido a la lógica institucional.

Cabe considerar, siguiendo la lógica que expone Foucault (1989) respecto de la secuencia institucional, que la familia, como primera institución disciplinadora, conformaba y entregaba a la escuela a un sujeto que ya había aprendido las normas fundamentales para 
ser alumno: nociones de respeto (principalmente al adulto), de orden, de sumisión a las reglas.

La "destitución de las instituciones modernas" (Lewkowicz, 2004) rompe esa secuencia institucional y se conforman, entonces, nuevas/otras lógicas descentradas en los procesos de inscripción de los sujetos jóvenes a la dinámica social.

La visibilización de los jóvenes y la irrupción en la escena -europea y latinoamericana- de los movimientos de jóvenes en la segunda mitad del siglo $\mathrm{XX}$, estuvo asociada a reclamos, proclamas, a hacer oír su voz y posicionarse como actores políticos. Los movimientos estudiantiles de aquel momento fueron -según distintos cronistas- profundos cuestionadores del orden social moderno y de las instituciones que lo sostuvieron en su consolidación. El ejemplo paradigmático de ello fue, sin dudas, "el mayo francés".

En Latinoamérica la mayor participación y visibilidad parecen relacionarse con la participación política profundamente ideologizada que se orientó, como sostiene Saintout (2009: 105), "a la conquista de los recursos materiales y simbólicos del Estado". La innegable influencia que ejerció la revolución cubana y la emblemática figura del Che Guevara crean un polo de adhesiones para gran parte de los jóvenes, que desde la década de los '60 venían conformándose en grupos enfrentados a favor de la revolución, o a favor de la conservación del orden. En Argentina, diversas corrientes internas se enfrentaban especialmente en los ámbitos culturales y políticos, haciendo renacer dicotomías sedimentadas (como expresa Teran, 2008: 289) en el proceso histórico: pueblo y doctores, políticos prácticos y letrados, ideología revolucionaria y populismo.

Este proceso asociado a la subversión del orden capitalista hegemónico, finalizó en cruentas dictaduras que diezmaron la participación política de los jóvenes en Latinoamérica y que, aunque ya no es necesario ahondar en detalles, ha dejado huellas hondas en la memoria colectiva. La dictadura argentina, a través del terrorismo de estado "apuntó al exterminio y disciplinamiento de los sectores sociales movilizados, [a la vez que] puso en marcha un programa de reestructuración económica que habría de producir hondas repercusiones en la estructura social y productiva" (Svampa, 2005: 22-23). 
La derrota política que subestimó -deliberadamente- la fuerza de este período con denominaciones como "utópicos, "románticos", "inocentes", significó tanto una derrota política como simbólica. A partir de aquel momento, se produjo una significativa ausencia de jóvenes en el espacio público, mientras el ingreso a un nuevo modelo capitalista desvertebraba (en términos de Svampa) el conjunto de lo social.

La cultura del desencanto y la individualización caracterizó la acción de los jóvenes de los 80 y los 90. La crisis del modelo neoliberal de fin de siglo nos coloca frente a unos jóvenes que, en palabras de Rossana Reguillo Cruz (2000: 14):

\footnotetext{
"han mutado, de cara al siglo veintiuno, hacia formas de convivencia que, pese a su acusado individualismo, parecen fundamentarse en un principio ético- político generoso: el reconocimiento explícito de no ser portadores de ninguna verdad absoluta en nombre de la cual ejercer un poder excluyente"
}

En la nueva cultura global los jóvenes comienzan a ser definidos -antes que como sujetos en moratoria social-, como sujetos de derecho. Desde el año 1989 la Convención sobre Derechos del Niño reconoce a niños y adolescentes como sujetos de pleno derecho de acuerdo con la Declaración Universal de los Derechos Humanos de 1948.

Existe una estrecha vinculación entre la formulación y reconocimiento de niños y jóvenes como sujetos de derecho y la ampliación de la ciudadanía. Es en este punto donde anclamos la vinculación y la relevancia que adquiere, para esta franja etaria, la inclusión en el curriculum escolar, de las prácticas vinculadas a la ciudadanía.

\subsubsection{2-Los jóvenes y las instituciones}

Las ideas mencionadas en el punto precedente, permiten comprender por qué se arriba a la noción de juventudes "en plural" y los efectos que esta distinción produce al focalizar a los sujetos comprendidos en ellas, en especial al momento de analizar la relación de los jóvenes con las instituciones tradicionales como la familia, la escuela, el trabajo y la política.

Es interesante observar cómo la familia, la escuela, el trabajo y la política, todas ellas instituciones tradicionales que -como señala Saintout (2009:9)- "enseñaban" el futuro, hoy no encuentran legitimidad para concretar su tarea. Realizaremos un breve análisis de cada 
una de ellas, para poder analizar luego con quién y cómo construyen los jóvenes lazo social y se construyen como sujetos políticos.

En su relación con la familia, se está transitando un proceso de cambio que va desde el "disciplinamiento primario" a diversas formas de establecer lazos filiares. Habría una ruptura en el modelo de familia patriarcal, orientada a la procreación (y la sexualidad responsable), al disciplinamiento de los sujetos jóvenes (los hijos) de acuerdo a los criterios fundantes de la modernidad occidental, esto es, como reproductora del orden social y la convivencia.

Dos procesos fueron claves en relación al anclaje social y político de los sujetos que se gestaban en la familia: la idea de solidaridad y unidad social y la división del trabajo (doméstico, inicialmente) a partir de la convivencia bajo un mismo techo y con reglas naturalizadas.

Esta familia (nuclear, heterosexual, célula básica de la sociedad) ha cambiado. Los atributos que definían a la familia clásica se han ido transformando en una multiplicidad de formas de familias y de convivencia (Jelin, 1998:19). Claramente, la constitución de la familia ha cambiado desde mediados del siglo XIX a la actualidad y los jóvenes evidencian una mayor disposición a encarar otros modos de relación filial, dado que el amor y la sexualidad, la economía y el orden político no remiten hoy a la idea de "familia".

Las ideas de solidaridad y unidad social pueden observarse -en hechos de la vida cotidianaseriamente afectadas, imponiéndose una tendencia, por arte de los jóvenes, a funcionar en pequeños grupos, clanes o tribus cerrados, con escasas posibilidades de interacción con otros sujetos ajenos al círculo íntimo que conforman (Feixa, 1999; Reguillo Cruz, 2000).

La relación de los jóvenes con la escuela se observa impregnada de imágenes que nos hablan de una relación marcada por el desencuentro de intereses. La escuela no concita el interés de los jóvenes, no solo por la calidad y el formato del tratamiento de los contenidos culturales a transmitir, sino por las relaciones sociales y vinculares que se establecen con los adultos y con los otros jóvenes.

En algunos casos, las distancias que separan a los jóvenes de la escuela resultan generadoras de conflictos que la escuela trata de sofocar. En otros, si lograr visualizar que su tratamiento 
sería el comienzo del diálogo entre una institución con pasado y los jóvenes que representan "el porvenir", los encausa hacia situaciones constructivas, casi siempre de limitada duración. Los jóvenes dudan del valor de la educación escolarizada; la escuela duda de esos jóvenes que desconoce: no encuentra alumnos en ellos. Y la escuela que vinculaba a los jóvenes con el mundo del trabajo hoy no puede cumplir con esa tarea.

El trabajo, que en momentos de modernidad sólida (Bauman, 1999) estructuraba la vida subjetiva y social, constituye hoy para muchos jóvenes una relación incierta, que cuando se logra establecer, resulta pasajera, instrumental, orientada a satisfacer el consumo. El trabajo, que junto con las demás instituciones mencionadas organizaba la vida moderna y marcaba el pasaje a la vida adulta, se ha modificado drásticamente. El trabajo -como organizador social- que se asumía "para toda la vida", no es así percibido mayoritariamente por los jóvenes, para quienes la incertidumbre, capacidad de reconversión, la capacitación, la tolerancia a la frustración y el desempleo son condiciones ante las cuales han transitado su historia como sujetos sociales.

Del mismo modo que el trabajo se presentaba estable y seguro, el trabajador era requerido como leal, esto es, dispuesto a satisfacer los requerimientos del empleador o del gremio. Hoy en cambio, la responsabilidad ante el trabajo encuentra el límite de la propia disponibilidad, ya que no se espera del trabajo solo la remuneración económica, sino que se articule también con otros deseos, además del consumo, como la armonía y el beneficio del tiempo libre.

El trabajo era percibido también como fundamentalmente masculino. Hoy las mujeres disputan al hombre el mercado laboral, dando cuenta de requerimientos de flexibilidad y pensamiento relacional que las colocan en espacios de relevancia social y económica (Wilkinson, 2002).

Y, finalmente, abordaremos algunos aspectos de la relación entre los jóvenes y la política y del proceso de construcción de los jóvenes como sujetos políticos. Atendiendo a la dimensión formal de la política, podemos decir que los jóvenes practican “... una denegación de la política altamente política" (Beck, U. 2002: 9). 
La vida cotidiana en la que se dirimen las acciones formales de los políticos asociadas a las formas convencionales, tradicionales de ejercer y disputar el poder, es despreciada por gran parte de los jóvenes. Pero esto no significa que los jóvenes hayan perdido interés por esta forma de pertenencia, sino que reclaman dotar a la práctica ciudadana de nuevos significados políticos. Para Reguillo Cruz (2013: 125)

“...[se] ha puesto al descubierto una conceptualización insuficiente y pasiva de la ciudadanía como resultado de una graciosa concesión de los poderes antes que -como de hecho lo viene demostrandouna mediación fundamental que sintetiza o integra las distintas identidades sociales que el individuo moderno puede actualizar (mujer, indígena, negro, profesional, consumidor, espectador, joven, público, homosexual etc.) para participar con derechos plenos de una sociedad".

La disputa por el sentido de nuevas formas de ciudadanía se hace visible en nuevas prácticas que, como decíamos en el Capítulo 1, son capaces de conmover las rígidas estructuras de las instituciones modernas, entre ellas, la escuela.

\subsubsection{3-La situación actual de los jóvenes en Latinoamérica}

La referencia temporal de este apartado se centra en el ingreso y desarrollo -no lineal- al régimen neoliberal que con matices, predomina en Latinoamérica.

Transcurrida la década de los 80 y como consecuencia de la fragmentación social que el modelo neoliberal produce en los 90, se registran mayor cantidad de actos de violencia social. Las crisis sociales producidas por la aplicación de un modelo económico y político desintegrador dieron lugar, en los últimos años del siglo $\mathrm{XX}$, a manifestaciones violentas en las que los jóvenes volvieron a ser protagonistas.

La situación de desigualdad y pobreza extrema, la falta de oportunidades para incorporarse a un modelo socio-productivo que exige complejas capacidades, son motivos de alarma para diferentes sectores del gobierno.

Para los gestores del modelo y los funcionarios de las agencias internacionales, los jóvenes pobres significan una amenaza, a la vez que una preocupación. En los documentos 
emanados de los organismos internacionales como ONU, UNICEF, OEA, OIT, se observa que dedican numerosos artículos a la descripción y propuestas de acción tendientes a orientar las políticas públicas de los países "emergentes".

En el nivel nacional se observa que las políticas públicas puestas en vigencia luego de la crisis social producida por la reestructuración del Estado llevada adelante por Menem-tanto las emanadas del Ministerio de Desarrollo Social de la Nación, como del Ministerio de Educación o de Trabajo-se orientan hacia políticas sociales que pueden considerarse compensatorias o focalizadas en poblaciones específicas. Diversos programas se ejecutan de manera articulada entre los distintos niveles de gobierno (nacional, provincial, municipal) y la sociedad civil (ONGs, gremios, entre otros). A lo largo de los 20 años transcurridos, tales políticas han tomado diferentes formatos y sentidos, que han sido analizados luego de investigaciones realizadas (Corea y Duschatzky, 2002; Cardarelli y Rosenfeld, 2005; Chapato y Errobidart, $2013)^{60}$, atendiendo al impacto que tienen sobre las prácticas de los sujetos, en especial los jóvenes.

De acuerdo con los datos de UNICEF (2008) las condiciones de vida que afectan a los adolescentes y jóvenes de América Latina y El Caribe, presentan los siguientes rasgos ${ }^{61}$ :

- Hay 106 millones de jóvenes entre 15 y 24 años en América Latina y el Caribe, el mayor número de jóvenes en la historia de la región.

- La pobreza afecta a la juventud latinoamericana y caribeña en forma desproporcionada; un promedio de $39 \%$ de ellos vive en la pobreza.

- La brecha entre los sectores de la población de altos ingresos y la de bajos ingresos en los centros urbanos afecta cada vez más las vidas de los adolescentes.

- Alrededor de un 25 a un 32\% de la población de 12 a 24 años de edad en la región vive con factores de riesgo tales como la deserción escolar, la maternidad adolescente, el desempleo, la adicción a las drogas o problemas con las autoridades.

\footnotetext{
${ }^{60}$ En los textos mencionados se advierte acerca de los riesgos de ciertas prácticas relevadas en espacios sociales que se enuncian como educativos, y resultan individualizantes, lindantes con el abandono, demagógicas en cuanto a la exacerbación de las culturas juveniles, que legitiman la exclusión de otros circuitos culturales reconocidos como universales.

${ }^{61}$ http://www.unicef.org/lac/Fast facts SP(1).pdf (visitado el 3 de agosto de 2013)
} 
- Hoy en día hay aproximadamente 420,000 adolescentes y jóvenes de 15 a 24 años que viven con VIH/SIDA en América Latina y el Caribe.

- En la mayoría de los países de la región, el acceso a los servicios de salud para los adolescentes y jóvenes sigue siendo inadecuado.

Con el propósito de mitigar la situación descripta funcionan en el territorio nacional diversos programas sociales que tienen a los jóvenes como destinatarios. Estudios recientes producidos por el grupo de Investigación IFIPRAC-ED (2010) en la ciudad de Olavarría informan que los programas sociales como Envión, Patios Abiertos, CAJ, requieren de la participación escolar y están orientados a la población-objeto de esta investigación, jóvenes entre 12 y 16 años (aproximadamente). Otros, como Callejeadas, se enuncian como orientados al sostenimiento de la escolaridad, en especial de la escolaridad secundaria.

De acuerdo a los datos producidos por el censo 2010, en la ciudad de Olavarría hay 7370 jóvenes entre 12 y 15 años. De ellos, se encuentran escolarizados (de acuerdo a cifras presentadas por la Dirección de Información y estadística de la DGE y C de la Provincia de Buenos Aires) el 77.18 \% entre escuelas estatales y privadas. Las autoridades consultadas se han mostrado reticentes a brindar información acerca del grupo que se encuentra por fuera del alcance estatal.

\subsubsection{Los jóvenes que integran la muestra}

Como se expuso en el Capítulo 1 (p: 63) integran la muestra inicial 570 jóvenes que asisten a la ESB en las escuelas seleccionadas para la investigación, del partido de Olavarría.

Luego de la aplicación de la encuesta inicial sabemos que 285 estudiantes son mujeres y 285 son varones, cuya edad está comprendida en un rango que oscila entre 12 y 18 años ${ }^{62}$.

En las escuelas urbanas y rural, los datos de sobreedad de los jóvenes (de acuerdo a la expectativa formal de gradualidad/edad/ trayectoria educativa) presentan escasos desvíos

\footnotetext{
${ }^{62}$ Anexo Metodológico V, Cuadro № 3: distribución de la población total, según edad
} 
de la media esperada ${ }^{63}$, relación que se altera en mayor medida en la escuela suburbana, donde en 3er año de la ESB se encuentran cursando la ESB jóvenes de 16, 17 y 18 años ${ }^{64}$.

En la escuela universitaria, se observa que los padres y madres de los jóvenes han alcanzado los niveles más altos del sistema educativo, en su formación. Son, mayoritariamente, profesionales independientes, empleados con jerarquías, empleados estatales, empresarios o productores agropecuarios. En la escuela privada y en la urbana centenaria, se registran los índices de estudios terciarios que siguen en la escala, y las inserciones laborales resultan similares a las descriptas con anterioridad ${ }^{65}$.

En la escuela rural solo una madre ha alcanzado los estudios terciarios (es maestra en la escuela primaria) y en la escuela suburbana, se registran los mayores índices de incipientes niveles educativos, donde los padres y madres no han finalizado la escolaridad secundaria y algunos tampoco han finalizado el nivel primario.

En la escuela suburbana se agrupan los mayores índices de desocupación de padres y madres, realizando, mayoritariamente, actividades vinculadas a trabajos transitorios y changas. Algunos padres son cuentapropistas del sector independiente (gomero, almacenero) y algunas las madres, vendedoras independientes de productos de distinta índole (cosméticos, ropa) ${ }^{66}$.

En la escuela rural, por su parte, solo un joven responde que su padre es propietario de las tierras que trabaja, correspondiendo el resto de las familias a empleados rurales.

Respecto de sus referencias a la ciudadanía, sus respuestas proveen a la investigación de la información inicial que se presenta a continuación.

\footnotetext{
${ }^{63}$ La relación gradualidad/años formal es: 1er año de ESB: 11-12 años; 2do año de ESB: 12-13 años y 3er año de ESB: 13-14 años

${ }^{64}$ Anexo Metodológico V, Tabla de contingencia № 1: Distribución de estudiantes según edad, por escuela

${ }^{65}$ Anexo Metodológico V, Tabla de contingencia № 3 y 5 ("Nivel educativo alcanzado por el padre, según escuela"; y "Nivel educativo alcanzado por la madre, según escuela")

${ }^{66}$ Anexo Metodológico V, Tabla de contingencia № 2 y 4 (“Ocupación del padre, según escuela”; y “Ocupación de la madre, según escuela")
} 
Los jóvenes responden, mayoritariamente, que ciudadanía son los derechos y deberes de los ciudadanos $^{67}$, utilizando en sus respuestas esta clasificación neutra que no da cuenta, en primera instancia, si se incluyen en ella o hablan de los otros como ciudadanos con derechos y deberes. En segundo orden, responden que ciudadanía es el conjunto de sujetos que integran un país, algunos hacen alusión "al pueblo".

En tercer lugar, dicen que ciudadanía es una materia (Construcción de Ciudadanía) (18.8\%) y un grupo minoritario (8\%) dice que no sabe o no responde la pregunta.

Un alto número de jóvenes estudiantes (61\%) participa de las actividades a las que ellos vinculan con las prácticas ciudadanas en el marco de las materias curriculares ${ }^{68}$. Muy pocos vinculan las prácticas (para ellos) ciudadanas con su participación en el Centro de Estudiantes u otro ámbito reconocido de formación política (5,3\%).

Respecto de su participación escolar en prácticas solidarias, preventivas, o en defensa de derechos, reconoce haber participado de alguna de ellas, el $27 \%$ de los encuestados ${ }^{69}$. De este porcentaje de participantes, el 50\% dice haber participado de actividades solidaras vinculadas con campañas de ayuda ante desastres naturales o campañas organizadas por Cáritas ${ }^{70}$.

Por fuera de la escuela ${ }^{71}$, realizan, mayoritariamente, actividades deportivas (principalmente los varones), miran tele e interactúan en redes sociales (mayoritariamente, las chicas). Ambas actividades atraviesan las ubicaciones espaciales y sociales de las escuelas.

\footnotetext{
${ }^{67}$ Anexo Metodológico V, Cuadro № 7: ¿Qué es para vos la ciudadanía?

${ }^{68}$ Anexo Metodológico V, Tabla de frecuencia № 3, según actividades vinculadas con la ciudadanía que realizan en la escuela.

${ }^{69}$ Anexo Metodológico V, Tabla de frecuencia № 4, según si ha participado o participa de actividades solidarias, preventivas, en defensa de alguien o de algo, puesta en valor de derechos, espacios políticos, etc

${ }^{70}$ Anexo Metodológico V, Tabla de frecuencia № 5, según qué actividad ha desarrollado (para los que respondieron sí)

${ }^{71}$ Anexo Metodológico V ,Tabla de frecuencia № 6, según qué actividades realiza cuando no está en la escuela
} 
Al ser consultados acerca de qué cosas les gustaría hacer que no hacen, muchos indican "nada", pero los que se animan a ensayar una respuesta, se orientan a actividades artísticas y ecológicas ${ }^{72}$.

Resultó notorio que en ninguna de las encuestas se realizara mención a la participación en programas o acciones gubernamentales o emprendidas por ONGs, o al hecho de ser beneficiarios de alguna beca o asignación estatal.

\subsubsection{Las estrategias políticas desarrolladas por los jóvenes en la escuela secundaria}

Retomando la teoría social de Bourdieu podemos decir que los campos tienen propiedades específicas y los capitales de los que disponen los sujetos que intervienen en ellos poseen dinámicas que los colocan en determinadas posiciones para jugar el juego que define a cada campo.

Las prácticas políticas de los jóvenes en el campo educativo, dentro y fuera del espacio escolar, orientadas por sus posiciones y disposiciones en el campo social, están guiadas por intereses más o menos conscientes, que definirán su accionar.

Para realizar ese análisis, prácticas y estrategias constituyen dos conceptos principales que se supone, a priori, permitirán comprender el accionar de los sujetos en su condición de agentes sociales.

Cabe considerar aquí que el concepto de estrategia en la obra de Bourdieu implica un corrimiento en su concepción de la acción de la estructura objetiva sobre las decisiones subjetivas de acción social. "Es abandonar la lógica mecanicista de la estructura en favor de la lógica dinámica y abierta del juego, y obligarse a tomar en cuenta, para comprender cada nueva jugada, la serie completa de jugadas anteriores (...) (Bourdieu, 2011: 34). Como señala el autor en el mismo texto, las constricciones que impone la estructura suelen estar contenidas en las características y el volumen del capital disponible y por ello desecha las

\footnotetext{
${ }^{72}$ Anexo Metodológico V, Tabla de frecuencia № 7, según qué actividades te gustaría realizar (y que no estás realizando)
} 
definiciones que consideran a las estrategias como expectativas conscientes y a largo plazo de un sujeto individual, para considerarlas como producto de los estados del capital disponible. En la acción, ante los requerimientos del campo, encuentra la posibilidad de invención o creatividad del sujeto.

Este modo de concebir las estrategias favorece la comprensión de ciertas prácticas que producen los jóvenes en el campo educativo que, considerando el debilitamiento que presentan algunas dimensiones de las estructuras tradicionales de sistema educativo y del sistema político, permiten la manifestaciones de nuevas formas de lo político que resultan de prácticas educativas intencionadas (o no).

En el análisis de las estrategias, otro elemento resulta de importante en esta investigación. El concepto de "intereses en juego", la illusio (el interés) se engendra históricamente en el campo y es una condición de su funcionamiento. En cada campo resulta importante conocer las condiciones sociales de construcción del interés en juego. En el problema en estudio, el campo educativo está atravesado por nuevas leyes de funcionamiento (como el mandato de obligatoriedad), resultando una proporción significativa de los jóvenes que intervienen en este estudio, los primeros destinatarios de tal oportunidad en su grupo social de pertenencia. Podría inferirse que la illusio con que arriban a la escuela secundaria está en construcción aunque viene precedido por las experiencias de la escolaridad primaria.

Las articulaciones entre la experiencia en el campo y la reflexión teórica han favorecido la construcción de tres categorías teóricas con las que se decide analizar las prácticas políticas de los jóvenes en el campo educativo. Ellas son la participación, la convivencia y la demanda.

La participación se entiende como la posibilidad de desarrollar prácticas sociales-políticas en procesos grupales. La participación en el espacio público, como lo presenta Arendt (2008), es mundo común que une a los sujetos a través de relaciones que no supongan fusión, sino que permitan mantener su condición y capacidad de acción y palabra.

La vida en común, la que se vive cotidianamente en las escuelas, requiere de reglas y de vínculos que hagan posible la convivencia. Los griegos nos legaron la idea de que la ley organiza la vida en común, establece alianzas, obligaciones, a la vez que incluye y enlaza a 
los sujetos entre sí. La ley con su función ordenadora está en crisis y en consecuencia, los sujetos necesitan re-definir los modos de vivir y habitar espacios sociales comunes.

Finalmente, cuando la opresión de las estructuras o las costumbres instaladas no logran canalizar las necesidades y/o deseos, estalla una fuerza social que pugna por disputar el sentido de lo instituido. Se establece entonces una demanda que pretende instalar, de manera consciente, una nueva regla, o emprender estrategias de disputa organizada en pos de cambiar las reglas del juego. Estas situaciones, recurrentes en las escuelas secundarias, pueden extinguirse una vez conseguido su propósito o continuar estableciendo nuevos modos de interacción social.

\subsection{La ciudadanía y su doble problemática, en crisis}

La cuestión de la ciudadanía vinculada a los estudios democráticos, no había tenido, a finales del siglo XX, una fuerte repercusión en los estudios sobre Estado y democracia. Durante los períodos de transición hacia la democracia que siguió a los regímenes autoritarios de las dictaduras de los años '70 y `80, se privilegió el enfoque sobre los aspectos formales de la democracia (Faúndez García, 2006), por sobre las preguntas por los ciudadanos y cuál sería el papel que jugarían en las nacientes democracias en un contexto social, político, económico y cultural que, claramente, se había transformado.

Transcurridos los últimos años del siglo XX, los estallidos sociales producidos como respuesta a la aplicación del "ultraliberalismo" (Oszlak, 2001), dejaron al descubierto no solo la crisis estructural, sino también la crisis del sujeto social de los nuevos tiempos.

Estudios como los realizados por Kymlicka y Norman (1997) en Canadá nos advierten acerca de las mutaciones que en ese contexto atraviesa al concepto de ciudadanía, que comienza a definirse por nuevos problemas y prácticas tanto sociales como políticas. En realidad, lo que advierten los investigadores es que se produce un vaciamiento de la dimensión política de la ciudadanía producida principalmente por el descrédito en que se encuentra la "clase" política y sus prácticas; y, por otro, porque los sujetos están ocupados en resolver cuestiones de índole social, ecológicas, y otras prácticas vinculadas con el consumo. 
La hipótesis formulada inicialmente en esta investigación, considera que la ciudadanía asociada al modelo Estado de Bienestar ha sufrido una fuerte erosión por la relevancia que progresivamente ha adquirido un nuevo modelo social, político, económico y cultural cuyo centro es el mercado y que los jóvenes se construyen como ciudadanos en un contexto social fragmentado, que ha propiciado la existencia de una ciudadanía que ha mutado en sus formas y su sentido.

Algunos de los autores mencionados nos señalan que en la actualidad se vive una ciudadanía restringida, devaluada, "de baja intensidad". Otros investigadores, indagan acerca de doble problemática que encierra el concepto de ciudadanía, profundizando en sus cualidades:

\footnotetext{
“Por un lado, es potencialmente ilimitado, ya que cualquier problema filosófico -político implica relaciones entre ciudadanos y Estado y, por otro, la constante confusión y discusión conceptual entre ciudadanía como condición legal y la ciudadanía como actividad deseable, según la cual la extensión y calidad del ser ciudadano dependa de la participación comunitaria que en ella el sujeto efectúe" (Andrade y Miranda, 2005: 2)
}

Atendiendo a su condición legal para García Delgado y Nosetto (2004) la ciudadanía significa pertenencia, identidad y derechos en relación a una determinada comunidad política que es parte de un proceso histórico no exento de luchas asociadas a la conquista de derechos (civiles, políticos, sociales, postsociales) que remiten a momentos específicos de relación con el Estado.

Atendiendo a su condición de actividad deseable del sujeto, la ciudadanía consiste, según las categorías construidas para este estudio, en la posibilidad de desarrollar prácticas orientadas hacia la convivencia, la participación y la capacidad de convertir necesidades en demandas que, trascendiendo la dimensión individual, operen en favor del bien común. Todas ellas, atravesadas por intenciones de disputas de poder.

Nos proponemos ampliar algunos aspectos para que nos permitan comprender en profundidad el concepto de ciudadanía. 


\subsubsection{Evolución histórica de la ciudadanía}

Ciudadanía refiere a una serie de condiciones por las que un sujeto se considera $-y$ es considerado- miembro pleno de una comunidad.

La idea de ciudadanía se asocia a la noción de polis griega, pero no nos detendremos en la exposición de tan complejo y extenso recorrido, cuando están disponibles análisis tan fecundos, desde Argentina, como el realizado por Cullen (2007), en una de sus obras recientes.

Nos centraremos, en cambio, en las significaciones que fue adquiriendo el concepto a partir de la construcción de los Estados Nacionales. Desde sus inicios, el Estado concibió esta condición definiéndola de manera externa al sujeto, reparando escasamente en el proceso subjetivo de construcción del ciudadano como miembro activo y responsable de una comunidad.

En un abordaje histórico, el concepto de ciudadanía remite a la obra clásica de Thomas Marshall (1949) para quien la ciudadanía abarca tres etapas o modelos que se han constituido en conquistas histórico- evolutivas: la ciudadanía civil, la ciudadanía política y la ciudadanía social.

En los estudios de ciudadanía clásica, como lo reconoce el trabajo de Marshall, se presenta un desarrollo acerca de cómo el Estado moderno va "otorgando" distintos tipos de ciudadanía a los sujetos. Esta perspectiva se reconoce en el campo académico como "ciudadanía formal" y está asociada a la pertenencia a un estado-nación.

Esta teoría sobre la ciudadanía se asienta sobre la base de un Estado que regula la relación con la sociedad, realiza la construcción simbólica de una nación e impone límites territoriales. Es uno de los pilares en los que se asienta el contrato entre el Estado y la sociedad. No escapa a los análisis de T. Marshall, ubicados en la posguerra europea, que la ciudadanía como status jurídico conllevaba como condición inherente a su existencia, la presencia de desigualdades e injusticias que se han ido reproduciendo a lo largo de la historia. Pero él confiaba en que el Estado garantizaría los servicios universales de educación y salud y así disolvería las diferentes culturas de clase, avanzando hacia una "civilización unificada". Al confrontar las tres dimensiones de la ciudadanía moderna, encontró en ellas 
tales contradicciones constitutivas que “...comprendió que la ciudadanía misma había funcionado como arquitecto de la desigualdad social" (Fraser y Gordon 1992: 68)

El análisis de las fases histórico- evolutivas la ciudadanía da cuenta de que la ciudadanía civil se habría desarrollado principalmente en el siglo XVIII, garantizando la legitimidad necesaria para consagrar los derechos individuales de propiedad, autonomía personal y justicia. La segunda fase de constitución de la ciudadanía política, se habría desarrollado principalmente en el siglo XIX con la consolidación de los estados nacionales y los gobiernos republicanos, consagrando para los sujetos el derecho a participar en el ejercicio del poder político, a través del acto de elegir y ser elegido. La tercera y última fase constitutiva de la ciudadanía social, se habría construido en el siglo XX y según las autoras

“...no solo abarcaría el derecho a un mínimo de seguridad económica, sino que implicaría también un derecho de mayor alcance, a compartir todo el patrimonio social y a vivir la vida de un ser civilizado según los patrones que prevalezcan en la sociedad"(1992: 68)

Siguiendo la evolución del concepto, a principios del siglo XVIII la ciudadanía significó el hecho de tener residencia en una ciudad. Esta concepción deviene en referencia a los primeros grupos que se liberaron de las relaciones feudales, adquiriendo el término connotaciones de libertad. Los derechos inherentes a ese status se denominaron derechos cívicos o civilese incluían: el derecho a la propiedad privada, a la libertad personal ${ }^{73}$, a la libertad de expresión, de pensamiento y de credo. La institución que representa este tipo de ciudadanía son los tribunales (como institución especializada que administra la justicia y garantiza la libertad).

La ciudadanía política, cuyo origen se sitúa en el siglo XIX, otorga este status a los sujetos en condiciones de participar -a través del derecho de elegir y ser elegido mediante el sufragiodel gobierno de un país. Esta etapa o fase de la ciudadanía se desarrolla solo cuando estuvo -relativamente-asegurada o consolidada la fase de ciudadanía civil. Inicialmente, los derechos políticos no formaban parte de los derechos ciudadanos, habiendo quedado como

\footnotetext{
${ }^{73}$ Dentro de las libertades individuales y en el terreno económico, el derecho civil básico es el derecho al trabajo, como práctica de un oficio que se ha elegido y para el que se ha recibido un adiestramiento técnico preliminar.
} 
privilegio de una reducida elite económica. La institución que representa este tipo de ciudadanía es el parlamento.

Como expresa Marshall (1992: 30)

“...es lógico que la sociedad capitalista del siglo XIX tratase los derechos políticos como un subproducto de los derechos civiles, y también lo es que durante el siglo XX se abandonase esta posición para vincular los derechos políticos directa e independientemente a la ciudadanía".

Se ha expresado ya que los derechos sociales son producto del siglo XX y que su trayectoria o evolución se solapa con los derechos políticos, tanto en lo que potencian como en aquello que excluyen o impiden. "El elemento social abarca todo el espectro, desde el derecho a la seguridad y a un mínimo de bienestar económico al de compartir plenamente la herencia social y vivir la vida de un ser civilizado conforme a los estándares predominantes en la sociedad" (Marshall, 1992: 23). Las instituciones que lo representan son el sistema educativo y los servicios sociales.

Vale recuperar la expresión del autor cuando afirma que "en otros tiempos fueron tres hilos de la misma hebra. Los derechos se entremezclaban porque las instituciones se amalgamaban." (op. Cit. 23)

Resulta interesante considerar otros análisis diferentes a los expuestos realizados por el mismo autor, como el hecho de considerar que la ciudadanía consiste en "un estilo de vida que se cultiva en el interior de cada persona, que no se le presenta (ni se le otorga) desde afuera" (Marshall, op.cit.:21).

Los debates sobre los alcances y significados en torno del concepto de ciudadanía, parecen activarse en los períodos posteriores a grandes crisis políticas y un ejemplo de ello son los que se registran en Latinoamérica con el retorno de la democracia en la década de los 80 y, nuevamente, luego de la crisis neoliberal que re-define los alcances del consenso de Washington, después de 1996.

En países como los que integran nuestra región, la ciudadanía en las tres dimensiones desarrolladas por Marshall ha sido motivo de profundas desigualdades. El caso de las mujeres es el más evidente, pero también lo sufren otros sectores y su desigualdad está 
asociada con la condición de subalternidad laboral y económica, de pertenencia a etnias y de género (Frasser y Gordon, 1992). Del mismo modo, la noción de ciudadanía política asociada al acto de elegir y ser elegido, ha sido impedida a los jóvenes hasta alcanzar la edad adulta de dieciocho años ${ }^{74}$.

Aun considerando las desigualdades señaladas con anterioridad, coincidimos con Svampa (2005) cuando sostiene que la Argentina logró un estado de integración social a través del pleno empleo, que la acercaba más a las sociedades salariales de los países desarrollados que a sus pares de Latinoamérica. Sin embargo, el proceso de desregulación estatal y su dinámica descolectivizadora significaron para muchos "...no solo la entrada a la precariedad sino la pérdida de los soportes colectivos sociales y materiales que durante décadas habían configurado la identidad nacional" (2005: 75).

Fundamentalmente, junto a la desregulación estatal se instaló la noción de fragmentación social en la que ya no se piensa la sociedad como un todo integrado (o a integrar), sino como partes que interactúan con dinámicas diferenciales. Se hace evidente, como señalan Fitoussi y Rosanvallon (2003), que la principal decadencia de la nueva era de las desigualdades es la decadencia de lo colectivo.

El proceso de cercenamiento de la ciudadanía asociada al Estado de Bienestar producido desde los '90 en adelante, condujo a un recrudecimiento de la individualización y a la pérdida de identidad delas clases medias y populares, convirtiendo a éstas últimas en "bolsones" de dominación y control neoliberal a través de programas sociales compensatorios.

En la actualidad, la ciudadanía puede comprenderse (Svampa 2005) atendiendo a dos aspectos: una, como status que se concede a los miembros de pleno derecho de una comunidad, lo cual significa "la problematización de las fronteras de pertenencia al colectivo social" y también problematiza "las consecuencias de la fragmentación e individualización de los derechos" (Svampa 2005: 12); otra, como un conjunto de nuevas prácticas por las cuáles

\footnotetext{
${ }^{74}$ En el año 2012, se realizó la promulgación de la Ley N²6.774 que incorporó el voto optativo para jóvenes a partir de los16 años
} 
los sujetos manifiestan su derecho a participar. Esto implica la valoración de nuevas formas y prácticas de participación.

Svampa reconoce, en relación a la individualización de los derechos y la ruptura de lazos sociales, tres tipos de ciudadanos: el ciudadano patrimonialista, el ciudadano consumidor (en sus dos versiones: el consumidor puro y el consumidor usuario) ${ }^{75}$, el ciudadano correspondiente al modelo asistencial-participativo, con los que se asocia la ciudadanía restringida. La ciudadanía restringida alude a aquellas prácticas que no poseen alcances universalistas ni aspiraciones igualitaristas y cuya definición y alcances están más bien orientados por la lógica del nuevo orden económico y político, independientemente de las posibilidades (individuales y colectivas, materiales y simbólicas) que detenten los sujetos.

Los tipos de ciudadanos que reconoce Svampa comprenden al ciudadano patrimonialista, cuya característica principal es la de ser propietario y la autorregulación de sus acciones en relación a su autonomía individual; el ciudadano-usuario de bienes y servicios que ofrece el mercado, que durante la gestión menemista tuvo gran aceptación del conjunto social y quedó instalado como estilo de ciudadanía; y el ciudadano asistencial-participativo, que "víctimas" y "prisioneros" del mercado, han quedado excluidos de su circuito productivo (pero no del consumo). Para ellos, el neoliberalismo ha definido una serie de programas sociales "que apoyados en la autoorganización comunitaria, tienden a promover el desarrollo de una ciudadanía restringida, de muy baja intensidad, bajo la mirada vigilante del Estado y el control constante de las agencias multilaterales de crédito" (Svampa 2005: 88).

Kymlicka y Norman (1997) recogen las preocupaciones actuales por el creciente desinterés ciudadano por los actos de la política, en especial el acto que consagra la ciudadanía política, situación que fundamentalmente se registra en países con democracias estables. Los recientes movimientos ciudadanos -como los indignados de España, los rebeldes griegos, las

\footnotetext{
${ }^{75}$ Sostenemos que la construcción de ciudadanía en una nueva etapa de la relación estado-sociedad, adquiere características distintivas de aquella mediada por la subjetividad estatal (Lewkowicz, 2004). No puede soslayarse en este análisis la emergencia de un nuevo sujeto social con status constitucional, como lo es el sujeto consumidor, cuyos derechos se expresan en la el art. 42 de la Constitución Nacional.
} 
manifestaciones de descontento social en Brasil- parecen indicar que hay un retorno a la política, que alienta algunos otros modos de ciudadanía, desde la acción de los sujetos. Se trata de prácticas ciudadanas que se impulsan desde los sujetos, desde las bases, no ya como prácticas que se generan desde las estructuras político-estatales.

Este tipo de práctica ciudadana se reconoce como "ciudadanía sustantiva" (Bottomore, 1992) y alude al proceso por el cual los sujetos, en un proceso reflexivo, se reconocen como constructores de ciudadanía; esto es, activan el desarrollo de prácticas políticas, porque su acción disputa el poder presente en el campo.

\subsubsection{Los desafíos de la ciudadanía en un contexto social contingente}

La contingencia del orden social y la fragmentación de la sociedad son aspectos ineludibles al momento de pensar en los sentidos que se construyen con las acciones de formación ciudadana que la política educativa y la escuela proponen a los sujetos jóvenes.

Esta investigación, que se propone estudiar las prácticas políticas de los jóvenes que conducen a la construcción de ciudadanía en contextos escolares, considera que la ciudadanía no es un estado que se otorga desde fuera de los sujetos sino que su práctica y ejercicio remiten a una construcción interior. Pero se considera, a la vez, desde una perspectiva propositiva y con una fuerte carga de puesta en valor de la educación como proceso de inscripción cultural, que las oportunidades de acción organizadas con otros producen registros subjetivos que propician el pasaje de los sujetos sociales a los sujetos políticos. Esta acción, ciertamente, no es llevada adelante solo por la escuela, sino que los sujetos están inmersos en configuraciones socioculturales que permean la tarea educativa de la escuela y que ofrecen otras oportunidades de acción.

Para caracterizar las prácticas políticas de los jóvenes que influyen en su construcción como sujetos políticos, es decir, como ciudadanos, abordaremos la distinción -hoy muy presente en los debates de la ciencia política-, entre la política y lo político. Puede advertirse de manera especial en los acontecimientos derivados del "nuevo orden social", que la 
democracia parece adquirir un estilo instrumental que va vaciándola de significado. Es su significado político, precisamente, lo que parece estar en cuestionamiento.

La doble significación de la política presenta una vía diferente para pensar cómo el aparente desánimo político de los jóvenes puede estar adquiriendo otro significado en la construcción de un nuevo orden, de una manera diferente de "estar juntos". Allí es donde esta investigación busca relevar qué nuevas/otras posibilidades se están gestando.

Lo político presenta, entonces, como un momento constitutivo del orden social. Es la posibilidad de emergencia, o reemergencia, del sujeto; es conflicto, es posibilidad de cambio, es apertura. La política es, por el contrario, la administración de lo instituido, es el gobierno, el poder, el sistema, la policía (Ranciêre, 2000)

Pensamos que esta distinción puede observarse en las escuelas: los jóvenes estudiantes pugnan por sus derechos (concedidos por ley pero no reconocidos en la práctica), por instalar nuevas prácticas, por vincularse de otro modo con el conocimiento, por instalar nuevos códigos de convivencia (volviendo a cargar de significado el concepto)y con ello generan conflicto. La burocracia estatal (el sistema y sus agentes en general), pugnan por mantener el orden y anular el conflicto: en esta situación, el desencuentro resulta inevitable. Pero también hemos relevado otras situaciones que escapan de la racionalidad descripta.

Desde esta perspectiva, en las escuelas también se relevan protestas, demandas, resistencia, como modos de manifestación de lo político sin que ello esté enmarcado en procesos revolucionarios u orientados a generar grandes cambios.

El desafío consiste, entonces, en relevar los sentidos que los jóvenes, en la escuela, construyen en torno de la ciudadanía 


\section{Bibliografía:}

ANDRADE, G. y MIRANDA, J (2005). “El concepto de ciudadanía en educación”. Pontificia Universidad Católica de Chile, Facultad de Educación, Santiago de Chile.

APPLE, M., ALZAMORA, S y CAMPAGNO, L. (2012). Poder, conocimiento y reforma educacional. Miño y Dávila, Buenos Aires.

ARENDT, H. (2008). La condición humana. Paidós, Buenos Aires.

BAUMAN, Z. (1999). Modernidad líquida. FCE, Barcelona.

(2007a..). Vida de consumo. FCE, Buenos Aires.

(2007b.). En busca de la política. FCE, Buenos Aires.

BECK, U. (comp) (2002). Hijos de la libertad. FCE, México.

BOBBIO, N. (1986). El futuro de la democracia. FCE, México.

México.

(1989). Estado, gobierno y sociedad: por una teoría general de la política. FCE,

BOMVILLANI, A.; PALERMO, A; VÁZQUEZ, M. y VOMMARO, P. (2008). Juventud y política en la Argentina (1968-2008). Hacia la construcción de un estado del arte. Revista Argentina de Sociología. Año 6 № 11.pp 44-73. Buenos Aires.

BORON, A. (2003). Estado, capitalismo y democracia en América Latina. CLACSO, Buenos Aires.

BOTTOMORE, T. (1992). Ciudadanía y clase social. Cuarenta años después. En MARSHALL, Th. y BOTTOMORE, T. Ciudadanía y clase social. Versión de Pepa Linares. FCE: México.

BOURDIEU, P. (1990). “La juventud no es más que una palabra”. En: Sociología y cultura. Grijalbo, México.

-(1993). “Espíritu de estado. Génesis y estructura del campo burocrático”. En:

Actes de la Recherche en Sciences Sociales, N 96-97, marzo de 1993.

-(1997). Razones prácticas. Sobre la teoría de la acción. Anagrama, Barcelona.

-(2001). El campo político. Plural editores, Bolivia.

-(2007).El sentido práctico. Siglo XXI, Buenos Aires. 
(2011).Las estrategias de la reproducción social. Siglo XXI, Buenos Aires

CHAPATO, M.E. y ERROBIDART, A. (comp.)(2013). La educación como práctica sociopolítica. Los sentidos de educar que se construyen desde abajo. Aportes para la comprensión de la educación bajo el imperativo de inclusión social. Miño y Dávila, Buenos Aires.

CARBONE, G. (2011).Seminario Libros de texto en la historia reciente de la educación argentina: manuales, libros por áreas e itinerarios hipertextuales. (1958-2008).

CAYCIT/CONICET. Universidad Nacional de Luján, Luján.

CARDARELLI, G. y ROSENFELD, M. (2005). Las participaciones de la pobreza. Programas y proyectos sociales. Paidós, Buenos Aires.

CASTORIADIS, C. (1983). La institución imaginaria de la sociedad. Tusquets, Barcelona.

CHAVES, M. (2006). Investigaciones sobre juventudes en Argentina: estado del arte en Ciencias Sociales. Dirección Nacional de Juventud y Universidad Nacional de San Martín. http://www.idaes.edu.ar/papelesdetrabajo/paginas/Documentos/05 15 Informedeinvestig acion MarianaChaves.pdf

-(2010). Jóvenes, territorios y complicidades. Una antropología de la juventud urbana. Espacio Editorial, Buenos Aires.

COREA, C. y DUSCHATSKY, S. (2002). Chicos en banda. Los caminos de la subjetividad en el declive de las instituciones. Paidós, Buenos Aires.

CORTINA, A. (2001). Ciudadanos del mundo. Hacia una teoría de la ciudadanía. Alianza editorial, Madrid.

CULLEN, C. (2007) (comp.). El malestar de la ciudadanía. La Crujía, Buenos Aires.

De SOUSA SANTOS, B. (2002). Reinventar la democracia, reinventar el Estado. CLACSO, Argentina.

DUSCHATZKY, S., FARRÁN, G. y AGUIRRE, E. (2010). Escuelas en escena. Una experiencia de pensamiento colectivo. Paidós, Buenos Aires.

FAUNDEZ GARCIA, R. (2006): Ciudadanía de baja intensidad: el aporte conceptual y algunas pistas para su estudio en el caso chileno. Consultado el 25 de junio de 2013 en https://es.scribd.com/doc/39258660/Ciudadania-de-baja-intensidad-en-Chile

FEIXA, C. (1999). De jóvenes, bandas y tribus. Ariel, Barcelona. 
FITOUSS, J.P.I y ROSANVALLON, P. (2003). La nueva era de las desigualdades. Manantial, Buenos Aires.

FLEURY, S. (2005). La ciudad de los ciudadanos. Biblioteca Virtual TOPwww.top.org.ar FOUCAULT, M. (1989): Vigilar y castigar. Siglo XXI, Buenos Aires

FRASER, N. y GORDON, L. (1992). Contrato vs. Caridad: una reconsideración de la relación entre ciudadanía civil y ciudadanía social. Revista Isegoria Na 8, PP 65-82.

GARCÍA DELGADO, D. y NOSETTO, L. (2004). "La Ciudadanía en una etapa de reconstrucción: imaginarios y desafíos". Boletín Virtual TOP (Tecnología para la organización pública) № 10. http://www.top.org.ar/boletin/boletinn10.htm

GOODSON, I. (2000). El cambio en el curriculum. Octaedro, España.

GUTIÉRREZ, A. (1994). Pierre Bourdieu: las prácticas sociales. CEAL, Buenos Aires. (2010). A modo de introducción. Los conceptos centrales en la sociología de la cultura de P. Bourdieu. En Pierre Bourdieu, El sentido social del gusto. Elementos para una sociología de la cultura. Siglo XXI editores, Buenos Aires.

JELIN, E. (1998). Pan y afectos. La transformación de las familias. FCE, Buenos Aires.

KYMLICKA, W y NORMAN, W. (1997). El retorno del ciudadano. Una revisión de la producción reciente en teoría dela ciudadanía. Revista La Política № 3 (pag. 5-40) Barcelona.

LAHIRE, B. (2009). Introducción. En Tiramonti, G.(comp): La escuela media en debate. Problemas actuales y perspectivas desde la investigación. Manantial/FLACSO, Buenos Aires.

LACLAU, E. (1990). Nuevas reflexiones sobre la revolución de nuestro tiempo. Nueva visión, Buenos Aires.

- (2005). La razón populista. FCE, Buenos Aires.

LEWKOWICZ, I. (2004): Escuela y ciudadanía. En: COREA, C. y LEWKOWICKZ, I. (2004). Pedagogía del aburrido. Escuelas destituidas, familias perplejas. Paidos, Buenos Aires MARCHART, O. (2009). El pensamiento político posfundacional. La diferencia política en Nancy, Badiu, Lefort y Laclau. FCE, Buenos Aires.

MARTIN BARBERO, J. (2003). La educación desde la comunicación. Tesis Norma, Buenos Aires.

MARSHALL, Th. (1949). Ciudadanía y clase social. FCE, México.

MARSHALL, Th. (1992). Ciudadanía y clase social. En MARSHALL, Th.y BOTTOMORE, T. Ciudadanía y clase social. Versión de Pepa Linares. FCE: México. 
O'DONNELL, G. (1993)."Estado, democratización y ciudadanía". Revista "NUEVA SOCIEDAD" NRO. 128 NOVIEMBRE- DICIEMBRE 1993, PP. 62-87.

-(2010). "Revisando la democracia delegativa". En:

http://www.difusioncultural.uam.mx/casadeltiempo/31 iv may 2010/casa del tiempo elV num31

OSZLAK, O. (1999). "De menor a mejor: el desafío de la segunda reforma del Estado". Revista Nueva Sociedad, № 160, Venezuela.

PEREZ ISLAS, A. (1998). Memorias y olvidos. Una revisión sobre el vínculo de lo cultural y lo juvenil. En "Viviendo a toda". Jóvenes, territorios culturales y nuevas sensibilidades.

Universidad Central. DIUC. Siglo del hombre, Bogotá.

PERUZZOTTI, E. (2011). "El otro déficit de la democracia delegativa. Retomando el debate acerca de la rendición de cuentas en las democracias contemporáneas de América Latina" En: http://observatoriodepolitica.com/avances/wp-content/uploads/2011/

PNUD (2004). La democracia en América Latina. Hacia una democracia de ciudadanas y ciudadanos. Taurus. Buenos Aires.

PUIGGROS, A. (1998). Qué pasó en la educación argentina. Desde la conquista hasta el menemismo. Kapelusz, Buenos Aires.

RANCIÊRE, J. (2000). “Política, identificación y subjetivación". En Arditi, A. (editor) El reverso de la diferencia: identidad y política. Nueva Visión, Caracas.

REGUILLO CRUZ, R. (2000).Emergencia de las culturas juveniles. Estrategias del desencanto. Tesis Norma, Buenos Aires.

RETAMOZZO, M. (2009): “Lo político y la política: los sujetos políticos, conformación y disputa por el orden social". Revista mexicana de Ciencias Políticas y Sociales. Vol.51 № 206. México may./ago. 2009

SAINTHUT, F. (2009). Jóvenes: el futuro llegó hace rato. Percepciones de un tiempo de cambios: familia, escuela, trabajo y política. Prometeo, Buenos Aires.

SOUTHWELL, M. (2011). “La educación secundaria en Argentina. Notas sobre la historia de un formato". En Tiramonti, G. (dir.): Variaciones sobre la forma escolar. Límites y posibilidades de la escuela media. FLACSO- Homo Sapiens, Rosario.

SVAMPA; M.(2005). La sociedad excluyente. La Argentina bajo el signo del neoliberalismo. Taurus, Buenos Aires 
TAMARIT, J. (1994). Educar al soberano. Miño y Dávila, Buenos Aires.

TERAN, O. (2008). Historia de las ideas en Argentina. Diez lecciones iniciales. 1810-1980. Siglo XXI, Buenos Aires.

TOURAINE, A. (2001). ¿Podremos vivir juntos? Iguales y diferentes. FCE, México.

-WILKINSON, H. (2002). Hijos de la libertad ¿Surge una nueva ética de la libertad individual y social?. En U. Beck (comp): Hijos de la libertad. FCE, México. 


\section{Capítulo 3}

\section{Historia, cultura y curriculum en la construcción de la ciudadanía en la escuela secundaria. $\mathbf{3 0}$ años de historia para comprender el presente}

\subsection{Introducción}

Las transformaciones del sentido asignado por las políticas actuales a la educación, se manifiestan en los distintos procesos de reformas educativas que ha experimentado la Argentina en los últimos 20 años. Tales transformaciones se materializan en prácticas concretas, que son mediadas por la historia y la existencia de una cultura escolar que, como se ha expresado anteriormente, es atravesada por la vida "extramuros" que contiene a la escuela.

En el contexto de la cultura escolar, el desarrollo del curriculum remite a una serie de negociaciones, luchas y resistencias a través de las cuales los actores del curriculum (agentes representantes del sistema educativo, jóvenes estudiantes y comunidad educativa) definen y ponen en marcha un proyecto educativo.

Las culturas escolares son consideradas como el texto en que se inscriben las decisiones curriculares tomadas por fuera de la institución escolar (las prescripciones macro) y, en tal sentido pueden darles un carácter idiosincrático. Pero también son el texto en el que se tejen las decisiones curriculares institucionales, si es que se realiza la tarea de producir un proyecto educativo propio que considere todos los componentes de la cultura escolar.

En este capítulo nos proponemos presentar, con una perspectiva teórica nutrida en la sociología del curriculum, las relaciones entre los sujetos de acción, las culturas escolares y las decisiones curriculares (en sus distintos niveles). Los sujetos del desarrollo curricular y sus prácticas - especialmente las prácticas políticas de los jóvenes estudiantes de la escuela secundaria- se localizan en los contextos escolares seleccionados para la investigación.

Con una mirada diacrónica, se analizan los diferentes períodos por los que ha atravesado el curriculum de formación/construcción ciudadana y las políticas educativas que lo sostienen, 
en los últimos 30 años. Se observan cambios de las políticas educativas que se manifiestan, en la mayoría de los casos, en modificaciones en el curriculum prescripto que reflejan las nociones de ciudadanía que se sostienen en cada período. La idea que subyace a este análisis es que las prescripciones curriculares operan como un primer nivel de concreción de los fines de la política educativa, que anticipa los contenidos de los que pretende dotarse a las prácticas de la enseñanza que se concretan en cada escuela particular.

Pero no todo el proceso educativo que se produce en el ámbito escolar puede ser explicado y/o comprendido a través de las prácticas que prescribe el curriculum formal. Nos referimos a la existencia de otro tipo de práctica curricular, no explícita, que conocemos como curriculum oculto. En relación a este concepto, se desarrollan los principales análisis de esta investigación, en los capítulos 4,5 y 6 en los que la vida escolar protagonizada por los jóvenes estudiantes en sus interrelacionesexpresa los sentidos que se construyen en relación a la política y a la ciudadanía.

En relación a un nivel más específico del proceso de concreción curricular se presentan en este capítulo las decisiones y configuraciones didácticas (Litwin, 1997) en relación a la enseñanza de la ciudadanía que se producen en las cinco escuelas que componen la muestra de la investigación en su devenir histórico.

A los efectos de conocer los cambios recientes referidos a la formación política y ciudadana encomendados a la escuela secundaria, se ha optado por un recorte temporal que abarca desde la recuperación de la democracia en el año 1983 hasta los primeros años de implementación de la Ley de Educación Nacional sancionada en el año 2006. Por un lado, se considera necesario establecer un límite temporal que acote el estudio y, al mismo tiempo, es posible plantear que en los tres momentos seleccionados tienen lugar cambios en el sentido de la educación secundaria que permiten identificar un proceso de transformación en cuanto a la función de la escuela y su incidencia en la construcción de identidades ciudadanas.

\subsection{Historia, cultura escolar y curriculum en la escuela secundaria}


Abordar la escuela desde un concepto de cultura escolar supone pensar que las instituciones educativas singulares mantienen una relativa autonomía respecto del sistema escolar, poniendo de relieve su capacidad para crear formas de pensar y hacer propias y configurar una sociedad escolarizada "...en la que cualquier modalidad de enseñanza adopta las formas escolares de transmisión y evaluación del saber..." (Viñao Frago, 2008: 90). El autor que citamos sostiene que la cultura escolar es una construcción que deviene del origen mismo de la institución escuela, que ha estado asociado a cierta inercia o resistencia a los cambios. El concepto de cultura escolar comparte rasgos de identidad con lo que fue denominado por Tyack y Cuban (2001, citado por Viñao Frago), gramática de la escolaridad. Estudios realizados desde perspectivas antropológicas o sociológicas, influidas por la Escuela de Birmingham, adoptan una modalidad de análisis más centrada en los sujetos, es decir en la comprensión de la construcción de significados entramados en la cultura escolar.

Es así que las culturas escolares moldean, dan forma a las regulaciones que se establecen desde el exterior, desde el sistema escolar y la sociedad.

Se reconocen aspectos visibles que constituyen la cultura escolar: los discursos, los aspectos organizativos y la cultura material de la escuela. Todos ellos, nos permitirán una mirada comprensiva acerca de cómo se acomodan las distintas escuelas a los mandatos de la última reforma, permitiéndonos vislumbrar, fundamentalmente, las posibilidades de dar lugar a la expresión de las culturas juveniles, y las prácticas políticas que éstos como sujetos son capaces de generar en su interacción.

El abordaje del concepto de curriculum nos remite a un extenso y profundo debate académico e ideológico que ha sido sostenido fructíferamente a partir de la segunda mitad del siglo XX. Autores consultados - y reconocidos en el campo de estudios del curriculumcomo Apple (1977), Berstein (2001), de Alba (1995), Díaz Barriga (1996), Gimeno Sacristán (1988, 2010), Giroux (1992), Giroux y Penna (1979), Goodson (1995, 2003)- desarrollan sus estudios en referencia al contexto socio-histórico que da sentido a las problemáticas emergentes en torno del curriculum.

Puede distinguirse una tradición anglosajona en cuanto a los estudios sobre el campo del curriculum, cuyo principal desarrollo se vincula (Goodson, 1988) con la existencia de la 
escuela de masas. De acuerdo con Gimeno Sacristán (2010: 25), la masificación de la educación "requiere que en aras de la igualdad se dosifiquen los contenidos y se organicen dentro de un sistema escolar desarrollado. Sin la contribución de ese concepto [curriculum] sería muy difícil entender la escolaridad, examinarla y criticarla".

Con matices distintivos, que se desarrollan y contraponen a lo largo de las obras de los autores mencionados, pueden reconocerse dos grandes momentos en los estudios sobre el curriculum: primero, un desarrollo del llamado curriculum formalista o académico (Gimeno Sacristán 1988: 46) que hace referencia, fundamentalmente, a los planteos y problemas "utilitaristas" de los planificadores y/o gestores de la educación. Otro desarrollo posterior, entramado con las perspectivas críticas producidas por los intelectuales de la escuela de Frankfurt y Birmingham, produce modelos teóricos a partir de los cuales se reformula el objeto de estudio y sus acercamientos metodológicos. Esta perspectiva resulta más propicia para comprender la práctica de la enseñanza en tanto práctica social, que permite relevar la trama oculta sobre la que se construye determinado orden social.

Reconocer en los estudios sobre curriculum las intenciones sociales, políticas y económicas que suelen permanecer silenciadas tras los discursos sobre la educación, es decir, principalmente desenmascarar las relaciones de poder y control que los grupos hegemónicos ejercen sobre la educación, produjo el punto de quiebre con los estudios tradicionales del curriculum y el surgimiento de la corriente llamada "Nueva Sociología de la educación", sobre la que realizaremos algunas precisiones.

Puede decirse que esta corriente de pensamiento y producción de conocimientos se inicia con las denuncias por parte de los estudiosos de la Escuela de Frankfurt acerca del papel reproductor del orden social que realiza la escuela, des-ocultando las relaciones de poder que definen sus modos de funcionamiento, la arbitrariedad en la selección de los contenidos de la enseñanza, el formato y disciplinamiento escolar, la función técnica predominante en la formación de los maestros, entre otros temas.

En la década de 1960 se inician estudios en Inglaterra con Young, Bernstein y Davies, en la perspectiva de la Sociología del Curriculum. Sobre ellos ejerce una notable influencia la denominada Escuela de Birminghan y el nuevo campo de conocimientos dirigido por Stuart 
Hall, que reconocemos bajo la denominación general de los Estudios Culturales (Kincheloe, J. 2000). Los estudios de Bernstein ([1990]; 2001), en especial los referidos a cómo el conocimiento se selecciona, clasifica, distribuye y evalúa, inspiraron el trabajo de Ivor Goodson (1995) y de Andy Heargraves (1995) para penetrar en las relaciones sobre el conocimiento, el poder y la educación, con una perspectiva social e históricamente construccionista. El construccionismo sociohistórico se orienta a la comprensión del curriculum articulando la dimensión teórica con la empírica, focalizando en la complejidad de la experiencia vivida por los sujetos en la que tiene principal incidencia la clase social. Reconoce en el aprendizaje una actitud activa del sujeto y que todo conocimiento nuevo procede de uno anterior. Los estudios de Stenhouse (1981) conciben al curriculum como un campo de comunicación entre la teoría y la práctica, entre las intenciones de la política educativa y la realidad de la práctica curricular escolar. Coloca además, un fuerte énfasis en la figura del profesor como investigador de su acción.

Estas perspectivas resultan más congruentes con la perspectiva sociológica macro adoptada en esta investigación, en tanto se entiende al campo educativo como un espacio social e históricamente sedimentado, tal como ha sido desarrollado de acuerdo con la perspectiva sociológica de Pierre Bourdieu, presentada en el Capítulo 1.

También en EEUU, la sociología de la educación influenciada por los teóricos de la escuela de Frankfurt presentó estudios -que aún persisten con innegable actualidad y vigencia-, como los realizados por Michael Apple, Henry Giroux, Peter Mc Laren, entre otros. Giroux y Mc Laren, desde la teoría social de la resistencia, se inclinan por los estudios de curriculum desde una perspectiva culturalista.

En 1968 Philip Jackson publica "La vida en las aulas", obra en la que sostiene que la educación es principalmente un proceso de socialización y que los contenidos, tareas e interacciones escolares poseen un significado latente que es preciso indagar, describir e interpretar. Llama a este proceso "curriculum oculto" y en él describe distintos elementos escolares que lo componen: la estructura del aula, el lugar del profesor, de los estudiantes, del conocimiento, de la autoridad y el poder, los materiales educativos, las evaluaciones, entre otros. 
Tanto desde la perspectiva neomarxista de la sociología de la educación (como es el caso de Michael Apple) como de la perspectiva culturalista (cuyos referentes principales son, a nuestro parecer, H. Giroux, P. Mc Laren y P. Aronowicz) en EE.UU. se avanza en el estudio del curriculum en la práctica, de las interrelaciones humanas mediadas por la cultura, la ideología y el poder. En España, José Gimeno Sacristán, Ángel Pérez Gómez, Jurjo Torres Santomé, entre otros, realizan estudios críticos y contextualizados respecto de las perspectivas citadas, al igual que los pedagogos latinoamericanos Alicia de Alba, Ángel Díaz Barriga y Paulo Freire, entre otros.

Puede decirse, parafraseando a M. Apple, que ya sea a través de los "parentescos ideológicos" como de las preocupaciones teóricas que se comparten entre los autores norteamericanos, los españoles y mexicanos mencionados, sus producciones han servido de base para proponer una serie de elementos constitutivos del curriculum que operan como dimensiones sedimentadas en que se producen las prácticas institucionales que nos interesan relevar.

\subsubsection{El desarrollo del curriculum y su práctica: algunas precisiones y delimitaciones}

La breve introducción realizada respecto del surgimiento de la teoría crítica del curriculum nos permite dar marco a nuestra investigación tomando como referencia las producciones de los autores mencionados.

Abordaremos el desarrollo del curriculum de la escolaridad secundaria, refiriéndonos al conjunto de prácticas que expresan un proyecto educativo coherente (Gimeno Sacristán, 1993), cuya enunciación tiene una cierta capacidad reguladora de la práctica en las instituciones y sobre los procesos de enseñanza-aprendizaje. El término curriculum no será utilizado solamente como un plan diseñado por técnicos y especialistas, ni como el desarrollo que se realiza en cada escuela particular, sino como una práctica social y cultural que incluye el tratamiento de situaciones complejas capaces de comprender y guiar la práctica de la enseñanza y el "entramado de experiencias que obtiene el alumno, incluidos los efectos del curriculum oculto" (Gimeno Sacristán, 1993: 230) y que contempla diferentes niveles de especificación y concreción. 
Definiremos a continuación aquellos aspectos del curriculum escolar que dan sentido a las categorías con las que se identifica la ciudadanía en esta investigación: participación, convivencialidad y demanda. Al mismo tiempo, se precisan los principales aspectos presentes en el desarrollo curricular y en su práctica que han sido considerados en el proceso teórico- metodológico de la investigación. Ellos son:

- Una síntesis de elementos culturales, entendiendo por ellos conocimientos, valores, creencias, costumbres y hábitos (de Alba, 1995). Resulta de interés destacar que el término síntesis permite acercarnos a dichos elementos no solo a través de las estructuras formales sino también cuando el curriculum deviene en prácticas concretas. Tales prácticas, se traducen en formas de hacer y pensar, mentalidades y comportamientos "...sedimentadas a lo largo del tiempo en forma de tradiciones, regularidades y reglas de juego no puestas en entredicho y compartidas por sus actores, en el seno de las instituciones educativas" (Viñao Frago, 2006: 73).

Es precisamente este conjunto de elementos sedimentados los que generan resistencias a los cambios y los que configuran, a la vez, las identidades institucionales. Estos rasgos o conjuntos de elementos tienen como característica -según Viñao Frago- que se trasmiten generación tras generación y proporcionan estrategias para el desarrollo y la integración de la vida cotidiana, ya sea dentro del aula, ya sea para "hacer frente" a las reformas que, en algunas oportunidades marcan su superficie pero no las penetra.

Siguiendo a de Alba (1995:74), consideramos que tales elementos sedimentados constituyen capas o niveles de significación, "...construcciones conceptuales que nos permiten pensar en el tipo de significaciones constitutiva de la síntesis de contenidos culturales que determinan el curriculum, así como aquellas que se van generando en el devenir históricosocial". Los niveles de significación, expresa Derridá (citado por de Alba), funcionan como capas de sentido que aparecen como sistemas complejos, como configuraciones al interior de las cuales se producen movimientos que pueden proceder de la propia estructura o que pueden tener su propia génesis, resultando un conjunto heterogéneo, a veces contradictorio, que otorga alguna racionalidad a las prácticas. 
Por su parte, los componentes del curriculum explícito -metas y objetivos, contenidos, criterios metodológicos, de evaluación y promoción, entre otros-, tanto en la instancia de su formulación como en las definiciones institucionales, y en tanto instrumentos de dominación de la estructura político-económica, están precedidos por articulaciones $\boldsymbol{y}$ negociaciones que expresan historias de luchas de imposición de un arbitrario cultural (Apple, 1977) y resistencia a esa imposición (Giroux, 1992) que se manifiestan de diferentes formas y sentidos en las prácticas concretas de los sujetos.

A través de sus estudios realizados en Inglaterra, Goodson (1995) había expresado que es en las aulas donde intersectan las prácticas con las ideologías. El autor destaca que sin una apreciación de las complejidades de la vida en las aulas no es posible develar su verdadera significación y las relaciones de poder que se esconden en ella.

Hargreaves (1995) agregará que ese proceso de análisis de la vida en las aulas y desarrollo del curriculum, que él llama de microanálisis, permite restablecer el pasado en el marco del presente. En el caso de nuestra investigación, seremos capaces de comprender el presente si podemos rastrear las huellas de las decisiones curriculares a nivel político y en los diferentes niveles de concreción de esas decisiones. Un aspecto tan sensible a los cambios de perspectiva política como es la formación de los ciudadanos no debería prescindir, en su análisis, del doble juego entre las prácticas de los sujetos y las transformaciones que operan a nivel de las políticas públicas.

- Una propuesta político-educativa, en tanto está vinculado a políticas públicas de mayor alcance. Esta consideración no debiera sujetar el curriculum a la política partidaria, en tanto se entiende que las políticas públicas, como cuestiones de Estado en la que se dirime la relación entre sociedad, cultura y educación, responden a programas y planificaciones a mediano y largo plazo en determinados períodos históricos por los que transitan los pueblos. Estas políticas ya no serán pensadas solo como líneas directrices de nivel nacional sino que debe considerarse la influencia de agencias de financiamiento y poder económico-político transnacional que delinean sus programas con alcances regionales.

La globalización genera instancias de acuerdos entre los países que participan de alguna de sus instancias y, así, las políticas educativas en los últimos treinta años resultan influidas por 
las recomendaciones supranacionales (como las "Metas Educativas 2021: La educación que queremos para las generaciones del Bicentenario" Naciones Unidas- CEPAL- OIT). En la última década, las recomendaciones de los organismos internacionales vuelven su discurso hacia la recomposición de la cuestión social que, en clave latinoamericana, significa pensar cómo salvar la brecha entre ricos y pobres y qué lugar tiene la educación en ese proceso. Por un lado, cabe atender a los dilemas que atraviesan y constriñen al espacio público frente al avance del sector privado y el individualismo extremo (Apple, 2010; Giroux, 2010) y, al mismo tiempo, cabe problematizar la potencialidad y los límites de una perspectiva de ciudadanía fundada en una cuestión de derecho individual ${ }^{76}$.

Lo que a nuestro entender significa un verdadero problema para la política educativa es que en un proceso de redefinición de lo social con características contingentes -como ha sido expuesto en el Capítulo 1- los proyectos políticos no alcanzan a responder a los problemas sociales que tiene la población. Dicho esto, no debe entenderse que la política educativa por sí sola podría aportar soluciones al conjunto del sistema político, pero sí deberían lograrse acciones articuladas y con un mismo sentido que las demás instancias políticas que definen un proyecto de gobierno.

Dice Cullen (2005:200):

“La imposición de un modelo globalizado en la economía, altamente competitivo, y sus exigencias de ajustes estructurales (...) presentan desafíos inéditos en relación con la escuela moderna, y entre ellos la necesidad de vivir en un mercado salvaje, a criticarlo y a poner los límites que la justicia social exige.

(...)Es necesario discutir los contenidos dela formación ética y ciudadana (...) y los criterios no pueden ser otros que los propios de una política educativa pública: que sean para todos (...) y que sean capaces de construir proyectos comunes"

Avanzando en el análisis de las dificultades inherentes a las decisiones de la política y de la práctica educativa, Gentili (2000: 27) expresa:

\footnotetext{
${ }^{76}$ Se piensa en potencialidad de los derechos individuales en tanto existe hoy una interpelación al sujeto a "hacerse cargo" de sí mismo y de sus acciones, cuestión que a la vez, a la luz de la individualización extrema, resulta un límite a la construcción y respeto por los derechos colectivos
} 
“Que la educación, la ciudadanía, la justicia y la democracia se vinculan entre sí, nadie lo duda. El problema es cómo lo hacen, sobre qué fundamentos se define tal vínculo, qué tipo de educación se relaciona con qué tipo de ciudadanía, de derecho, de sociedad, de justicia o de democracia"

En el caso de la enseñanza y la construcción de ciudadanía advertimos, al igual que lo exponen los autores, que la ciudadanía como práctica sufre un profundo malestar en estos tiempos porque las características del entorno social global organizado en torno del mercado obligan a redefinir los conceptos estructurantes con que ha sido concebida durante la modernidad con centro en el Estado, y ahora sus características hay que buscarlas, más bien, en las prácticas de los sujetos.

- Aspectos estructurales-formales y procesuales-prácticos de un curriculum. Se parte de considerar que ninguno de estos aspectos se encuentra en estado puro. Esto es, la formulación de los aspectos formales ha estado mediada por procesos previos, del mismo modo que los procesos han sido guiados por algún tipo de norma formal. Pero a los efectos de presentar una clasificación, siguiendo a Gimeno Sacristán (1994), quien distingue aspectos formales y materiales por un lado y un campo práctico, por otro, distinguiremos aspectos estructurales-formales y procesuales-prácticos de un curriculum.

Los aspectos estructurales- formales están compuestos principalmente por leyes y reglamentaciones que estructuran la educación formal y -en alguna medida-la vida escolar. En el plano empírico se trata de comprender, por un lado, el sistema legal y los documentos que a partir de éste se producen para ordenar el sistema educativo: resoluciones específicas, las reglamentaciones, los $\mathrm{NAP}^{77}$, los contenidos ${ }^{78}$, documentos metodológicos orientativos para los agentes del sistema, así como los programas de capacitación y evaluación puestos en funcionamiento a partir de la existencia de cambios estructurales.

Pero a la vez comprende, en el campo práctico, aspectos procesuales del desarrollo del curriculum, donde cobran importancia, además de las puesta en vigencia de los elementos

\footnotetext{
${ }^{77}$ Núcleos de Aprendizaje Prioritarios, dictados por el Consejo Federal de Educación a partir del año 2004, cuyo propósito es asegurar la unidad del sistema educativo nacional.

${ }^{78}$ Contenidos curriculares por áreas disciplinares aprobados por el CFE para la LEN
} 
formales, la ubicación de cada escuela, su historia particular, su cultura, sus actores (docentes, estudiantes, comunidad) como sujetos históricos, la interpretación de las prescripciones curriculares que estos realizan, las prácticas y las condiciones materiales en que se producen las prácticas, entre otros aspectos.

En este punto retomaremos los aportes de Goodson (2000: 51) quien señala que es amplia la gama de niveles donde el curriculum se produce, gestiona y reproduce. Acordamos también con el autor respecto de que, a los fines de una investigación no es posible abarcar todos los escenarios y por ello nos encontramos ante diferentes riesgos: si tratamos solo el curriculum prescripto es posible que obtengamos una visión desconectada de la realidad; si solo miramos una práctica de enseñanza es posible que no logremos inferir de ella alguna referencia al curriculum formal.

Un concepto central en el análisis de las prácticas políticas en la escuela es, como se dijo, el de curriculum oculto (Jackson, 1998) que define, precisamente, aquello que sucede por fuera de las intenciones formales que se expresan en los currícula oficiales, aquellos principios y supuestos que se cuelan en las interacciones y que requieren, desde la perspectiva del análisis curricular reconceptualista, de un análisis situado.

El curriculum oculto define la variedad de influencias educativas que no están formalmente enunciadas en el curriculum prescripto, no son explicitadas por los profesores y habitualmente no son reconocidas como resultados no previstos de la interacción en las aulas. Comprenden las habilidades adquiridas por los estudiantes respecto de las formas de transgredir las normas, las simulaciones, los comportamientos adaptativos para agradar a los profesores, presentación de tareas, vocabulario, entre otros o lo que hoy conocemos como "aprendizaje del oficio de alumno".

Las influencias que los profesores ejercen sobre sus alumnos, nombradas como enseñanzas implícitas (Jackson, 1999), comienzan aún antes del encuentro pedagógico en el aula, con la selección y secuenciación de los contenidos, las opciones metodológicas, el lugar de la evaluación ya sea como parte del proceso del enseñanza o como instrumento de control. También incluye la distancia entre lo que los profesores se proponen enseñar y lo que 
realmente transmiten en su práctica, como nociones de autoridad, respeto, afecto, responsabilidad y también autoritarismo, violencia, subordinación, chantaje.

En relación a la enseñanza de la ciudadanía, las enseñanzas implícitas pueden derivar de contenidos enunciados como democráticos e igualitaristas pero que en la práctica, se tornen autoritarios, discriminatorios o expulsivos. Esto es, porque según explica Cullen (2005:198) el positivismo pedagógico que confinó a la educación ciudadana a "... los sótanos de lo no enseñable", acompañado de un fuerte ritualismo le quitó apoyatura teórica y didáctica a los temas políticos de la formación ciudadana. De este modo

\footnotetext{
"La enseñanza moral y los aprendizajes sociales contribuyeron a la formación de una parte central del "curriculum oculto", ya que sus saberes (la ética y la política) no podían entrar en la cultura escolar explícita porque el dogmatismo de los hechos, que caracteriza al positivismo, rechazaba toda validez teórica y racional de los problemas morales" (Cullen, 2005: 198)
}

Con estas consideraciones debemos destacar que ha sido una cuestión metodológica central a la investigación decidir qué ver y qué oir en la dinámica de la vida cotidiana de las escuelas seleccionadas.

En el intento de articular ambos niveles de manifestación del curriculum (estructural-formal y procesual- práctico) reconocemos, siguiendo a Jackson (1998: 73), que ambos "se relacionan entre sí de diversos e importantes modos". En relación al curriculum formal resultan altamente significativas las definiciones de la política curricular en cuanto a la relevancia que este curriculum otorga a la construcción de una ciudadanía activa y la batería de estrategias oficiales puestas en marcha a los efectos de dotar a éstos contenidos de una nueva investidura: inicialmente, la contratación de especialistas reconocidos en el campo de la política y de los estudios de juventud para la elaboración de los diseños curriculares y, luego, la capacitación de los docentes, la producción bibliográfica, la creación de nuevos/otros circuitos de formación política que acompañarían a los aprendizajes de 
contenidos curriculares tales como los Centros de Estudiantes y los Consejos de Convivencia ${ }^{79}$.

Tanto en el curriculum procesual- práctico como en el curriculum oculto, las decisiones de los sujetos (agentes del sistema: docentes, directivos, especialistas) y sus prácticas, los modos de concebir la política y las prácticas orientadas a favorecer la construcción ciudadana en la escuela, por un lado, y las prácticas cotidianas de los jóvenes en interacción con las propuestas escolares y las que se produjeron por sus propias iniciativas -a veces como prácticas de resistencia-, constituyen la compleja trama a partir de cuyo análisis se pretende interpretar cómo se construyen los jóvenes como sujetos políticos en la escuela secundaria actual.

- Los sujetos del desarrollo curricular. En sentido amplio, consideramos sujetos de desarrollo curricular a docentes, alumnos, padres y otros miembros de la comunidad que participan de actividades vinculadas al desarrollo de la vida escolar.

Dadas las características del funcionamiento cotidiano escolar, la mayor parte de las acciones que han sido relevadas se corresponden con la presencia de docentes y de jóvenes por sobre la presencia escolar de la familia o el entorno social de la escuela. La existencia de prácticas y estilos de interacción propios del entorno social no escolar otorgan identidades específicas a la vida cotidiana de las escuelas, cada una con el estilo que cada comunidad provee, permitiendo suponer que las fronteras entre el adentro y el afuera escolar (Duschatzky, 1999) se encuentra debilitada de manera inversamente proporcional a la fuerza de la cultura escolar.

En los contextos escolares relevados operan diversos sentidos en interacción en torno de la ciudadanía y la política, de acuerdo a las posiciones y disposiciones que moldean -de modo

\footnotetext{
${ }^{79}$ En la ciudad de Olavarría, donde se localiza la investigación, se relevó una práctica de formación ciudadana no prevista desde el curriculum formal pero sí por la articulación resultante entre diferentes niveles de la política provincial. Así, se ponen en marcha los Consejos Deliberantes Estudiantiles, que se conforman en las escuelas y luego sesionan en el Concejo Deliberante Municipal, con las mismas reglas que ese órgano de gobierno. Este aspecto, ha sido desarrollado en el Capítulo 1, p:69
} 
no determinista- a los sujetos. Este conjunto de disposiciones correspondiente con la noción de habitus desarrollada por Bourdieu, producen esquemas de percepción, de concepción y de acción (Bourdieu, 2007:99) que operan al momento de desarrollar una práctica e impregnan, con sus significaciones, a determinadas situaciones y a procesos. Por ejemplo: algunos docentes de la escuela secundaria de reciente creación que compone la muestra, ubicada en un barrio marginal de la ciudad, han construido significaciones adversas respecto de la presencia de los jóvenes pobres que asisten a esa escuela secundaria. Cabe señalar -como ya ha sido desarrollado por diferentes autores como Acosta (2008); Kessler (2002); Tiramonti (2011)- que la escuela secundaria argentina se ha caracterizado por sus prácticas selectivas y expulsivas hacia los sectores sociales pobres y esa historia sedimentada en las culturas escolares opera como un constructo aún persistente en las prácticas de algunos docentes. No podemos obviar en este análisis que tales construcciones constituyen obstáculos a la hora de desarrollar el curriculum formal, contribuyendo con sus prácticas a reforzar la imagen estigmatizada con que significan a los estudiantes de ese sector social.

Las tradiciones escolares sedimentadas se incorporan “...a las prácticas de los sujetos merced a una delicada decantación del habitus" (Cuesta, citado por Viñao Frago, 2008: 108) y, con ello, impregnan las significaciones que conllevan las prácticas, en la interacción de los sujetos -adultos y jóvenes- que habitan la escuela secundaria.

La persistencia del habitus anteriormente señalado puede observarse también en la relación de algunos profesores con los sectores sociales medios y altos, para quienes la escuela secundaria ha sido históricamente pensada. En este caso, esos profesores reconocen a los jóvenes como legítimos herederos (Bourdieu y Passeron, 1969) pero entran en contradicción con sus propias concepciones cuando muchos de esos jóvenes cuestionan los valores y las normas tradicionales vigentes en las escuelas.

Es preciso señalar que, tras la crisis de sentido que conlleva la masificación de la escuela secundaria, los desencuentros adquieren significaciones diferentes para los actores jóvenes y adultos del curriculum. Mientras en conversaciones informales algunos docentes manifestaron su parecer respecto de que para algunos jóvenes la escuela no tiene sentido y están allí por el mandato de obligatoriedad de la escuela secundaria, esos jóvenes a los 
que hacían referencia le atribuían otros sentidos a su permanencia en la escuela, como el encuentro con amigos o la posibilidad de conseguir un trabajo estable. Como expresa Núñez (2013: 46), la escuela significa para algunos jóvenes “...el reconocimiento de derechos, el desarrollo personal y de tiempo vital importante, y que si bien para muchos de ellos la escuela representa obligación y rutina, eso resulta contenedor y ordenador"

En relación a los jóvenes que participan cotidianamente del curriculum en acción, desde nuestra perspectiva se caracteriza su accionar como sujetos portadores de cultura -de las culturas juveniles-, destacándose su condición de jóvenes por sobre su condición de alumnos. Visualizar esta condición, entendemos, nos ha permitido relevar con mayor amplitud o disponibilidad los sentidos que encierran sus prácticas escolares, que ellos definen como "no políticas" aunque confronten permanente con las prácticas políticas autorizadas por la escuela. Nos ayudará también a colocar en un primer plano de análisis sus intereses y sus expresiones, lo cual resulta un desafío metodológico y un esforzado ejercicio de escritura.

\subsection{La política y a la formación ciudadana en el curriculum de la educación secundaria. Una revisión histórica para comprender el presente}

Proponemos desarrollar un recorrido que muestre la vinculación entre el Estado, la vida democrática y la educación para comprender los rumbos de las políticas educativas-y sus implicancias prácticas- en distintos momentos históricos comprendidos en los últimos 30 años en Argentina. En cada uno de los períodos se introdujeron cambios significativos, en el sentido de alteración del orden precedente.

Este recorrido histórico tiene por fin actualizar la memoria, “...una memoria nutritiva, diferente de la memoria muerta, hábito de repetición, vacía" (Kaufmann, 2007). Entendemos que la historia persiste en el presente y que su lectura (echando mano a una memoria nutritiva) nos permitirá comprender e interpretar las situaciones relevadas. Con el propósito de activar la memoria y nutrirnos en ella, presentaremos las características que asumieron los cambios en cada una de las escuelas que integran la muestra seleccionada para de este estudio, en el contexto histórico de su creación y desarrollo posterior. 


\subsubsection{El período 1983-1989: la democratización de la escuela secundaria tras la devastación} de la dictadura militar

Los primeros pasos de la anhelada democracia que se inicia en el año 1983, luego de la dictadura militar de 8 años, que dejó como saldo 30.000 desaparecidos -entre otras cuestiones devastadoras para el país-, fueron los intentos de democratización de la educación y el reposicionamiento de las prácticas ciudadanas democráticas, combatiendo los resabios de autoritarismo heredados de períodos precedentes.

En este primer período de reinstalación de la democracia, el gobierno de Alfonsín se caracterizó por una fuerza democrática institucionalizante que alcanzó a la educación como una de las primeras medidas de su gobierno. El desarrollo de esas medidas puede reconocerse como síntesis de elementos culturales de la época, que expresaban un sentir general.

De las lecturas realizadas puede inferirse que fueron dos las acciones más relevantes de la propuesta político-educativa en este período: la realización del II Congreso Pedagógico Nacional y el Plan de Alfabetización Nacional, que colocó al país en índices de alfabetización comparables a los alcanzados por Uruguay, a nivel regional ${ }^{80}$.

El II CPN tenía como principal objetivo realizar, en la renacida democracia, un ordenamiento legal en vistas a elaborar una futura Ley Orgánica Federal de Educación (sucesora de la ley 1420), que condensara las voces de actores representativos de todo el país y diera unidad al -ya disperso- sistema educativo. La presencia y participación en los debates de grupos conservadores imprimió sesgos y orientaciones a las formulaciones del CPN que, finalmente, no fueron aplicadas por este gobierno.

Fueron preocupaciones relevantes de la época superar la parcialidad de los curriculum heredados de la dictadura y la necesidad de generar nuevamente, lineamientos básicos que garantizaran "la unidad en la diversidad", sustentados en principios de regionalización (Carbone, 2012: 20). Durante el período señalado se produjeron decretos y resoluciones que

\footnotetext{
${ }^{80}$ Fuente : Anuario Estadístico de América Latina y el Caribe, CEPAL, 1993
} 
modificaron sustancialmente los contenidos disciplinares y la metodología de trabajo en los distintos niveles del sistema educativo nacional heredado de la dictadura, en relación a “...los valores inherentes a la democracia, el reconocimiento y el respeto por las diferencias, así como la discusión racional, éticamente sustentada y la búsqueda de consensos básicos" (Carbone 2012: 27).

Entre los aspectos formales del curriculum del nivel secundario se desarrollaron una serie de medidas destinadas a eliminar restricciones y prohibiciones instaladas por el régimen militar: se incorporaron docentes cesanteados por el régimen y se restableció la acción gremial; se promovieron los centros de estudiantes; se eliminaron los exámenes de ingreso; se produjo un aumento importante de la matrícula en el nivel, especialmente en las escuelas dependientes del $\mathrm{CONET}^{81}$; se modificó el régimen de evaluación; se introdujeron modificaciones -no estructurales- cambiando de manera parcial los planes de estudio.

En lo que hace a las políticas curriculares para la educación secundaria, se desarrollaron proyectos tendientes a modificar el carácter enciclopédico que arrastraba el curriculum de este nivel desde sus orígenes. En relación al tema de interés, se señala una modificación en la estructura curricular que tiende a lograr unidad y coherencia en el primer ciclo de la enseñanza. En él, se destaca la implementación secuenciada de la materia Educación Cívica en 10 , 20 y tercer año del nivel secundario diferenciándose en sus contenidos de su antecesora en el período de la dictadura (Formación Moral y Cívica). Plantea una secuencia progresiva de los contenidos de la construcción ciudadana, cuya principal característica consistía en la disposición a los debates y las prácticas democratizantes que se producían en las instituciones educativas.

Estas acciones fueron acompañadas de la re-habilitación de los centros de estudiantes suspendidos por la dictadura-, y el impulso a la participación estudiantil en cuestiones comunitarias y sociales ${ }^{82}$. Así mismo se instala nuevamente la cuestión del "gobierno propio

\footnotetext{
${ }^{81}$ Puiggrós (1998: 138) señala: "el número de estudiantes inscriptos en establecimientos del Consejo Nacional de Educación Técnica (CONET) se elevó de 182.750 en 1983 a 219.053 en 1987".

${ }^{82}$ Se produce una alta participación de estudiantes secundarios y universitarios como educadores en el marco del Plan Nacional de Alfabetización.
} 
escolar" (Puiggrós, 1998), impulsando la participación de la comunidad educativa activa en una propuesta clara de avance hacia la democratización del gobierno escolar. Se pusieron en marcha experiencias innovadoras como los Consejos de Gobierno Escolar y en la provincia de Buenos Aires, tras la sanción de la Ley 4182/88 se crearon los Consejos de Escuela, llegando a funcionar 1800 de ellos.

Pero también, y a pesar del clima de euforia y compromiso democrático de este período, diversos autores consideran que no se produjeron cambios sustantivos y profundos en el sistema educativo, quizá como resabios de la cultura autoritaria que se reflejan, sedimentadas en las prácticas cotidianas de los actores. Estas sedimentaciones se hacen evidentes permeando prácticas actuales, como se analizará en capítulos subsiguientes. Por ejemplo, parece preciso señalar que en la escuela centenaria, no se realiza ninguna mención a la dictadura militar cuando se revisa su historia, y solo se menciona como un hecho significativo para la institución, durante el período 1970-1993, el desarrollo del Proyecto 13 (Proyecto 13 de ANEMS, ley 18.614).

Debemos señalar que distintos autores consideran que este fue el último gobierno que pensó a la escuela como garantía de unidad nacional y universalidad. A partir del siguiente período se inaugura la existencia de un Ministerio de Educación sin escuelas y un cambio de eje en la función política asignada a la educación, que se concretará con la descentralización y el traspaso (compulsivo y sin presupuesto) de los servicios educativos a las provincias, entre otras medidas de reforma estructural del sistema educativo argentino.

Como es sabido, el Dr Alfonsín no llegó a finalizar el período de gobierno para el que había sido elegido, adelantándose el traspaso del gobierno al presidente electo en 1989, Dr Carlos Menem. A partir de allí se produjo una verdadera transformación en las funciones del Estado, de la que no resulta ajena la política educativa.

3.3.2. El período 1992- 2006: primera etapa de reformas del Estado bajo el modelo neoliberal. Descentralización de la educación y la redefinición de los sentidos de la educación formal 
Como fue dicho, el Dr Menem asumió la presidencia de la Nación en el año 1989. La gestión de su gobierno, en acuerdo con las recomendaciones de los organismos internacionales que lideraban esta etapa del capitalismo globalizado, ejecutó una profunda reestructuración del estado caracterizada, en la primera fase, por una reducción de funciones y en una delegación de responsabilidades del gobierno central hacia las provincias. En nuestro país, la educación pública resultó resguardada por la eficacia del proceso modernizador anterior y, a pesar que en otros campos el traspaso a manos privadas fue completo, no resultó así con la educación. La nueva Ley habilitó una mayor injerencia de organizaciones privadas en el campo educativo, pero el grueso de la función permaneció en el ámbito estatal, que contaba con fuerte respaldo de la sociedad.

En ese contexto se debate y aprueba la Ley Federal de Educación que significó una transformación profunda y rotunda en el sistema educativo nacional, en todos los niveles. Los debates del Congreso Pedagógico Nacional y sus conclusiones sirvieron de base para la elaboración de la Ley Federal de Educación N²4.195.

\footnotetext{
“En efecto, durante esa amplia y prolongada convocatoria a la sociedad civil, los principales actores que intervienen en el campo de la política educativa nacional lograron algunos acuerdos básicos acerca de una serie de reformas de fondo de la educación básica nacional: la descentralización de la educación a las provincias, la extensión de la obligatoriedad escolar, la revisión de los contenidos y métodos pedagógicos, la prioridad a los sectores más desfavorecidos, la articulación con el mundo del trabajo y la reformulación de los planes y políticas de formación docente". (Tedesco, J.C. y Tenti Fanfani, E., 2001)
}

Los autores mencionados, señalan que la Ley Federal de Educación realiza una transformación del sistema educativo que comprendió diferentes ejes: a) modificación de la estructura del sistema, reorganización de los niveles de enseñanza y extensión de la obligatoriedad, b) renovación de los contenidos curriculares y aprobación por el CFE de los Contenidos Básicos Comunes (CBC), c)institucionalización de un sistema nacional de evaluación; d) implementación de políticas compensatorias, e)transformación institucional a través de modernización de la gestión educativa; f) aumento de la inversión en el sistema educativo. 
A partir de la sanción de la LFE el gobierno completó la transferencia de las escuelas y servicios educativos a las provincias y a la MCBA, siendo competencia del Ministerio de Educación "asegurar el cumplimiento de los principios y objetivos establecidos en la ley teniendo en cuenta criterios de unidad nacional, democratización, descentralización y federalización, participación, equidad..." (Art. 51 de la LFE N² 24195).

La política de transferencia ha sido caracterizada como una política de desregulación del sistema educativo que no implica una ausencia de regulación sino un cambio en su direccionalidad normativa (Tedesco, J.C. y Tenti Fanfani, E., 2001). Asociada a este proceso, se proclama la autonomización de las escuelas, compelidas a formular sus propios proyectos educativos, acompañadas $u$ orientadas por una profusa bibliografía procedente de la aplicación de la LOGSE española respecto de la elaboración de proyectos de centros educativos.

En cuanto a la estructura del sistema, se establece la obligatoriedad de diez años de escolaridad, que se inician en la sala de 5 años del Nivel Inicial y finalizan en el noveno año de la Educación General Básica (EGB) la que consta de nueve años distribuidos en tres ciclos. Luego continúa la Educación Polimodal (no obligatoria), con tres años de duración.

En este período -precisamente en el año 1994- la escuela centenaria es re-definida como "unidad pedagógica", cuestión que implicó una cierta continuidad y criterios pedagógicos compartidos entre los niveles implicados: inicial, EGB y Polimodal. Se le permitió entonces, conservar la lógica interna que caracterizaba a las escuelas normales.

Las escuelas primarias parroquial, rural y suburbana, incorporan el tercer ciclo de la EGB con diferentes características. La escuela parroquial que ha logrado a través del tiempo prestigio académico y un respaldo comunitario sólido, diseña y concreta la construcción de un nuevo edificio en el que podrán funcionar la EGB completa para luego, realizar la inauguración del nivel Polimodal.

La escuela rural incorpora la sala de 5 años correspondiente al nivel inicial y se completa el tercer ciclo de la EGB, dependiente del nivel primario, incorporando 80 y 90 años. Se construyen, con aporte de la comunidad y en menor medida del Estado provincial, nuevas aulas para satisfacer las necesidades de esta ampliación de servicios. 
La escuela suburbana incorpora el dictado de 8 ㅇ y 9 으 años para completar la EGB. Se realizan agregados precarios de salones para tal fin.

En el año 2003 se crea la escuela universitaria que se pone en marcha en el año 2005 con el dictado del nivel Polimodal. Se trata de una escuela nacional dependiente del Consejo Superior de la Universidad que le da origen y funciona en territorio provincial. Goza de autonomía para la construcción de su diseño curricular, aunque debe articular los contenidos propios con los contenidos básicos comunes del diseño curricular establecido por la DGCyE de la Provincia de Buenos Aires.

La transformación institucional, finalmente, destaca la relevancia de cada escuela en la concreción del curriculum, puesto que cada una deberá asumir la responsabilidad de elaborar un currículo institucional que incorpore características propias en función de las condiciones, necesidades y perspectivas de cada comunidad. Este aspecto marca el inicio de una modalidad de gestión de las escuelas con identidades particulares, diferenciándose de la relativa homogeneidad ${ }^{83}$ que el sistema educativo imprimió, históricamente, en todas ellas.

3.3.2.1. El tercer ciclo de la EGB en la Provincia de Buenos Aires. La extensión de la obligatoriedad de la educación se definió, en la Provincia de Buenos Aires, incorporando el "nuevo" trayecto a la estructura y cultura de la Educación Primaria, denominada desde la LFE como Educación General Básica.

Palamidessi (2000: 5) identifica en la implementación de este segmento del sistema "una estructura poliforme y fragmentada como producto de las estrategias de incorporación de matrícula de las últimas dos décadas y de la pluralidad de definiciones respecto de la localización del Tercer Ciclo en cada jurisdicción"

La puesta en marcha de este ciclo dio lugar a dos tipos institucionales: la EGB "completa" y la EGB "articulada". Las escuelas correspondientes al primer tipo contenían en su edificio los tres ciclos de la EGB por lo que tuvieron la tarea de adaptarse a la incorporación del tercer ciclo que atendería a unos alumnos con edades diferentes a las que estaban acostumbrados a atender; las escuelas correspondientes al segundo tipo, contenían en sus instalaciones los

\footnotetext{
${ }^{83}$ Esta idea de relativa homogeneidad no desconoce la existencia de circuitos diferenciados de educación que se profundizan y fragmentan al igual que la sociedad, como ha sido presentado en el Capítulo 1 de esta tesis.
} 
dos primeros ciclos y 70 año ahora perteneciente al tercer ciclo y, entonces, los estudiantes debían completar 80 y 90 años en instituciones del nivel secundario cercanas bajo la dirección pedagógica y administrativa de agentes educativos del nivel primario. La "ligazón" o articulación ${ }^{84}$ entre los ciclos fue uno de los elementos más conflictivos del período, con profunda repercusión en la dimensión pedagógica y en los fines políticos de la inclusión educativa de los jóvenes ${ }^{85}$.

Se generó un significativo desencuentro entre las culturas escolares de la educación primaria, que se habían definido con criterios y lógicas muy diferentes a lo largo de la tradición educativa y la de la educación secundaria, en especial en aquellas escuelas que debieron atender a los sectores populares que por primera vez, veían ampliadas sus posibilidades educativas.

Las "articulaciones" ${ }^{86}$ en muchos casos desembocaron en enfrentamientos entre maestros y profesores, entre representantes de los distintos niveles escolares en la nueva estructura, tensiones entre las lógicas institucionales sedimentadas por largos años de organización escolar que, en síntesis, atentaron permanentemente en la construcción de una identidad y un adecuado funcionamiento para el tercer ciclo del nivel básico. Se produjo, además, una fuerte competencia gremial por la definición de los cargos del tercer ciclo entre docentes con formaciones muy diferentes para lógicas escolares también muy diferentes.

De las escuelas que componen la muestra, todas las existentes en la década de los 90 responden al tipo de EGB completa, por distintas variables del contexto: en la escuela centenaria, porque la secuencia primaria-secundaria constituía un rasgo fundacional; en la

\footnotetext{
${ }^{84}$ Por articulación se entiende un proceso de "enlace" que debieron llevar adelante un alto número de escuelas en la Provincia de Buenos Aires, ante la ampliación de la obligatoriedad escolar. Así, las escuelas primarias debieron "acordar" con las escuelas secundarias próximas articulaciones verticales y horizontales a los fines de "asegurar la continuidad y secuencia vertical del proceso educativo y la coherencia horizontal de sus componentes" (Hirschberg, 2000:5)

${ }^{85}$ Se implementaron diferentes estrategias de acompañamiento y contención de los jóvenes en el tercer ciclo de la EGB, tanto al interior del sistema como externos (como programas sociales por los que se proponía que transitaran los jóvenes de los sectores populares, a efectos de ayudarlos a "sostener" la ampliación de la escolaridad obligatoria).

${ }^{86}$ Los cambios operados en las instituciones y en los sujetos producto de los cambios en la estructura y organización del sistema educativo trajo aparejadas situaciones desconocidas hasta ese momento: en un mismo edificio escolar de nivel secundario funcionaron, de manera simultánea, hasta 4 establecimientos educativos diferentes de nivel primario.
} 
escuela parroquial, porque la transformación del sistema constituye una oportunidad de crecimiento para un grupo educativo de gestión privada; en la escuela rural, porque la distancia de $84 \mathrm{~km}$ con otras escuelas de la ciudad imposibilitaba la articulación con alguna otra escuela y en la escuela suburbana, porque no había en el radio próximo a la escuela ofertas educativas públicas de nivel secundario que posibilitaran la articulación. A ello se sumaban las particularidades del contexto sociocultural, signado por desencuentros entre la escuela y las familias, que anticipaban -según los relatos obtenidos- los conflictos que surgen poco tiempo después.

Políticos, especialistas y técnicos esperaban que la incorporación del tercer ciclo en la EGB, favoreciera la articulación entre los niveles primario y secundario, disminuyendo los altos índices de desgranamiento y repitencia que se registraban en los primeros años de la educación secundaria. Sin embargo, un informe de investigación de S.U.T.E.B.A. (1997) señala que resulta necesario desmitificar la supuesta capacidad de recuperación o retención que el tercer ciclo pudo, efectivamente, aportar a la articulación entre los niveles primario y secundario anteriores. El informe final de la investigación realizada sobre el desempeño escolar de alumnos de 8o año, da cuenta de resultados que muestran elevados índices de deserción, compensación de contenidos, repitencia y ausentismos prolongados (Balduzzi y Suárez, 1997).

El tercer ciclo no logró construir una "identidad institucional propia", no terminó de ser primarizado -en el sentido de adecuarse a tales lógicas de organización-, y tampoco perteneció ya al segmento de la educación secundaria (por entonces, Polimodal). Como se reconoce en el Marco General para la Educación Secundaria (DGCyE, 2008), la creación del tercer ciclo obedeció a las demandas de un momento histórico que impuso ${ }^{87}$ la extensión de una educación básica y obligatoria para los alumnos y alumnas de la provincia, quizá sin que estuvieran previstas otras condiciones necesarias, como disponer de infraestructura, sensibilizar a la comunidad educativa sobre los cambios que se producirían en el mediano plazo, entre otros.

\footnotetext{
${ }^{87}$ La imposición se expresa, por un lado, en las políticas dominantes en el mundo globalizado respecto de la ampliación de la obligatoriedad educativa (Tedesco, 2001) y responde, a nivel interno, a dar respuesta a una promesa social de acceso igualitario a la educación secundaria.
} 
El tercer ciclo, lejos de articular los niveles educativos, desdibujó la función de la escuela secundaria, aunque mantuvo sus prácticas selectivas y expulsivas. Como expresa Balduzzi (2004) en el informe de investigación elaborado para SUTEBA: "Si bien los alumnos de los sectores más pobres vuelven a la escuela en la mayoría de las provincias, sus perspectivas de permanecer no son muy promisorias considerando el modelo pedagógico del Tercer Ciclo". Los jóvenes -prosigue- reingresan y permanecen en $8^{\circ}$ año sin expectativas (ni posibilidades) de avanzar, por lo que anticipa altas tasas de deserción como resultado de las modalidades pedagógico-administrativas que acompañan la obligatoriedad del tercer ciclo.

La creciente fragmentación de la sociedad y la aplicación de las "recetas" neoliberales de la primera etapa del proyecto iniciado por el gobierno del Dr. Menem, comenzaban a dar cuenta de los profundos cambios que se producían en la función de la escuela. La ampliación de la obligatoriedad escolar con el formato descrito vino también a contener a un alto número de jóvenes vulnerabilizados por las políticas de exclusión y sobre quienes recaían acusaciones sobre el aumento de la conflictividad social.

Martignoni (2005: 274) analiza este aspecto y asocia las estrategias implementadas desde la EGB con la retención y contención social necesarias, expresando que

\footnotetext{
“...la retención y la contención social en la jurisdicción bonaerense [...] si bien no resuelven el problema estructural de la pobreza, permitiría al Estado -junto a otras estrategias como la descentralización y la evaluación de la calidad- establecer nuevas regulaciones que difuminando el conflicto y compensando la falta de legitimidad política (Weiler, 1996), garanticen el control y la "gobernabilidad social" en un escenario altamente fragmentado y desigual"
}

3.2.2.2. El diseño curricular en la provincia de Buenos Aires. Esta jurisdicción elabora su diseño curricular a partir de criterios de selección, organización y formulación de los CBC emanados del ME y aprobados por el CFCE, discriminando los contenidos en conceptos, procedimientos y actitudes.

Respecto de los CBC correspondientes a la Formación Ética y Ciudadana, el ME (1995: 332) expresa que el S.E. 
“...ha de posibilitar la formación integral del hombre y la mujer, tiene como referentes la necesidad de una educación para la vida democrática, la conservación ambiental, la salud, el amor y la sexualidad, el trabajo, el respeto y la defensa de los derechos humanos.

(...)

Los contenidos necesarios para esta formación deberían atravesar todos los saberes que se trabajan en la escuela y todos los gestos institucionales mediante los cuales enseña la escuela".

En documentos específicos, los CBC para la educación General Básica para Ética y Formación Ciudadana, se desarrollan en cinco bloques de contenidos (personas, valores, normas sociales, procedimientos generales y actitudes generales) cuyo orden de enunciación no supone un orden jerárquico, sino que queda a criterio de cada jurisdicción (en sus respectivos niveles de concreción) el ordenamiento de los contenidos mencionados.

Se proponen bloques de articulación con las disciplinas que, a diferencia de este grupo de contenidos, significan una organización curricular prescripta en una grilla horaria específica, se explicitan las expectativas de logro para cada nivel y se sugieren vinculaciones con otros bloques temáticos de contenidos para Ciencias Sociales, Lengua, Matemática, Ciencias Naturales, Tecnología, Educación Artística, Educación Física.

En el diseño curricular de la provincia de Buenos Aires, la selección y organización de los CBC se formuló, según se enuncia en los documentos oficiales, atendiendo a criterios de significatividad social, extensión y profundidad; integración y totalización, articulación horizontal y vertical, actualización, apertura, jerarquización, claridad y sencillez (DGC yE, 1995).

En relación al tratamiento de los CBC de Formación Ética y Ciudadana (DGCyE, 1995), el documento que los presenta, expresa que la provincia de Buenos Aires no contempla espacios curriculares específicos para la Formación Ética y Ciudadana, y que son prescriptos para la EGB como transversales ${ }^{88}$ a las asignaturas del curriculum. Tales contenidos expresa- serán objeto de reflexión y sistematización específica de la filosofía, la psicología, las ciencias de la salud, las ciencias sociales y el derecho.

\footnotetext{
${ }^{88}$ Los temas transversales se incorporaron al diseño curricular como contenidos que por su relevancia, transponían los límites de las disciplinas. El problema del trabajo con la transversalidad de algunos contenidos, es que las condiciones institucionales no siempre acompañaron las prácticas pedagógicas que requiere su desarrollo.
} 
Esto nos permitirá comprender, siguiendo a Cullen (2005) otro aspecto de la transversalidad: el que está vinculado con las prácticas institucionales y los proyectos de las comunidades educativas.

Estas prescripciones fueron interpretadas por las escuelas de manera desigual, pero con un denominador común: las cuestiones administrativas derivadas de su implementación colocaron en un segundo plano la dimensión pedagógica de la tarea de construcción del tercer ciclo obligatorio y aquellos contenidos que quedaron por fuera de las asignaturas, recorrieron diversos rumbos.

En la escuela centenaria, los contenidos de Formación Ética y Ciudadana que debían trabajarse de forma transversal a las materias del curriculum, según los datos obtenidos ${ }^{89}$, “...como no había una materia específica, nadie se encargaba de que esos contenidos se trataran. La cuestión que demandaba todos los esfuerzos era la relación con las escuelas que articulaban con ésta".

Las escuelas "articulantes" arribaron a la escuela centenaria representadas por jóvenes con perfiles socioeconómico y cultural diferentes del que tradicionalmente atendió la escuela. La estrategia de los agentes fue: los jóvenes procedentes de las escuelas articulantes conformaron un tercer ciclo que permaneció en el turno de la tarde con los cursos de la escuela primaria y los jóvenes que cursaron la escolaridad primaria en la escuela centenaria, "pasaron" al turno de la mañana con el nivel Polimodal. Es decir que se agrupó (y se segregó) por turnos a los jóvenes de distinta procedencia social.

Mientras que en la escuela parroquial se trabajó "amorosamente" ${ }^{90}$ la incorporación de 8 ํ y 9o años, acompañando a los jóvenes en el inicio de la adolescencia y ofreciendo diversos proyectos solidarios (conciertos rasgos de caridad católica) para la formación integral, en la escuela secundaria suburbana, se relevan muy pocos datos de la historia de la implementación de la ESB porque la escuela secundaria está conformada -

\footnotetext{
${ }^{89}$ Entrevista realizada a la vicedirectora de ESB en el año 2009. La docente, previo proceso de "reconversión laboral para desempeñarse en el tercer ciclo de la EGB", concursó por un cargo directivo en la ESB.

${ }^{90}$ Término utilizado por la directora de la ESB en el año 2010 durante una entrevista, y refiere al cuidado de los "nuevos" jóvenes que arribaban o continuaban en la escuela. La docente se desempeñó como maestra (de nivel primario) y profesora (de EGB 3) y fue designada en el cargo de directora de la Escuela Secundaria cuando ésta fue creada.
} 
mayoritariamente- por agentes que desconocen el pasado de las escuelas que hoy conforman la secundaria suburbana en estudio. Agregan que “...y no tienen tiempo de encontrarse con las de primaria porque a contraturno trabajan en otros servicios" ${ }^{\prime 91}$. Un aspecto que dificulta el conocimiento del proceso de construcción de la escuela secundaria y su relación con el tercer ciclo de EGB es la alta movilidad de los docentes. En entrevistas y conversaciones informales muchos de ellos revelan que cuando tienen oportunidad de acceder a cargos en escuelas "más organizadas", abandonan a ésta de reciente creación.

Reconstruimos, a partir de entrevistas con los jóvenes que continúan el nivel secundario en la misma escuela, una relación atravesada por la violencia material y simbólica entre docentes y estudiantes.

La escuela rural incorporó el tercer ciclo de la EGB y para ello, la cooperadora con auxilio técnico del Consejo Escolar construyó dos nuevos salones. Comenzó una nueva dinámica de relación para los jóvenes, que veían aumentada la cantidad de docentes con quienes interactuar, pero continuó funcionando la EGB 3 como un "pluriaño" dependiente de la dirección de la ex -primaria.

La escuela dependiente de la Universidad no contaba con estos niveles educativos, pues fue creada a partir del nivel Polimodal.

La LFE se mantuvo hasta el año 2006, cuando en otro contexto social, político y económico planteado por el fracaso de la primera etapa de recorte neoliberal, se dio lugar a una segunda etapa de reposicionamiento estatal orientada a reconstruir el lazo social y asegurar la gobernabilidad del sistema.

3.3.3. El período que se inicia con la Ley Nacional de Educación № 26206/06 en la segunda etapa de reformas del estado: el reposicionamiento estatal en educación, bajo el mandato de inclusión social.

\footnotetext{
${ }^{91}$ Segmento de la entrevista realizada a la directora de la escuela secundaria suburbana en 2010. Esta situación nos permite develar algunas de las dificultades que existen para construir un proyecto educativo institucional con continuidad.
} 
“...aunque la gestión de Néstor Kirchner está lejos de constituir una refundación política, como sostienen fervorosamente sus defensores, tampoco puede ser interpretada sin más, en términos de continuidad lineal respecto de los años noventa, como afirman ciertos críticos". M. Svampa. Cambio de época, 2008

La cita de Svampa (2008) con que se inicia el análisis de este último período, nos aproxima a la complejidad que presenta el escenario político y social de nuestros días. Esta etapa puede ubicarse en el proceso global que Oszlack denomina "segunda generación de reformas del Estado". Desde sus inicios, se inscribe en un modelo de reposición de un Estado asistencial para los sectores pobres con escasas posibilidades de superación de la exclusión y hacia ello orienta su acción a través de diferentes áreas y programas de gobierno. La educación es una de ellas. Según algunos autores, desde el gobierno se trazan

\footnotetext{
“Ejes de la política que parecieran redefinirse desde una renovada cúpula simbólica a partir de la cual el Estado asumiría un rol protagónico -en el marco de nuevas articulaciones con la sociedad civil y la educación- para comenzar a dar respuestas a las necesidades y demandas de un contexto fragmentado y con altos niveles de inseguridad y peligrosidad"(Martignoni y Gióvine, 2008:80).
}

Las modificaciones que en esta etapa se realizan en el campo de la educación se asientan en escenarios sociales y escolares desestabilizados (Carbone, 2014) que quedaron como saldo de la desestructuración estatal y de la aplicación de la Ley Federal de Educación para la escuela pública. Algunos informes de investigación consultados (ME, 2000) detallan como problemas más acuciantes heredados de la aplicación de la EGB: deserción, inasistencias reiteradas, repitencia, sobreedad, altos índices de compensación de materias, que se resumen como "fracaso escolar e ineficiencia del sistema".

Puede decirse que la educación siguió los pasos de la desintegración y la fragmentación que se registran en el plano social, político y económico. Pero, además, un aspecto que se reitera en la actualidad y que aparece como insuficientemente abordado por la gestión escolar, es la relativa y escasa articulación entre los niveles de primaria y secundaria, desconociendo los logros de la primera, y los requerimientos pedagógicos de la segunda.

Ha resultado inquietante, durante los períodos de permanencia en el campo, registrar las dificultades de los estudiantes en el dominio de habilidades básicas que debieran lograrse en la escuela primaria para garantizar el inicio y continuidad de la educación secundaria, como 
lo son la adquisición de la lectura y la escritura. Esta situación, que se detectó principalmente en las escuelas públicas de sectores desfavorecidos ${ }^{92}$, pareciera estar naturalizada por los agentes del sistema o bien algunos prescinden de ese dato, proyectando la responsabilidad de tales "ausencias" en los jóvenes o en su familia.

En la formulación de los contenidos se producen dos cambios importantes en relación a la LFE: el pasaje de CBC a contenidos del diseño curricular, y la formulación, desde el Consejo Federal de Cultura y Educación, de Núcleos de Aprendizaje Prioritarios. Señala Carbone (2014:79) que

\footnotetext{
"La amplitud del concepto de NAP y su despliegue en los enunciados por ciclos y años mantenía la tendencia inaugurada en el período anterior a superar la densidad de contenidos, a los que ceñirse literalmente y poner el acento en la articulación entre los conceptos, sus abordajes y formas incipientes de acercamiento a sus métodos de descubrimiento. Las propuestas adjudicaban a las escuelas un alto nivel de iniciativa para configurar el curriculum."
}

Estos Núcleos fueron refrendados por todas las provincias del territorio nacional en el marco del CFE y se asumen sus contenidos como saberes básicos que orientarán los diseños curriculares jurisdiccionales. Como lo expresa el documento oficial (ME, 2011) tienen por finalidad otorgar visos de unidad al sistema educativo que quedó desmembrado luego de la descentralización:

\footnotetext{
"Ios NAP plasman los saberes que como sociedad consideramos claves, relevantes y significativos para que niños, niñas, adolescentes y jóvenes puedan crecer, estudiar, vivir y participar en un país democrático y justo tal como el que queremos"(M E, 2011:9).
}

Considerando la estructura educativa, que vuelve a ser modificada, la educación secundaria prevista en la nueva ley establece 6 años de escolaridad, distribuidos en dos ciclos de 3 años cada uno: 3 años de educación secundaria básica (ESB) y 3 años de Educación Secundaria Superior (ESS). Como se expresa en diversos documentos, el retorno a la unidad del nivel

\footnotetext{
${ }^{92}$ Es preciso mencionar que en escuelas públicas que atienden a clases medias, los cursos que son producto de articulaciones o nuevas creaciones atendiendo a las demandas más allá de las posibilidades materiales, también exhiben este lamentable logro.
} 
secundario favorecería la recuperación de las características sociales, culturales, etarias del grupo destinatario, así como la cultura institucional y la práctica docente propias de este nivel.

En la provincia de Buenos Aires, al igual que en el nivel nacional, se sancionan las mismas tres leyes que posicionan a los jóvenes como sujetos de derecho: La Ley de Promoción y Protección Integral de los Derechos de los Niños, Niñas y Adolescentes (Ley № 13298/06), la Ley Fuero Familiar y responsabilidad Penal Juvenil (Ley № 13 634/07) y la Ley de Educación (Ley № 13688/07). En el marco de una filosofía político-educativa que enuncia a nivel normativo su intención de posicionar a los sujetos en el centro de la escena, en una actitud activa y propositiva, se toman decisiones curriculares en la provincia de Buenos Aires que son indicativas de los cambios que se producen respecto del tratamiento de la construcción de ciudadanía en el ámbito escolar.

El Marco General para la Educación Secundaria (DGCyE, 2008:9) establece que

\footnotetext{
"Esta nueva propuesta para el sistema educativo provincial implica un profundo cambio en la concepción político-pedagógica de los sujetos destinatarios y se plasma en una nueva organización de la Educación Secundaria que ubica este tránsito educativo como el espacio de escolaridad que atiende a sujetos púberes, adolescentes y jóvenes, y tiene como objetivo fundamental lograr inclusión, permanencia y acreditación de la educación secundaria de todos los alumnos y alumnas bonaerenses, para lo cual resulta indispensable realizar una nueva propuesta de enseñanza".
}

La obligatoriedad de la educación secundaria bajo el mandato de inclusión social da cuenta de la complejidad y conflictividad de la decisión política nacional -que a su vez, atiende a las prescripciones internacionales- teniendo en cuenta los magros saldos que han quedado como producto de la aplicación de la LFE.

En relación a este cambio estructural del sistema educativo, se producen los siguientes cambios en las escuelas que integran la muestra:

-la escuela centenaria incorpora formalmente a la estructura de nivel secundario a 7으, 8 ㅇ y 9o años, aspecto que no dista significativamente de las prácticas que desarrolló durante el período anterior por su origen como unidad pedagógica. La resistencia de esta comunidad educativa a la "primarización" del tercer ciclo fue explícita y, si bien en los aspectos 
curriculares formales respetaron las decisiones prescriptas, la síntesis de valores culturales que impregnan a la unidad pedagógica que aún pretende ser esa escuela, mantuvo cierta cultura que aproximó, de manera inequitativa, a los jóvenes a las costumbres del nivel secundario. La justificación de mantener 8 ㅇ y 9o en el mismo turno que Polimodal -por razones de espacio y organización logística-, contribuyó a ello.

-la escuela rural "reconvirtió" el tercer ciclo en ESB. Formalmente, dejó de depender de primaria, para convertirse en una extensión de una escuela secundaria urbana de reciente creación-distante a $84 \mathrm{~km}$-. Esa dependencia se realizó en el plano formal y en los aspectos administrativos, pero la gestión pedagógica, el control de la dinámica cotidiana escolar, continuó realizándola la directora del nivel primario, que estaba presente diariamente en la escuela $^{93}$. Un elemento disruptivo en la dinámica de la comunidad lo constituyó la apertura del ciclo de secundaria superior y en esta situación de conflicto, los estudiantes desempeñaron un accionar relevante para nuestro tema de investigación, asunto que será abordado en los capítulos siguientes.

-en la escuela suburbana, el tercer ciclo de la EGB transformado por la nueva Ley en ESB (educación secundaria básica) pasó a formar parte de una nueva escuela: la escuela secundaria № 10, que a partir del año 2007 atenderá a jóvenes de diferentes barrios periféricos. El proceso de construcción del edificio que albergaría a la nueva escuela sufrió demoras $^{94}$, por lo que la "nueva escuela" comenzó a funcionar y aún funciona en distintos edificios, compartiendo la sede de dos escuelas primarias suburbanas, entre las que desarrollan su tarea itinerante el equipo directivo, administrativo y el personal docente.

\footnotetext{
${ }^{93}$ Durante los tres años de trabajo de campo, ningún miembro del equipo directivo de la escuela secundaria urbana se hizo presente en la sede de la escuela rural. En una entrevista realizada con la directora de nivel secundario, ésta expresó las dificultades que ese "anexo" le significaba y su imposibilidad de viajar, puesto que en el cargo no estaban previstos viáticos por traslado, ni disponía de tiempo para hacerlo. Esta escuela secundaria de reciente creación cambió cuatro veces de directora durante el período relevado. El nexo entre las dos organizaciones lo constituyó la figura de la preceptora, que liquidaba sueldos, informaba de licencias, vacantes, evaluaciones y promociones de los estudiantes.

${ }^{94}$ El predio resultó adjudicado a dos escuelas simultáneamente en el año 2005 y las directoras comenzaron a disputarse la obra. Por otro lado, la construcción quedó paralizada por desfinanciamiento de la provincia de Buenos Aires, según argumentaron funcionarios de Consejo Escolar.
} 
-la escuela privada confesional adecuó a los nuevos requerimientos su oferta educativa, situación para la que venía preparándose y trabajando de manera planificada y colaborativa desde la transformación anterior. La difusión "boca a boca" acerca del clima escolar y los resultados académicos logrados en esta escuela, junto con una presencia mediática ${ }^{95}$ nueva, gestionada por la propia institución como parte de sus estrategias de comunicación, impulsaron una fuerte demanda de ingresantes que llevó a la ampliación de su matrícula.

-la escuela dependiente de la universidad debió incorporar los tres años correspondientes a la nueva estructura de educación secundaria básica (ESB) para poder adecuarse a las exigencias de la nueva ley. Debieron tomarse decisiones que significaron acalorados debates, en relación a la ampliación edilicia, conformación del equipo de gestión, ampliación de la planta docente de acuerdo a los requerimientos de un nuevo curriculum que los especialistas construyeron como soporte del nivel existente, correspondiente a Secundaria Superior (SS).

\subsubsection{Prescripciones curriculares y regulación del sistema provincial de educación}

Con el enunciado de los fundamentos legales, políticos y pedagógicos mencionados anteriormente, la DGC y E sancionó la Res. № 3233/06 que aprueba los Diseños Curriculares para 10 y 20 años de la Educación Secundaria Básica (para ser implementados en los años 2007 y 2008). En el mapa curricular ${ }^{96}$ se incorpora la materia Construcción de Ciudadanía.

La denominación de la materia da cuenta de una perspectiva renovada que resulta coherente con el discurso político de esta nueva época. Es posible observar, tanto a nivel nacional como internacional y en los documentos emanados de las usinas ideológicas de los

\footnotetext{
${ }^{95}$ Los estudiantes de la escuela parroquial comenzaron a obtener posiciones destacadas en diferentes eventos académicos y deportivos de la ciudad y la región. Se suma a ello la información que difunde el equipo de gestión acerca de distintos proyectos solidarios y culturales de los que forman parte.

${ }_{96}$ Expresión utilizada en los Documentos de Capacitación de la DGC y E (2006) con que se hace referencia al conjunto de materias y su secuencia en cada año.
} 
organismos multilaterales, documentos orientativos ${ }^{97}$ en los que se destaca el protagonismo de los jóvenes en la escuela y en la política.

Según se expresa en el Marco General de Política Curricular de la Provincia de Buenos Aires (DGCyE, 2006: 19), un aspecto novedoso y a la vez constitutivo del cambio de perspectiva en la construcción de la nueva escuela secundaria es la concepción de los niños y jóvenes como sujetos de derecho:

“...en el marco de la Convención Internacional sobre los Derechos del Niño, la Dirección de Cultura y Educación concibe a los niños/as y jóvenes como sujetos de derecho, es decir, como actores sociales clave, protagonistas activos de la comunidad y, por lo tanto, no solo portadores de derechos futuros, sino sujetos que deben ejercer sus derechos en el presente. Desde esta perspectiva los niños/as, adolescentes y jóvenes son ciudadanos/as plenos/as. No deben esperar a la mayoría de edad para gozar de su ciudadanía, sino que se constituyen en ciudadanos desde su nacimiento"

Tal concepción se evidencia también en Diseño Curricular (DC) para la Educación Secundaria de la Provincia de Buenos Aires según se expresa en la fundamentación de la asignatura Construcción de Ciudadanía (2006: 13), en tanto la perspectiva de derecho requiere de una ciudadanía activa, "que se enseña y se aprende como práctica y ejercicio del poder, y no solo como abstracción". El diseño curricular da cuenta de "una ciudadanía que se construye, se desarrolla y se ejerce tanto dentro como fuera de la escuela: al aprender, al expresarse, al educarse, al organizarse, al vincularse con otros jóvenes y con otras generaciones" (2006: 13)

El documento mencionado más adelante especifica:

\begin{abstract}
"la concepción de ciudadanía que asume esta materia es lo que se denomina desde los estudios específicos, ciudadanía “activa” (Bustelo, 1998), "proactiva o “activa crítica” (Sinnigiglia, Borri y Jaimes, 2006). Cada uno de estos términos tiene un desarrollo socio-histórico particular (...) no entran en contradicción uno con otro sino que se complementan (...) en pos de la acción política para la transformación social" (DC, 2006:33)
\end{abstract}

\footnotetext{
${ }^{97}$ Desde fines del siglo XX los organismos multilaterales de crédito y sus "usinas ideológicas" producen reuniones, documentos, materiales, destinados a orientar la implementación de políticas sociales. Esta práctica puede observarse en los textos de divulgación de dichos organismos en sus páginas web, en las presentaciones de documentos como las Metas Educativas 2021, entre otros.
} 
Así entendida la ciudadanía, el DC propone nueve ámbitos ${ }^{98}$ para el abordaje de prácticas ciudadanas juveniles: ambiente, arte, comunicación y tecnologías de la información, estado y política, identidades y relaciones interculturales, recreación y deporte, salud, alimentación y drogas, sexualidad y género, trabajo. Esta selección de ámbitos se correlaciona con las situaciones de la vida social que caracteriza a la sociedad contemporánea.

Esta concepción amplia de la ciudadanía es consecuente también con los propósitos enunciados en los Núcleos de Aprendizaje Prioritarios (NAP) acordados para Formación Ética y Ciudadana de 10,2 y $3 e r$ años de la ESB (2011), donde se recomienda propiciar situaciones de enseñanza teniendo en cuenta los siguientes ejes: formación ética, derechos humanos, identidades y diversidad, ciudadanía participativa.

En el DC la propuesta metodológica propone que se desarrolle a través del trabajo en proyectos, en función de temas/problemas de interés de los grupos de jóvenes. Para cada ámbito se desarrolla una fundamentación teórica, ejes temáticos, ejemplos de proyectos, trabajo didáctico sugerido y bibliografía, de modo de orientar las decisiones de cada proyecto escolar.

Las características del contenido curricular y la concepción de joven (que reemplaza a la figura del alumno), el contenido de los ámbitos y, especialmente, la necesidad de anclar el proceso de enseñanza en las particularidades de los grupos de escolares, requirieron de procesos formativos para los docentes, de manera simultánea a la implementación del nuevo diseño. La tarea de capacitación de los docentes aspirantes a desempeñarse en la materia se realizó en los años 2007, 2008 y $2009^{99}$.

\footnotetext{
${ }^{98}$ Expresa el DC (p: 40): "Se denomina ámbitos a los espacios sociales posibles de definir según intereses/temas/problemas del contexto sociocultural, sobre los cuales hay luchas sociales para el establecimiento de derechos, obligaciones y responsabilidades de los sujetos, y donde se establecen y negocian sus posiciones diferenciales. Dicho en otros términos, son espacios sociales de construcción de ciudadanía que se recortan para su abordaje en un contexto de aula"

${ }^{99}$ Durante los años indicados, la capacitación fue obligatoria para los aspirantes a desempeñarse en la materia y luego continuó siendo voluntaria, hasta la actualidad.
} 
De acuerdo con la información suministrada por los agentes del $\mathrm{CIE}^{100}$, los primeros destinatarios de la capacitación fueron los profesores de la disciplina Educación Física quienes efectivamente se hicieron cargo del desarrollo inicial de la materia Construcción de Ciudadanía. La lógica detrás de esta decisión -que no se ha logrado documentar, sino que el dato se ha reconstruido a través en las entrevistas- es que los jóvenes guardarían una relación más horizontal y, por lo tanto, más democrática, con los profesores de educación física que con el resto de los docentes. Esta situación preferencial tuvo una duración inferior al primer año de prueba en las cinco escuelas seleccionadas para la investigación, pues los profesores de educación física no contaban con "habilidades" para desarrollar una dinámica de enseñanza-aprendizaje al interior de los salones de clase ni conocimientos necesarios para desarrollar los contenidos específicos de la materia. Según fue informado, fueron reemplazados por docentes "dispuestos" a hacerlo, más que por aquellos que acreditaran formación específica.

Diferentes documentos consultados ${ }^{101}$ refieren a la necesidad de democratizar la escuela y las aulas para llevar adelante el tratamiento metodológico de los temas de interés enmarcados en alguno de los ámbitos previstos. Este aspecto, como podrá observarse en el desarrollo de los capítulos 4, 5 y 6, dará cuenta de las condiciones reales objetivas de la práctica que se imponen a un discurso transformador. Esta situación es analizada desde la perspectiva figuracional desarrollada por Elías (1996), que plantea cómo las transformaciones en las configuraciones sociales se produce de manera mucho más lenta que los sujetos que transitan por ella.

La incorporación de la materia Construcción de Ciudadanía en el mapa curricular no es la única estrategia de formación ciudadana activa que se propone. La DGCyE, cuando hace referencia al gobierno escolar de la ES, menciona a los estudiantes "como participantes

\footnotetext{
${ }^{100}$ Centro de Investigación Educativa con sede en Olavarría, dependientes de la Dirección de Educación Superior de la DGCyE de la Provincia de Buenos Aires, que actualmente funciona como área de Capacitación Docente.

${ }^{101}$ Además de los DC, se han consultado documentos de la Dirección de Capacitación de la DGCyE, como "Introducción al diseño curricular: Programación y Enseñanza" (2006); "Introducción al prediseño curricular “Construcción de Ciudadanía. Propuestas de trabajo" (2007)
} 
activos del gobierno y la gestión escolar". Se establece, además, la obligatoriedad de conformación de Centros de Estudiantes ${ }^{102}$, de participación de los jóvenes en la elaboración de Acuerdos Institucionales de Convivencia y se alienta la elaboración y puesta en marcha de proyectos participativos, solidarios, de voluntariado. En la ciudad de Olavarría, se ponen en marcha en el año 2008 los Consejos Deliberantes Estudiantiles, como actividad extracurricular que vincula a los estudiantes con los problemas comunitarios y con un modo de debatir y tomar decisiones a modo de funcionamiento parlamentario.

Con la nueva Ley de Educación en la provincia de Buenos Aires se producen cambios no solo en el nivel curricular, sino que también se impulsa la modificación de la concepción vigente de gestión de las escuelas (DGCyE, 2009), al impulsar la incorporación de los Centros de Estudiantes al gobierno escolar ${ }^{103}$.

Tales prescripciones cobran diferentes formas de existencia en las escuelas relevadas. Presentaremos un cuadro-síntesis de la situación encontrada en el campo.

\footnotetext{
102 abc.gov.ar. "La Ley de Educación de la Provincia de Buenos Aires (Ley № 13688) plantea que la Escuela Secundaria tiene que: "Reconocer a los adolescentes y jóvenes como sujetos de derecho y a sus prácticas culturales como parte constitutiva de las experiencias pedagógicas de la escolaridad para fortalecer la identidad, la ciudadanía y la preparación para el mundo adulto". Por lo que buscará: "Garantizar los mecanismos de participación de los alumnos en el gobierno escolar para favorecer y fortalecer el ejercicio de la ciudadanía y la gestión democrática de las instituciones del Nivel"(Título II "Estructura del sistema educativo", Capítulo V "Educación Secundaria", Art. 28)"

La Res ministerial 4900/05 aprueba el modelo de estatuto para Centros de Estudiantes que en sus consideraciones generales establece: "en un contexto democrático la constitución del ciudadano incluye la toma de decisiones de dimensión social, por lo que es imprescindible que la comunidad educativa considere las demandas y cuestionamientos de sus miembros, brinde atención y espacio para sus iniciativas, y sobre todo, garantice experiencias positivas con respecto al derecho de opinar y proponer" y agrega que "reconocer la sustantividad política de lo pedagógico implica generar espacios institucionales de diálogo y pensamiento crítico, en busca de la resignificación de lo público".

${ }^{103}$ DGCyE: Documento “La educación Secundaria en la Provincia de Buenos Aires”, 2009.
} 


\subsubsection{Cuadro comparativo de las prácticas políticas formalizadas en las escuelas secundarias tomadas como campo}

\begin{tabular}{|c|c|c|c|c|c|}
\hline $\begin{array}{l}\text { Escuela: } \\
\text { Circuitos } \\
\text { formales }\end{array}$ & $\begin{array}{l}\text { ESB } \\
\text { centenaria }\end{array}$ & $\begin{array}{l}\text { ESB dep. de } \\
\text { Universidad }\end{array}$ & ESB rural & $\begin{array}{ll}\text { ESB de } \\
\text { gestión } \\
\text { privada }\end{array}$ & $\begin{array}{l}\text { ESB } \\
\text { suburbana }\end{array}$ \\
\hline $\begin{array}{l}\text { Centro de } \\
\text { Estudiantes }\end{array}$ & $\begin{array}{l}\text { Funciona CE } \\
\text { desde el año } \\
1973\end{array}$ & $\begin{array}{l}\text { Funciona CE } \\
\text { desde } 2006\end{array}$ & No tiene & $\begin{array}{l}\text { Funciona } \\
\text { desde } 2009\end{array}$ & No tiene \\
\hline $\begin{array}{l}\text { Materia } \\
\text { Construcción de } \\
\text { Ciudadanía }\end{array}$ & $\begin{array}{l}\text { Se dicta en la } \\
\text { misma franja } \\
\text { horaria que las } \\
\text { demás } \\
\text { materias }\end{array}$ & $\begin{array}{l}\text { Se dicta en la } \\
\text { misma franja } \\
\text { horaria que } \\
\text { las demás } \\
\text { materias }\end{array}$ & $\begin{array}{l}\text { Se dicta en } \\
\text { la misma } \\
\text { franja } \\
\text { horaria que } \\
\text { las demás } \\
\text { materias }\end{array}$ & $\begin{array}{l}\text { Se dicta en la } \\
\text { misma franja } \\
\text { horaria que } \\
\text { las demás } \\
\text { materias }\end{array}$ & $\begin{array}{l}\text { Se dicta a } \\
\text { contra-turno. } \\
\text { No asiste el } \\
75 \% \text { de los } \\
\text { estudiantes }\end{array}$ \\
\hline $\begin{array}{l}\text { Acuerdos } \\
\text { Institucionales } \\
\text { de Convivencia }\end{array}$ & $\begin{array}{l}\text { Existen desde } \\
\text { su puesta en } \\
\text { marcha en el } \\
\text { año } 2002\end{array}$ & $\begin{array}{l}\text { Se } \\
\text { construyen } \\
\text { en el año } \\
2006\end{array}$ & No tiene & $\begin{array}{l}\text { Existen } \\
\text { desde su } \\
\text { puesta en } \\
\text { marcha en el } \\
\text { año } 2002\end{array}$ & $\begin{array}{l}\text { Está siendo } \\
\text { escrito por } \\
\text { autoridades, } \\
\text { equipo y } \\
\text { docentes }\end{array}$ \\
\hline $\begin{array}{l}\text { Concejo } \\
\text { deliberante } \\
\text { estudiantil }\end{array}$ & $\begin{array}{l}\text { Tiene } \\
\text { representan- } \\
\text { tes desde } \\
2010\end{array}$ & $\begin{array}{l}\text { Tiene } \\
\text { representant } \\
\text { es desde } \\
2010\end{array}$ & $\begin{array}{l}\text { No } \\
\text { tiene } \\
\text { representan } \\
\text { tes }\end{array}$ & $\begin{array}{l}\text { Tiene } \\
\text { representant } \\
\text { es desde } \\
2010\end{array}$ & $\begin{array}{l}\text { No } \\
\text { tiene } \\
\text { representante } \\
\text { s }\end{array}$ \\
\hline $\begin{array}{l}\text { Programas } \\
\text { extra- } \\
\text { curriculares } \\
\text { orientados a la } \\
\text { socialización }\end{array}$ & $\begin{array}{l}\text { "Normal } \\
\text { solidario" } \\
\text { desde } 2007\end{array}$ & $\begin{array}{l}\text { Centro } \\
\text { Cultural "La } \\
\text { ronda" desde } \\
2007\end{array}$ & No tiene & No tiene & No tiene \\
\hline
\end{tabular}




\subsection{Nuevo reto a la historia, la cultura y al curriculum escolar}

Han sido presentadas en este capítulo las ideas que consideramos más relevantes para explicar y comprender las transformaciones que ha ido sufriendo la concepción política de formación y construcción de ciudadanía a través de las propuestas curriculares, en los tres períodos seleccionados.

Hemos recurrido para ello a las categorías de la teoría del currículo que mencionamos al inicio del capítulo: síntesis de elementos culturales que sedimentan en las instituciones, propuestas político-educativas, aspectos estructurales y procesuales prácticos que caracterizan el desarrollo del curriculum prescripto y del curriculum oculto, y finalmente, la impronta que imprimen los sujetos de dicho proceso educativo. Hemos presentado, a la par, análisis de los procesos socio-históricos que han configurado la dinámica del funcionamiento actual de las escuelas que integran la muestra, en los que destacamos la recuperación de la ciudadanía democrática, la emergencia del ciudadano como consumidor y la actual ciudadanía plural y activa.

Atendiendo a la dinámica de cada historia y cultura escolar y las características que asumen las configuraciones didácticas que hemos logrado relevar, nos preguntamos por las posibilidades y las potencialidades de las escuelas, en tanto instituciones/organizaciones sociales, para llevar adelante una empresa de la relevancia que adquiere la construcción de ciudadanías activas y críticas para los tiempos actuales, focalizando la acción en el sujeto y su capacidad transformadora teniendo como sustento, una estructura facilitadora para la emergencia creadora. El reto para la nueva escuela secundaria parece centrarse primero, en su capacidad para democratizar realmente $-\mathrm{y}$ no solo discursivamente- las relaciones sociales y, luego, generar dispositivos pedagógicos capaces de potenciar reflexivamente a todos los jóvenes que hoy se encuentran incluidos por la nueva LEN, atendiendo a sus intereses y expectativas no ya como sujetos en moratoria social sino como sujetos de derecho. 


\section{Bibliografía:}

ACOSTA, F. (2008). Escuela media y sectores populares. Posibilidades y potencia de la escuela moderna. La Crujía, Buenos Aires.

APPLE, M. (1977). Ideología y Curriculum. Akal, Madrid.

APPLE, M.; ALZAMORA, S y CAMPAGNO, L (2010). Michael W. Apple: Poder, conocimiento y reforma educacional. Miño y Dávila- UNLP., Argentina.

BALDUZZI, J. y SUÁREZ, N. (1997). Impacto de la implementación del 8o año en las escuelas Bonaerenses. Sindicato Único de los Trabajadores de la Educación de la Provincia de Buenos Aires (SUTEBA), Buenos Aires.

BALDUZZI, J. (2004). Desigualdad y exclusión educativa en el "tercer ciclo" de la Provincia de Buenos Aires. Secretaría de Educación y Cultura Departamento de Investigación. SUTEBA, Buenos Aires.

BERNSTEIN, B. [1990](2001). La estructura del discurso pedagógico. Vol 4. Morata: Madrid. BOURDIEU, P. y PASSERON, J. C. [1969] (2003). Los herederos: los estudiantes y la cultura. Siglo XXI, Buenos Aires.

-(2007): El sentido práctico. Siglo XXI. Argentina.

CARBONE, G. (2010). “Manuales de educación primaria en Argentina (1984-1993). De las políticas soñadas a los proyectos inconclusos". En Kaufmann, C. (2012): Textos escolares, dictadura y después. Miradas desde Argentina, Alemania, Brasil, España e Italia. Prometeo, Buenos Aires.

CARBONE, G. (2014) (coord.). Libros de texto en una cultura escolar desestabilizada. Santiago de Arcos, Buenos Aires. (en prensa)

CULLEN, C. [1997] (2005): Críticas a las razones de educar. Temas de filosofía de la educación. Paidos, Buenos Aires.

DE ALBA, A (1995). Curriculum: crisis, mito y perspectivas. IICE- Miño y Dávila, Buenos Aires. 
DÍAZ, N. (2009). “Procesos de estructuración y definición del curriculum para el ciclo básico de la escuela secundaria en la transición democrática argentina (1983-1989)”. Tesis de Maestría en Educación con orientación a Gestión Educativa. Orientador: Mariano Palamidessi. Universidad de San Andrés. Sin editar.

DÍAZ BARRIGA, Á. (1996). El curriculum escolar. Surgimiento y perspectivas. Aique, Buenos Aires.

DUSCHATZKY, S (1999). La escuela como frontera. Reflexiones sobre la experiencia escolar de los jóvenes de sectores populares. Paidós, Buenos Aires.

ELIAS, N. (1996). La sociedad cortesana. FCE, México D.C.

GENTILI, P. (2000). Códigos para la ciudadanía. La formación ética como práctica de la libertad. Santillana, Buenos Aires.

GIMENO SACRISTÁN, J. (1993) “Diseño del curriculum, diseño de la enseñanza. El papel de los profesores". En: Comprender y transformar la enseñanza .Gimeno Sacristán, J. y Pérez Gómez, A (1993): Morata, Madrid.

GIMENO SACRISTÁN, J. [1988] (1994). El curriculum: una reflexión sobre la práctica. Morata, Madrid.

GIMENO SACRISTÁN, J. (2010). ¿Qué significa el curriculum? (adelanto). Sinéctica, (34), 1143. Consultado el 15 de febrero de 2014. Disponible en http://www.scielo.org.mx/scielo.php?script=sci_arttext\&pid=S1665109X2010000100009\&lng=es\&tlng=es. .

GIROUX, H. (1992). Teoría y resistencia en educación: una pedagogía para la oposición. Siglo XXI, Buenos Aires.

GIROUX, H. y PENNA, A. (1979). "Educación social en el aula: La dinámica del curriculum oculto". En Giroux (1997),Los profesores como intelectuales. Paidós, Madrid.

GIROUX, H. (2010). La educación y la crisis del valor de lo público. Desafiando la agresión a los docentes, los estudiantes y la educación pública. Criatura editora, Montevideo. 
GOODSON, I. (1988). Historia del curriculum. La construcción social de las disciplinas escolares. Consultado el 27 de febrero de 2014 en: http://www.ub.edu/geocrit/sv-46.htm (1995). "Carros de fuego": etimologías, epistemologías y la emergencia del curriculum. En: Goodson (2000): El cambio en el curriculum. Octaedro, Madrid. (2000). El cambio en el curriculum. Octaedro, Barcelona. (2003). Estudio del curriculum. Casos y métodos. Amorrourtu, Buenos Aires. HARGREAVES, A. (1995). Profesorado, cultura y posmodernidad. (Cambian los tiempos, cambia el profesorado).Morata, Madrid.

HIRSCHBERG, S. (2000. Informe de investigación: implementación y localización del Tercer Ciclo de EGB. Las prescripciones y su impacto en los actores institucionales. Unidad de investigaciones educativas. Ministerio de Educación.

JACKSON, PH. [1998](1998). La vida en las aulas. Morata, Madrid. --(1999). Enseñanzas implícitas. Amorrourtu, Buenos Aires.

KAUFMANN, C. (2007). El fuego, el agua, la historia. La dictadura en los escenarios educativos: memorias y desmemorias. Libros del Zorzal, Buenos Aires.

KESSLER, G. (1996). La experiencia escolar fragmentada. Estudiantes y docentes en la escuela media en Buenos Aires. IIPE- UNESCO, Buenos Aires

KINCHELOE, J (2000). Introducción. En Goodson, I. El cambio en el curriculum. Octaedro, Barcelona.

LITWIN, E. (1997). Configuraciones didácticas. Una nueva agenda para la enseñanza superior. Paidós, Buenos Aires.

MARTIGNONI, L. (2005). Estrategias de inclusión en la educación pública argentina. En Corbalán, A (2005), Enredados por la educación, la cultura y la política. Biblos, Buenos Aires. 
MARTIGNONI, L y GIÓVINE, R (2007). “Nuevas y viejas interpelaciones a la familia en el discurso escolar". En Propuesta Educativa № 30. FLACSO, Buenos Aires.

MARTíN- BARBERO, J (1998). De los medios a las mediaciones. Gili, México.

NúÑEZ, P. (2014).La política en la escuela. La Crujía, Buenos Aires.

OSZLAK, O (1999). De menor a mejor: el desafío de la segunda reforma del Estado. Revista Nueva Sociedad, № 160, Venezuela.

PALAMIDESI, M. (2000). “Presentación”. En: Estudios y documentos 1.Educación General Básica. "Investigaciones sobre el Tercer Ciclo". Dirección Nacional de Investigación Educativa. Ministerio de Educación.

PUIGGRÓS, A. (1998). Qué pasó en la educación Argentina. Desde la conquista hasta el Menemismo. Kapelusz, Buenos Aires.

STENHOUSSE, L (1981).Investigación y desarrollo del curriculum. Morata, Madrid.

SVAMPA, M. (2005). La sociedad excluyente. La Argentina bajo el signo del neoliberalismo. Taurus, Buenos Aires.

SVAMPA, M. (2008). Cambio de época. Movimientos sociales y poder político. Siglo XXICLACSO, Buenos Aires.

TEDESCO, J. C. (2001). Introducción: los cambios en la educación secundaria y la función de los planificadores. En: Braslavsky, C. (comp), La educación secundaria. ¿Cambio o inmutabilidad? Análisis y debate en los procesos europeos y latinoamericanos contemporáneos. IIPE- Santillana, Buenos Aires

TESDESCO, J. C. y TENTI FANFANI, E. (2001). “La reforma educativa en la Argentina. Semejanzas y particularidades". Documento para el Proyecto: Alcance y resultados de las reformas educativas en Argentina, Chile y Uruguay. Ministerios de Educación de Argentina, Chile y Uruguay, Grupo Asesor de la Universidad de Stanford/BID-Buenos Aires. Consultado 
el 20 de febrero de 2013. Disponible en www.info.worldbank.org/etools/docs/library/.../reforma\%20educativa\%20final.p...

TIRAMONTI, G. 2011. La escuela secundaria argentina: dinámicas de selección y diferenciación. V.41 N.144 SET. /DEZ. 2011 CADERNOS DE PESQUISA. Sao Paulo.

TORRES SANTOMÉ, J. (1996). El curriculum oculto. Morata, Madrid.

VIÑAO FRAGO, A. (2006). Sistemas educativos, culturas escolares y reformas. Ediciones Morata, Madrid.

VIÑAO FRAGO, A. (2008). "La escuela y la escolaridad como objetos históricos. Facetas y problemas de la historia de la educación". En Mainer, J. (coord.) Pensar críticamente la educación escolar. Perspectivas y controversias historiográficas. Presas Universitarias de Zaragoza, Zaragoza.

\section{Fuentes documentales:}

Dirección General de Cultura y Educación. Provincia de Buenos Aires (2007): Diseño curricular para la Educación Secundaria. Construcción de Ciudadanía. 10 a 3er año.

Metas Educativas 2021 “La educación que queremos para la generación de los bicentenarios". OEA. Organización de Estados Americanos para la Educación, la Ciencia y la Cultura (2010), Documento final, Madrid.

Ministerio de Cultura y Educación (2000). “Informe de investigación: La estructura curricular básica del tercer ciclo de la EGB en ocho jurisdicciones". Disponible en:

$\underline{\text { www.diniece.me.gov.ar }}$

Ministerio de Cultura y Educación (2000). “Investigación sobre el tercer ciclo” Dirección Nacional de Investigación Educativa. www.bnm.me.gov.ar/giga1/documentos/EL001007.pdf 


\section{Capítulo 4:}

\section{La convivencia, entre lo legal y lo justo: prácticas que habilita y obtura la dinámica social de la escuela}

\subsection{Introducción}

En este capítulo se analizan los procesos y las prácticas a través de las cuales los jóvenes, inmersos en las dinámicas escolares, desarrollan diversos modos de construcción de la vida en común. En los escenarios sociales contemporáneos, las formas de organización social han cambiado y la escuela -con sus normas y disciplina propias del microclima escolar- parece estar readecuando los criterios para organizar el desarrollo de su vida cotidiana.

Reconocemos que las reglas de lo social (contingentes, no universales) están siendo redefinidas, los jóvenes -que parecen "desconocer" su rol de alumnos- tensionan en la producción de un nuevo escenario escolar.

Tanto las prácticas y estrategias de los jóvenes como las particularidades de los nuevos escenarios, no podrán ser comprendidos sin considerar los proceso sociohistóricos a través de los cuales cada comunidad particular ha ido construyendo su relación con la escuela y sedimentando su impronta en las acciones de los jóvenes. Sobre la cultura institucional de cada escuela que integra la muestra, nos hemos extendido en el Capítulo 3.

Las escuelas representan en la actualidad uno de los pocos espacios públicos en los que los jóvenes tienen la posibilidad de encontrarse con otros sujetos - de su edad y adultos que no pertenecen al ámbito familiar-, con quienes decidir el modo en que producen nuevas/otras prácticas de convivencia. La convivencia, como proceso relacional se analiza considerando dos aspectos entrelazados: por un lado como un proceso de construcción de identidades, en el que la idea de lo común se forja con el lazo social y por otro, con la internalización de lo legal, ligado a un sentido de justicia.

La convivencia en sus dos aspectos, si bien es contemplada como tema y contenido prescripto por el curriculum oficial, se pone en acción principalmente como contenido del curriculum oculto, en el que se manifiestan la cultura escolar y los habitus construidos en la 
cultura de clase de los docentes y de los jóvenes que interactúan en el espacio público que es la escuela.

Un supuesto que organiza este capítulo es que la construcción de la vida en común requiere de la existencia de espacio público. En ese sentido, la escuela -aún la escuela de gestión privada que se incluye en la muestra- es entendida como un espacio público que tiene entre sus principales atribuciones, la formación político-ciudadana de los jóvenes. Desde nuestra perspectiva, la política está asociada de manera indiscutida con el bien común (Castoriadis, 2003).

La nueva Ley provincial de Educación № 13.688/07 interpela desde su formulación discursiva a las instituciones educativas para que implementen estrategias tendientes a la democratización de las relaciones escolares y puedan cumplir así el mandato fundamental de inclusión social. Las dificultades para desarrollar la vida en común en las sociedades actuales donde, como dijimos, lo social es contingente y la desigualdad social en extremo injusta, ha llevado a que la cuestión de la inclusión social se haya convertido en el eje principal de la política educativa.

Las nuevas prescripciones curriculares ${ }^{104}$ impactan sobre las reglas que rigen en el campo educativo y tensionan con la estructura de la vida escolar, asentada sobre unas relaciones de poder que han sido sostenidas desde otro modelo de Estado. Pero el debilitamiento de los límites entre el adentro y el afuera escolar que se produce progresivamente desde la entrada a un nuevo orden social ha horadado la fuerza de la escuela para instituir, aunque persisten en la cultura escolar (Viñao Frago, 2006) sedimentos de sus valores fundacionales y, en los sujetos, habitus específicos que siguen orientando el desarrollo del curriculum que organiza la vida cotidiana.

La fragmentación social que señala Svampa -entre otros autores- en sus investigaciones recientes sobre Argentina, es reconocida como uno de los elementos de transformación del espacio público. De acuerdo con Giroux (2010), el neoliberalismo dominante hace ver a las

\footnotetext{
${ }^{104}$ Remitirse al Capítulo 3, punto 3.2.3.1. Prescripciones curriculares y regulaciones del sistema provincial de educación.
} 
escuelas más como un espacio de demandas de derechos privados que como un espacio público en el que se aprenden y desarrollan los valores para la vida social.

Desafiando la relevancia que ha adquirido el individualismo en las últimas décadas, en este trabajo distinguimos a los procesos estructurantes de la vida social como dimensión fundante de la política, posición que aún es detentada por sectores críticos -entre ellos, ciertos docentes, padres, jóvenes. En ese sentido, el posicionamiento crítico de este estudio en relación con la vida social, se sostiene en los estudios de Arendt (2008), quien argumenta que la condición humana se define por la interacción con otros, y que el hombre (genérico) es, antes que un ser racional, un ser social. Solo a partir de este reconocimiento, nos dice la autora, se comprenderá el sentido de la dimensión política de la vida social ${ }^{105}$.

El espacio público, como lo presenta Arendt, es mundo común que une a los sujetos a través de relaciones que no supongan fusión, sino que permitan mantener su condición y capacidad de acción y palabra. La participación de ese mundo o espacio común nos representa como iguales, pero en un sentido diferente al que utilizaban los griegos: mientras para los griegos el espacio público se identificaba con la libertad (porque los liberaba del dominio de la familia), para los modernos se identifica con la justicia, en tanto somos iguales ante la ley (Birulés, 2007:22)

La vida en común -la vida social- requiere de regulaciones que establezcan un cierto "orden". Atendiendo a las fragmentaciones sociales existentes, cada fragmento presenta sus particularidades y, en ellos, criterios implícitos o explícitos de un orden que los participantes respetan, aunque en su análisis acordemos con que siempre será incompleto, provisorio, dinámico.

En tiempos de declive de las instituciones modernas que sostuvieron la idea de lo social como unidad, se hace necesario indagar por los sentidos que ordenan la vida en común de

\footnotetext{
${ }^{105}$ Se sabe que existe un extendido debate en torno de la primacía de lo social sobre lo político y su relación inversa, al interior de la ciencia política, pero no será desarrollado en profundidad pues no es un tema específico de este trabajo.
} 
los jóvenes de este estudio, así como el significado de "lo común", que no refiere ya a "todos por igual”, ni a todos quienes comparten el espacio público ${ }^{106}$ de la escuela.

En las democracias modernas, la idea de libertad está representada en los derechos concedidos al sujeto reconocido como ciudadano. En ese sentido, Cullen (2003) expresa que el espacio público moderno se ha definido por dos tipos principales de libertades: la de opinión pública y la de participación, que hacen de él un espacio político. Estas libertades aparecen como contenido explícito del proceso educativo en la escuela secundaria, considerando por un lado, que los destinatarios han abandonado la niñez (o comienzan a hacerlo cuando ingresan a este segmento educativo) y que en consecuencia, comienzan a formar un juicio -y opinión- propias, independientemente del maestro y la familia ${ }^{107}$.

El reconocimiento de libertades individuales y asociativas de los sujetos, que se reconocen, a la vez, legalmente como tales, entran en colisión con los mandatos de disciplinamiento institucional, sedimentados en la cultura escolar. Pero aún bajo algún tipo de tutelaje institucional, los jóvenes de la ESB, actores de esta investigación, son considerados como sujetos sociales autores de sus opiniones y sus prácticas, y portadores de una cultura reconocida como propia.

Otro aspecto importante de considerar en el análisis del espacio público y la actuación de los jóvenes estudiantes en él, es la condición de renuncia que el espacio público lleva como definición: en el espacio público, los sujetos subordinan su deseo de libertad individual, para

\footnotetext{
${ }^{106}$ Carlos Cullen (2003) realiza un análisis acerca de los usos del concepto "público" y, así, encuentra que: el espacio público que indica la ausencia de restricciones de acceso, se identifica con la libertad de circulación; en la diferenciación entre lo público y lo privado, lo público se asocia al poder coercitivo del Estado y lo privado a la libertad de pensamiento y creencias; en otro sentido, lo público se asocia a lo que se dice - como libertad de expresión- y lo privado, a lo que permanece secreto; público como conjunto de personas (que miran, o escuchan o participan de una reunión o espectáculo) alude a la libertad de reunión; cuando su uso enuncia la libertad de estar juntos, de participar en la búsqueda de "significaciones básicas comunes", de diálogo, estamos refiriendo a libertad política.

${ }^{107}$ Distintos autores consideran que en la escuela primaria, la influencia y el contacto con la familia es más fluido y constante, situación que se modifica sustancialmente en la escolaridad secundaria.
} 
poder convivir ${ }^{108}$ : sin renunciar a las pulsiones individuales, no hay convivencia posible, y éste es un punto de tensión entre el individualismo y el interés por el bien común que se puede observar en la sociedad y en la escuela.

\subsection{Acerca de cómo se construye la vida común en las escuelas en estudio}

Desde el plano formal, las prescripciones curriculares son comunes a las cinco escuelas que componen la muestra. Las prescripciones curriculares contemplan tanto los contenidos disciplinares como los regímenes específicos que regulan la dinámica escolar: el régimen de convivencia y el régimen académico para la educación secundaria ${ }^{109}$.

En relación a los contenidos curriculares que abordan el tratamiento de la convivencia escolar, en cuatro de las cinco escuelas se agrupan en la materia Construcción de Ciudadanía. En la escuela dependiente de la Universidad, la materia se divide en dos materias cuatrimestrales: Sociedad y Estado y Medio ambiente y Ciudadanía. En cuanto a los regímenes (de convivencia y académico), ambos adquieren particularidades en cada una de las escuelas, de acuerdo con su historia, la cultura institucional y las prácticas curriculares que les otorgan singularidad.

\subsubsection{El cambio de nivel como un encuentro/desencuentro con otros diferentes}

Para los jóvenes, el ingreso a la escuela secundaria es vivido como un pasaje de la vida de niño al comienzo de la juventud. Esta nueva situación despierta expectativas, desafíos y temores, ya que abandonan la relativa seguridad construida en el pasaje por la escuela primaria, donde la relación con las maestras -aún en la diversidad de situaciones relevadasse producía sobre la base del trato directo, generalmente desde el afecto y del vínculo

\footnotetext{
${ }^{108}$ La subjetividad se retrae ante el bien común, constituyéndose con otros parámetros donde los deseos individuales se subordinan al deseo colectivo (Arendt, 2008). Este aprendizaje, en la secuencia institucional moderna, se inicia en la familia y continúa en la escuela.

${ }^{109}$ Las Resoluciones 587/11 y 1480/11 aprueban el nuevo Régimen Académico para la Educación Secundaria. Hasta entonces, existía un Régimen Académico que regía la trayectoria escolar de los alumnos en la ESB y otro para el nivel Polimodal.
} 
cotidiano y prolongado en el tiempo. Acomodarse a nuevas y numerosas relaciones sociales es, quizá, el primer aprendizaje significativo que realizan los jóvenes ingresantes a la escuela secundaria $^{110}$.

Braian, estudiante de tercer año ESB de la escuela rural dice:

"ese es el mayor cambio. Ahora nosotros tenemos que adaptarnos a eso, porque tener un profesor distinto en cada materia, es un cambio. Nosotros nos tenemos que adaptar a ellos, aprender a que cada uno enseña de manera distinta (...) y te trata de manera distinta"

Se observa entonces, un proceso de socialización en la diferenciación y en la distancia relativa que comienzan a experimentar con otros actores escolares, desprendiéndose de las relaciones mediadas por el vínculo "maternante" de la maestra y orientándose hacia un modo de relación social más formal. Sobre esta cuestión, que moldea un modo de estar en la escuela que afecta las relaciones sociales y los aprendizajes, dan cuenta las investigaciones de Dubet y Martuccelli (1998) y de Gimeno Sacristán (1996), sobre lo que denomina períodos de transición entre un nivel y otro, y donde los aprendizajes por fuera del curriculum disciplinar, aquellos que se sitúan en el ámbito del curriculum oculto, son los que concentran la mayor atención y energía por parte de los jóvenes. Coincide esta transición con cambios biológicos significativos, que marcan otra transición intensa: de la niñez a la juventud.

En la escuela secundaria, el contacto con diversos profesores que encarnan en sí mismos (según los relatos de los jóvenes) la disciplina objeto de la enseñanza, los obliga a ensayar actuaciones que requieren de nuevas estrategias ${ }^{111}$ que adquieren (a veces torpemente) con el paso del tiempo, acomodándose o no a las nuevas circunstancias ${ }^{112}$.

\footnotetext{
${ }^{110}$ Aun así, cabe establecerse la diferenciación en las relaciones "puertas adentro del aula" donde se crea un mayor nivel de intimidad y pertenencia que con la escuela en general, donde sus posiciones anteriores cambian y hasta parecen diluirse en el nuevo escenario.

${ }^{111}$ Nos referimos a estrategias vinculadas con el desempeño social, principalmente.

${ }^{112}$ Solo una -de las cinco escuelas en estudio- ofrece el nivel secundario únicamente. En las demás, los grupos de ingresantes al nivel secundario se conforman mayoritariamente por jóvenes que han realizado su educación primaria en el mismo establecimiento educativo.
} 
En relación a la conformación de grupos de pares, en las escuelas que presentan una continuidad entre educación primaria y secundaria, la conformación de los grupos iniciados en el nivel primario se mantiene por un período prolongado. Estas conformaciones grupales que, por un lado, otorgan cierto margen de acción y seguridad a sus miembros se constituyen, a la vez, en obstáculos al momento de pensar en producir acciones y participaciones que trasciendan los límites de los pequeños grupos de amigos e incluyan al conjunto de jóvenes del aula.

Una explicación posible de la persistencia de este modo de socialización cerrada, de este "blindaje" de los pequeños grupos, es la escasez de situaciones en que los docentes (profesores, preceptores, personal encolar en general) se ocupan especialmente de hacer propuestas que rompan esa lógica de funcionamiento social.

Solo en la escuela dependiente de la universidad se registró el tratamiento de este tema de manera reflexiva, haciendo referencia a las consecuencias sociales más complejas de este modo de socialización de los jóvenes y se encaró como un trabajo conjunto por parte de los adultos educadores. El trabajo pedagógico observado al interior del aula, en el desarrollo de algunas materias, incluyó un tratamiento explicativo -inicialmente- y reflexivo luego, sobre conductas particulares, en relación a problematizar el funcionamiento de los jóvenes en grupos cerrados, para ayudarlos a percibir al grupo más amplio del aula. Propusieron, entonces, acciones que implicaran compartir situaciones de trabajo dentro y fuera del aula pero también dentro y fuera de la escuela- reconociéndose con conceptos más amplios que "ser amigos íntimos" como posibilitadoras de la realización de tareas conjuntas.

Resultó significativo observar entre los jóvenes de las distintas escuelas, las dificultades para percibir, escuchar y atender a "los otros" que no constituyen su núcleo íntimo de referencia. Las cuestiones de agrupamientos por género tampoco fueron problematizadas durante el período de trabajo de campo ${ }^{113}$.

\footnotetext{
${ }^{113}$ Los agrupamientos en relación al género, si bien ha sido asumida desde la psicologización de la socialización juvenil como típica en este período, es poco considerada como motivo de abordaje reflexivo por los agentes escolares.
} 


\title{
4.2.2. La construcción del mundo común en una sociedad que individualiza
}

\author{
“¿SOMOS UNA SOCIEDAD DE YOICOS? Hay sin dudas, razones para creerlo si \\ se pasa revista a las expresiones en boga de nuestro tiempo: falta de \\ solidaridad, decadencia de valores, cultura del narcisismo, trampa del \\ egoísmo, pensamiento reivindicativo, hedonismo, son términos que \\ resuenan en el espacio público" (Beck, 2002:7)
}

El autor alemán, expresa sus preocupaciones por los sentidos que se construyen en esta etapa de la modernidad ${ }^{114}$, y reflexiona acerca de los alcances de esta subjetividad individualista extrema y las dificultades que este estilo de vida conlleva para la construcción de la vida en común. Analizando los casos relevados, parece difícil encontrar los límites y los procesos que establecen tales límites, entre el mundo interno -subjetivo- y el mundo externo -común- vivido por los jóvenes.

Consideramos, tal como lo hemos desarrollado en los primeros capítulos, que la relación educación-democracia y estado requiere de la escuela como un ámbito de encuentro, de participación y de construcción de ciudadanía; pero, ¿qué puede hacerla escuela con el individualismo instalado como modo dominante de las relaciones sociales?

En la escuela centenaria se producen con frecuencia peleas entre los jóvenes cuyo motivo resulta desconocido -en primera instancia- para los agentes escolares y que se manifiestan con golpizas y agresiones físicas entre jóvenes. En algunas oportunidades, se pelean con estudiantes de otra escuela; en otras, con estudiantes de la misma escuela. Los hechos se producen en la vereda, en la escalera de acceso al edificio, con intervención de vecinos, padres y, en ocasiones, también de la policía.

En una jornada de trabajo, la estudiante "representante de convivencia" de un curso, relata que el día anterior había asistido a una reunión con el equipo directivo y el equipo técnico de

\footnotetext{
${ }^{114}$ Si bien los pensadores (Beck, junto a Guiddens y Lash) de la corriente sociológica reflexiva van a considerar un escenario -relativamente- optimista fundado en la confianza en la creatividad del sujeto para salir de las crisis, este tipo de pensamiento resultó viable en el contexto europeo anterior a las crisis económicas que se registraron a partir de 2010 en los países miembros de la CEE.
} 
la Dirección de Pedagogía Social y Psicología Comunitaria (PSyPC), porque los adultos querían plantear

"que los jóvenes estamos muy irritados, que por la mínima expresión del otro que no te guste, ya saltás a la defensiva y empieza la violencia, que puede ser física o psicológica". Agrega, explicando al grupo:

"La piña te puede doler dos o tres días, pero la psicológica, te puede durar toda la vida"

La joven expresa que no comparte esa visión, porque nadie se preguntó, a lo largo del taller sobre convivencia del que participaron todos los delegados de cursos, por qué los jóvenes están "irritados" (remarca la joven haciendo señas de comillas con sus dedos).Simultáneamente, el director de la escuela expresó, en una nota radial y lo repitió en el taller, que "tenía que llamar a los chicos a la reflexión, porque ante la comunidad, están quemando la escuela"115. Esta frase detonó una manifestación de indignación por parte de los jóvenes, mientras la profesora de Construcción de Ciudadanía pretendía acallarlos. Expresaron que era necesario hablar, y que los adultos se tenían que hacer cargo más responsablemente, "porque algunos no entienden nada" -expresó Pedro, de 15 años, en referencia a los adultos (profesores y demás agentes escolares) que no escuchan los problemas que plantean los jóvenes.

Profundizando en el análisis y avanzando en las razones de las peleas y las causas de la supuesta "violencia e irritabilidad de los jóvenes", analizamos dos aspectos en relación a ella: uno, que si bien existe un entorno social irritado y violento, la escuela por sí misma también genera violencia -en especial violencia simbólica, en el sentido desarrollado por P. Bourdieu y Passeron (1977)- en tanto ejerce coerción sobre los jóvenes para que cumplan con normas y reglas fundacionales que los adultos tampoco puede ya sostener. Pero imponen sus acciones a través del ejercicio de un poder legitimado socialmente -aunque no

\footnotetext{
${ }^{115}$ La expresión hace referencia a la mala imagen de la escuela que los chicos están generando hacia la comunidad. Es necesario aclarar -porque lo señalaron los jóvenes estudiantes con expresa indignación- que nunca intervinieron representantes del equipo directivo ni profesores para disuadir o disolver las peleas entre los jóvenes. En cambio sí lo hicieron preceptores, el kiosquero de enfrente a la escuela y padres que esperaban a sus hijos en la puerta de la escuela.

Esta falta de participación del equipo directivo en situaciones comprometidas de los jóvenes, es indicativa, según relataron, de un "caretaje" que ellos "no se bancan".

Nota de la autora: caretaje hace referencia a mostrar una apariencia
} 
hegemónico- ante el cual los jóvenes deben ensayar tácticas que les permitan subvertir el orden, sin romper las tramas de la estructura en que están inmersos, porque de lo contrario, quedan expulsados del sistema.

Otra vertiente para este análisis daría cuenta de cuestiones del orden de la vida privada de los jóvenes que irrumpen en la escena escolar y estallan, dejando a los actores escolares sin capacidad de reacción o con temor al compromiso que trasciende la función de la enseñanza, puesto que la tarea educativa parece haberse diluido. Los jóvenes tampoco sienten culpa ni se sienten en necesidad de brindar explicaciones, dado que las causales de las situaciones críticas son de otro orden distinto al del orden escolar ${ }^{116}$.

Una situación con reflexiones juveniles de similares características sucede en la escuela secundaria dependiente de la universidad: en una ocasión, a una estudiante le falta el celular de su mochila en el salón de clases del curso al que asiste y transcurre un mes sin que se encuentre un responsable del hecho, ni un culpable, situación que estremece la estructura de valores educativos de esta escuela, muy joven y fundamentada en una solidaridad reflexiva que con persistencia sostienen adultos y jóvenes.

Hubieron charlas privadas, talleres dentro del curso, con otros cursos, intervención de delegados del CE, reuniones de padres, enojos de padres, denuncias en la red social Facebook...pero no se percibió ningún indicio del hecho, produciéndose una lesión en el imaginario institucional que sostenía la armonía y la transparencia de las relaciones sociales $^{117}$.

\footnotetext{
${ }^{116}$ Una de las protagonistas de la última pelea, producida en la escalera principal de la escuela, se encontraba en el curso y en privado, hablamos sobre el tema. Las causales -como en todos estos casos, señala la jovenestán vinculadas a cuestiones amorosas, el trofeo en disputa es un joven de otro colegio, requerido por dos estudiantes de éste. "Nadie de la escuela tiene que meterse, porque no tiene nada que ver con la escuela"dice. "Pero la pelea, en la que además se lastimaron, sucedió en la escuela -argumenté". "No tiene nada que ver, podría haber sido en el club o en la plaza" responde. Lo significativo de este hecho es que la joven considera que nadie de la escuela se tiene que involucrar, y los profesores y el equipo directivo, por su cuenta, no lo hacen. Aquí parece haber una sintonía entre las decisiones de adultos y jóvenes, pero parecen diferir los sentidos con que actúan.
}

${ }^{117}$ Pasado un tiempo, en una de las entrevistas individuales interrogo a una de las jóvenes (14 años) y ella relata que su celular había sido sustraído por una chica de otro curso para leerle los mails a efectos de 
Una observación que resulta valiosa para este caso: mientras que los jóvenes estudiantes de los años superiores se manifestaban sinceramente conmovidos por la pérdida del lazo identitario de armonía en la escuela, los "más chicos" de la secundaria básica, no vivenciaron este hecho con la misma magnitud. Y los adultos que generaban situaciones para interpelar y conmover- a los "nuevos", no encontraban modos de llegar a tener con ellos reflexiones profundas que produjeran identificación con el ideario escolar.

Podría interpretarse que el crecimiento de la matrícula que experimentó esta escuela en poco tiempo (en tres años, desde la incorporación de la ESB al nivel Polimodal que venía funcionando, la escuela triplicó la cantidad de alumnos), resultó demasiado veloz y arrasador como para poder sostener un ideario ${ }^{118}$, las reglas y normas fundacionales ante un público heterogéneo y ante los requerimientos de una nueva ley que modificó todas las estructuras existentes.

Pareciera ser que la masividad (cuestión que atraviesa esta lógica de ruptura del aro protector de la escuela) interpela las normas (viejas o nuevas, como en el caso de la escuela centenaria y la joven escuela universitaria) que pretende instituir la escuela, y el sentido de las normas. Los idearios y las normas que conforman la cultura escolar no afectan a algunos de los nuevos jóvenes que transitan sus aulas, donde lo público y lo privado se invaden mutuamente, desconcertando a los adultos de la escuela en el caso de la escuela secundaria universitaria, y generando distanciamiento ¿ $\mathrm{e}$ indiferencia? en el otro.

comprobar o desechar la infidelidad de su novio, de quien dudaba. Y que luego, "no pudiendo devolverle el teléfono porque era como mandarse en cana (sic), lo arrojó por la ventanilla del automóvil en el que regresaba a su casa, finalizado el día escolar". Pero que eso ya había pasado y ahora se llevaban bien.

${ }^{118}$ En esta escuela, no existe reglamentación de las sanciones. La escuela ha optado por un estilo de regulación de tipo más familiar que formal. 


\subsection{Convivencia y diferencia}

\subsubsection{El tratamiento de la diversidad en la escuela secundaria: cuestiones de sexualidad y género}

Las cuestiones de género y de sexualidad aparecen como tema de interés y de conversación recurrente en la población de jóvenes en estudio.

En la escuela suburbana que atiende a un sector pobre de la ciudad, las diferencias entre varones y mujeres en el primer año de la escolaridad secundaria parecían infranqueables. Al lenguaje despectivo -en especial de los varones hacia las mujeres- se sumaban descalificaciones flagrantes al momento de realizar una tarea, proyectar acciones, establecer contactos para desarrollar alguna acción pedagógica conjunta. Las chicas no parecían inmutarse al escuchar los adjetivos con que los chicos aludían a su condición de novias, amantes, enredistas, fabuleras. Ellas, a su vez, les hacían saber en cada ocasión que ellos eran "muy chicos", poco atractivos y zonzos para sus gustos y aspiraciones, cuestión que molestaba sensiblemente a los varones. Flirteaban explícitamente con los coordinadores de la Facultad y de la Mutual que dirigían el proyecto de trabajo ${ }^{119}$ que se registraba.

Las chicas, cuyas edades oscilaban entre 12 y 15 años en el primer año de la ESB, manifestaban inquietudes por obtener mayor conocimiento respecto de las relaciones sexuales pues no deseaban "atarse" a nada por tener un hijo, querían "disfrutar de la vida" pero no sabían a quién recurrir por información", porque les daba vergüenza hablar con sus madres, y menos aún lo harían con alguno de los profesores.

Aun cuando las diferencias de género y la sexualidad constituyen un ámbito específico del diseño curricular de la materia Construcción de Ciudadanía y es el centro del Programa

\footnotetext{
${ }^{119}$ Estos registros se obtienen en ocasión en que también se encontraban allí estudiantes avanzados de la Facultad de Ciencias Sociales (UNICEN) que realizaban un trabajo conjunto con la Mutual de Arte Popular Macondo Creativa destinado a estudiantes de ESB de la escuela suburbana.
} 
Nacional de Educación Sexual Integral ${ }^{120}$, en algunas escuelas no fue abordado específicamente por los adultos ${ }^{121}$.

El estilo comunicacional distante y formal de las clases -ceñido al contenido disciplinar en algunos casos o como medio de conversación sobre cualquier tema en otros-, no permite generar un vínculo sostenido en la confianza y el respeto, condición necesaria para sostener procesos educativos respecto de un tema tabú en nuestra sociedad. Aún en los recreos, el lenguaje utilizado por los docentes era distante $y$, en general, se establecía una comunicación para ejercer algún tipo de reproche o reprimenda. Las relaciones podrían definirse como de permanente enfrentamiento, agresión y permanente situación de violencia (material y simbólica).

Este formato de relaciones no se modificaba -aún con coordinadores y coordinadoras externos a la escuela- si estaba presente algún adulto representante del mundo escolar. En este clima vincular y social, no parece posible entablar diálogos educativos (de enseñanza disciplinar o de enseñanza social) ${ }^{122}$.

Entonces las chicas buscaron otros espacios para obtener lo que necesitaban: buscaban a las coordinadoras de los talleres de la Facultad de Ciencias Sociales y Macondo, para hablar, en distintos encuentros, sobre cuestiones de violencia de género, de métodos anticonceptivos, de relaciones de pareja.

\footnotetext{
${ }^{120}$ El Programa Nacional de Educación Sexual Integral (Ley nacional No 26.150), ha sido acompañado por contenidos para ser incorporados al diseño curricular por el Consejo Federal de Educación, en el año 2008.

${ }^{121}$ Al preguntar sobre esta omisión, la respuesta obtenida en las escuelas públicas suburbana y centenaria, fue que "es tema de la profesora de Biología".

${ }^{122}$ En el año 2006 se sanciona la Ley Nacional № 26.150 "Programa Nacional de Educación Sexual Integral" donde se establece que "todos los educandos tienen derecho a recibir educación sexual integral en los establecimientos públicos, de gestión estatal y privada de las jurisdicciones nacional, provincial, de la Ciudad Autónoma de Buenos Aires, y Municipal". La Organización Mundial de la Salud señala que: "Ia sexualidad es un aspecto central del ser humano presente a lo largo de su vida. Abarca al sexo, las identidades y los papeles de género, la orientación sexual, el erotismo, el placer, la intimidad, y la reproducción. Se vivencia y se expresa a través de pensamientos, fantasías, deseos, creencias, actitudes, valores, conductas, prácticas, papeles y relaciones interpersonales. La sexualidad puede incluir todas estas dimensiones, no obstante, no todas ellas se vivencian o se expresan siempre. La sexualidad está influida por la interacción de factores biológicos, psicológicos, sociales, económicos, políticos culturales, éticos, legales, históricos, religiosos y espirituales."
} 
Los varones recurrentemente hacían alusión a la condición de "trolos" como referencia descalificativa por la elección sexual, hacia otros muchachos. Indagados sobre esta cuestión, dos o tres manifestaron "hay que matarlos", pero no fue posible penetrar en ese discurso dominante entre ellos. Esa reacción homofóbica parece estar asentada en sus relaciones sociales extraescolares, por las pocas expresiones emitidas como respuesta a los interrogantes de la investigadora.

Consultados docentes y autoridades escolares sobre el tratamiento de cuestiones de sexualidad y género en las aulas, argumentan que no es posible "con estos chicos"123 desarrollar estos temas. Además -agrega la asistente social- "...ellos están de vuelta a todo, no hay nada que no sepan. Son rapidísimos, nos dan vuelta". Este diálogo nos muestra que este sujeto, adulto responsable de la educación de los jóvenes, no ha advertido la distancia y la diferencia entre la práctica, los saberes y el conocimiento, Con su argumentación descalifica la función educadora de la escuela.

Sin embargo, las prescripciones curriculares vigentes $y$, en particular las correspondientes al Diseño Curricular para la ES Construcción de Ciudadanía (2007), al considerar a los jóvenes como sujetos en contextos socioculturales específicos, plantea como tema la relación “ciudadanía-sujeto-contexto" (p. 38) y a partir de allí define como uno de los ámbitos ${ }^{124}$ de construcción de ciudadanía, la sexualidad y el género. En la escuela, el equipo técnico actúa sobre la base de prejuicios construidos respecto de los jóvenes -posiblemente de los jóvenes de este sector social en particular- pero no han intentado sostener un diálogo que les permita conocerlos, comprenderlos e iniciar alguna estrategia educativa ${ }^{125}$. Como expresa

\footnotetext{
${ }^{123}$ Acerca de la expresión "con estos chicos", se interrogó a la docente respecto de si ella consideraba que con "otros chicos sí". Luego de responder afirmativamente, brindó numerosos ejemplos de lo que es posible hacer en otras escuelas con otros alumnos, entre ellas, a la que concurren sus propios hijos.

124 "Se denomina ámbitos a los espacios sociales posibles de definir según intereses/temas/problemas del contexto sociocultural, sobre los cuales hay luchas sociales para el establecimiento de derechos obligaciones y responsabilidades de los sujetos, y donde se establecen y negocian sus posiciones diferenciales. Dicho en otros términos, son espacios sociales de construcción de ciudadanía que se recortan para su abordaje en el contexto del aula." (DGCyE. 2007,p. 40)

${ }^{125}$ Tal es la distancia y el estilo burocratizado que ha adquirido la función de este equipo técnico en la escuela mencionada, que no asisten a la casa de los jóvenes -cuando las situaciones lo requieren- porque les incomoda hacerlo, y los citan por teléfono completando en las actas "no asiste" y concluyendo: "falta de interés por la escolaridad".
} 
Morgade (2006) se observa un “...desajuste entre las subjetividades supuestas y las reales, mensajes y metamensajes contradictorios sobre lo que se espera de ellos y de ellas y lo que realmente se les ofrece, y muchos otros etcs"

En las expresiones de los adultos se revelan representaciones prejuiciosas y que consideran que la cuestión de la sexualidad involucra especialmente a las mujeres. En sus diálogos explican las estrategias de las chicas para evitar un embarazo o para quedar embarazadas, y "de este modo, pasar a cobrar la Asignación Universal por Hijo ${ }^{126 ", ~ e x c l u y e n d o ~ a ~ l o s ~ j o ́ v e n e s ~}$ de este asunto. Construcciones subjetivas que expresan un arraigado machismo en temas de sexualidad, impregnan los contenidos de las prácticas pedagógicas no explicitas.

Sin embargo, permanecer cautivos del discurso hegemónico sobre la sexualidad y el género, impide a muchos adultos que se desempeñan en el sistema educativo comprender que algunos jóvenes están construyendo otras lógicas, ancladas en una subjetividad que se entreteje en una referencialidad barrial y sociocultural específica. El caso de Bárbara, es elocuente en este aspecto: ella es alumna de 3er año de esta escuela, y abandona el grupo escolar porque cursa un embarazo adelantado, que elige-dice-. Su nueva situación la coloca en un lugar de privilegio en el barrio "con una embarazada no se mete nadie. Una vez que sos madre, no te joden más" -relata con seguridad ${ }^{127}$. Su hija/o será un pasaporte a otro status social en la trama de las relaciones barriales, en un tiempo inmediato. Tampoco se preocupa por un futuro distante, más lejano, ni proyecta su situación y la de su hijo.

Esta situación es análoga a algunas de las situaciones que describe el antropólogo Philips Bourgeois (2010) en su etnografía del bajofondo de Harlem: del mismo modo que los

\footnotetext{
${ }^{126}$ La página web oficial de ANSES describe: “Esta asignación fue creada por medio del decreto Nro. 1602/09, del Poder Ejecutivo Nacional, y comenzó a regir a partir del 1ro. de noviembre de 2009. (...) Es un beneficio que le corresponde a los hijos de las personas desocupadas, que trabajan en el mercado informal o que ganan menos del salario mínimo, vital y móvil". Consiste en el pago mensual de una retribución equivalente a un salario.

${ }^{127}$ Bárbara no acepta casarse con su pareja (circunstancial pero que le propone hacerlo), situación que lleva a su madre a buscar apoyo en la escuela para convencer a la joven. Ella mantiene su negación a la unión legal, porque quiere que su hijo/a lleve su apellido y porque no quiere que nadie maneje su vida ni su dinero (en relación al subsidio por maternidad y a la posterior AUH). Expresa" Por primera vez voy a tener dos cosas que van a ser solo mías: un hijo y guita"
} 
portorriqueños entran al mundo de la droga porque quieren "ser alguien", porque buscan ser respetados, Bárbara toma su embarazo como escudo y encuentra que la maternidad le permite ganar respeto. "Nadie te jode más", es una afirmación más que elocuente para dar cuenta de la actitud asumida por la joven.

Resulta claro que el discurso de los adultos del sistema y el curriculum oculto tienden a legitimar, como sostiene Morgade, la femineidad y la masculinidad tradicionales -en ésta y en otras escuelas donde se realiza la indagación- evitando con sus prácticas ritualizadas, amparadas en prejuicios sobre los jóvenes pobres y sedimentadas en la cultura escolar, la construcción de subjetividades juveniles que vivan libremente su sexualidad.

La imposición tácita de pre-juicios y estereotipos sobre la sexualidad de los jóvenes y las cuestiones de género, operan en contrario a las intenciones del diseño curricular y condicionan las relaciones sociales orientadas al bien común, a la justicia y al derecho, y refuerzan las prácticas existentes de discriminación.

En la escuela privada parroquial las cuestiones vinculadas a la sexualidad se abordan formalmente en las materias del campo de la biología. Amparados en la autonomía que la ley les otorga -según palabras de la directora- las escuelas privadas católicas adoptan sus propios criterios y producen materiales específicos para la formación integral de las personas y la orientación de la sexualidad en el marco de un proyecto de familia. Durante la permanencia en la escuela, no se registró ninguna actividad específica orientada a este fin. Igualmente, parece endeble el argumento que indica que la sexualidad es considera en el marco de un proyecto de familia, si solo se aborda su dimensión biológica.

En las conversaciones informales con los jóvenes y en las sesiones de focus group, colocaron rápidamente el tema de la identidad de género. Los rasgos predominantes, a través de sus expresiones, son de intolerancia a la diferencia y a rotular las cuestiones de homosexualidad como "desviación" o enfermedad. La homosexualidad femenina no fue puesta en discusión por ellos. En tercer año, un joven expresó su condición gay en un pequeño grupo y ante la presencia de la investigadora, pero no estaba dispuesto a hacer pública su condición. La opinión discriminatoria de la mayoría parece inhibir las expresiones auténticas de las 
elecciones de género. Los grupos de mujeres con que se vinculaba y desarrollaba sus actividades escolares este joven, lo trataba con naturalidad, incorporándolo como a una más del grupo.

En la escuela centenaria, el tratamiento de las cuestiones de género tuvieron una referencia especial en tanto el trabajo con la técnica de focus group se realizó el día 14 de julio, cuando se cumplía un año de la sanción de Ley de Matrimonio Igualitario ${ }^{128}$.

Puesta en común la información sobre el aniversario de la Ley mencionada, las jóvenes fueron las más reticentes a aceptar las implicancias y el reconocimiento de derecho a las minorías gays. Sus comentarios fueron:

\footnotetext{
-A mí me parece bien, pero no estoy a favor de que puedan adoptar un hijo. Por más de que lo habilite la ley, no estoy de acuerdo (Agustina)

-Esta ley tiene sus virtudes y sus defectos. Ellos, si se quieren casar que se casen, está todo bien. Le puede pasar a cualquiera, que hagan su vida. Los van a cargar muchísimo... (Manuela)

-discriminación!! (acusan varios)

-yo no estoy de acuerdo con el casamiento (Antonella). Porque cuando se creó el mundo se creó sobre la base de hombre y mujer

-ahí entra el tema del respeto. Porque cada uno elige cómo hacer (Tomás)

- También es por el qué dirán...qué dirán si mis papás son los dos hombres!! (Agustina)

-si te dicen algo, te entra por acá y te sale por acá (Tomás)

- hoy vivimos mucho del qué dirán (Agustina)

-a nosotros nos importa más el qué dirán que lo que queremos hacer (Manuela)

-Yo no estoy de acuerdo, pero si hay dos personas que sienten eso todos tenemos que aceptarlos, para eso está la democracia (Antonella)

-pero no estoy de acuerdo con la adopción, porque sería un mal ejemplo para el chico (Manuela)
}

\footnotetext{
${ }^{128}$ El 14 de julio de 2010 se modificó el código civil y se sancionó en Argentina la Ley 26.618 y decreto 1054 , denominado "Ley de Matrimonio Igualitario"
} 
Nuevamente se pone en juego, además de las actitudes discriminatorias y acusatorias, la percepción de la elección de identidad de género como una enfermedad y algo que les pasa "a ellos": los otros, los que son distintos. Puede percibirse en los enunciados de los jóvenes, una escasa o nula comprensión de la aceptación y reconocimiento de la diferencia como una condición de la vida en sociedad.

Los aspectos anteriormente señalados están atravesados también por el pudor juvenil, la mirada en espejo "con el que dirán" social, propio de las identidades de una ciudad intermedia (Gravano, 2005) que se construye y se sostiene -en variadas situaciones- sobre la base de prejuicios tradicionales.

La influencia de los líderes populares musicales parece contribuir al rescate de algún atisbo de aceptación de la diferencia: "Pero mirá Ricky Martin!!” Y comienzan a analizar que quizá no sea una enfermedad, en torno de lo cual se produce un ruidoso debate. Alguien -una chica- concluye: "Hay que poder respetar la decisión de los demás"

Uno de los jóvenes de 2으 año ESB, Tomás, quien se presenta a sí mismo como un chico problema, es quien plantea las cuestiones que el grupo no quiere escuchar. El curso está compuesto por 32 estudiantes, con segmentaciones grupales manifiestas, pero con disposición a intercambiar la conformación de los grupos si se los piden, aunque esto no significa que estén igualmente dispuestos a escucharse entre sí, considerar la opinión del otro, o emprender algún proyecto colectivo.

Tomás plantea: "Me parece que no están siendo del todo sinceros. Todos discriminan y todos se preocupan por lo que dirán los demás. Por ejemplo: quién tendría una novia o novio que no sea flaca, se vista bien, eh??"

Sus compañeros le gritan palabras insultantes, en tonos irónicos, y él me dice: "A mí no me importa lo que me digan ellos, sé quiénes son, tienen mi edad. El problema es cuando te lo dicen los profesores!"

Este grupo marcó con claridad y firmeza los límites de las relaciones con los adultos. Señalaron la existencia paralela de la vida que tiene sentido para ellos y la que les impone la escuela. Identifican momentos en que ambos mundos entran en contacto, situación que 
tratan de evitar porque esas intersecciones no resultan beneficiosas para ellos: los adultos no les resultan confiables.

La escuela dependiente de la universidad y la escuela rural, comparten el 10 de diciembre, una jornada de información, debate y reflexión en torno de la temática de lograr una sexualidad responsable en el marco de los derechos de los jóvenes.

La Jornada, declarada de interés institucional, se desarrolló durante el turno de la tarde ${ }^{129}$ en las instalaciones del campus universitario. Los estudiantes integrantes del CE y los delegados de cada curso organizaron talleres de debates entre los jóvenes, eligiendo a algunos docentes, médicos de la ciudad, representantes de la Comisión Local de DDHH e integrantes del CHE SIDA ${ }^{130}$ como expositores de temas complejos y coordinadores de los debates.

Los organizadores manifestaron en la entrevista realizada, que eligieron dispositivos variados porque es necesario

"que todos los jóvenes cuenten con información, en variedad de formatos: por eso hubo diversas manifestaciones artísticas y culturales para colocar en el centro el conocimiento y generar el debate".

Los jóvenes de la escuela rural viajaron $80 \mathrm{~km}$ para estar presentes ${ }^{131}$. Para ellos fue un evento cultural, recreativo y educativo de relevancia porque en la escuela rural nunca se habla de "eso" y rara vez pueden hablarlo con sus familias.

Pocos días después se desarrolló la técnica del focus group en la escuela rural. Una joven lamenta que la sexualidad sea un tema tabú, porque

"muchas chicas se quedan embarazadas y se casan muy jóvenes, quedando "atadas" a vivir en el campo criando chicos y limpiando, con un marido al que no quieren pero del que dependen económicamente".

\footnotetext{
${ }^{129}$ Esta escuela es de doble jornada

${ }^{130}$ Agrupación que nuclea a personas que viven con el virus HIV, que funciona en la Facultad de Ciencias Sociales de la UNICEN

${ }^{131}$ Viajaron 8 estudiantes (todos los que cursan la ESB), acompañados por 2 madres que manejaban los vehículos particulares que los transportaron. Las madres trajeron a sus hijos más pequeños, y todos asistieron a distintos talleres.
} 
Aquí se expresa una lógica diferente a la sostenida por Bárbara, la estudiante de la escuela suburbana, lo que daría cuenta de diferentes perspectivas de las jóvenes frente a un mismo tema, que aborda desde otro lugar las implicancias que para una mujer joven tiene el embarazo.

Analizan grupalmente los riesgos para la salud que conllevan la práctica desinformada de la sexualidad, y analizan la situación de una joven-niña de 13 años que realizó un aborto clandestino y salvó su vida "de milagro"-dicen- "aún con el acompañamiento de sus padres, que tampoco tenían suficiente información sobre el tema".

Los docentes, consultados ante la ausencia de tratamiento del tema en el contexto de las materias curriculares, explican que no lo han hecho antes y que no se sienten preparados para hablar "de estos temas" con los estudiantes. Solo una docente lo hace, la misma que los acompaña a la Jornada del 1 o de diciembre.

Varios asuntos quedan implicados en las expresiones de los docentes que se autoexcluyen del tratamiento del tema: la escasa formación -¿e implicación?- personal y profesional para abordar temáticas que trascienden la disciplina, la relativa ausencia de capacitación para los docentes en cuestiones de género y sexualidad, las dificultades para articular con la comunidad de padres y hacer de éste un tema de interés colectivo, entre otras opciones.

La mayoría de los jóvenes, mientras tanto, siguen resolviendo sus inquietudes y situaciones problemáticas acudiendo a la escasa información confiable que reciben a través de la escuela y los medios de comunicación y en la transmisión "boca a boca” entre amigos.

\subsubsection{Organizar la vida en común, pero entre iguales}

En la escuela de gestión privada la convivencia es armónica, según la voz de los jóvenes. Dicen sentirse cómodos con los adultos: en general los llaman por sus nombres, reconocen a los hermanos, organizan actividades conjuntas (familia- escuela) tales como viajes, fiestas, competencias artísticas o deportivas; manifiestan sentirse protegidos y estimulados.

Se observa a los jóvenes circular por todos los espacios; pueden quedarse en el salón de clases si lo desean, entrar y salir de la dirección, usar los artefactos electrónicos cuando los 
necesitan. Tiene proyectos de visitar lugares de su interés en la ciudad y en otras ciudades, participan de acciones solidarias (donativos), se sienten orgullosos de su colegio, como de su estigma de "chetos ${ }^{132 " .}$

\section{Expresan:}

"en esta escuela te sentís seguro. Acá nunca se roba, ni te pegan. Podes dejar las cosas olvidadas en el baño y sabes que lo vas a buscar a la oficina de Teresa (la directora), porque alguien lo llevó para allá".

La referencia a la seguridad, la distancia cada vez más marcada con el resto de las escuelas de la ciudad, no es motivo de interrogación para estos jóvenes, ni se problematiza con sentido crítico la desigualdad social.

Como señalan Tiramonti y Ziegler (2008) en un estudio reciente sobre la educación de las élites, los chicos de esta escuela se sienten cuidados y contenidos y la convivencia con los adultos de la escuela reafirma su condición de clase y su posición dominante. De acuerdo con los datos que pudieron construirse durante el proceso de indagación, el sentimiento de pertenencia a un sector social privilegiado ${ }^{133}$ y el refuerzo positivo que sobre este aspecto realiza la escuela, se construye desde la inscripción al Jardín de Infantes y se continúa en los niveles de primaria y secundaria. Es habitual que los padres hayan asistido a esta escuela y que sean practicantes católicos, aunque esto no es un requisito para el ingreso escolar. En los últimos diez años la matrícula de la escuela experimentó -de acuerdo a los datos ofrecidos por personal de gestión- una evolución hacia los sectores económicamente más acomodados ${ }^{134} y$, simultáneamente, ha crecido el prestigio de escuela como una institución acogedora y de buen nivel académico. Al interior del colegio reina un clima de cohesión y armonía.

\footnotetext{
${ }^{132}$ Nota de la autora: para este grupo, ser cheto tiene que ver con tener dinero, posición social, compartir con un pequeño grupo un vocabulario, gustos, proyectos.

133 La idea de "sector social privilegiado" se utiliza en esta oración en el sentido de incluido en el sector productivo del modelo económico, acompañado a la vez de contención y cuidado en el ámbito familiar, situación que se continúa en el ámbito escolar.

${ }^{134}$ Tiramonti y Ziegler denominan de este modo a los sectores sociales de altos ingresos, con estudios alcanzados hasta el nivel terciario y/o universitario, que se desempeñan laboralmente en el ámbito privado (2008, p.83)
} 
Aunque se relevaron situaciones de discriminación hacia la diferencia de género, hacia los otros percibidos como "negros ${ }^{135 "}$, estos temas no problematizados con intención formativa aunque los profesores con los que se compartió durante el trabajo de campo, dan muestras de conocer las expresiones de los jóvenes.

Uno de los estudiantes de segundo año, es denominado por el curso como un "negro" que a la vez es "cheto". ¿Cómo explican esto? -pregunté-

"Porque es un negro en sus gustos, escucha cumbia y se viste re-mal -explica Agustina- pero tiene plata y viene a esta escuela, y es como uno más de nosotros". "Y no sabe el auto que tiene!!" -agrega Sebastián.

Los jóvenes ponen en relieve la diferencia cultural, los gustos como criterio de distinción (Bourdieu, 1988) pero esta diferencia parece ser subsanada con la condición económica que el joven ostenta.

Una situación equivalente -pero inversa- se observa en un ingresante de primer año, hijo de un pequeño comerciante del barrio, que encuentra dificultades para relacionarse con los estudiantes del curso que han sido compañeros entre sí desde la escuela primaria o el Jardín de Infantes. El joven no se integra ni es integrado, y un grupo de chicas, que registran que yo lo observo y pretendo hablar con él, se acercan en el recreo y me informan que "tiene problemas de adaptación y que no creen que se quede mucho tiempo en esta escuela".

Los dos casos presentados nos permiten inferir que la convivencia entre los jóvenes de esta escuela parece ser construida entre iguales y que la escuela, como espacio público de encuentro, no integra a jóvenes provenientes de distintos sectores sociales.

Ha sido tomado este caso como ejemplo significativo de las dificultades que encuentran las instituciones para generar situaciones de inclusión social a partir de una convivencia responsable, en la que los sujetos depongan sus deseos personales ante el bien común.

\footnotetext{
135 Para este grupo, los "negros" son los diferentes, los que no comparten sus gustos; son pobres y peligrosos
} 
La diversidad de públicos en interacción y la variedad de estilos organizacionales escolares, no nos permite pensar en criterios comunes para organizar la vida escolar como convivencia. Se piensa más bien, que solo las configuraciones sociales que hayan comprendido que las posibilidades de construir acuerdos y proyectos comunes que depende de sus propias capacidades organizativas, serán las que -superando las nostalgias de una escuela que ya no existe en su normatividad, institucionalidad y sentido del igualitarismo- lograrán condiciones de organización más exitosas: esto es, que sean capaces de contener y educar.

\subsection{Las implicancias de asumirse como "sujetos de derecho" en la construcción de la convivencia escolar}

Consideramos que en el reconocimiento de sí mismos como sujetos de derecho que realizan los jóvenes están implicados diferentes procesos: uno proceso externo, vinculado a la intencionalidad de las políticas y los agentes escolares, y el interno, propio, subjetivo, que deben realizar los sujetos, en este caso, los jóvenes.

En estos tiempos, la cuestión de reconocimiento de los jóvenes en su condición de sujetos de derecho no se encuentra solo el discurso dominante de la nueva LEN sino que fluye por distintos canales en la sociedad en general, lo cual tiene repercusión en la escuela. Ello habilita una formación discursiva que ha permeado la subjetividad juvenil, en ocasiones inclinándola a favor del individualismo y los logros personales. La tarea de la escuela, entonces, sería reorientar esa potencialidad de los tiempos actuales hacia la construcción de sentidos de cooperación social y de respeto por las normas sociales, en un difícil equilibrio entre la libertad y el orden.

El punto es que, de tan compleja que se presenta la tarea, los resultados suelen ser exiguos. Como expresa Cullen (2004: 58-59):

“...se fue configurando un discurso que suele llamarse liberalismo educativo. Algunas de sus marcas más notables son: -la igualdad de oportunidades educativas (...);-el efecto homogeneizador de la educación (...);-el progreso de la mismísima humanidad por la educación; -el derecho humano e inalienable a la educación. 
Tanto se repite este discurso y desde tantos lugares tan disímiles, que ya nadie deja de pronunciarlo, porque ya nadie cree en su realidad"

Nos proponemos relevar, en este punto, qué aspectos de la dinámica escolar son resignificados por los jóvenes en relación a su construcción como sujetos de derecho.

\subsubsection{El valor de la enseñanza de los derechos y de la historia de la comunidad}

En la escuela rural, la comunidad ${ }^{136}$ da muestras de haberse enterado hace ya mucho tiempo que debe gestionar no solo las estrategias de organización de la vida en común, sino también otras condiciones fundamentales de existencia: la escuela primaria funcionó inicialmente sobre un vagón de ferrocarril acondicionado por los vecinos. El trabajo de la maestra era pagado por las familias y los estudiantes asistían a fin de año a una escuela pública de la ciudad vecina de La Madrid a rendir exámenes para cada materia curricular y, así, les acreditaban los saberes obligatorios. En el año 1960, la escuela fue reconocida por la provincia de Buenos Aires, con lo que se asignan maestras "oficiales", nombre y número. Como seguían funcionando en el vagón, la comunidad emprendió la construcción, durante los fines de semana, del edificio escolar, con dinero proveniente de los pobladores de la zona en un terreno cedido para tal fin ${ }^{137}$.

La distancia con el centro administrativo del partido y la decisión de los vecinos por tener una escuela, impregnaron las características de la impronta fundacional. La acción de la comunidad en la gestión de la vida cotidiana escolar, seguirá presente por mucho tiempo, aún en las prácticas que se relevaron.

Los jóvenes estudiantes de la ESB participan activamente de las decisiones que construyen diariamente la dinámica escolar, participando de las reuniones ocasionales de las madres o de las reuniones formales de las cooperadoras escolares (de primaria y de secundaria). Esta

\footnotetext{
${ }^{136}$ Para este caso, es posible hablar de comunidad educativa: la escuela es el centro de gran parte de las actividades educativas, sociales y culturales de esta zona rural. En torno de la existencia de la escuela los vecinos tienen la posibilidad de socializar, debatir, proyectar y conocer, puesto que se organizan distintas actividades, cursos con INTA, talleres para madres (tejido, jardinería, computación).

${ }^{137}$ Esta referencia se obtiene de la revista que en las horas de Lengua y Construcción de Ciudadanía, los estudiantes de ESB producen, con motivo del cincuentenario de la escuela, y que fue motivo de una gran fiesta.
} 
dinámica de participación -explican en la entrevista colectiva- viene funcionando desde la primaria, porque ellos participan de las reuniones de la cooperadora o las reuniones informales para organizar viajes, fiestas, y trabajan activamente en su concreción. Puede decirse, que hay una experiencia colectiva de participación.

El conocimiento (disciplinar) ha sido una herramienta fundamental para cualificar su modo de participación de las reuniones. Así lo expresan ${ }^{138}$ :

Braian-cuando empezamos a trabajar con los derechos y nos dimos cuenta de que siempre los habíamos tenido pero no sabíamos, quisimos ir a contárselo a los chiquitos

Johana: porque a nosotros nos habían explicado los derechos, pero no los entendíamos bien, no lo entendíamos bien, no los entendíamos, no les dábamos importancia. Era una cosa más. En cambio cuando entrás acá [a la secundaria] y tenés la materia... [en referencia a la materia Construcción de Ciudadanía]. Nosotros creíamos que era estudiarse toda la constitución, como si fuera otra materia más. Pero cuando entramos acá y vimos la materia Construcción de Ciudadanía y vimos que era otra cosa, -Braian: nos dimos cuenta de que todos los tenemos pero no todas las personas los pueden disfrutar Johana: ...no sé si disfrutar, sino aprovechar, porque hay gente que no sabe ni leer ni escribir. Entonces cómo va a usar los derechos que tiene, si no sabe (remarca la palabra)

Braian: Antes no participábamos, y los viajes los vamos a hacer nosotros. Entonces empezamos a participar

Entrevistadora: Y los dejan opinar?

Johana: Si, si

Mayra: Eso fue más apoyo de Gabriela. Porque ella nos decía: ustedes tienen que participar, tienen que opinar como hacen los demás

Entrevistadora: Y los dejan?

Mayra: sí, pero les cuesta.

Johana: para los grandes también fue difícil

Braian: y también la familia te cambia, porque antes estabas en la mesa y no participabas porque estaban hablando los grandes, y a veces ni te interesaba o pensabas yo no me meto porque no sé. $Y$ ahora es distinto: primero escuchás y después opinás, porque te das cuenta que vos también sabés.

$\mathrm{J}$ : para ellos también fue difícil

Braian: porque vieron que sus hijos crecen

La cuestión de comprender que trabajar con los derechos "era otra cosa" se vincula directamente al modo en que el contenido educativo (curricular, en este caso) es introducido al grupo y luego reelaborado. La comunicación y el vínculo con la docente Gabriela es el medio, colabora a formar la trama que favorece este tipo de aprendizajes que impacta en el corazón de la formación política. Estos jóvenes "se dieron cuenta" -porque

\footnotetext{
${ }^{138}$ Extracto de la entrevista grupal realizada en la escuela rural.
} 
antes no lo sabían- que son sujetos de derecho y como tal, comenzaron a accionar en distintos escenarios de su vida. La vida cotidiana de la escuela cambió con la participación de ocho jóvenes ${ }^{139}$ que saben que pueden disputar a los adultos criterios por el orden escolar.

El reconocimiento del poder del conocimiento para construir opiniones fundadas que permitan comprender la trama de la vida cotidiana, fue nuevamente relevado en una jornada con jóvenes de diferentes escuelas de la ciudad, en el encuentro "La práctica local y el seguimiento de las leyes", organizada por el "Observatorio Social Legislativo" de la Pro secretaría de Desarrollo Institucional de la Cámara de Diputados de la provincia de Buenos Aires $^{140}$.

Durante el desarrollo de la jornada mencionada los estudiantes de la escuela secundaria dependiente de la universidad motivaron, con su intervención en los talleres, debates conceptuales políticos de fondo, al plantear a los especialistas coordinadores, que no se estaba poniendo en debate, la contradicción -evidente para el joven de 16 años - entre la "igualdad de oportunidades" que enuncian las leyes, con la desigualdad de posiciones de los sujetos que la fragmentación social hace explícita ${ }^{141}$.

${ }^{139}$ El día de la entrevista colectiva estaban presentes solo tres. De los restantes, al menos tres manifestaron en las entrevistas que en otros ámbitos -en especial en la familia nuclear- no se animan a ejercer plenamente su derecho -en especial a sostener posiciones diferentes-, pero sí lo pueden hacer con grupos de pares "y no dejarte llevar por el que habla más, como era antes".

${ }^{140}$ Se realizó el 24 de agosto de 2010 en la sede de UNICEN- Olavarría y contó con la participación de jóvenes de gran parte de las escuelas secundarias de la ciudad. De las escuelas que integran la muestra, la escuela rural, la escuela privada y la escuela suburbana no participaron.

${ }^{141}$ Luego de su intervención ante un auditorio compuesto por aproximadamente 30 estudiantes de nivel secundario de la ciudad y de la zona, docentes acompañantes y funcionarios y empleados de la Cámara de Diputados, un coordinador le pide que explique cómo construye esos saberes y si puede ejemplificar, para que sus palabras sean entendidas por todos. El joven relata que en las materias "Política y Estado" y "Salud y Sociedad" de tercer año (ESB) debaten e investigan los temas que tienen que ver con los Derechos de los niños y jóvenes. Pero también analizan "Ios tema de sociología y política que se están discutiendo en el mundo, y este es uno de ellos: porque cuando se habla de igualdad de oportunidades, el planteo es individual, cada joven debiera lucha por tener la oportunidad de una educación de calidad. Pero si se habla de igualdad de posiciones, la responsabilidad social y política es del Estado, de garantizar trabajo, salud y educación, para que haya un piso común de posiciones desde donde pensar la educación". Cuando termina de hablar, los demás jóvenes lo aplauden, le gritan "te votamos". Y fue elegido, al cierre del taller, para leer en el plenario las conclusiones a las que se arribó en esta Jornada de trabajo. 
Otros jóvenes, mientras tanto, estaban de pic-nic en el aula, comiendo y bebiendo las viandas que los organizadores habían distribuido abundantemente. Si bien no todos los jóvenes se involucraron en el Taller -tampoco los docentes acompañantes-, la participación de quienes se conmovieron con los temas en tratamiento fue intensa. Cada grupo escolar presentaba realidades diversas que eran atendidas con atención por los demás jóvenes, que interrogaban con verdadero interés por conocer los distintos vericuetos que presenta el desarrollo gradual de la obligatoriedad de la escuela secundaria.

En la escuela secundaria universitaria la dinámica escolar parece organizada en torno de la convivencia democrática. La convivencia se organiza sobre la base de la confianza mutua entre los distintos actores. La tarea mediadora de los preceptores en los conflictos facilita la comunicación y la reflexión. Todos los alumnos provienen de otras escuelas y, en general, en los primeros años conservan los grupos de referencia de la escuela de procedencia. Algunas dinámicas de clases reorganizan -deliberadamente- los grupos, al igual que los talleres extracurriculares y las actividades socioeducativas que se llevan a cabo en el Centro Cultural "La Ronda".

El conocimiento, como se observa en las referencias a los casos de las dos escuelas mencionadas, posiciona a los jóvenes con una actitud decidida y valerosa en la defensa de sus pensamientos, y este posicionamiento modifica la dinámica de las relaciones de la vida cotidiana, escolar y social e impacta sobre la convivencia.

\subsubsection{Los derechos que se reconocen por fuera de la escuela}

En la escuela suburbana, las relaciones sociales no logran encontrar su equilibrio. La nueva escuela secundaria recoge las buenas y las malas experiencias construidas en la escolaridad primaria, que ha dejado sus huellas de socialización, tanto en los jóvenes como en los docentes.

El equipo de gestión escolar del nivel secundario emprende acciones nuevas, pero la gran afluencia de jóvenes procedentes de otras escuelas primarias y el cambio frecuente de los docentes, no contribuyen a consolidar grupalidades ni estilos de trabajo. 
Respecto de la organización de la convivencia escolar, el equipo de gestión ha decidido pedir ayuda a otras organizaciones. Las "contribuciones" que las organizaciones del entorno realizan a la escuela, deben comprenderse en el marco de las actuales relaciones entre el Estado y la sociedad civil, que en etapa de reposición del Estado están produciendo "una nueva forma de organización política más amplia que el estado: un conjunto híbrido de flujos, organizaciones y redes en las que se combinan y solapan elementos estatales y no estatales (...)" (de Sousa Santos, 2005: 48).

Una de las organizaciones con la que comienza a trabajar la escuela suburbana, es la Mutual Macondo Creativa ${ }^{142}$, reconocida por el Estado como Mutual en el mismo año que comienza a funcionar la escuela secundaria (2008). Los directivos escolares, desbordados por las demandas del sistema y las demandas de los jóvenes y sus familias, recurren a la Mutual en busca de alternativas "para hacer algo con estos chicos"143.

Desde el momento en que se produjeron los primeros encuentros, se establecieron algunos criterios de acción y reflexión sobre los incumplimientos de tales cuerdos. La propuesta de trabajo en Macondo se centró en la realización de actividades artísticas, como un taller de cerámica, que a la vez permitiera trabajar valores en torno de la convivencia social ${ }^{144}$.

Los jóvenes, que en la escuela no tienen prácticas de intercambio pedagógico con los adultos, se mostraron reticentes al diálogo y a la participación. Con el paso de los días, en la Mutual Macondo expresaron su percepción acerca de la comunicación y la participación en

\footnotetext{
${ }^{142}$ En un artículo reciente (Errobidart, 2013) se explica el proceso mediante el cual el Estado otorga a las Mutuales una función social de articulación con las organizaciones estatales. Para impulsar su desarrollo facilita subsidios con fondos provenientes de agencias internacionales que sostienen tal función.

${ }^{143}$ En el primer contacto entre la asistente social de la escuela con los coordinadores de la Mutual Macondo Creativa y los docentes y estudiantes de la Facultad de Ciencias Sociales (mantenido en el mes de abril), la docente ilustró con caricaturescas escenas la relación de los agentes escolares con los jóvenes ingresantes a primer año ESB en el año 2010: jóvenes que corrían por los pasillos y patio para alcanzar el paredón, saltar y huir del espacio escolar, y corriendo detrás de ellos dos o tres adultos con el propósito de atraparlos; situaciones de golpes, insultos, roturas de vidrios, puertas, útiles: una especie de batalla sin sentido. Inspectoras, padres, policías acudían en auxilio de actores "de los dos bandos" mientras el conflicto se acrecentaba.

${ }^{144}$ Para que esto fuera posible, se acordó con los agentes escolares que no estuvieran presentes durante el desarrollo de los talleres. Asistían a la Mutual en las horas de la materia Construcción de Ciudadanía. Cuando se hizo cargo de ella una profesora de Biología, asistía a la Mutual, pero se quedaba tomando mates en la cocina.
} 
las decisiones grupales, asumiendo distintas posturas. Quienes habitualmente no hablaban, manifestaron que no lo hacen para evitar burlas o represalias, "no solo de los chicos, sino de los maestros o la directora". Quienes habitualmente hablan, manifestaron no estar habituados a que los consulten. "Nunca nos preguntan qué queremos hacer. Siempre nos dicen qué hacer, igual no nos escuchan" fueron sus expresiones. Interrogados acerca de quiénes actúan así y dónde, manifestaron que siempre es así en las escuelas (expresaron el plural) y en la casa, a veces, también.

"Es difícil confiar en los grandes -reflexionan tres estudiantes mujeres- porque en general, cuando te encariñas con alguien se va y te deja pagando"; entonces prefieren no hacerlo. La desconfianza es un elemento presente en casi todos los actos compartidos. Si un coordinador faltaba, creían que no venía más; si les corregían alguna pieza producida, también era un disgusto, hasta llegaron a romperla. Algunos de estos jóvenes están construyendo su personalidad sobre una débil autoestima, la confianza en sí mismos está minada por la descalificación de los adultos (para algunos jóvenes, en sus hogares; para la mayoría en las distintas escuelas por las que han transitado). Ser llamados "burros", "miseria humana", "inútiles", no resulta sorprendente para ellos, relataron.

Las acciones de autovaloración subjetiva y las reflexiones acerca de sus potencialidades latentes producidas a partir de las actividades en la Mutual, no introdujeron cambios en el comportamiento ni en el rendimiento escolar. Solo pasaron a calificar con " $A$ " la materia "Construcción de Ciudadanía".

Pero, sin dudas, los jóvenes en su interior realizaron cambios como producto del aprendizaje social que realizaron. Sintieron que su trabajo era valorado, que ellos eran tenidos en cuenta $^{145}$. Hacia el final del año, en una entrevista, pregunto a Emilio -uno de los varones

\footnotetext{
${ }^{145}$ Flor no asistió a Macondo durante dos semanas. Los coordinadores preguntaban por ella a sus compañeros y en la escuela, donde dijeron que estaba enferma. A su regreso a la Mutual fue recibida con alegría pero luego reprendida por no haberse encargado de avisar, para no despertar intranquilidad. "No sabía que era tan importante aquí" -dijo sonriente y emocionada. Los coordinadores hablaron entonces al grupo, proponiéndoles organizar algún tipo de red para mantenerse comunicados entre sí, como una forma de cuidado y protección. Luego conversaron sobre los riesgos de los jóvenes en la calle, en sus casas. Los jóvenes armaron una red de contactos que hasta ese momento no tenían.
} 
más escéptico y vulnerable del grupo- con qué asociaba las prácticas ciudadanas y respondió "con Macondo y la facultad". "Aquí aprendimos -expresó Yamila en un encuentro de evaluación- que somos parte de la sociedad, que los demás tienen que respetarnos y tenernos en cuenta" ${ }^{146}$.

La vida cotidiana vivida de este modo, no se asemeja a la construcción de un sentido proactivo de convivencia, ni de una ciudadanía que se oriente a buscar estrategias para vivir con otros. La vida con los otros-adultos-representantes del sistema escolar, transcurre como sumatoria de confrontaciones e imposiciones. No fueron observadas situaciones en las que la resolución de los conflictos estuviera mediada por la palabra, pues no hubo escucha de argumentos que sostuvieran las posiciones, ni disposición para iniciar diálogos.

Ante el conflicto que se desata con los estudiantes de 5to año que se niegan a entrar a los salones de clases porque no funcionaba el calefactor, se produce el siguiente diálogo entre los estudiantes (ya en segundo año):

Emilio: El año pasado éramos nosotros los quilomberos, este año son los de 5to. Yo los apoyo en todo Jessica: Eso no está bien ¿̇por qué los voy a apoyar, si nuestro calefactor anda y el salón está bien? Además ellos a nosotros no nos ayudaron nunca Emilio: A mí no me importa, si hacen quilombo, me voy con ellos.

Se trata de reflexionar con ellos sobre las dos posiciones: Emilio se une a quien presente resistencias a la autoridad adulta, más allá de la validez del reclamo; Jessica expone una apreciación moral, y a la vez, destaca que a ellos nunca los ayudaron. Pero ninguno de los dos logra recuperar la dinámica comunicativa que se había logrado en la Mutual.

\subsubsection{Tensiones entre el disciplinamiento escolar y el discurso sobre los derechos de los jóvenes}

En la escuela centenaria la convivencia sigue referenciándose en la tradición escolar. La disciplina, el cumplimiento de horarios, vestimenta, aspecto físico, prohibiciones para los

\footnotetext{
${ }^{146}$ Al año siguiente fueron trasladados a otra escuela y dejaron de concurrir a la Mutual. No perdieron el contacto con los estudiantes de CS, que realizaron las prácticas de su carrera con ellos. Pero estas acciones, no dejaron de ser "sogas de auxilio", como expresan Corea y Duschatzky (1999).
} 
estudiantes (como fumar, comer en clase, usar el teléfono celular, correr por los pasillos y en el patio, guardar las formas y el buen trato, no escupir, entre otras), siguen siendo pautas de comportamiento y convivencia propios de la historia y la cultura escolar. Pero no son iguales para los docentes, situación que es advertida y señalada por los estudiantes:

-Por ejemplo: viene una profesora que tiene clase con nosotros a las 12 y dice: qué hambre!! Y manda a uno a comprar un sándwich. Pero a nosotros no nos dejan comer ni un chicle!

-Con el uso del celular, las preceptoras y los profesores en general, no cumplen los acuerdos: entra la preceptora y le dice a una profe "Mira las fotos!" Y la mira, o mira y manda mensajes. Pero nosotros no podemos usarlo.

Interrogados acerca de si tienen un espacio para reclamar ante esas situaciones que afectan la vida en común, se establecen dos posturas: los que dicen que sí tienen ese espacio, sostienen que

"vos podés ir y plantear lo que te pasa, o si nunca da clase (como algunos profesores), o si te insultan (como el año pasado que una profesora le dijo "idiota" a un compañero) y el directivo puede bajarle la nota"

Y la otra mitad plantea que no tienen espacio real para efectuar el reclamo:

“¿Quién se atreve a hacerlo -plantean- si sabés que después van a estar en tu contra? Y eso es llevarte la materia".

Otro aspecto que les preocupa es lo que ellos llaman "violencia verbal" de los adultos sobre ellos, situación que, entienden, produce "dolor psicológico":

-...porque si todos los días te están diciendo que sos molesta, que sos loquita, enfermita...vos te aguantas, pero llega un día en que explotás

- mirá yo tengo ira acumulada. Lo traté con mi familia y esto me lo dijo mi psicólogo. Y me la produce la escuela

La situación que plantea Tomás (el joven que expone su caso de ira acumulada) da lugar a que los compañeros opinen sobre la personalidad "difícil" del joven. Entonces Tomás explica:

-yo retomo lo que ella decía antes de la violencia verbal de los adultos. Si otro chico te dice "boludo" o inútil, no te molesta, lo arreglás con él de igual a igual. Pero si te lo dice un adulto comienza a comerte la cabeza porque vos estas en inferioridad de condiciones, no lo podés insultar porque te vas, te echan, y después pasas a tener un problema mayor con tu familia... yo estoy enfermo de aguantarme todo esto! 
El ejercicio de violencia simbólica de quienes detentan el poder (docentes, preceptores, personal auxiliar, directivo) tiene como destinatarios a los jóvenes comprendidos en la franja etaria de secundaria básica. La relación con los estudiantes de secundaria superior, es diferente.

Consultados los estudiantes sobre esta hipótesis, analizan que "los grandes tienen más herramientas para defenderse", "como se conocen más, se tratan distinto".

Los adultos por su parte, expresan que "no están acostumbrados a trabajar con chicos tan chicos y que además, no podés ponerles amonestaciones"; "si no los tenés cortitos hacen lo que quieren"; "yo sigo poniendo amonestaciones porque si no, esto es un libertinaje y en esta escuela, no van a hacer una "escuela murga"'. Otros docentes y preceptores, manifiestan que es necesario encontrar otros modos de vincularse con los más chicos, pero que es parte de la tradición escolar el trato recto, que con los problemas agravados de indisciplina, se ha endurecido.

La situación predominante en la relación de convivencia adultos- jóvenes es de imposición y dominación forzada.

En relación al tipo de ciudadanía que este estilo de convivencia propicia para los jóvenes que despiertan a la vida social con algún grado de reflexividad ${ }^{147}$, se entiende, a partir de los fragmentos expuestos, que ellos visualizan dos planos: la convivencia como un modo de vivir con sus pares y la convivencia como el conjunto de estrategias que construyen para sostener las relaciones necesarias e insustituibles con los adultos.

\subsection{En búsqueda de reglas que organicen la vida en común}

Una preocupación manifestada por un alto número de jóvenes, es la de volver a encontrar un sentido al establecimiento de normas que regulen la vida en común.

${ }^{147}$ Es necesario aclarar que en esta escuela como en otras, un alto número de jóvenes estudiantes de la ESB no han sido interpelados aún por aspectos relativos a la dimensión política de la vida escolar (o en otros ámbitos), o no se han manifestado en los dispositivos metodológicos empleados. 
No es ésta una necesidad que no encuentre referentes en las escuelas de la provincia de Buenos Aires, puesto que desde la década de los 90 y específicamente desde el año 2002 las escuelas han sido interpeladas para trabajar sobre éstas normas ${ }^{148}$.

En el año 2009 la DGCyE de la PBA aprueba la Res. 1709/09 que establece la implementación de los Acuerdos Institucionales de Convivencia en todas las escuelas secundarias de la provincia y destaca que

\begin{abstract}
"el objetivo prioritario de esta resolución es construir vínculos democráticos y respetuosos para encontrar distintas formas de resolver los conflictos en las escuelas. Crear una buena convivencia es un gran desafío e implica comprometerse y pensar, entre jóvenes y adultos, cómo lograr un clima escolar de respeto mutuo, en donde sea posible enseñar y aprender"
\end{abstract}

Sin embargo, las disposiciones oficiales, las recomendaciones y los documentos orientativos para la implementación de la norma parecen haber quedado, en algunos casos, atrapados en la gramática escolar (Tyak y Cuban, citado por Viñao Frago, 2006) del mismo modo que los diversos talleres propuestos por los equipos técnicos del estado provincial fueron despojados de su sentido, quedan los AIC y el CIC convertidos en "cáscaras vacías".

Los jóvenes entrevistados, estudiantes en la escuela centenaria, se sienten preocupados por "el desborde" que sufre la escuela ${ }^{149}$. Florencia (14 años), estudiante de 2o año de ESB reflexiona:

\footnotetext{
${ }^{148}$ Res. 1593/02: Establece los criterios para la implementación del proceso de formulación de Acuerdos Institucionales de Convivencia (AIC) en las escuelas dependientes de la Dirección de Educación, Polimodal y Trayectos Técnico-Profesionales, el cual se realizará de acuerdo con las pautas obrantes en Consideraciones generales sobre Adolescencia y Modelos Normativos, Convivencia escolar en Democracia y Criterios para la elaboración de Acuerdos Institucionales de Convivencia.

${ }^{149}$ En el transcurso del año 2010, entre los meses de abril hasta las vacaciones de invierno, la escuela "sufría permanentes amenazas de bombas" por lo que se debían suspender las clases. Esto derivó en serios enfrentamientos entre las inspectoras del área y los padres, entre padres y el poder ejecutivo municipal, entre padres de los distintos niveles educativos, hasta que en el segundo cuatrimestre, la tensión se disipó y las amenazas cesaron (se guardan registros de medios gráficos que documentan la situación).

En el año 2011, nuevamente la escuela centenaria entra a la escena pública por la reiteración de peleas callejeras entre alumnos/alumnas de la escuela, con intervención de fuerzas policiales, padres, actores del entorno escolar (se adjuntan los registros de medios gráficos que documentan la situación)
} 
“...es muy difícil que 840 alumnos, más los docentes y el resto del personal-cifra que supera las 1000 personas en el turno de la mañana-, encontremos los modos de llevarnos bien. Hace falta reglas, normas que todos respetemos..."

En la escuela suburbana, en cambio, los jóvenes no registran acciones propuestas por la escuela para organizar la convivencia ${ }^{150}$ y tampoco lo demandan ellos. En esta escuela no hay reglas, comenzando por el incumplimiento de la asistencia: lo jóvenes van cuando quieren. En todos los planos (pedagógico, administrativo, alimentario) se observa una relajación de las normas que desborda la responsabilidad inmediata del equipo directivo. Ejemplo de ello es el incumplimiento de las asistencias mínimas de los alumnos, pero también el de los docentes, ya que se pudo observar que algunos de ellos no cumplen con la formalidad de avisar con la debida anticipación su inasistencia -o justificarla luego- y ante la escasez de docentes, las inspectoras han recomendado "dejar pasar la situación".

La vida escolar transcurre como si transitaran planos superpuestos, sin comunicación entre ellos: los adultos con un discurso en un plano, los distintos grupos de jóvenes, por otro, las prescripciones de la política educativa, por otro. El equipo directivo y los docentes, sostienen un discurso oficial sin significación, como formando parte de un juego. Baste de ejemplo, la siguiente situación: como ya se ha dicho, los jóvenes de la ESB habían encontrado que un modo de irritar a los adultos que pasaba por la reiteración de escapadas de la escuela. Entonces la directora, junto con una portera, decidieron sacar los picaportes de las puertas exteriores y de los salones de clases, con lo cual los estudiantes pasaban largo tiempo buscando "herramientas" con las cuales abrir las puertas. Cuando pregunto por esa situación, la directora me dice: “¿Querían inclusión? Ahí tienen! De acá no se me va nadie”.

Sin embargo, la dinámica relacional es diferente entre los adultos de la Mutual de Arte Popular y con los estudiantes de Comunicación Social (CS).

Al iniciar el trabajo, durante los primeros encuentros, el coordinador de la Mutual les planteó los modos posibles de permanecer en el lugar: cuidar el espacio y los objetos de

${ }^{150}$ Existen documentos llamados "Acuerdos Institucionales de Convivencia", pero no son reconocidos por los jóvenes como acciones destinadas a pensar la vida en común. 
trabajo, respetarse unos a otros del mismo modo que todos los coordinadores (estudiantes universitarios y coordinadores de la Mutual) los tratarían a ellos, respetando las consignas de trabajo que le dan sentido al encuentro. Todos se saludarían al entrar y al irse, se llamarían por su nombre de pila, avisarían cuando alguien no puede ir, se harían responsables de tareas, comenzarían a funcionar como un grupo que persigue una meta ${ }^{151}$.

Después de este establecimiento de reglas comenzaron las primeras tareas a cargo de los estudiantes de CS, sobre reconocimiento y valoración de los demás, sobre significar la tarea en conjunto y establecer los intereses en vistas de especificar una meta. Las acciones y los resultados parecían por momentos desalentadores. Trabajaban juntos durante la producción de piezas, pero al momento de las argumentaciones y explicaciones sobre sus productos no lograban escucharse entre sí, se burlaban, boicoteaban a los compañeros y coordinadores. Cada día, se invertía más tiempo en la tarea de reflexionar y rastrear las causas de sus conductas o identificar qué situaciones les generan malestar, en un intento de objetivar con ellos las situaciones sociales irritativas y analizarlas ${ }^{152}$.

En la escuela rural, como en la escuela privada y en la escuela dependiente de la universidad, las normas existen pero en raras oportunidades es necesario llegar a su consulta para resolver la organización de la vida en común. Atendiendo a las diferencias del sentido social y educativo que cada una imprime, tienen en común que son organizaciones pequeñas, donde el encuentro cara a cara se produce cada vez que es necesario. Y que existe entre los actores de la comunidad, una concordancia en la valoración de la acción cultural de la escuela.

\footnotetext{
151 "La meta” se propuso como una construcción colectiva a lo largo de los encuentros iniciales, que sirvieron para establecer los modos de convivencia. La idea que se acordó fue la de producir una revista de jóvenes y para jóvenes, y la primera tarea fue producir historias fotográficas de sus barrios.

${ }^{152}$ Se restablecían los acuerdos y se continuaba. Habitualmente concurrían 12 jóvenes a la mutual, pero solo imponían su voz 4 o 5. Los demás no participaban en las decisiones u opiniones.
} 
El control del cumplimiento de las normas es más eficaz en las escuelas con bajo número de estudiantes y docentes, aunque no es solo el control explícito, favorecido por la cantidad, lo que ordena la vida en común. Quizá lo que favorece la convivencia entre un número reducido de personas, es el establecimiento de acuerdos. Entre los docentes, podríamos decir que existe la misma pluralidad de criterios que entre los jóvenes, y las mismas dificultades para aceptar las normas establecidas cuando no se comparten ${ }^{153}$.

En el caso de la escuela rural, es más llamativo aún su funcionamiento, al que podríamos llamar asambleario o cooperativo, pues no existe en ella equipo directivo que establezca algún criterio de acción organizativa y pedagógica.

Como se explica en el capítulo 3, la escuela depende administrativamente de una escuela secundaria con sede en la ciudad y el equipo directivo no ha concurrido en ninguna situación al establecimiento rural. Las situaciones pedagógico-administrativas cotidianas son consultadas a la preceptora y cuando han existido causas que requieren de autoridad reconocida para resolver o destrabar situaciones de conflicto, se ha recurrido a la directora de la escuela primaria ${ }^{154}$.

La vida cotidiana escolar es compartida también por las madres que concurren a llevar a sus hijos y permanecen esperándolos hasta que finaliza la jornada ${ }^{155}$.

\subsection{Acerca la convivencia posible que se enseña/se aprende en las escuelas}

\footnotetext{
${ }^{153}$ En relación a la pérdida de identidad compartida "del cuerpo docente" de las escuelas modernas, en un artículo se plantea que "los sujetos que transitan las aulas de la formación docente pertenecen en su mayoría al conjunto social fragmentado, individualizado, que vive resolviendo situaciones inmediatas y con escasas posibilidades de proyectarse a un futuro" (Errobidart, 2011, p.84)

${ }^{154}$ La directora de la escuela primaria se desempeña hace 15 años en ese cargo. Reside en la zona rural y es reconocida como autoridad por la comunidad educativa rural. En un caso específico referido al manejo de fondos para un viaje, surgió un conflicto de posiciones y debió intervenir para resolver la situación, quedando las partes en acuerdo, luego de su intervención.

155 Las distancias existentes entre el hogar y la escuela generan esta dinámica social que rodea el desarrollo de la educación escolar. Las familias -en especial las madres- se constituyen en actores relevantes de las decisiones escolares. Un estudio realizado por D. Milstein (2003) da cuenta de ello y ha contribuido a la comprensión de esta situación de co-gestión escolar.
} 
En este capítulo hemos abordado las prácticas de los jóvenes plausibles de ser reconocidas por ellos mismos y por los demás sujetos en interacción en el campo educativo- como constructoras de convivencia y, en base a ellas, hemos relevado los procedimientos a través de los cuales las escuelas pueden fortalecer o reorientar los significados que producen. Las escuelas seleccionadas son, en todos los casos, ámbitos de encuentro, espacio público donde se producen encuentros con otros distintos de sí mismos, ámbitos compartidos donde es posible generar debate político en torno de los temas de interés juvenil.

En todos los escenarios relevados las reglas que organizan la vida en común disponen de los mecanismos formales para que éstas puedan ser reelaboradas y así establecer (en especial, a través de los $\mathrm{AIC}$ ) formas de organización que se constituyan en referentes de la vida cotidiana y también de próximas acciones mediatas e inmediatas, en la escuela, en la calle, en el barrio. Las tensiones entre las culturas escolares y los intereses y expectativas de los jóvenes para compartir el espacio común continúan desencontrados y algunos adultos parecen temer el encuentro, manteniendo la distancia y un cierto control formalizado.

Los jóvenes expresan sus posiciones ante la violencia en el trato, el malestar en la escuela, la discriminación, la preferencia por la convivencia entre sujetos de similares características, la violencia frente a "los enemigos" -por diferentes circunstancias- y algunos profesores, aun conociendo los riesgos de algunas posiciones, prefieren no involucrarse.

En las condiciones analizadas se reconoce como un aspecto relevante de la política social, y educativa en particular, asumir a los jóvenes como sujetos de derecho en acto, aquí y ahora. Sin este aspecto, no sería posible asumir a un constructor de ciudadanía activo. Sin embargo, el curriculum oculto escolar opera, en especial en las escuelas con larga tradición de disciplinamiento moderno, para disolver los gérmenes de dicho reconocimiento. Los jóvenes que han experimentado la condición de sujetos de derecho en otros ámbitos por fuera de la escuela tensionan con la cultura escolar y protagonizan situaciones e incidentes que irrumpen en las escenas cotidianas y que la escuela rápidamente intenta sofocar. Hemos relevado también procesos y prácticas que, mediados por la palabra, el conocimiento y el reconocimiento de la historia y el ejercicio de derechos, posibilitan una convivencia orientada al bien común. 
La convivencia reglada por las normas y usos escolares aunque se proponga asociada con la búsqueda del bien común se advierte, en la mayoría de las prácticas relevadas, en retroceso $y$, desde las escuelas, no parecen generarse acciones que la reconozcan en su complejidad para poder luego, recuperarla como proceso de trabajo.

Pero se hace necesario señalar que los espacios formativos de convivencia inadvertidos por la dinámica escolar pueden ser retomados y fortalecidos por otros espacios por los que transitan los jóvenes. Tales son los casos que se analizaron de los jóvenes de la escuela suburbana con la Mutual de Arte, el proyecto extracurricular "Normal solidario" que impulsan algunos docentes de la escuela centenaria y que poco a poco comienzan a extender a los jóvenes de la ESB. Conectados en algún punto con la existencia de la escuela se abren nuevas oportunidades de encuentro, de intercambio y de reconocimiento que convocan y contienen a los jóvenes. 


\section{Bibliografia:}

ARENDT, H (2008). La condición humana. Paidos, Buenos Aires.

BECK, U. (2002) (comp.). Hijos de la libertad. FCE, Buenos Aires.

BIRULES, F (2007). Introducción. ¿Por qué debe haber alguien y no nadie? En Arendt, H.: ¿Qué es la política? Paidós, Buenos Aires.

BOURDIEU, P y PASSERON, J.C (1977).La reproducción. Elementos para una teoría del sistema de enseñanza. Laia, Barcelona.

BOURDIEU, P. (1988): La distinción. Criterios y bases sociales del gusto. Taurus, Barcelona. BOURGOIS, P (2000). En busca de respeto. Vendiendo crack en Harlem. Siglo XXI, Buenos Aires.

CASTORIADIS, C (2003). Sobre el político de Platón. FCE, Buenos Aires.

COREA y DUSCHAYZKY (1999). Chicos en banda. Programas sociales, políticas públicas y subjetividad. Paidos, Buenos Aires.

CULLEN, C. (2003).La construcción de un espacio público como alterativa a la violencia social en el contexto de la globalización. En Feldfeber, M. (2003). Los sentidos de lo público. Reflexiones desde el campo educativo. Noveduc, Buenos Aires.

(2004). Perfiles ético-políticos de la educación. Paidós, Buenos Aires.

DE SOUSA SANTOS, B (2005). Reinventar la democracia. Reintentar el Estado. CLACSO, Buenos Aires.

DUBET, F. y MARTUCCELLI, D.: (1998). En la escuela. Sociología de la experiencia escolar. Losada, Moreno.

ERROBIDART, A (2011): Acerca de los muros que separan la acción de la pasión, la enseñanza de la educación, la docencia de la vida. En Chapato y Errobidart (comp): Historias, actores e instituciones. Estudios sobre prácticas educativas en tiempos de cambios y turbulencias. Miño y Dávila, Buenos Aires.

-(2013). "Para construir otra mirada del mundo" Sentidos que se construyen, entre el ayer y hoy, en los procesos de educación popular. En Chapato, M. E. y Errobidart, A. (comp.) La educación como práctica sociopolítica. Los sentidos de educar que se construyen desde abajo. Miño y Dávila, Buenos Aires. 
FELDFEBER, M (2003). Los sentidos de lo público. Reflexiones desde el campo educativo. ¿Existe un espacio público no estatal?. NOVEDUC, Buenos Aires.

GIMENO SACRISTAN, J. (1996). La transición a la educación secundaria. Morata, Madrid. GIROUX, H. (2010). La educación y la crisis del valor de lo público. Desafiando la agresión a los docentes, los estudiantes y la educación pública. Criatura editora, Montevideo.

GRAVANO, A (2005) (comp): "Apertura" En: Imaginarios sociales de la ciudad media. Emblemas, fragmentaciones y otredades urbanas. Estudios de Antropología Urbana". Editorial de la Universidad Nacional del Centro de la Provincia de Buenos Aires. Tandil.

MILSTEIN, D (2003). Higiene, autoridad y escuela. Madres, maestras y médicos. Un estudio acerca del deterioro del Estado. Miño y Dávila, Buenos Aires.

MORGADE, G (2006): Sexualidad y prevención: discursos sexistas y heteronormativos en la escuela media. Revista del Instituto de Investigaciones en Ciencias de la Educación. № 24 IICE, Buenos Aires.

TIRAMONTI, G y ZIEGLER, S (2008): La educación de las elites. Aspiraciones, estrategias y oportunidades. Editorial Paidós. Buenos Aires.

VIÑAO FRAGO, A. (2006). Sistemas educativos, culturas escolares y reformas. Ediciones Morata, Madrid. 


\section{Capítulo 5:}

\section{La política y lo político en la participación juvenil en escuela secundaria básica: espacios que se habilitan, prácticas que tensionan las lógicas de la escuela}

\subsection{Introducción.}

¿Cómo y por qué los jóvenes deciden su participación en cuestiones políticas escolarizadas y qué significación adquieren sus prácticas para ellos?

La participación comprometida de los sujetos es un requerimiento de las democracias, tema que en los últimos tiempos ha mostrado una notable presencia en los medios de comunicación de Argentina -como también en otros países- y ha sido objeto de diversos tratamientos desde distintos campos disciplinares.

En este capítulo pretendemos arribar a una comprensión de la participación de los jóvenes en la política. Luego de analizar los diversos modos de hacer y ejercitar la política por parte de los políticos, de manifestarse y expresar posiciones de los sujetos en general y observar las expresiones de los jóvenes a través de sus prácticas políticas, entendemos que la participación política (clásica) ha desbordado los sistemas institucionales y que hoy se ha establecido, en particular desde los jóvenes, como señala Beck "una denegación de la política que es altamente política" (Beck 2000: 16).

Para Bourdieu, "existen condiciones sociales que posibilitan el acceso a este microcosmos [en referencia al campo político], como, por ejemplo, el tiempo libre (...) Además del tiempo libre, hay otro factor que es la educación" (Bourdieu, 2001:12). En Argentina, las prácticas políticas juveniles que de manera explícita se incorporan en el sistema educativo se ubicaron, históricamente, en la escuela secundaria.

El estudio de la vida política en las escuelas secundarias -de acuerdo con una investigación pionera sobre la juventud en Argentina realizada por Cecilia Braslavsky (1986)-, nos permite analizar cómo las prácticas performativas de ciudadanía -aquellas que se definen por su contenido político-, se desarrollan dentro de canales o circuitos formales de acuerdo al 
sistema político oficial, encauzadas dentro de sistemas institucionalizados como los partidos políticos, los centros de estudiantes, los sindicatos y los gremios.

El contenido de las prácticas ha sido objeto de cambios según el sentido que los distintos gobiernos han querido imprimir en las generaciones jóvenes, puesto que, como se ha dicho, desde el momento de su constitución el Estado Nacional ha delegado en la escuela la formación política de los ciudadanos.

La ciudadanía -en sus tres dimensiones clásicas- ha sido definida como una condición externa al sujeto, condición que es otorgada por un Estado que regula, incluye y excluye a los sujetos, según una serie de parámetros que rigen la vida social. Entre esos parámetros, la mayoría de edad se constituye en el principal criterio de reconocimiento de esta condición, límite de la moratoria social impuesta a niños y jóvenes.

El ciudadano clásico por excelencia resulta ser el sujeto definido por su relación con la ley. La ley y la historia -que construye el pasado común, de acuerdo con Lewkowicz (2004)- son quienes posibilitan la construcción del lazo social. Este modo de funcionamiento no ha significado, a lo largo de los años de hegemonía de un modelo clásico de democracia y política, un proceso que involucre reflexivamente a los sujetos. La práctica ciudadana no ha despertado por sí sola, una reacción participativa, con propulsión a la fraternidad y la solidaridad, principios sostenidos durante y a partir de la revolución francesa. Puede argumentarse, que estos principios resultan poco compatibles con el individualismo y la competitividad capitalistas, resultando más eficaces los términos asimilados a su uso, de igualdad (formal) y libertad. La dimensión política de las prácticas ciudadanas en la escuela, se encauzó dentro de tales términos.

La formación ciudadana ha estado, desde los inicios del sistema educativo, al servicio de la continuidad de la democracia representativa y la escuela secundaria encarnaba este mandato de formación de los sujetos políticos. Ella entregaba a la sociedad sujetos forma[tea]dos para el ejercicio más acabado de la ciudadanía política: ejercer el acto de elegir y ser elegido. 
Los jóvenes que integran la muestra de este estudio, manifestaron las siguientes posiciones frente a los circuitos de la política formal en las escuelas:

-En las escuelas centenaria, dependiente de la universidad y privada parroquial, los jóvenes conocen las dos instancias formales de participación: Centro de Estudiantes (CE) y Concejo Deliberante Estudiantil (CDE). En la escuela suburbana y en la escuela rural, desconocen al CDE. En la escuela rural conocen el CE (saben de su existencia, pero no funciona en ella) y en la escuela suburbana desconocen de qué se trata esta organización.

-En las tres primeras escuelas, a excepción de los delegados de cursos, todos dicen que participan de las dos formas de participación política votando (a la comisión directiva del CE y a los representantes escolares en el $C D E$, respectivamente). Creen que es útil este ejercicio para cuando participen de elecciones de gobierno nacional, provincial y municipal.

No consideran que ésta forma de organización estudiantil sirve como instancia de funcionamiento gremial. Ante las dificultades de la vida y con el gobierno escolar, acuden a otras instancias: compañeros, docentes tutores o padres.

Las formas de participación de mayor significatividad para los jóvenes presentan otras características y derivas que nos proponemos analizar e interpretar en este capítulo.

\subsection{La participación de los jóvenes en los canales instituidos de formación política en la escuela secundaria}

Nos preocupa abordar las tensiones en torno de la participación política de los jóvenes, en las sociedades contemporáneas, en su complejidad conceptual y práctica.

Las prácticas políticas de los jóvenes se focalizan en la escuela aún cuando la crisis que ésta atraviesa se inscribe en lo que muchos autores visualizan como el quiebre de las instituciones tradicionales. Pero, aún así, los gobiernos apelan a la escuela para "incorporar a cómo de lugar" (parafraseando a Reguillo Cruz, 2004) a los jóvenes excluidos a una estructura que ya los ha expulsado y no tiene certezas acerca de los modos para poder contenerlos. 
En el recorrido definido para dar lugar a las expresiones y las prácticas juveniles de participación relevadas en las escuelas seleccionadas, nos proponemos en primer término, analizar algunos aportes provenientes de estudios del campo político específicamente, y también de la psicología social y de los estudios culturales.En segundo lugar, analizaremos prácticas de participación política juveniles -en general- $y$, en particular, de participación política en las escuelas secundarias.

\subsubsection{Perspectivas para comprender la participación política}

Desde la teoría política, la cuestión de la participación de los sujetos en cuestiones sociales y políticas ha cobrado mayor relevancia y complejidad en tanto se ha producido un desborde de las instituciones. Dice Liboreiro (2004: 525)

\footnotetext{
" Si se busca una definición actual aplicable al universo de las ciencias sociales, puede decirse que la participación es el conjunto organizado de acciones tendientes a aumentar el control sobre los recursos, decisiones o beneficios, por personas o grupos sociales que tienen niveles de injerencia relativamente menores dentro de una comunidad u organización. (...) De acuerdo a la definición que formulamos, la participación es el conjunto de acciones organizadas (A. Pearse y M. Stiefel, 1979) lo cual no niega el carácter participatorio de algunas experiencias no previstas o diagramadas"
}

La participación, vinculada a la acción de los sujetos en el espacio público, ha sido ampliamente tematizada por Hanna Arendt y, en relación a la perspectiva de esta autora, se establecerán algunos conceptos orientativos para el análisis posterior.

El concepto de "acción humana" dentro de la noción de Vita Activa desarrollada por la autora, se homologa a participación política en sentido amplio, ya que el mismo nos permite comprender la acción política de los sujetos en la sociedad.

"La acción, única actividad que se da entre los hombres sin la mediación de cosas o materia, corresponde a la condición humana de la pluralidad, al hecho de que los hombres, no el hombre, vivan en la tierra y habiten en el mundo. Mientras que todos los aspectos de la condición humana están de algún modo relacionados con la política, esta pluralidad es específicamente la condición — no sólo la conditio sine qua non, sino la conditio per quam - de toda vida política (Arendt, 2008).

Destacamos de la cita precedente, la condición de pluralidad que asiste a la participación y a la innegable vinculación que establece la autora, de la participación (o acción) con la vida 
política que requiere, por lo tanto, de su desarrollo en la esfera pública. Las acciones privadas, por lo tanto, no estarían comprendidas en esta definición.

Retamozo aporta otro elemento de relevacia para nuestro análisis, al considerar la acción según Arendt:

“La política, de este modo, recupera la dimensión de la pluralidad y la contingencia ya que en el espacio público las decisiones no están determinadas ni tienen un contenido prefijado. La isonomía -la igualdad de los ciudadanos en tanto participantes de la polis para tener voz y ser escuchados- es la condición de posibilidad de la conformación de ese espacio público" (2009: 74)

Desde una perspectiva acuñada en el seno de los estudios emprendidos por la psicología social en el campo político, Delfino y Zubieta (2010) desarrollan un trabajo ordenador respecto de las definiciones, acciones y modalidades de la participación política, que si bien no está centrado en jóvenes, aporta ideas sustanciales para ampliar y profundizar la lectura sobre las situaciones relevadas.

Una primera observación al respecto nos permite establecer una diferenciación entre la participación política convencional y la participación política no convencional. En la primera, diversos autores citados, dan cuenta de acciones como votar, formar parte de reuniones de partidos o agrupaciones políticas reconocidas, leer en los diarios noticias sobre política, relacionarse con políticos, etc. La segunda incluye tácticas o prácticas de presión, peticiones, manifestaciones, boicots, protestas que pueden o no ser violentas (contra la propiedad o las personas). Estas prácticas pueden tener impacto en la comunidad o el barrio, o bien pueden dirigirse para reclamar al gobierno, a una empresa, etc.

Las definiciones consultadas asimilan el uso de "participación" a "acción", y no son consideradas como tales sentimientos y otras formas pasivas que no impliquen una práctica concreta. Para que las prácticas de participación sean consideradas políticas, es necesario diferenciarlas de otras prácticas que no lo son, como prácticas sociales o caritativas. Definen a las prácticas políticas como "el comportamiento que afecta o busca afectar acciones de gobierno" (Delfino y Zubieta, 2010: 212). Destacan también que la participación política es acumulativa, y quiene realizan una acción de este tipo, tienden a realizar otras. 
En el marco de los estudios culturales, Martínez (2008), apoyado en un texto de Roxana Reguillo Cruz (2004), analiza dos formas diferentes de participación juvenil: la participación instrumental y la participación desdramatizada.

La primera, es asociada en su estudio con los estilos de participación generados por las instituciones de las que participan los jóvenes: "La idea de la postura instrumental es la incorporación de los jóvenes a las instituciones normalmente constituidas para la participación, a saber: la escolarización, el mundo del trabajo y la política formal" (Martínez, 2008: 150). La acción de los jóvenes en estos espacios -sostiene- es inducida por la perspectiva del mundo adulto, tendiente a configurar un escenario normativo y reproductivo, que no representa la verdadera acción y pensamiento de los jóvenes, porque ellos están "desencantados de las estructuras y simbologías modernas y lo que ellas representan".

La participación desdramatizada, por su parte, atiende a "una conceptualización del sujeto joven centrada en el placer, en el nomadismo y en prácticas que no tendrían otro argumento de ser que la perpetuación indefinida de un goce sin tiempo y sin espacio" (Martínez, 2008: 153). Este modo de participar, de expresarse, parece haber eliminado de su horizonte de acción el conflicto, situación que ubicaría a los jóvenes "por fuera" del territorio social. Así lo expresa Reguillo (2004: 52):

\footnotetext{
“En tal sentido considerar que las expresiones juveniles pueden sustraerse al análisis sociopolítico de la sociedad en la que se inscriben es asumir, de un lado, una posición de exterioridad (jóvenes más allá de lo social) y por otro, una comprensión un poco estrecha de lo político (reducido a sus expresiones formales, más bien a "la política").
}

Con estos modos de participación están diciendo, de acuerdo con Reguillo, "no- así", en su resistencia a formar parte de estructuras de las que descreen y que, por otro lado, los ha utilizado, ya sea para reproducir la estructura, que requiere de unos incorporados y otros incluidos, o para perseguir fines sobre los que no fueron consultados.

Martínez (2008) señala que en sus investigaciones sobre participación juvenil se destaca la centralidad otorgada al devenir de los sucesos de su vida cotidiana, señalados como espacios de negociación y resistencia ante los permanentes embates que pretenden colonizar su 
"mundo de la vida". Pareciera no haber estrategias prediseñadas sino tácticas fragmentadas, coyunturales, pero que está expresando la crisis de las instituciones.

A modo de síntesis, presentamos los aspectos más relevantes tomados de cada perspectiva de estudio desarrollada anteriormente:

a) de los aportes de las ciencias políticas, reconocemos el carácter plural de la participación, su desarrollo o acción en el espacio público, su carácter político en tanto todo encuentro entre sujetos implica diferencia y conflicto y el carácter isonómico de la participación, según los aportes de H. Arendt

b) de la psicología social, basándonos en los aportes de Delfino y Zubieta, se destaca la diferenciación entre prácticas políticas (en tanto comportamiento que afecta o busca afectar acciones de gobierno) institucionales o no, donde la actuación de los sujetos requiere de ser voluntaria; éstas prácticas presentan un carácter acumulativo, en tanto los sujetos tienden a participar en otras situaciones.

c) de los estudios culturales sobre prácticas juveniles, abordados desde los textos de Reguillo Cruz y Martínez, se destaca la distinción entre el carácter instrumental (institucionalizado) o desdramatizado de las prácticas juveniles, el carácter de resistencia ("así-no") que pueden presentar y la centralidad otorgada por los jóvenes a las acciones cotidianas.

\subsubsection{Las prácticas políticas formales en las escuelas secundarias}

En relación a la política, estudios anteriores (Milstein, 2009) nos muestran cómo la escuela ha ido perdiendo ese halo de institución aséptica y des-ideologizada que pudo construir como una especie de anillo protector para que no ingresara a su territorio ningún otro discurso que pudiera interpelar al discurso hegemónico (esto es: el sostenido por el Estado). Los cambios producidos en la escuela secundaria apuntan a democratizar y transformar la sociedad y para ello, la escuela debe afrontar desafíos centrales, como el de su propia democratización y transformación.

En las escuelas que integran la muestra, el curriculum se resignifica a la luz de las tradiciones instituidas y de las construcciones culturales subjetivas que portan los sujetos que las 
integran. Tal como expresa Elías (1996: 24-25) -entendiendo nosotros a cada escuela particular como una configuración- "Es posible que las configuraciones sociales constituidas por los hombres entre sí cambien, en el transcurso de una serie de generaciones, tan poco, que los implicados en ellas puedan considerarlas como formas de sociedades inalterables, siempre iguales"

Esta referencia se asocia a la constatación realizada en el campo respecto de escuelas que forjaron una identidad, una cultura de tal pregnancia, que las propuestas de transformación curricular y de gestión se incorporan mediante procesos de acomodación a esas identidades. Las tradiciones escolares son desafiadas por los nuevos mandatos, que exigen incorporar a los estudiantes al gobierno escolar, por ejemplo, sin que medien acciones concretas para que la escuela se piense y proyecte en el marco de los actuales requerimientos ${ }^{156}$.

La ESB centenaria y de la escuela secundaria universitaria ${ }^{157}$ por distintas razones son requeridas por los sectores sociales que ven en la escuela secundaria un paso necesario hacia los estudios universitarios o el trabajo, que es asegurado por las redes familiares. Una situación similar se produce en la escuela privada que cumplió 50 años en el bicentenario.

En el caso de la ESB rural, la nueva escuela secundaria construye su identidad a partir de la pregnancia de la inicial escuela primaria y del tercer ciclo de EGB. La escuela primaria también cumplió 50 años al mismo tiempo que el país festejaba su bicentenario. En el caso de la ESB suburbana creada en el año 2007, la tradición heredada del tercer ciclo de EGB se reconstruyéndose día a día, en un marco de contradicciones y desencuentros ${ }^{158}$, pero en la búsqueda, de algunos pocos estudiantes y docentes, de mejores alternativas de acción.

\footnotetext{
${ }^{156}$ El art. 28 de la nueva Ley Nacional de Educación establece: "Garantizar los mecanismos de participación de los alumnos en el gobierno escolar para favorecer y fortalecer el ejercicio de la ciudadanía y la gestión democrática de las instituciones del Nivel" (Título II "Estructura del sistema educativo", Capítulo V "Educación Secundaria", Art. 28).

${ }^{157}$ La primera da cuenta de una identidad cultural forjada en el normalismo (fue creada en 1910). La segunda, si bien puede considerarse de reciente creación (7 años), está imbuida de los ideales académicos y culturales de la Universidad Nacional que le da origen. Estas dos escuelas públicas de la ciudad aún son elegidas por los sectores sociales medios y altos, con expectativas de que sus hijos continúen estudios superiores.

${ }^{158}$ Las trayectorias de las organizaciones educativas se describen en el Capítulo 3. Sin embargo, puede decirse que la puesta en marcha "formal" y burocrática de la escuela en cuestión, dista de las representaciones que los
} 
En los contextos escolares presentados se relevó el contenido curricular referido a la ciudadanía y la participación Algunas prácticas se produjeron en el marco de la reproducción de los contenidos curriculares y otras, fueron percibidas como contestatarias y orientadas a la construcción de nuevos significados y modos de hacer emerger lo político por circuitos no previstos por el sistema formal.

Así encontramos que los contenidos definidos para la política en las escuelas, circulan en los espacios curriculares (materias) definidos para tal fin; como práctica política reglamentada y ejercicio anticipatorio de la democracia representativa, en los Centros de Estudiantes ${ }^{159}$ y en los recientes Concejos Deliberantes Estudiantiles ${ }^{160}$.

Estos tres formatos mencionados, son parte del contenido del curriculum prescripto o explícito. Torres Santomé (1996) analiza a través de sus estudios sobre curriculum oculto, cómo lo que realmente se aprende en las aulas, corresponde a destrezas relacionadas con la obediencia a los sistemas establecidos. En ese sentido, argumenta:

"Este proceso de despersonalización y de preparación de la juventud para incorporarse y asumir las reglas del juego de un modelo de sociedad, de producción y de relaciones

sujetos vinculados con la educación (en alguna de sus formas) tenemos respecto de la escuela, sino que daría cuenta, más bien, de lo que Lewkowicz (2004) denomina "galpones".

${ }^{159}$ A partir de la sanción de la ley 13688 de la provincia de Buenos Aires en el año 2007, se establece la obligatoriedad de la creación de Centros de Estudiantes en todas las escuelas secundarias de la provincia (Res 4900/07) bajo el supuesto de que la participación política para la vida democrática, requiere de aprendizaje y el Estado debe garantizar un marco normativo y orgánico como herramienta para el desarrollo de los procesos que impliquen democratización en las instituciones, legitimidad de la representación y respeto por los derechos de la comunidad educativa.

El art. 6 establece que "Los Inspectores, equipos de conducción y docentes deberán promover e impulsar la constitución y desarrollo de los Centros de Estudiantes mediante el sostenimiento de acciones institucionales y educativas conducentes"

${ }^{160}$ Los Concejos Deliberantes Estudiantiles constituyen una iniciativa de Jefatura de Gabinete de Ministros que, desde la Secretaría de Relaciones Parlamentarias, impulsa el "Programa Nacional para la Mejor Calidad Parlamentaria". A través del mencionado programa, convenian y acuerdan en primer término con los gobiernos provinciales y luego, con los Concejos Deliberantes Municipales, la creación de un Concejo Deliberante Estudiantil. En el caso de Olavarría funciona reglamentado por la Ordenanza Municipal № 3180/08 (puesto en vigencia en setiembre de 2010)

Su propósito se enmarca en el fortalecimiento de la democracia representativa y la exploración de líneas de avance en prácticas de democracia directa (www.mejordemocracia.gov.a)

El programa apunta a instrumentar dentro de los Concejos Deliberantes, Legislaturas provinciales y el propio Congreso de la Nación herramientas de calidad comola ISO 9001 para mejorar los distintos procesos administrativos que se utilizan, como por ejemplo, el soporte en la formulación de las leyes. 
laborales en el que se pretende que la mayoría de las personas no puedan intervenir y decidir, es también contestado no solo desde movimientos sindicales y partidos políticos progresistas, sino también por el propio colectivo docente y estudiantil"

Sin ánimo de desatender las consideraciones de los autores que analizan las relaciones de poder que se producen y reproducen en las escuelas, es pertinente preguntarse por las características que asumen estas prácticas y cómo son vividas por los jóvenes.

\subsubsection{Conquista y abandono de la política formal en la escuela: el caso de los CE}

El recorrido histórico de este análisis se apoya en un estudio realizado por Valeria Manzano (2011:41), que nos permite "historizar el movimiento estudiantil en su imbricación con la emergencia, consolidación y cuestionamiento de la juventud como categoría cultural y política, y de las y los jóvenes como actores culturales y políticos."

Su estudio permite identificar cuatro períodos en la expresión de la dinámica política estudiantil. Se remonta hasta el año 1958 cuando los estudiantes secundarios bajo el lema "laica o libre" ${ }^{161}$ salen a manifestar en defensa de una causa que no es estrictamente propia, pero que, profundizando el análisis, da cuenta de la reorganización y visibilidad que cobra el movimiento estudiantil que había sido desmantelado y silenciado por la Revolución Libertadora.

Si bien esta efervescencia es reprimida por todo el aparato estatal después de la sanción de la ley y las federaciones estudiantiles ${ }^{162}$ reducidas en su número y capacidad de expresión, éstas no desaparecieron y en distintas oportunidades emitían comunicados y sentaban posturas, como sucedió en el año 62. Relata Manzano que, con notable ironía, la FEMES

\footnotetext{
${ }^{161}$ Bajo esta consigna se organiza el movimiento estudiantil que se opone a la decisión del presidente Frondizi de reglamentar el art. 28 del decreto de ley 6.403 "por el cual se establece la posibilidad de que las universidades particulares o "libres" expidieran títulos profesionales, ya que esta decisión habilitaba el avance del clero en los demás niveles educativos y los "monopolios" en la educación (Manzano 2011: 42)

${ }^{162}$ Luego de la disolución de la UES (Unión de Estudiantes Secundarios) de vertiente peronista, se reconocen especialmente dos agrupaciones: FEMES (Federación Metropolitana de Estudiantes Secundarios), que responde al comunismo y la UNES (Unión Nacionalista de Estudiantes Secundarios), representantes de la derecha.
} 
informa que los estudiantes parecían más interesados por bailar twist que por las causas políticas, visto el inicio de la cultura de masas. Pero, al mismo tiempo, se abre un período de profundo malestar en las escuelas, en las que los jóvenes manifestaban su reclamo por las injusticias, la rigidez de las reglas, el autoritarismo.

A partir del año 69 y como manifestación contra el autoritarismo del presidente de facto, General Onganía, los jóvenes se suman a las revueltas que se comienzan a expresar en el país y la politización de los movimientos estudiantiles crece.

En 1973, con la llegada de H. Cámpora al gobierno, se inicia lo que se denomina la "primavera democrática" donde los estudiantes secundarios encuentran un espacio de manifestación de sus expectativas, dando cuenta de la expresión de una cultura juvenil contestataria (Cattaruzza, 1997, citada por Manzano). Gran parte de la juventud -no solo los estudiantes secundarios- se organizó bajo la conducción de Montoneros y la línea interna "Tendencia" propuso la creación de la Juventud Universitaria Peronista y la recuperación de la UES. En el mismo año, se impulsó la creación de organismos de participación estudiantil ${ }^{163} \mathrm{y}$ al poco tiempo se crearon 300 centros de estudiantes en todo el país.

La actividad de los CE no constituía únicamente actividades vinculadas con la escuela, sino -y principalmente-actividades de tipo social y político: pintar escuelas, reparar aulas y hospitales, trabajo político en los barrios y hasta un zanjado en Salta, para el que se trasladaron 500 estudiantes desde Bs As. Las autoridades de la UES eran elegidas por Montoneros y en 1974 se advertía "el encumbramiento de la derecha peronista en las estructuras gubernamentales, algo que se percibió con crudeza en el ámbito educativo" (Manzano, 2011: 46)

En 1974, el Ministro de Educación Ivanissevich prometió restituir el orden y al inicio de 1975 cerró todos los Centros de Estudiantes.

\footnotetext{
${ }^{163}$ De acuerdo a las fuentes consultadas por la autora de referencia en este punto, las propuestas iniciales fueron dos: la UES proponía la formación de "Mesas de Trabajo" que vinculaban a docentes y alumnos y los estudiantes comunistas, centros de delegados por curso. Las mesas no funcionaron, y a pesar de la iniciativa comunista, la amplia mayoría de los CE eran "controlados" por la UES.
} 
A partir de 1976 la dictadura militar desplegó el terrorismo de estado, cuyo reguero de muerte tuvo como blanco especial a la juventud. Además del alto número de desapariciones, un hecho emblemático de la época lo constituye el secuestro y desaparición de estudiantes secundarios en La Plata, cuando concurrían a una asamblea para discutir sobre el costo del boleto estudiantil. Este episodio, luego fue conocido como "La noche de los lápices" ${ }^{164}$. Su propósito fue que movilizaciones como la del 73 no volvieran a repetirse. Las secuelas de miedo, desencanto y des-compromiso social, aún persisten entre los jóvenes, trasmitidas por las generaciones pasadas.

Con la recuperación de la democracia en 1983, los jóvenes encuentran una nueva esperanza en el gobierno del Dr. Alfonsín. Durante su gobierno se establece el marco legal para restituir los centros de estudiantes, que recuperaran el compromiso político que había diezmado la dictadura, pero que también se distinguiría del ser revolucionario que azuzaba en los años 70.

Entre las agrupaciones que se re-organizan o emergen en este período se reconocen a Franja Morada, Juventud de la Unión del Centro Democrático y la Juventud Comunista.

La década de los 90 aparece marcada por "el fin de los grandes relatos", "la falta de interés en la política y la participación" y la idea dominante de que los jóvenes están atrapados por el consumo y la comunicación virtual. Sobrevuelan el escenario latinoamericano las representaciones de la juventud pobre, asociada con la delincuencia y la peligrosidad (Reguillo Cruz, 2000). Sin embargo, los jóvenes están activos y muchos de ellos se movilizan en repudio y reclamo de justicia, por el asesinato de otros jóvenes, la represión de la que continúan siendo objeto, de la explotación mercantil.

En la actualidad argentina los medios de comunicación se hacen eco del discurso dominante que anuncia la recuperación de la política, la participación y el trabajo social por parte de los jóvenes. No nos acompaña la historia para realizar un análisis con distanciamiento (Elías,

\footnotetext{
${ }^{164}$ Este hecho se constituirá en un hito para la reconstrucción de la memoria colectiva en las escuelas secundarias. Tal es así, que a partir del año 2006 se lo incorpora en el calendario académico como "El día Nacional de la Juventud"
} 
1990) de esta situación por lo que este trabajo intentará dar cuenta de situaciones particulares donde la escuela, los jóvenes y la política, resignifican su relación.

\subsubsection{Los jóvenes y los espacios de participación que se habilitan desde el campo educativo y el campo de la política: los CE y el CDE}

Los documentos oficiales expresan que, con el propósito de fortalecer la participación estudiantil en el gobierno escolar ${ }^{165}$ y el aprendizaje de la vida democrática, los agentes del sistema impulsarán la creación de Centros de Estudiantes en todas las escuelas de la provincia de Buenos Aires. A la vez, la ciudad de Olavarría -como se ha expresado anteriormente- participa del "Programa Nacional para la Mejor Calidad Parlamentaria" y, siguiendo sus objetivos, el Concejo Deliberante Municipal impulsa la participación de las escuelas secundarias en el Concejo Deliberante Estudiantil. Ambas iniciativas convergen en las escuelas secundarias, pero no de manera igualitaria: los jóvenes que concurren a la escuela suburbana y la escuela rural no han sido convocados a conformar ninguna de esas dos instancias de ejercicio democrático.

Al indagar, los jóvenes expresan distintas significaciones a la presencia o ausencia de esos u otros canales formales de participación política estudiantil.

a) La escuela centenaria sostiene, desde la vuelta a la democracia (específicamente, desde el año 1988) el funcionamiento formal del Centro de Estudiantes ${ }^{166}$. A partir de la sanción de la nueva Ley provincial de Educación y la unificación de la educación secundaria, los estudiantes más jóvenes son progresivamente incorporados a estas prácticas por iniciativa

${ }^{165}$ Portal abc.gov, nivel secundario/gobierno escolar

${ }^{166}$ Cabe la mención al hecho de que desde 1999 -con la implementación del Nivel Polimodal- la actividad política estudiantil quedó circunscripta a ese sector de la población joven. Por lo tanto, recién a partir del año 2007 se recupera para la franja etaria comprendida entre los 12 y los 15 años, la formación y las prácticas políticas en el contexto escolar. 
de la gestión y por los estudiantes de los cursos superiores, al conocimiento y dinámica del Centro de Estudiante. También a la integración de las listas participantes de las elecciones ${ }^{167}$.

La forma de transmisión que han elegido para explicar a los más jóvenes en qué consiste el Centro de Estudiantes ha sido la organización de una charla informativa, de la que participan los estudiantes integrantes de la agrupación dirigente y un representante de la gestión escolar. Se realiza en el salón de actos de la escuela, en 2 turnos de 300 y 150 estudiantes cada uno.

Luego, instan a los estudiantes a participar integrando listas que se propongan para competir en las elecciones. Una vez conformadas las listas de las agrupaciones participantes, los candidatos pasan por los cursos a informar sobre los propósitos de su propuesta, los mecanismos de la elección y mostrar el acuerdo de este modo de acción con la gestión, exhibiendo proyectos de mutua colaboración. Las propuestas consisten básicamente en colaborar con mejoras edilicias, diversos entretenimientos para los estudiantes, facilidades y acompañamiento ante dificultades en el estudio y el señalamiento explícito (en todos los casos) de que ellos no tienen referencias política-partidaria ${ }^{168}$.

En un trabajo de focus froup realizado con estudiantes de 3er año de ESB de la escuela centenaria, los jóvenes expresan con claridad su desinterés por participar el Centro de Estudiantes. Consideran

"...que no tiene nada que ver con lo que a nosotros nos interesa, con lo que nos pasa en las aulas, o si llegás tarde" (Celina, 14 años) y

\footnotetext{
${ }^{167}$ El año 2009 se conforma el primer CE integrado por estudiantes de ESB y ES, situación que las autoridades denomina "Acto histórico". Fue reformulado el reglamento y sobre un total de 9 cargos puestos a elección, cuatro serían cubiertos por estudiantes de ESB.

${ }^{168}$ Durante el trabajo de campo participé en dos períodos de campañas electorales, que no variaron entre sí. En la primera se presentaron dos listas; en la segunda, solo una. En la primera elección, una de las agrupaciones incluía a una militante de la CTA local, situación que era percibida con cierta desconfianza por los jóvenes entrevistados: “...para qué quieren venir a hacer política acá? En la escuela no tienen que hacer política. Mi papá dice que igual, en esta escuela no van a ganar" (Ezequiel, 13 años). La joven (15 años) mantenía un perfil muy bajo dentro de la agrupación posiblemente porque era una de las más pequeñas en edad y "los grandes" no se veían dispuestos a generarles espacio y protagonismo. Pero no ganaron las elecciones.
} 
“...tampoco con lo que pasa en el recreo o a la salida de la escuela. A nadie le interesa, a los profesores tampoco ${ }^{169, \prime}$ (Juan, 15 años)

Al interrogar a Celina acerca de cómo resuelven sus problemas, responde que tratan los temas con las profesoras/profesores tutores y si es muy grave, "con tus viejos".

La participación en el Centro de Estudiantes adquiere un carácter formal, responde a prácticas que Martínez (op cit.) denomina "instrumentales" y que Reguillo Cruz (2004) señala que se produce "a como dé lugar", esto es, respondiendo a una definición de la política educativa que puede prescindir del real interés de los sujetos y que las escuelas no encuentran aún el modo de transmitir. Algunos estudiantes, inclusive, lo consideran como

"una herramienta de los directivos que tienen a un grupo de alumnos conformes con las decisiones que ellos toman" (Francisco, 15 años).

Respecto al Concejo Deliberante Estudiantil, éste funciona desde el año 2010 en la ciudad y es ésta Escuela una de las primeras en colocar allí sus representantes ${ }^{170}$. La totalidad ${ }^{171}$ de los estudiantes de ESB interrogados desconocen la existencia y, por lo tanto, el funcionamiento, del Concejo Deliberante Estudiantil. Cuando se les amplía la información y se recuerda la situación concreta en que los estudiantes de los años superiores pasaron por los salones presentando las propuestas que luego votaron, lo recordaron. Pero entonces ¿cómo decidieron su voto?

Mayoritariamente, decidieron el voto por conocimiento personal de los aspirantes. "Es piola", "Es primo de...", "lo conozco del club". Otros (la minoría) votó al que exponía el

${ }^{169}$ La respuesta de Juan condujo a un tema que despierta gran efervescencia entre los jóvenes y tiene que ver con las peleas que se registran en el último tiempo, en especial entre las mujeres. Se han reiterado, en distintas oportunidades, situaciones de agresiones físicas entre chicas, llegando a rodar por el piso mientras son arengadas por otros/otras que miran e incentivan la riña. Este tema se recuperará en capítulos posteriores.

${ }^{170}$ De hecho, integrantes del cuerpo de concejeros municipales -cuyos hijos son alumnos de esta escuela en estudio- fue a ésta a la primera escuela que convocaron para interiorizar a las autoridades escolares y comprometerlas a participar del Programa. Este modo de participación no está aún integrado a la dinámica escolar.

${ }^{171}$ Se preguntó a través de un dispositivo grupal que se aplicó curso por curso, si conocían el funcionamiento del Concejo Deliberante Estudiantil. El 100\% de los estudiantes de ESB respondió que no. Concluyo que desconocían el nombre de este dispositivo de participación política juvenil. 
proyecto más interesante. Los jóvenes no se preocupan de distinguir entre los distintos espacios de participación.

\subsubsection{La política y lo político en la materia Construcción de Ciudadanía}

La materia Construcción de Ciudadanía se desarrolla durante los tres primeros años de la Educación Secundaria, y "procura generar un espacio escolar donde los sujetos comprendan y aprendan la ciudadanía como construcción socio-histórica y como práctica política (Resolución de la DGCyE de la Pcia de Buenos Aires, $\mathrm{N}^{\circ}$ 2496-07)”. Se observa que pretende ser una materia distendida, en la cual la relación entre las/los docentes y estudiantes sea armónica y genere instancias de participación.

En la escuela centenaria, el desarrollo de Construcción de Ciudadanía mantiene intacta la jerarquía docente (que también es la distancia).

Las características que en la práctica presenta su desarrollo, dista de las prescripciones curriculares vigentes en el año $2009^{172}$. Fue el equipo directivo de la escuela, "en función de los intereses que se reflejan en el proyecto institucional" (entrevista con la Vicedirectora ESB), quién definió los temas de los proyectos a desarrollar a lo largo de cada año, vinculados con el ámbito "ambiente" (DC, 2006) ${ }^{173}$ por corresponder -según el criterio expresado- con una de las orientaciones que ofrece la escuela en el nivel secundario superior. Los temas vinculados al cuidado del medio ambiente fueron extraídos del DC correspondiente al área de Biología.

Pudo observarse que el desarrollo práctico de esta materia mantuvo características comunes con el resto de las materias que integran el diseño curricular, a pesar de que las prescripciones curriculares orientan hacia prácticas más democráticas y reflexivas:

“En la escuela y en el aula se establecen relaciones entre las personas y con el Estado. Serán en primer lugar estas relaciones las que deben realizarse desde un enfoque de derechos y en el ejercicio de una ciudadanía activa. Entonces, en coherencia con el encuadre teórico-metodológico de la materia, debe

\footnotetext{
${ }^{172}$ En ese año, la materia no debía llevar calificación numérica, sino conceptual.

${ }^{173}$ En el Capítulo 3, p: 119 se presenta y desarrolla este tema desde la perspectiva curricular.
} 
existir una democratización de las instituciones educativas, y el aula debe ser un espacio democrático del ejercicio del derecho y la responsabilidad de enseñar, y el derecho y la responsabilidad de aprender" (Diseño curricular, Pcia de Buenos Aires, 2007)

Durante las clases de ese año, me encontraba como observadora y participaba de algunos debates. En una oportunidad, la profesora de un curso de tercer año ${ }^{174}$, dispuso “...hablar de lo que pasó ayer en la marcha de estudiantes secundarios y conocer sus opiniones" ${ }^{175}$.

Había sucedido lo siguiente: los Estudiantes de Olavarría, reunidos en la Federación de Estudiantes Secundarios de Olavarría ${ }^{176}$, reclamaron a la Mesa de Inspectores, un espacio de diálogo para la re-apertura de los Juegos Deportivos Olavarrienses, que fueron suspendidos años antes por los incidentes de violencia que generaban (esto, según la voz de los organizadores: profesores de educación física e inspectores de las distintas áreas). En oportunidad de haber presentado el reclamo a la Jefatura de Inspección, se prometió a los estudiantes una instancia de diálogo que no se concretó. Es así como deciden una movilización estudiantil que finalizó con una sentada frente a la sede de la Inspectora Jefe Regional $^{177}$.

Pero cuando los estudiantes solicitaron la autorización en las escuelas para asistir al acto organizado por ellos mismos, se produjeron distintas reacciones entre los directores y tomaron decisiones diferentes, con mayor o menor impacto al interior de las comunidades educativas. En aquellas escuelas que favorecieron la participación, los directivos acompañaron a los jóvenes marchando por las calles con ellos; otros no les permitieron retirarse de la escuela -como modo de impedir la participación en la marcha y posterior sentada- generando una fuerte deserción, escapadas, pero sobre todos, una profunda enemistad con los estudiantes.

\footnotetext{
${ }^{174}$ No fue en cualquier curso que se dio lugar a la charla: allí cursaba uno de los partícipes principales del conflicto del día anterior.

${ }^{175}$ Aunque resulte paradojal, la profesora que abrió el espacio para la reflexión, no favoreció ningún momento para un análisis intencional, para presentar posiciones relativamente objetivas que favorecieran la comprensión de los sucesos. Se produjo una catarsis por parte de los estudiantes, y ninguna contención, orientación o reflexión de su parte.

${ }^{176}$ Ver Anexo Metodológico VI: “La FESO se manifiesta el jueves por las Olimpíadas”

${ }^{177}$ Es interesante mencionar que la convocatoria se realiza a través de las redes sociales como Facebook y Twitter, mayoritariamente. Participaron estudiantes de colegios estatales y privados.
} 
En la escuela centenaria no solo no se favoreció la participación, sino que tampoco se habilitó a los tutores o docentes del espacio de Construcción de Ciudadanía para tratar el tema con los estudiantes. Pero el cumplimiento de esta medida no fue tomada de manera homogénea por los docentes a cargo, ya que 2 de las 5 divisiones que funcionan en esa escuela propiciaron el diálogo para que los estudiantes manifestaran sus posiciones y malestar.

Las principales manifestaciones que realizaron los jóvenes giraron en torno de la "distancia entre sus intereses y los de la escuela", la "mentira" que significa

"este simulacro de participación política de los estudiantes en la vida escolar, porque cuando queremos hacer algo que realmente nos moviliza, donde podemos demostrar que somos capaces de organizarnos -no solo los de esta escuela, sino de todas las escuelas - no nos dejan ir, ni nos prestan la bandera!!" (haciendo alusión a la negativa de la directora a que llevaran a la marcha la bandera de la escuela -y su enojo posterior porque los estudiantes la robaron y luego la devolvieron) ${ }^{178}$ Matías (3er año ESB)

"los grandes creen que solo ellos pueden manejar las cosas. Y en este caso, señora, no es así. Acá somos los estudiantes los que nos tenemos que poner de acuerdo, porque entre nosotros tenemos códigos" Matías (3er año ESB)

"ellas [en referencia a la Mesa de Inspectores, pero incluye a los adultos en general] ni siquiera cumplen lo que nos prometen! Y no quieren las olimpíadas porque no quieren trabajar. ¿Sabe cuántos profesores van a la cancha? Los de educación física y gracias"... (Belén, 3er año ESB)

No hubo reclamos al CE (puesto que sus integrantes también participaron de la marcha), sino que este modo de agrupamiento juvenil se genera en una zona intermedia entre el adentro y el afuera escolar, porque involucra a diferentes actores del sistema (inspectores, directores, estudiantes), pero los hechos se producen -mayoritariamente-fuera de la escuela.

Esta acción movilizó a un alto número de estudiantes de la ESB, en especial los jóvenes que se encuentran cursando el 3er año y que habían participado en los juegos del año anterior. Como ellos manifestaron,

\footnotetext{
${ }^{178}$ Estudiante de tercer año de ES, delegado ante el Centro de Estudiantes de la Escuela
} 
"fue la primera vez que nosotros fuimos a la cancha o al campo de atletismo con los colores de la escuela; cantamos, nos agarramos a piñas con los XX; estábamos todos juntos, los chicos, los grandes [se refiere a los estudiantes]. Hasta Marta fue $!^{179}$..."(Daniel, 15 años)

Consultado acerca de los motivos de las peleas, responde: "son cosas que no tienen que ver con la escuela; algunas son cosas viejas, como decirles "grasas" o "pitucos"”"180.

Otros jóvenes (la mayoría), en cambio, decidieron no involucrarse en la situación. Los que fueron consultados, manifestaron que no se sentían convocados por los juegos deportivos, ni por los grupos que "siempre" generan algún conflicto, "que prefieren hacer la suya y venir a la escuela pasado desapercibidos", que "nadie te fiche", "no meterte en quilombos" porque a la larga "en esta escuela terminás perdiendo".

Las referencias mencionadas permiten reflexionar acerca de la existencia -o no- de los nuevos modos de politizar el "espacio de la política", este espacio en el que los jóvenes se manifestaron y reclamaron a los adultos lo que les había sido prometido y luego negado ${ }^{181}$, sin considerar el peso de la cultura institucional que entra en conflicto con las disposiciones de algunos jóvenes que disputan poder con los adultos.

b) La escuela secundaria dependiente de la universidad se organiza, desde el mandato fundacional, en torno de formar sujetos críticos y ciudadanos participativos. Su apertura disputa la población con las ex -escuelas Normal y Nacional de la ciudad, hijos de profesionales y/o familias que depositan en la educación expectativas vinculadas al futuro profesional de sus hijos.

\footnotetext{
${ }^{179}$ Marta, es la Jefa de Preceptores, la agente de mayor antigüedad de la escuela centenaria.

180 “Los grasas" es el apodo con que todos los jóvenes Ilaman a los estudiantes de la ex escuela industrial; "Ios pitucos" son los estudiantes de la ex -escuela nacional y los "presos" a los estudiantes de la ex - escuela normal. Entre ellos se producen la mayor parte de enfrentamientos en las olimpíadas, que en los últimos años, han llevado a su suspensión.

${ }^{181}$ Al cabo de 30 minutos de la sentada estudiantil - así mantenían cortada la calle-, con escasa presencia de adultos, sin ningún control policial, fueron convocados por la inspectora ante quien reclamaban. Se constituyó una comisión integrada por representantes de cada escuela, dos directores que estaban presentes y funcionarios de la región. Las Olimpíadas se realizaron en noviembre de ese año.
} 
De acuerdo con las encuestas exploratorias realizadas al inicio de este trabajo, el $27 \%$ de padres y el $39 \%$ de las madres de los jóvenes han finalizado estudios superiores y los jóvenes son inducidos -mayoritariamente- por sus padres para ingresar a esta escuela.

Los jóvenes circulan con libertad y bullicio no solo por el edificio de la escuela sino también por otros ámbitos del campus universitario donde está emplazada. Las clases presentan una dinámica activa, las actividades parecieran estar centradas en el aprendizaje de los jóvenes. En los recreos tocan la guitarra o el órgano (tienen a su disposición instrumentos y equipos de audio que usan en actividades escolares o cuando lo desean ${ }^{182}$ ) o pasan música, van al parque o compran sándwiches $u$ otros alimentos que las agrupaciones de los últimos años venden para subvencionar su viaje de egresados.

En el mes de marzo me encuentro presente en la Asamblea de Elección de la Junta Electoral $^{183}$. Todos los cursos de la escuela, sentados en el césped del amplio campus, la vicedirectora y dos docentes y un preceptor, comienzan la charla explicando que se trata de incorporar a los ingresantes y recordar a los demás alumnos, de qué se tratan las elecciones del CE, los pasos reglamentarios a seguir, la constitución de agrupaciones, las funciones de los estudiantes en la comisión directiva y la función de la Junta Electoral (que deberán elegir ese día).

Los estudiantes escuchan (son aproximadamente 300), charlan entre ellos, contestan mensajes de texto desde su celular; algunos toman mates, pero también atienden lo que va sucediendo en el frente de la escena.

La vicedirectora explica que ella irá nombrando los cargos a cubrir. Algunos se postularán y votarán a mano alzada por cada uno de los cargos de la Junta Electora. Hay aplausos y silbidos ante cada postulación y el acto transcurre amablemente. Un profesor se queja de

\footnotetext{
${ }^{182}$ Los equipos del "parque tecnológico escolar" fueron adquiridos mediante la participación en un concurso de proyectos participativos (articulación escuela-comunidad) organizado por la Fundación Loma Negra. Esta fundación subvencionó la creación de un Centro Cultural y los elementos requeridos para su puesta en marcha, en el año 2007.

${ }^{183}$ Momentos antes, los estudiantes preparaban los equipos de audio, entran y salen de las oficinas buscando distintos elementos.
} 
que es poco serio hacerlo de este modo, que es necesario trabajarlo al interior de las clases. "Así lo tendrían que hacer" le responde la vicedirectora, devolviéndole la responsabilidad.

Se presentaron dos listas: una que tiene la conducción del CE desde los inicios, con pequeñas variantes, pero relacionada a las agrupaciones de Franja Morada de las Facultades próximas y una nueva agrupación, integrada por hijos de militantes de distintas organizaciones (JP, CTA, SUTEBA, FPV), vinculadas al kirchnerismo o peronismo.

En mayo, ganó las elecciones la agrupación "Acción participativa estudiantil" (CTA- FPV). En uno de los días de permanencia en la escuela, tomo contacto con los jóvenes que se encuentran conduciendo el CE para presentarles el pedido de encuentro que solicitaban desde una escuela rural ${ }^{184}$. Se entusiasman con la propuesta y entonces viajamos al campo para establecer un vínculo con los estudiantes de la escuela rural. Los jóvenes de "Acción participativa estudiantil" fueron anfitriones en dos oportunidades de los jóvenes ruralistas: la Jornada "Sociales en acción" y la Jornada de lucha contra el SIDA.

En este CE, la comisión directiva está integrada mayoritariamente por estudiantes de la ESB. Les comento que ese dato me llama la atención y recibo las siguientes respuestas:

"La agrupación que integramos ("Acción participativa") tiene un fuerte compromiso político con el Frente para la Victoria. Los años superiores de la escuela, están influidos por el apoyo que en los inicios recibieron de los CE de las Facultades, en especial, de Franja Morada. Ahí sabíamos que no ganábamos. Entonces nos orientamos a trabajar con los primeros años, que ya reúnen muchos más alumnos que los cursos superiores" (Matías, 14 años $^{185}$ )

“Pero además, nosotros somos compañeros de militancia en otro espacio, la Juventud de la CTA, entonces conocemos el nivel de formación política de nuestros compañeros. No es como en la escuela Normal, por ejemplo: allí tenemos una compañera que no puede hacer base con nadie. Los más grandes la sectorizan porque es de ESB, aunque ella los dá vuelta políticamente" Mariela, 17 años, presidenta del CE)

\footnotetext{
${ }^{184}$ Mientras hacía el trabajo de campo en una escuela rural distante a $80 \mathrm{~km}$ de la ciudad, los jóvenes estudiantes, sabiendo que yo trabajo en la Universidad, me piden si puedo ponerlos en contacto con el CE de la escuela secundaria. Este encuentro será abordado en profundidad en el Capítulo 6.

${ }^{185}$ Matías es militante de la Juventud de la CTA e hijo del Secretario General de la misma organización.
} 
"Si querés, te contactamos con ella para que puedas hacer tu investigación en esa escuela. Y en otras, ya que estamos armando una red importante" (Sofía, 17 años)

Este modo de participación política juvenil también remite a un modo instrumental de participación política en tanto está direccionada por adultos, aunque no del ámbito escolar sino del ámbito partidario y remite a los propósitos de la política oficial.

Es interesante observar la estrategia desplegada por la agrupación para conseguir el mayor caudal de votos, que había sido orientada por la agrupación de jóvenes de la CTA, por esa red mayor a la que refiere Sofía. No puede desconocerse el fervor y entusiasmo con que los jóvenes militantes de esta agrupación realizan su tarea política, diferente, en este aspecto, a todos los demás grupos analizados.

Pocos días después, los estudiantes de esta agrupación aparecieron en la escuela vistiendo remeras que decían CTA (en el pecho) y FTV (en la espalda). Esta situación produjo comentarios ("zurditos", "montos", "ponete el uniforme", etc) entre sus compañeros de curso y en otros, que se mostraban irritados.

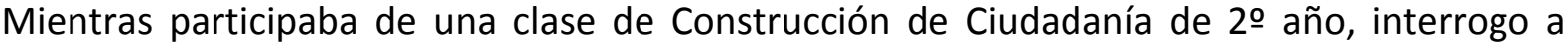
algunos jóvenes por el motivo de la irritación que producían las remeras.

Las respuestas del grupo se orientan hacia la referencia partidaria, puesto que no quieren ser "ni cómplices ni enemigos de ellos por un partido político" (Jaime, 13 años). Ellos expresan que quieren un CE de estudiantes "independiente" de los partidos políticos, dice Fede, compañero de grupo de Jaime.

En otra oportunidad, los dirigentes del CE estuvieron toda la mañana organizando las Jornadas de debate por el Día Nacional de la Juventud, con apoyo de un grupo de docentes y algunos preceptores, pero no asistieron los representantes de la lista minoritaria. Habían acordado con las autoridades de la escuela que a las 10 de la mañana se suspenderían las clases para dar lugar al trabajo en cinco talleres y a la tarde, desarrollarían distintas actividades artísticas, invitando a bandas y artistas de otras escuelas de la ciudad. 
Representantes del CE, pasaron en los días previos por los salones de clases, explicando el sentido de la Jornada e invitando a los estudiantes a sumar propuestas y especialmente a venir dispuestos a participar. En el salón donde me encontraba compartiendo el trabajo de la materia "Salud y Sociedad" (2 año ESB), los estudiantes dieron muestras de desinterés que se observaba exagerada-: hablaban en voz alta (gritaban) mientras la compañera explicaba, le daban la espalda, se reían. Intervino el profesor y alguien se animó a decir "Basta! No nos interesa!".

Cuando se retira -después de dejar su mensaje- el profesor interroga, con preocupación:

"Prof.: Bueno, quiero que hablemos sobre esto...y decirles que están desperdiciando una oportunidad que en mi época no existía...a mí me cayó muy mal que se revelaran así con un compañero que viene a hacerles una invitación, que los representa.... (un joven levanta la mano)

-No nos representa -dice el joven- (Jaime, 13 años)

-No, no (dicen otras/otros)

Prof.: -Entonces tienen que participar y exponer sus ideas. Si no, es como siempre: nos quedamos representados por gente que no nos gusta, a los que les echamos la culpa de todo, pero nosotros no hacemos nada

-Nosotros no sabíamos de lo que hablan (sí del día de la Juventud, digo de la Jornada). Nunca informan, ni invitan a organizar, hacen reuniones cerradas (Jaime)

- No es así!! Las reuniones son abiertas a todos (Victoria, 14, integrante de la comisión directiva del CE) y esto se está organizando hace mucho tiempo

-Yo mucho no les creo, porque después no hacen nada de lo que prometen, o hacen cosas que no son para nosotros $^{186}$ (Emilio, 14 años)

-Es todo político (Fede, 14 años)

-Lo que pasa es que el otro CE se llevó todo, la plata, todo

${ }^{186}$ Quedan murmurando acerca de su descontento porque el CE marchó con los CE de las facultades, gremios y partidos políticos, reclamando por el aumento del boleto de colectivo. Ellos no creen que esa sea la función del CE de la escuela. ¿Cuál sería? -les pregunto. "Trabajar por cosas que a nosotros nos interesan, por problemas nuestros"-me responden pero no me dan ejemplos de cuáles serían esas cosas. 
-Es todo política -dicen a coro los varones de un grupo-

Prof.: todo es política, no hacer nada también

-Pero estamos hartos de este desprestigio permanente, de los varones que solo dicen "todo es política", invalidando el debate, porque no saben hablar (Lorena 14, indignada)

(coro de mujeres apoyándola, se vuelve un debate entre varones y mujeres)

-Por algo en la Comisión Directiva somos 12 mujeres y solo 4 varones, que nos respetan- termina Victoria

-Mejor no hagamos otra lista, no hagamos nada, que nadie participe (Jaime)

Las chicas se paran, les gritan hablan, hacen ademanes. El profesor corta, reordena las partes del debate ${ }^{187}$-que ya no era productivo pues no se escuchaban entre sí- y vuelven al contenido de la clase.

Aquí se estaba gestando otra situación que no alcanzaba a dilucidar: por un lado, el CE se veía muy activo, con fuerte apoyo de los adultos de la escuela y de un alto número de estudiantes. Los otros estudiantes que hacían oir su voz en oposición, parecían responder al grupo "no te metas", pero no exponían ideas en los debates sino solo oposiciones que no lograban argumentar.

La Jornada del 16 de setiembre se desarrolló en medio de choques entre los estudiantes que conducen el CE y los estudiantes que adhieren a la lista que perdió las elecciones más aquellos estudiantes que reclaman menos politización partidaria en la escuela.

En un clima festivo, con "La marcha de la bronca ${ }^{188 " ~ c o m o ~ m u ́ s i c a ~ d e ~ f o n d o ~(a ~ a l t o ~ v o l u m e n), ~}$ la presidenta del CE da inicio a la Jornada, explicando el sentido de la fecha y hacia el cierre dice:

“Estas Jornadas nos deben llevar a preguntarnos, mirándonos en esos jóvenes que lucharon por una causa justa, ¿cuál es nuestro rol ahora?; ¿cuál es nuestra función dentro y fuera de la escuela?; ¿qué nos hacen creer que somos o hacemos?; ¿qué visión tienen los adultos de nosotros?"

\footnotetext{
${ }^{187}$ Intenta un cierre reflexivo que no parece muy fecundo en el grupo de varones. Pero lo intenta, además, desde su lugar de varón.

188 "Marcha de la bronca" es una canción de Pedro y Pablo, artistas que supieron interpretar el sentimiento popular en el año 1970 y que fue emblemática para los jóvenes de esa época y luego, resignificada a la salida de la dictadura de los años 1976-1982
} 
Terminó su discurso invitándolos a todos a la plaza central de la ciudad, donde se reunirán los jóvenes de todos los colegios secundarios (hay carteles en las paredes reforzando esta invitación) ${ }^{189}$.

En los talleres se registraron ${ }^{190}$ escenas como las que se relatan a continuación:

Taller "Música": la dinámica consiste en escuchar una canción y leer la letra y comentarla (los organizadores trajeron copias de la letra que reparten entre los demás estudiantes). Comienzan escuchando “Me gustan los estudiantes", de Violeta Parra ${ }^{191}$

Cuando termina y piden opiniones, pensamientos que surgen o comentarios en general, nadie habló. Los profesores coordinadores contextualizaron a la autora y comenzaron a leer la letra. Reflexionaron que

"al decir la autora "los estudiantes" hace una generalización, porque se trataba de un grupo de estudiantes, como en todos los movimientos sociales, no participaba todo el mundo o no lo hacían de la misma manera y con el mismo compromiso"

Continuaba el silencio de los estudiantes presentes y el profesor (politólogo y profesor de historia) dijo "También es verdad que la palabra está en crisis..."

Comenzaron a hablar algunos, vinculando el movimiento chileno con el mayo francés, discutiendo los modos de participación. Hablaban los estudiantes más grandes, los de ESB estaban en silencio. Discutieron acerca del valor de la democracia y si es posible otro modelo, no autoritario. Un profesor pide que hablen los de ESB

Una joven de ESB dice: "A veces no se habla porque los otros te critican, te agravian". Los profesores prometen que eso no sucederá en este espacio.

\footnotetext{
${ }^{189}$ A esa reunión fueron pocos jóvenes, mayoritariamente militantes del FPV, con remeras identificatorias (puede verse nota periodística en el Anexo VI)

${ }^{190}$ La Jornada de Reflexión se organizó en cinco talleres con distintas temáticas; Literatura, fotografía, prensa, música y audiovisual. Conté con la colaboración de una becaria para realizar los registros (escritos y grabaciones), pero debimos elegir a cuál taller asistir.

${ }^{191}$ Excepto los organizadores y los dos profesores que ayudaban en la coordinación los estudiantes no conocían la canción ni a Violeta Parra (sí a Mercedes Sosa, que la interpreta en la versión seleccionada). Los coordinadores las conocieron en otros espacios de formación política -relatan al ser consultados- o en su casa, como música escuchada por sus padres.
} 
Promediando el taller, hablan de la participación: discuten acaloradamente sobre qué es participar, si solo es en el CE y cómo el grupo que lidera el CE se "apoderó" de todos los espacios escolares: el centro del debate fue el Concejo Deliberante Estudiantil.

- Ustedes se encargaron de que el resto - los que no pensamos como ustedes- no nos enteráramos de ese proyecto hasta que pasaron por los salones informándonos de los proyectos que ya habían armado, no de que cualquier estudiante podía presentar proyectos, ya no había tiempo (El Colo, 17 años)

-No es responsabilidad nuestra que ustedes se enteren, les llegó la información al mismo tiempo que a nosotros; estarían ocupados en algún torneo de rugby (dice irónicamente Valeria, 17 años)

-El Colo -furioso-: Nadie, nadie nos informó de ese proyecto!! Y si no pueden participar en ningún deporte tampoco es problema mío

Los profesores ordenan el diálogo -previa explicación de que a ellos tampoco se les pidió que trabajaran en los cursos sobre ese tema- y preguntan en un momento:

-¿Qué autoimagen tienen ustedes de ustedes mismos? A ver, los de ESB..

-¿Cómo jóvenes? -dice una chica de 12 años- ¿yo soy joven o niña? Soy adolescente... (discuten sobre el sentido de adolecer y acuerdan que todos son jóvenes porque ya no se sienten niños: pueden pensar, opinar, tienen cierta independencia de los padres, se hacen responsables de muchas cosas)

-Yo creo -dice María, 13 años- que nosotros somos estudiantes puros...

-¿Cómo puros? ¿Qué es puros? -pregunta el profesor

-Sin meternos en política

-Antes se veía a los jóvenes solo como estudiantes...ahora somos muchas cosas más, tenemos otros intereses (Valeria, 17 años)

-Hay sectores que no quieren que participemos. Hay cierto conservadurismo que dice que la participación de los jóvenes en política está mal; pero hay otras áreas: deporte, cultura, arte (Sofía, 17 años)

Y siguen hablando de que en esta escuela se incentiva la participación más que en otras, ya que en todos los espacios se habla de política, se les generan espacios de participación y se los hace responsables de sus actos.

Hacia el cierre, tenían que hacer un afiche que expresara los temas que habían debatido. 
-Pongamos libertad (propone Valeria)

-Y bueno, pongamos guerrilleros, socialistas...(El Colo)

Valeria toma un marcador y comienza a escribir, visiblemente irritada, colocando los nombres de cada uno al lado de cada palabra. "Hagámosnos cargo" dice. Y El Colo, grita "Yo no dije eso", negando sus recientes palabras

Interviene un profesor diciendo: “Háganlo seriamente, por favor. Esto tiene ya un grado de trivialidad lamentable".

El cierre se realizó con la presentación de los afiches. Pero sin que los estudiantes prestaran atención a este momento. Los organizadores se sintieron decepcionados. ¿Qué pasó? Se preguntaban...

La jornada por el día de la juventud también se desarrolló con una participación instruccional ${ }^{192}$, coercitiva desde la institución CE y vacía de significado para gran parte de los jóvenes que no forman parte de la disputa política tradicional. Los jóvenes que no se sintieron atraídos por la convocatoria, siguieron escuchando su música, conversando con sus compañeros más íntimos, aprovechando la situación de aula abierta para reunirse con amigos de otra división.

Durante el tiempo que duró la gestión de "Acción Participativa Estudiantil”, se registró una activa participación de los jóvenes estudiantes (en especial los del CE y sus seguidores más comprometidos), en causas que afectaban a sectores más amplios que los estudiantes de la escuela. Antes de que finalizara el año fueron a pintar escuelas, animaron fiestas para niños en barrios marginales y pusieron luto en la foto del muro de Facebook, por la muerte del ex presidente Kirchner.

En el muro de Facebook de la agrupación, escribe una militante:

${ }^{192}$ Llamo participación instruccional aquella participación que es promovida por las instituciones (en este caso, político-educativas) a efectos de inculcar algo y que en general, tiene un formato distinto del académico. 
No quiero que se termine el año, tengo ganas de que sigamos yendo a escuelas, a barrios... Haciendo esto, llevando a todos los chicos una herramienta tan importante que les sirva para luchar, reflexionar, proponer, transformar, sigamos sosteniendo que los centros de estudiantes tienen que estar conformados en todas las escuelas! Gracias por tan lindo año y que sean más de compromiso, los quiero mucho!

Inician el año académico 2011 renovando la invitación a participar en la DVDteca, haciendo una colecta para comprar cortinas y organizando las Jornadas por la Memoria, la verdad y la Justicia. Se involucran en todos los actos de la APDH local y en la escuela. En el mes de abril integran la Coordinadora contra el aumento del boleto estudiantil, junto a estudiantes universitarios, gremios, partidos políticos. Su organización los llevó a participar en numerosas reuniones con los CE de las facultades, solicitar autorización para marchar con ellos como estudiantes de la escuela universitaria y también afrontar expresiones de disgusto de muchos padres, tal cual lo manifestaron en reuniones que se realizaron por tal motivo.

La marcha se realizó y fue multitudinaria, con representantes de diversos sectores de la ciudad. Concurrieron representantes de partidos políticos, sindicatos y estudiantes (especialmente universitarios), con sus banderas identificatorias, redoblantes, bombos y cánticos.

Transcurridas dos semanas tengo un encuentro casual ${ }^{193}$ con una de las integrantes de la conducción del CE, que me comenta con visible preocupación:

“-¿Sabés que se nos presentó otra lista?

-Es común -le respondo. ¿Y estás preocupada?

-Sí, parece que ellos han hecho un trabajo de base que tiene mucha adhesión...Vamos a perder el Centro

-Pero ¿qué hicieron ellos a diferencia de ustedes?

-Pavadas, boludeces, pero parece que es eso lo que quieren, no sé...Mirá que hicimos cosas grosas, como la marcha del boleto, la reunión de jóvenes militantes, el debate con los candidatos a intendente... hasta una fiesta, que parece ser lo que más convoca..."

\footnotetext{
${ }^{193}$ Nos encontramos en una fotocopiadora y la joven se acercó a contarme "la novedad" con notable angustia. No estaba dentro de sus previsiones
} 
En junio, la nueva agrupación "Unidos por el cambio" gana las elecciones de Centro de Estudiantes $^{194}$. La nueva agrupación que lidera el CE comienza con gran entusiasmo a organizar su tarea, la que fue definiendo una vez ganadas las elecciones.

Mientras tanto, en la escuela, que ha crecido considerablemente en número de alumnos y de docentes, comienzan a suceder situaciones que resultan novedosas y que no encuentran en las estrategias conocidas, alternativas válidas de intervención: grupos que resultan "inmotivables", hurtos, peleas con agresiones físicas.

EI CE y la anterior agrupación, que continúa trabajando, no saben/no pueden penetrar en la lógica de las nuevas situaciones. Los estudiantes -en especial los estudiantes de ESB que no integran las agrupaciones- se resisten a participar de aquello que les proponen desde cualquier estructura (escolar o agrupación estudiantil). Parecen responder al "así-no" que menciona Reguillo.

c) En la ESB rural, el CE tendrá significaciones diferentes.

Los estudiantes de la ESB son ocho en total. Cuatro mujeres y cuatro varones. Alegres, las mujeres muy expresivas y dispuestas a conversar de varios temas. La comunidad que rodea a la escuela es pequeña y las actividades que se realizan desde la escuela, involucran a los sujetos que la componen ${ }^{195}$. La escuela es un espacio público de encuentro, en los términos en que Arendt plantea las relaciones entre los hombres iguales o en igualdad de condiciones, da lugar a la polis. En su distintción, Arendt observa que

\footnotetext{
"la polis se diferenciaba de la familia en que aquella solo conocía iguales, mientras que la segunda era el centro de la más estricta desigualdad. Ser libre significaba (...) no gobernar ni ser gobernado. Así, pues, dentro de la esfera doméstica, la libertad no existía..." (2008: 44).
}

\footnotetext{
${ }^{194}$ En la última semana de abril, un grupo de estudiantes dispuestos "a hacer algo por nosotros y la escuela", comienza a organizar una consulta colocando una urna a la entrada de la escuela, con la consigna "pone acá tu propuesta para el nuevo CE". En pocos días, la urna se fue llenando. Convocaron a estudiantes de todos los años y armaron una lista. Obtuvieron una amplia mayoría de votos.

${ }^{195}$ Algunas personas que se hacen presentes con su apoyo y con trabajo en las actividades que plantea la escuela, no tienen hijos en edad escolar (algunos no tienen hijos). Pero la escuela es un polo de encuentro social, más allá de la relación directa de "padres" de "alumnos".
} 
En una comunidad pequeña donde adultos y jóvenes participan juntos de gran parte de los eventos sociales, las relaciones familiares, la supervisión adulta se extiende a casi todos los ámbitos de participación juvenil.

Junto con las necesidades psicosociales de diferenciación y distanciamiento del mundo adulto que caracteriza a esta etapa de la vida de los jóvenes, las prácticas curriculares específicas de la educación secundaria comienzan a adquirir una significatividad no revelada hasta el momento en ninguno de las otras escuelas analizadas: los contenidos curriculares, tanto en su expresión conceptual comoen las prácticas que se generan, les revelan a estos jóvenes dimensiones no conocidas hasta entonces:

-en primer término, amplían su horizonte de relaciones sociales en tanto la escuela secundaria y la organización disciplinar del curriculum implica un aprendizaje respecto del tratamiento con cada docente como persona singular, diferente. Aprenden nuevos lenguajes -en general correspondientes con cada disciplina- y aprenden nuevos estilos comunicacionales y relacionales. Hasta ese momento su esquema relacional estaba circunccripto, en la escuela primaria, a tratar con una sola maestra (la escuela primaria, también es plurigrado y a la figura central de la maestra, ha sido incorporada una docente de plástica, otra de inglés y un profesor de educación física). Este aprendizaje los posiciona en un status diferencial respecto del de sus padres que mantinen relaciones sociales acotadas (por las distancias, por el tiempo laboral extendido propio de las actividades rurales). Dicenlos jóvenes:

- Inv. ¿Qué diferencia encontraron ustedes entre la escuela primaria y la secundaria?

J: y, acá te exigen más.

Braian: mucha diferencia. Es como que el estudio es más cargado y más recto

Inv.: ¿Y en relación al trato con "la" maestra y los profesores?

J: en eso bien, en eso bien

B: a mí me cayeron bien los profesores

Braian: ese es el tema, es el mayor cambio. La maestra es como si fuera de tu familia, ahora con los profesores, es como tratar con gente distinta cada día 
$\mathrm{J}$ : ahora nosotros tenemos que adaptarnos a eso, porque tener un profesor distinto en cada materia, es un cambio. Nosotros nos tenemos que adaptar a ellos, aprender a que cada uno enseña de manera distinta. Con Gabriela, por ejemplo, es como que jodemos más. Con Rosana, que es recta, estamos sentados y trabajando

B: ...es de matemática. Tenemos buen trato y eso, pero hasta ahí no más. Paula es como si fuera uno de nosotros

Braian: es más integrada con nosotros

J: no sé si más integrada. Es como que Rosana cumple su lugar de profesora, se sienta en su escritorio y te da la actividad; Gabriela te da la actividad y toma mates, y...porque es Gabriela, no más

-en segundo término, el contenido conceptual de las materias de ciencias sociales y prácticas del lenguaje, abordado a partir de las situciones significativas o rutinarias de la vida cotidiana, les permiten otra lectura del entorno. Este nuevo posicionamiento frente a la vida los ha empoderado: sienten necesidad y orgullo de mostrar sus producciones, una práctica que hasta ahora noera habitualen los jóvenes.

Braian: es como que Gabriela trata de integrarnos y de hacernos ver de otra manera las cosas

A: ¿y de qué manera?

J: ella trata de que seamos más como somos nosotros, que seamos libres, que no tanto reglamentado. Por ejemplo Rosana nos da para estudiar y tenemos que hablar y decirlo como ella dice, y

Braian: Y con Gabriela no, nos deja que nos expresemos nosotros

A: Todo el trabajo sobre Derechos Humanos ¿con quién lo hicieron?

B: con Gabriela

A:¿qué fue lo que para ustedes, les cambió la mirada?

Braian: los derechos de los niños

J: a mí, el centro de estudiantes

F: la participación, que teníamos que comprometernos nosotros

J: nosotros teníamos que traerle los temas a ella

Braian: a veces es como que no encontrábamos los temas, no sabíamos qué traer

$\mathrm{J}$ : a veces decimos que queremos libertad y cuando la tenemos no sabemos qué hacer. Tenemos que aprender a usarla

(En un momento, uno de los varones bosteza).

Inv.: estás aburrido 
Juan: -No, es que hoy me levanté a las 3:30. Teníamos que hacer la yerra con mi papá y mi hermano (lo señala, es otro de los chicos que están en el plurigrado). Y la maestra Gabriela nos había dicho que a las 8 teníamos que estar acá porque venía usted (15 años)

Inv.: ¿qué esperan de mí?

Joana- Es que nosotros queremos mostrarle todo lo que hacemos, para que usted vea que podemos seguir en la secundaria. Que terminar la secundaria es un derecho muy importante para nosotros. Yo quiero ser veterinaria, pero mis padres ahora no me pueden llevar a Olavarría a estudiar, porque soy muy chica y no tenemos parientes allá ¿con quién me voy a quedar? (14 años)

Telmo: -Nosotros hemos hecho muchas cosas que llevamos a Olavarría para que allá vean todo lo que acá hacemos: participamos de los cursos del Inta; hicimos un libro ${ }^{196}$, lo presentamos en la feria del libro iY hasta le vendimos uno al intedente! (todos se ríen); fuimos al diario, a la radio... Fuimos a Buenos Aires, al teatro, al museo, a la cancha de Boca, estuvo re-bueno...(15 años) ${ }^{197}$

Las experiencias pedagógicas transitadas en la escuela secundaria, les ha permitido visualizarse (individual y colectivamente) como sujetos inmersos en una estructura. Las expresiones de los jóvenes permiten interpretar que han "descubierto" la existencia de unas relaciones de poder con las que tendrán que "negociar" para conseguir sus objetivos. Los jóvenes progresivamente iban perdiendo la inocencia y descubriendo la trama de sus posiciones -y posibilidades- como sujetos sociales y políticos.

Luego de participar de las Jornadas anuales “Sociales en Acción" ${ }^{198}$, los jóvenes le piden a la profesora de Construcción de Ciudadanía abocarse a la puesta en marcha de un CE y comienzan a trabajar sobre la reglamentación vigente.

Descubren en el CE una estrategia de agremiación que les permitirá -según explican- tener una identidad que refracte sus inquietudes y acciones, sin la intermediación de sus padres y los docentes de primaria.

\footnotetext{
${ }^{196}$ Efectivamente, hicieron un libro de cuentos sobre distintas historias que vinculaban a los protagonistas con temas de derechos humanos. El libro se inició con motivo de la conmemoración del 24 de marzo, y desde ese proyecto -originado en la materia Construcción de Ciudadanía con apoyo de la profesora de Lengua- aportaron los docentes de todas las demás materias "Hasta el de Educación Física, que nunca tiene tiempo para nada" me dicen riéndose los chicos.

${ }^{197}$ Ví sus producciones didácticas, sus comunicaciones: fotos, afiches, folletos y la revista periódica La Zona que distribuyen y venden.

${ }^{198}$ Me comprometí con ellos para que fueran invitados a una jornada de jóvenes que organiza la Facultad de Ciencias Sociales de UNICEN (con sede en la ciudad de Olavarría), ya que su interés es vincularse con otros jóvenes y abordar sus problemas.
} 
Es muy interesante advertir cómo lo político se expresa en unas prácticas participativas institucionales que son resignificadas y apropiadas por un grupo que encuentran en ellas las vías para legitimar y formalizar sus intereses. EI CE se constituye en un espacio público que, constituido por iguales, es ámbito de debates y generación de proyectos. El CE promete ser un espacio donde se presenten intereses genuinos de los jóvenes, donde la participación sea efectivamente voluntaria.

En esta escuela, donde la pequeña cantidad de actores caracteriza las interacciones, los roles tienden a diluirse en las relaciones cotidianas, pero la participación política coloca a los jóvenes en un espacio diferencial de los adultos.

En la escuela privada confesional, la participación de los estudiantes transcurre por los canales institucionalizados sin sobresaltos, dando cuenta de la situación "cómoda" (Kessler, $2002)^{199}$ en que transcurre la vida cotidiana escolarizada en esta comunidad.

En el año 2009 se pone en marcha por primera vez un Centro de Estudiantes, que surge con relativa autonomía de las autoridades escolares ${ }^{200}$. Esto es: surge por la iniciativa de un grupo de estudiantes que buscaba, según sus expresiones:

"movilizar a los estudiantes, tener voz en los debates, las reuniones, empezar a hacer escuchar nuestra palabra, pero en conjunto, no individualmente" (Manuela, 14 años)

"queremos poner música en los recreos, hacer concursos, festejar cumpleaños...También reunirnos con chicos de CE de otras escuelas" (Micaela, 15 años)

La Comisión Directiva del CE estaba constituida básicamente por estudiantes de ESB (3er año) y su Presidente fue una mujer. La tarea que se habían propuesto les llevaría un arduo trabajo, pues se trata de una escuela donde la relación de protección y amor que se establece entre el equipo directivo y los estudiantes parece neutralizar la posibilidad de conflicto.

\footnotetext{
199 “La certeza de poder modificar, negociar, discutir o al menos operar con las reglas del juego institucional está en la base de esta percepción de comodidad" (Kessler, 2002,pag. 31)

${ }^{200}$ En este caso, no fue necesario que el equipo directivo movilizara a los estudiantes en todas las instancias y procedimientos, o incentivara la constitución de las comisiones convenciendo a los estudiantes.
} 
Algunos jóvenes expresan:

“¿Para qué meterse en un CE? Todo lo que tenemos que organizar lo hacemos con Inés (la Directora) a quien conocemos desde que veníamos a la escuela primaria." (Diego, 14 años)

"Si queremos ayudar a alguna institución, siempre nos organizamos con alguna de las profesoras más piolas, o con las Guías ${ }^{201}$. Hacemos muchos proyectos de salida de la escuela, y ayudamos, hacemos colectas" (María, 14 años)

En el año 2010 eligen sus representantes para integrar el Concejo Deliberante Estudiantil. El proyecto que llevaron al CD trata de educación vial, un problema creciente en la ciudad y en él los estudiantes relevaron prácticas inapropiadas por parte de conductores de automóviles y transportes escolares, que merecían -según expresaban- reflexión y re-educación.

La participación orientada por prácticas de voluntariado, solidarias, es el modo de acción que con mayor frecuencia realizan estos jóvenes. Las mismas se desarrollan en el marco de proyectos organizados por la institución escolar o por otras instituciones (ONG, Parroquia, etc.) de la ciudad.

En la materia Construcción de Ciudadanía, los contenidos son seleccionados por el docente, en relación a ejes o proyectos que se planean desde la institución. Los docentes son elegidos en función de su perfil moral-social más que por la formación disciplinar o por las prácticas ciudadanas que realice. El criterio adoptado es que el mismo docente (o religioso) se desempeñe en las distintas divisiones de mismo año y con ello se aseguran un docente con mayor contacto con los jóvenes, que en general, se constituye en su tutor.

Los estudiantes no manifiestan o dejan entrever habitus ${ }^{202}$ que los orienten a llevar sus posiciones o reclamos adelante, hasta una instancia de debate o confrontación. Durante el tiempo que permanecí en el campo, la característica principal de esta configuración es el trato filial, cargado de cuidado psíquico y físico.

\footnotetext{
${ }^{201}$ En referencia al grupo Guías de Scout, que funciona en la parroquia lindera con la escuela

${ }^{202}$ En el sentido que le otorga Bourdieu, como estructuras estructurantes
} 
Acordando con las expresiones de Kessler (2002) en cuanto a las posibilidades de elegir las escuelas para sus hijos que tienen los sectores medios y altos, se analiza que la correlación de intereses es tal, que diluye el interés de los jóvenes por cambiar algo del entorno.

En la ESB suburbana, habilitada y puesta en marcha en el edificio una escuela primaria del barrio en el año 2007, están matriculados 32 jóvenes en 1er año ESB en el año 2009. El primer contacto que se obtiene, se produce con la asistente social que concurre a una Mutual del barrio buscando "orientaciones y ayuda para contener a los chicos dentro de la escuela"

Concurrimos a la escuela en el horario de la materia Construcción de Ciudadanía. Esta materia funciona en contraturno de la ESB, por lo tanto, en ese horario solo hay alumnos y maestros de la escuela primaria. De los 32 estudiantes solo asisten 15 o 17: suelen tener clases en el comedor o en el patio, porque a esa hora no hay salón disponible.

Aunque hay una docente a cargo, observo que en la clase no se logra articular una tarea pedagógica, en sentido restringido o ampliado. Interrogo a los estudiantes acerca de qué temas están trabajando. "Ninguno", me responden. ¿Y a qué vienen?-pregunto a una de las jóvenes. "A charlar"-me responde.

Otro día, cuando vamos entrando en mayor confianza, les pregunto cuáles son los temas de su interés. "Los novios" dicen las chicas y se sonríen; pero también los efectos del cigarrillo, el porro, el alcohol. Le pregunto si usan las redes sociales de comunicación y todos me muestran que usan celulares y que también concurren al ciber. Los varones, mayoritariamente a jugar en red, las chicas a "estar" en facebook, o mandar mails.

Cuando se concreta un trabajo conjunto entre la escuela y la Mutual de Arte Popular ${ }^{203}$ ubicada en el barrio, la escuela "delega" su responsabilidad respecto de la transmisión cultural para proponerle a la gente de la Mutual "que hagan lo que quieran; o puedan...aclaran-". Para el equipo de gestión escolar se trataba, principalmente, de resolver un

\footnotetext{
${ }^{203}$ Esta articulación ya fue analizada en el capítulo anterior
} 
"problema" de espacio para el dictado de la materia Construcción de Ciudadanía". No hubo intercambios respecto de los contenidos curriculares de la materia

En una oportunidad de diálogo, se pregunta a un grupo de estudiantes varones "qué sería importante para ellos, en un futuro, si tuvieran un hijo" a lo que respondieron: "trabajo, una casa, comida y educación”. La investigadora pregunta: “¿Educación en qué sentido?” “En que vaya a la escuela" ${ }^{204}$.

Mientras en momentos de tranquilidad reflexionan y reconocen algún tipo de valor en la escuela, en otras oportunidades, al preguntarles para qué van a la escuela -si durante gran parte del día están intentando fugarse-, responden: "porque tenemos que venir", "para cobrar el plan", "porque nos mandan", "porque ahora es obligación", "porque me aburro en mi casa", "para no estar en la calle". Entre las mujeres el discurso varía, ya que 4 de las 5 que asisten con regularidad quieren seguir estudiando. Una de ellas, dice:

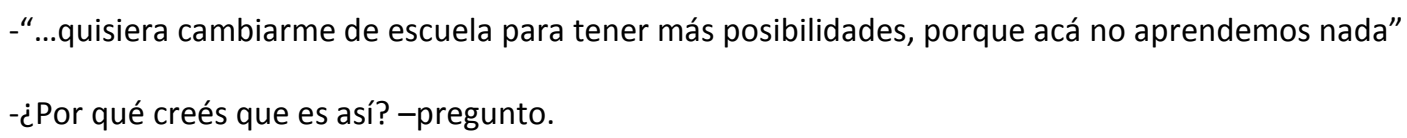

-(Se ríe) acá las profes vienen loquitas, ya entran a los gritos, nos hacen sentir menos. Y entonces los chicos se portan re mal, les dicen cualquier cosa y se enloquecen. Algunas no enseñaron nunca nada todavía" (era el mes de junio). "En cuanto mi mamá consiga otro trabajo, me cambia a San Antonio" (Florencia, 14 años)

Las relaciones entre los estudiantes y los adultos (preceptores, directivos, docentes) son tensas; parece que van a estallar en cualquier momento. $Y$ así sucede a diario. Pero el peso del rol adulto parece imponerse sobre las efervescencias juveniles.

En la vereda de la escuela, sin embargo, se alteran las posiciones de los sujetos. Una mañana, mientras llegaban a la escuela, jóvenes y adultos, una estudiante con su padre esperan a una profesora y cuando ésta baja de su auto la acorralan y comienzan a hacerle reclamos por las agresiones verbales recibidas por la estudiante y por la descalificación pública a la que ha sido sometida en días anteriores. Al salir de la escuela la directora, el

\footnotetext{
${ }^{204}$ Este diálogo lo mantiene un estudiante de la carrera de Profesorado de Comunicación Social, con quien compartíamos tarea en la Mutual de Arte Popular.
} 
padre la "hace volver" a su lugar y finalizan "la charla" con una serie de amenazas hacia la docente, que miraba asustada. No ha sido esa la única relación escolar que se revirtió en la vereda, esto es: situaciones consideradas agraviantes por los jóvenes que tuvieron su repercusión en el ámbito familiar y las familias acudieron en defensa de sus hijos. No ingresaron a la escuela, resolvieron en la calle, ya que ese territorio no es dominio de docentes.

En el segundo cuatrimestre debieron mudarse a otra escuela porque a ésta la cerraron por reparaciones. Las clases se desarrollaban en el comedor, en la galería. La preceptoría funcionaba en un ex baño de docentes. Era una situación de real hacinamiento. La materia Construcción de Ciudadanía no se dictó, puesto que la docente renunció y los nuevos, usaban de licencias reiteradamente.

En el inicio del siguiente año, al realizar una encuesta a los estudiantes de ESB, me preguntan los chicos y chicas de 20 año, qué es el CE, qué es el Concejo Deliberante Estudiantil. No me asombró que no supieran ${ }^{205}$ y comencé a explicarles. Los jóvenes comentaban:

-Y a nosotros para que nos van a enseñar eso, ¿no? ¿Para qué? Si somos de cuarta...Esta escuela es de cuarta (Emilio, 15 años)

-¿¿ué vos querés ser presidente? -dice Emanuel (16 años)

Todos se ríen y "cargan" contra Emilio

-A mí me parece importante lo que dice Emilio -opino- ¿Por qué a ustedes no? ¿Y sus derechos?

-Sí, son importantes, pero acá no, señora, acá está todo mal. Nosotros tampoco le creemos a nadie, así que no nos importa lo que creen de nosotros

Inv: Bueno, ahora ya lo saben y pueden demandarlo ustedes

${ }^{205}$ Como se desprende de otros estudios (Kessler, 2002; Núñez 2010; Chaves 2010), en las escuelas a las que concurren jóvenes de sectores pobres no se ponen en práctica estos mecanismos de participación estudiantil. Pareciera que los fundamentos que de modo taxativo establece la ley de educación y los fundamentos de las reglamentaciones que los ponen en marcha, en la práctica resultan prescindibles cuando de jóvenes pobres se trata. 
La conversación en torno del CE y CDE no tuvo otra trascendencia que ese diálogo. En cambio, sí se involucraron más con las cuestiones de ciudadanía ${ }^{206}$. Si bien ninguna alusión destacó el trabajo escolar, ellos manifestaron "sentirse ciudadanos" en Macondo (la Mutual de Arte Popular) y en la murga "El color de tu corazón" que funciona en la Sociedad de Fomento de un barrio próximo.

-¿Y qué es sentirse ciudadano? -pregunté

-Sentir que sos parte -cerró Emilio. Que si faltás te pregunten qué te pasó, que te saluden, que opines

- y que no se burlen (Yamila, 16 años)

-que no rompan las cosas, [como] las fotos (aclara en relación a la producción que decidieron llevar a la Facultad)

La participación de los jóvenes en la escuela queda circunscripta a protagonizar algún evento crítico por el que son recriminadas sus conductas, en general orientadas a romper (con violencia) el orden escolar.

Después de compartir casi tres años con los jóvenes creemos que las prácticas de choque, disruptivas, destinadas a descargar su ira y a molestar al otro (a veces no se sabe quién es el destinatario) no pueden considerarse prácticas de participación política. Expresan, en el espacio público, su malestar. Expresan que ese espacio no es educativo en el sentido de transmisión cultural, de inscripción social y que la escuela (ese edificio sin institución y sin contenido educativo), es una organización de control a la que le dice "así-no".

\subsection{La desigualdad social que se expresa en la participación política en la escuela}

Un análisis de la política como participación y de lo político de la participación nos propone repensar en las condiciones de desigualdad explícita que se generan, también, en las propuestas educativas de las prácticas eminentemente políticas en ambas acepciones del

\footnotetext{
${ }^{206}$ En referencia a las preguntas orientadoras hacia la construcción de ciudadanía, a su ejercicio de derechos ciudadanos, como se expresa en los instrumentos de relevamiento utilizados.
} 
término. Resulta interesante observar en el cierre del capítulo, que los vaivenes históricos de los procesos de apertura de los CE guardan similitudes en esta época con la política de los años 70. No parecen ser éstas, tanto en el relato histórico como en las prácticas relevadas, por ejemplo, en la escuela dependiente de la universidad, ámbitos plurales de debate y acción genuina motorizada solamente por los intereses de los jóvenes estudiantes sino también, ámbitos de ejecución de prácticas impulsadas por una estructura superior.

Sin embargo, simultáneamente, no puede desconocerse el valor que adquiere lo político de la participación política para algunos de los y las jóvenes involucrados en el proceso analizado en esta investigación, destacándose el fervor, la entrega y el compromiso con propósitos loables. El conocimiento escolar y la formación política partidaria realizaron en los jóvenes militantes una construcción política significativa, según expresaron en diversas oportunidades.

En relación a la participación de los jóvenes en los CE y CDE, se la analiza también como una práctica cuidada por las agrupaciones y los partidos políticos para que se desarrollen en las escuelas de mayor tradición y peso social de la ciudad. La ley (en relación a la reglamentación del funcionamiento de los $\mathrm{CE}$ y los $\mathrm{CDE}$ ) se cumple donde es más visible y donde los intereses en juego son compartidos entre los miembros que se disputan entre sí el poder político (y se aseguran la formación de sus herederos): esto es una referencia directa a las prácticas analizadas de la escuela centenaria y la escuela dependiente de la universidad. Para los jóvenes que participan y disputan los espacios formales en ambas escuelas mencionadas, la política en tanto práctica y sistema de gobierno, tiene sentido en tanto les posibilita participar de espacios de poder. Algunos jóvenes de la escuela centenaria tienen conciencia de la referencia política más amplia; otros, solamente se sienten motivados por el orden interno escolar. En las dos escuelas, el impacto de las prácticas analizadas se produce sobre los participantes directos de las dos instancias formales y en algunos casos, como los relevados en el focus group de la escuela dependiente de la universidad, para sus fervorosos adversarios. Los demás jóvenes estudiantes (los profanos, según Bourdieu) prescinden de tales disputas pero quedan fuera de ese proceso formativo. 
En la escuela privada confesional, los jóvenes parecen posponer deliberadamente su participación política para "más adelante" confiados, quizá, en los adultos (dentro y fuera del espacio escolar) que los representan en el plano político referenciados en su capital económico y que un día llegarán, posiblemente, ellos mismos, a ser.

Contradice a los discursos políticos dominantes la ausencia de un trabajo político en la escuela suburbana, donde no se relevan indicios de la voluntad de cumplir con la Resolución 4900/05 (de creación de los Centros de Estudiantes) por un lado, ni con el derecho a la formación política, por otro. Los jóvenes irrumpen en la escena escolar con una participación disruptiva que expresa el malestar que les genera un trato desigual que los subestima.

Tampoco hay trabajo político externo en la escuela rural, pero se destaca allí el trabajo pedagógico de un grupo de docentes que activa la participación política del grupo de jóvenes.

Este grupo de jóvenes, al igual que otros jóvenes en la escuela dependiente de la universidad, sostienen una participación política por fuera de los canales formales que es fortalecida por el conocimiento disciplinar y por prácticas democratizantes que revalorizan la inclusión en el DC de la materia Construcción de Ciudadanía.

En los casos analizados donde desde la instancia curricular se ponen en acción dispositivos y configuraciones didácticas que despiertan o contienen los intereses de los jóvenes apelando a procedimientos que los ejercitan en su condición de sujetos de derecho, lo político de la participación vigoriza las prácticas y las subjetividades de los jóvenes.

Puede sintetizarse que las situaciones analizadas son complejas cada una en sí mismas y que varían de acuerdo con los contextos en los que se analizan. Pero esta diversidad en los modos de accionar de las configuraciones escolares coloca en primer plano la desigualdad solapada bajo el imperativo de la inclusión social y política de una sociedad fragmentada. 


\section{Bibliografía:}

ARENDT, H. (2008): La condición humana. Paidós, Buenos Aires

BOURDIEU, P. (2001). El campo político. Plural Editores, Bolivia.

BRASLAVSKY, C (1986). La juventud argentina: Informe de situación, Centro Editor de América Latina, Buenos Aires.

CHAVES, M. (2010). Jóvenes, territorios y complicidades. Una antropología de la juventud urbana. Espacio editorial, Buenos Aires.

DELFINO, G. y ZUBIETA, E. (2010): Participación política: concepto y modalidades. Anuario de investigaciones / Volumen XVII.Facultad de Psicología - UBA / Secretaría de Investigaciones. Pp: 211-220, Buenos Aires

ELÍAS, N. (1990). Compromiso y distanciamiento. Península, Barcelona.

(1996). La sociedad cortesana. Fondo de Cultura Económica, México.

KESSLER, G. (2002). La experiencia escolar fragmentada. Estudiantes y docentes en la escuela media de Buenos Aires. IIPE-Unesco- Buenos Aires

LEWKOWICZ, I. (2004). “Escuela y ciudadanía” En: Corea, C. y Lewkowicz, I. Pedagogía del Aburrido. Escuelas destituidas, familias perplejas. Paidós, Buenos Aires.

LIBOREIRO E. (2004).Participación. En: Di Tella, T.: Diccionario de Ciencias Sociales y Políticas. Ariel, Buenos Aires.

MANZANO, V (2011). "Cultura, política y movimiento estudiantil secundario en la Argentina en la segunda mitad del siglo XX". Revista Propuesta Educativa №35. Año 20 jun 2011.01. PP: 41-52. FLACSO- Argentina.

MARTINEZ, J. (2008). Participación política juvenil como políticas del acontecimiento. Revista Argentina de Sociología. [online]. 2008, vol.6, n.11, pp. 148-168.[citado 2012-09-21], Disponible en: http://www.scielo.org.ar/scielo.php?script=sci_arttext\&pid=S1669$32482008000200008 \&$ Ing=es\&nrm=iso>. ISSN 1669-3248.

MILSTEIN, D. (2009). La Nación en la escuela. Viejas y nuevas tensiones políticas. IDES- Miño y Dávila, Buenos Aires

NUÑEZ, P. (2010). "Política y poder en la escuela media: disputas en torno a la participación juvenil en el espacio escolar" En: Saintout, F. (comp.) Jóvenes argentinos: pensar lo político. Prometeo, Bs As. 
REGUILLO CRUZ, R. (2000). Emergencia de las culturas juveniles. Estrategias del desencanto. Tesis Norma, Bogotá.

(2004). "La performatividad de las culturas juveniles". Revista Estudios de juventud № 64/04 pp: 49-56. Guadalajara

RETAMOZO, M (2009). Lo político y la política: los sujetos políticos, conformación y disputa por el orden social. Revista Mexicana de Ciencias políticas y Sociales. Vol. LI. № 206 mayoagosto 2009. Pp: 69-91. Universidad Autónoma de México. DF, México

ROMERO, C. (comp.) (2009). Claves para mejorar la escuela secundaria. La gestión, la enseñanza y los nuevos actores. Noveduc, Buenos Aires.

TORRES SANTOMÉ, J. (1996). Globalización e interdisciplinariedad: el curriculum integrado. Morata, Madrid. 


\section{Capítulo 6:}

\section{Cuando la acción de los jóvenes desafía lo que la escuela puede procesar: absorción de la protesta juvenil o constitución de la demanda. Su impacto en la subjetividad de los jóvenes.}

\subsection{Introducción}

Las acciones de resistencia, presión y producción de conflictos protagonizadas por estudiantes en las instituciones escolares del nivel secundario, adquieren diversas significaciones tanto para los jóvenes como para las instituciones. Tales acciones ponen en evidencia las transformaciones operadas tanto en las instituciones en la construcción de estrategias para sostener, proponer, consensuar un orden que les permita llevar adelante la tarea de educar, como en las capacidades de los jóvenes para organizarse y establecer sus demandas.

En los últimos tiempos la sociedad argentina ha asistido, especialmente a través de los medios masivos de comunicación (como TV, diarios), a las protestas estudiantiles que desembocaron en tomas de colegios u otro tipo de manifestaciones en el espacio público. Sobre éste fenómeno, que es coincidente con los cambios que se han registrado en la relación del Estado con las instituciones educativas que han sido mencionadas a lo largo de la investigación, se han producido también lecturas académicas que aportan distintas miradas interpretativas de estas situaciones.

Al respecto Núñez (2011:7) sostiene que las expresiones políticas estudiantiles no debieran deslindarse de otras prácticas políticas que suceden fuera del ámbito escolar, tanto en Argentina como en otros países de Latinoamérica. Propone una doble lectura de la situación que incluye: “...el modo en que se despliega la politicidad en la escuela secundaria así como acerca de las características de la cultura política de nuestra sociedad -que impregna las prácticas políticas en el ámbito escolar", considerando a ambos procesos interrelacionados. 
En este capítulo se abordan analíticamente diferentes situaciones en que los jóvenes producen acciones de reclamos y protestas, como formas de expresión y / resistencia al orden que pretende instalar la escuela. Las diferentes maneras de manifestar disconformidad, necesidades, reclamos serán abordadas considerando las herramientas conceptuales que provenientes del campo de la teoría política, permiten encontrar en ellas elementos capaces de justificar por qué las prácticas desarrolladas por los jóvenes pueden producir o no subjetividad política.

Para esto es necesario considerar al menos dos ejes de análisis: las tensiones entre la historia y la cultura escolar y la fuerza de las nuevas prácticas políticas que instalan los jóvenes, por un lado y, por otro, profundizar en el análisis en los procesos de acción y decisión que enfrentan los sujetos y que desembocan en demandas que se expresan con mayor o menor nivel de conflicto.

Las instituciones educativas, como otras instituciones disciplinarias, construyeron su orden interno a través de las regulaciones estatales que le otorgaron consistencia y sentido en relación a un proyecto moderno cuyo centro era el Estado Nación. En ese contexto, los sujetos conformaban una subjetividad adaptada a los requerimientos de la vida social, en su tránsito institucional. En la vida política de las escuelas secundarias sucedía algo parecido. Las prácticas políticas consideradas legítimas por la cultura escolar, eran aquellas que podían ser homologadas con las prácticas de la política institucionalizada, es decir, con lo que Bourdieu (2001) ha Ilamado “el campo político"207. Es de interés reconocer que

\footnotetext{
“el campo político es un microcosmos, vale decir un pequeño mundo social relativamente autónomo en el interior del gran mundo social. Allí encontramos un cúmulo de propiedades relaciones, acciones y procesos que encontramos en el mundo global, pero estos procesos, estos fenómenos, tendrán aquí una forma particular" (Bourdieu, 2001: 10)
}

\footnotetext{
${ }^{207}$ Este concepto ha sido abordado en relación a la democracia y al Estado, en el Capítulo 2
} 
Las escuelas secundarias han sido, a lo largo de la historia, las instituciones encargadas de formar a los jóvenes en el ejercicio de la política que se desarrolla en ese microcosmos político. Así, formaba a los jóvenes para entender las prácticas de los "profesionales" del campo y, con el paso del tiempo, ser uno de ellos.

Núñez (2011) sostiene que en la actualidad existe una dislocación entre la cultura escolar y la cultura juvenil que resulta ser la fuente donde abrevan la mayor parte de los desacuerdos entre los jóvenes y las propuestas escolares, y tanto la política como lo político constituyen un tema central de ese desencuentro.

Al revisar los episodios relevados y los sentidos que los jóvenes atribuyen a sus prácticas políticas- en la escuela, interpretamos que es en esa dislocación donde se encuentra el intersticio por donde se cuelan los reclamos y demandas juveniles.

Realizaremos a continuación una lectura conceptual y el planteo de problemas en torno de la constitución de la demanda, tal como son presentados por Retamozo (2009a y 2009b).

\subsection{Acerca de la demanda y los sujetos sociales que participan de ella.}

Podemos decir, siguiendo a Retamozo (2009ạ: 113), que la demanda "se inscribe en la lógica del deseo, en la percepción de una incompletud"

Apoyado en los estudios de Laclau y Mouffe (2004), Retamozo sostiene que las posiciones sociales de los sujetos están atravesadas por situaciones de subordinación que no necesariamente podrán constituirse en demandas. Cuando logran constituirse como tales, pueden abordarse considerando diferentes alcances o dimensiones:

-para Laclau (2005) se hace necesario distinguir entre petición y reclamo. El primero se asemeja a una solicitud hacia quien es reconocido como autoridad y no implica confrontación o violencia; el segundo en cambio, constituye una "interpelación imperativa de un agente hacia otro para satisfacer la solicitud" (Retamozo, 2009a: 115) 
-desde una perspectiva psicológica -basada en estudios de Lacán- Laclau distingue "entre la necesidad como hecho puramente biológico de la demanda que indefectiblemente está mediada por el lenguaje" (Retamozo op cit. Pag. 116)

-finalmente, desde un análisis filosófico, entiende a la demanda como un espacio propio en la lucha por el reconocimiento, y dirá, siguiendo a Hegel (1992: 113), que si "la autoconciencia es en y para sí en cuanto que es en sí y para sí para otra autoconciencia; es decir, solo en cuanto se la reconoce", entonces en ese deseo elaborado como demanda encontramos las huellas del paso de la subjetividad al sujeto" (Retamozo 2009b:116)

Estas tres perspectivas expuestas por Laclau para la comprensión de la demanda, nos permiten focalizar en tres aspectos que serán centrales en nuestro análisis:

-no todo reclamo o petición se constituye en demanda

-la demanda requiere de lenguaje que la explicite y genere códigos compartidos

-la demanda, cuando existe, produce el pasaje de la subjetividad al sujeto social y político

La elaboración de la demanda es un aspecto fundamental en este análisis, puesto que no toda falla del orden social es capaz de converger hacia una demanda. Para que esto suceda es necesario que los sujetos la perciban como tal y se desencadene un deseo por subsanar la situación. El deseo y la acción son elementos constitutivos de la demanda.

Un elemento relevante en el análisis de la demanda, como se ha dicho, es su existencia discursiva; esto es aquello que nombra al proceso real. Este aspecto es interesante de ser visualizado y analizado en tanto la eficacia del discurso se nutre de los significados sedimentados en el conjunto social que conforma la demanda.

El estudio de la densidad de las demandas sociales permite también avanzar en un tema de preocupación para Laclau (2000) y se vincula con la capacidad del sistema institucional para cancelar el conflicto y la capacidad de las demandas para interpelar aspectos de orden social para transformarlos.

A partir de significar una situación social particular de injusticia o indeseabilidad, la demanda interpela al orden social. Pero en su inicio, cuando se generan procesos abiertos en los que 
comienza a elaborarse la demanda, ésta no tiene una dirección ni un contenido prefijado a priori. Cuando la demanda toma forma no se inicia de manera automática ya que el orden social tiene sus mecanismos de absorción, cancelación o desplazamiento para intentar mitigar el efecto de la demanda (Retamozo, 2009b: 115)

Estas posibilidades de demandas que constituyan sujetos sociales solo son posibles en un espacio, cuando el orden social no logra suturar la dinámica social, cuando lo social resulta contingente.

En su análisis, Retamozo considera que para que la demanda se constituya como tal, es necesario advertir sobre las posiciones que ocupan los sujetos intervinientes: de acuerdo con Laclau y Moufe (2004), la subordinación y la opresión son términos claves para comprender el proceso de constitución de la demanda. Y agrega Retamozo (2009b: 113114):

\footnotetext{
“En una perspectiva convergente, Santos (2006) admite la multiplicidad de relaciones de subordinación pero identifica seis espacios estructurales donde pueden reconocerse formas distintas de poder y surgir allí diferentes demandas. De esta manera nos llama la atención sobre espacios, temporalidades y campos presentes en las formas de sociabilidad contemporánea: a) el espacio tiempo doméstico con su forma de poder patriarcal; b) el espacio tiempo de la producción con su forma de poder de explotación; c) el espacio tiempo de la comunidad donde el poder se plasma entre los que pertenecen a la comunidad y quienes no; d) el espacio estructural del mercado, donde la forma de poder es el fetichismo de la mercancía; e) el espacio tiempo de la ciudadanía, cuya forma de poder aparece en la relación vertical entre los ciudadanos y el Estado y f) el espacio tiempo mundial en cada sociedad que se vincula con el poder de un intercambio desigual entre países. Para nuestra discusión es extremadamente importante rescatar esos "espacios tiempos" que el autor identifica para pensar allí la elaboración de demandas sociales."
}

Resulta de interés la inclusión de la (extensa) cita, porque si bien las situaciones relevadas se producen en las escuelas secundarias seleccionadas para la investigación, algunas de esas demandas han existido históricamente por fuera de la escuela. En tiempos en que los problemas del contexto social amplio no llegaban al interior de la escuela, éstos no constituían un tema del que la escuela debiera ocuparse. Y cuando las situaciones de subordinación y opresión se producían al interior de la escuela, los mecanismos de absorción 
del conflicto estaban reglamentados y la escuela rápidamente se libraba del problema. Hoy la situación ha cambiado: las escuelas deben resolver las acciones de demanda que se producen en su seno, atendiendo a las situaciones de incompletud y desasociego que experimentan los sujetos que llegan a ella por distintas razones (interés, mandato familiar u obligatoriedad).

Otra perspectiva para el estudio de las demandas sociales la representan los estudios llevados a cabo por M. T Sirvent y su equipo de trabajo, que nos permite ubicar la demanda social en el campo educativo. En ese sentido, la autora la define:

\footnotetext{
"Demanda social es la expresión organizada y colectiva de necesidades y reivindicaciones que los miembros de un grupo social buscan implementar a través de decisiones institucionales y/o públicas. En nuestros trabajos hemos desarrollado la perspectiva de construcción social, histórica y colectiva de una demanda social como producto de la acción colectiva de un grupo. El concepto de demanda social debe ser entendido como las necesidades definidas por clase social, fracciones de clase, organizaciones, grupos e inclusive individuos estratégicamente situados frente al Estado. Esta perspectiva de la demanda social nos introduce en el ámbito de las relaciones Estado y Sociedad Civil, en una perspectiva de una sociología política de la educación permanente (Sirvent, 2007:88).
}

Este modo de pensar la demanda como acción social, histórica y colectiva, surgida como consecuencia de necesidades sin resolver, nos permite adentrarnos también en la densidad de las relaciones contemporáneas entre el Estado y la sociedad civil, sin intervenciones o mediaciones institucionales.

Abordar el tratamiento de las demandas que realizan los jóvenes en el espacio escolar (aunque no siempre dirigido a la escuela o a los agentes involucrados en ella), nos permitirá indagar sobre uno de los supuestos que operan con fuerza en esta investigación: que las actuales condiciones institucionales (en general, no solo de la escuela) favorecen mayor visibilización de los sujetos y la construcción o producción, a través de sus prácticas, de nuevos/otros escenarios: en el caso que nos ocupa, en relación a la vida política.

Las situaciones relevadas generaron una serie de interrogantes que han sido profundizados en cada una de las situaciones que presentaremos a continuación de las preguntas. 
¿Cuáles son las condiciones contextuales que favorecen la percepción de la incompletud y del deseo, necesarios para que se inicie el proceso de demanda? ¿Cómo se expresan las relaciones de poder en la escuela y qué acciones generan?

¿Cuándo una necesidad se convierte en demanda en el campo institucional escolar? ¿Todas las demandas tienen la misma intensidad o impactan del mismo modo en el orden social incompleto que las genera?

¿Qué lugar ocupan el conocimiento y la construcción compartida de ese conocimiento, para que los sujetos intervinientes se constituyan en sujetos colectivos?¿qué significados adquieren para los sujetos, estos procesos de construcción de la demanda, que de acuerdo a diversos autores que iremos mencionando, es lo mismo que hablar de la constitución de sujetos políticos?

\subsection{Cuando la institución escolar absorbe y cancela los reclamos de los jóvenes estudiantes}

La institucionalización de las normas sociales fue concebida, desde la escuela, sobre la base de una jerarquía adulta capaz de modelizar el tipo subjetivo requerido para vivir en sociedad.

"Tradicionalmente, la escuela fue entendida como uno de los principales agentes de socialización de los jóvenes, tanto para la producción del orden social como para la formación de subjetividades capaces de habitarlo (Rousmaniere et al, 1997) o reproducirlo" (citado por Tiramonti y Ziegler, 2008: 97)

Las relaciones escolares centradas en la autoridad adulta son un aspecto de disputas sobre el que los jóvenes presionan por la constitución de un nuevo orden escolar.

Desde el punto de vista de los jóvenes la edad ha dejado de ser un parámetro de autoridad y de responsabilidad y reclaman reciprocidad en el trato para morigerar la condición de subalternidad que históricamente la escuela (los docentes) produce sobre los estudiantes, ubicándolos en situación de "moratoria social". Sobre este reclamo incide el reconocimiento formal de derechos que asiste a niños y jóvenes y del reconocimiento que ha realizado la 
legislación educativa vigente, que pondera la participación de los jóvenes en los ámbitos de decisión (gobierno) escolar.

Esta realidad es significada de distintos modos en las escuelas (por jóvenes y adultos).

En las escuelas que componen la muestra, se identifican diversos estilos relacionales que se extienden más allá de los límites escolares. Se ha constatado que cuando entre las familias de los estudiantes y la institución educativa existe compatibilidad de criterios y valores compartidos, la jerarquía de la organización se naturaliza en las relaciones ${ }^{208}$. Cuando no hay compatibilidad ni encuentro de sentidos, se produce una dislocación que torna a las relaciones escolares ininteligibles y al ejercicio de la autoridad como una imposición que genera resistencia.

\subsubsection{También la justicia en moratoria social}

En la escuela centenaria el uso del celular está prohibido por dos razones (expresa una preceptora): porque hay una resolución que así lo establece ${ }^{209}$ y porque la escuela tiene que cubrirse ante la posibilidad de robos, aunque no son frecuentes.

El incumplimiento de esta norma es motivo de "llamadas de atención" a los estudiantes, acompañado de sanciones y conversaciones que suelen interrumpirse con algún hecho que los adultos consideran grave, como el que se relatará.

Las regulaciones de su uso esconden, en general, desigualdades y manifestaciones de un modo de ejercer el poder arbitrario, que se ejerce sobre los sujetos subordinados, en este caso, los estudiantes. Según sus relatos, la prohibición del uso del teléfono celular rige para todos los sujetos de las relaciones escolares, tal como lo han expresado en los AIC. Pero algunos docentes y preceptores utilizan sus celulares cuando les resulta necesario y no se sienten responsables de dar explicaciones o considerarse "en falta".

\footnotetext{
${ }^{208}$ Esto ha sido referido también en investigaciones realizadas por Kessler (2002) y Titamonti y Ziegler (2010)

${ }^{209}$ La preceptora alude a la Resolución № 1728 del año 2006 de la DGCyE que prohíbe el uso de los teléfonos celulares en las escuelas bonaerenses.
} 
Esa situación es vivida con una fuerte carga de indignación por los jóvenes, por lo injusta y reveladora de un estilo autoritario de ejercicio del poder. Cada vez que se produce un conflicto, aparecen en escena los temas de "justicia e injusticia", derivados de los estilos institucionales de resolución de tales conflictos.

El uso del teléfono celular oculta una desigualdad en el trato y en el cumplimiento de los acuerdos que los mismos adultos proponen, para el desarrollo de la vida en común.

La cultura institucional dominante habilita a los docentes a sostener y contener la rebelión pronta a estallar producto de este tipo de prácticas que marcan los modos de relaciones que se construyen en la escuela y que mantienen la relación de desigualdad.

Una mañana, un grupo de jóvenes -cuyo número fue creciendo a medida se "corría la voz"-, organizaron una sentada frente a la dirección de la escuela, reclamando por el trato igualitario, respeto mutuo y pautas justas. La consigna se exhibía escrita en hojas de cuadernos, cuestión que denotaba la inmediatez de la decisión. La "falla" o la injusticia se produjo en una hora de clase en que un estudiante de 50 año fuera echado del aula por mandar un MSN, mientras que en la misma hora, la profesora realizó la misma acción.

La mayor parte de conflictos relevados en la permanencia en la escuela, no fueron "desencadenados" por estudiantes de ESB, que observaban expectantes el desarrollo de los acontecimientos, pero algunos jóvenes se animaban y acudían a acompañar los reclamos de los estudiantes mayores. También al interior de la agrupación estudiantes hay jerarquías y posiciones ${ }^{210}$ que se respetan, sobre todo cuando el emergente se produce en uno de los dos niveles: si es el conflicto surge en ESB, es más posible que los estudiantes del ciclo superior se interesen e involucren, pero esta reacción no es recíproca, y según expresan algunos jóvenes consultados sobre esta actitud, descreen que ellos puedan aportar a los problemas "de los grandes".

\footnotetext{
${ }^{210}$ Se observa una diferenciación entre dos niveles educativos al interior de la enseñanza secundaria en la escuela centenaria: los "chiquitos" de la ESB (educación secundaria básica, asociada de manera constante -por docentes y estudiantes- al tercer ciclo de la EGB de la ley anterior; y la educación secundaria superior, asociada al nivel Polimodal correspondiente a la ley anterior.)
} 
Esta diferenciación no es nueva en la cultura escolar centenaria sino que, a lo largo de su historia -tomando el relato de una preceptora que ha integrado el staff de gestión escolar a lo largo de los últimos veinte años, en la misma escuela- se ha mantenido de esa forma. Gimeno Sacristán (1996:16), en un estudio acerca de la implicancia de las transiciones escolares, expresa:

"En las culturas y en los pueblos existen ceremoniales para marcar el paso del tiempo en su historia, como también se ponen hitos a la vida de los individuos en el paso o proceso de incorporación al grupo de adultos. Resaltar el proceso de cambio en los individuos y en las culturas tiene como finalidad hacer públicos los cambios en el status y en los papeles que cada quien desempeña en el grupo, así como señalar el reconocimiento que la colectividad hará de cada individuo".

Retomando las posibilidades de construcción de una demanda en el contexto escolar analizado, éstas no parecen muy posibles de producirse ya que la fuerza del imaginario institucional, hace que los propios sujetos-actores (los estudiantes de ESB) no se visualicen a ellos mismos con la potencia para llevar adelante acciones de esta envergadura. Esta tarea está reconocida como posibilidad en "los más grandes".

En la vida cotidiana institucional se va conformando una subjetividad política "en moratoria", en correspondencia con los mandatos fundacionales escolares que dan cuenta de una época en que la ciudadanía estaba asociada un proceso de construcción externa al sujeto.

\subsubsection{La gran familia diluye los conflictos}

En la escuela privada religiosa el uso de los teléfonos celulares es también motivo de desacuerdos y reclamos por parte de estudiantes y docentes (profesores y preceptores).

La posición de un grupo de estudiantes de 20 año es clara y determinante. Puede revelarse su postura en el siguiente diálogo, a partir de la pregunta “¿Cómo resuelven el uso de los teléfonos celulares?"211:

\footnotetext{
${ }^{211}$ Durante el tiempo de estadía en el campo se observó que todos los estudiantes llevaron a la escuela $-\mathrm{y}$ usaron- sus celulares. Con motivo de su uso, se relevaron diferentes situaciones de discusión y reprimendas a
} 
A1: -no nos dejan pero lo usamos igual

A2: -legalmente, solo te dejan tenerlo prendido cuando tenés algún familiar enfermo

A3: ...y lo dejas en el banco del profesor

A4:-naaaaaa ¿quién hace eso, Flor? No careties. Nadie pide permiso!

(La profesora a cargo del curso pretende explicarme algo. Un alumno dice irónicamente "No la comprometan")

El diálogo nos permite inferir que existen distintos niveles de acuerdo: uno explícito y formal entre las autoridades del colegio, los docentes y los estudiantes, respecto de la prohibición del uso del celular durante el desarrollo de las clases (pueden utilizarlo en los recreos) ${ }^{212}$; otros acuerdos al interior de los salones de clases entre docente y estudiantes (como en el caso relatado); y acuerdos entre los propios estudiantes, que en general contravienen las normas y los acuerdos particulares con los docentes.

Pero las situaciones que irritan a los jóvenes -que así lo expresan-, son aquellas en las que se producen situaciones de cumplimiento desigual e inequitativo del celular por parte de los docentes:

Inv: lo bueno es que ustedes hagan un acuerdo y lo cumplan, docentes y alumnos.

A4: -no, los profes no lo cumplen

A1: -es verdad, ellos no lo cumplen!!

A3:-lo peor es que sus excusas siempre parecen tener más valor "está mi hija enferma", "me llaman de otra escuela" ¿Y a nosotros que nos importa? ¿Qué saben ellos de qué hablamos nosotros cuando usamos el TE?

Esta nueva transcripción del diálogo devela también la trama del ejercicio de poder en la escuela, que revela una posición adultocéntrica a partir de la cual construyen los docentes su autoridad. Los estudiantes que se sienten violentados en sus derechos y en sus afectos expresa una joven, en relación a las excusas mencionadas: "nos contesta así cuando nos dice

los jóvenes por parte de la directora y conversaciones de la directora con los profesores. Por esa razón se realiza la pregunta mencionada en el desarrollo de un focus group.

${ }^{212}$ Se denomina explícito y formal porque forma parte de un documento escrito (los Acuerdos Institucionales de Convivencia), suscripto por los actores mencionados. Una nota singular es que el colegio admite su uso en el recreo y por lo tanto no prohíbe -como en otras escuelas- que lo lleven. 
que nos quiere y nos tiene confianza!"- recurren a distintas instancias para expresar sus reclamos, pero no al Centro de Estudiantes porque en su pensamiento "no es para estas cosas"

Inv: ya dijeron que al CE no recurrirían, pero entonces ¿cómo reclamarían? ¿Manifestaron ante alguien su disconformidad? Porque si no, nunca resuelven cosas...

A1:-sí, están las tutoras

A5:- a veces no hablamos por no ser el curso problemático

Inv: ¿ustedes reclaman cosas?

A4: -Si!!

A6:-Más las chicas que los chicos

A7:-es que las chicas siempre tienen problemas

Inv: ¿con qué tienen más problemas?

A7:-con los profesores. Bah! Con una profesora en particular

A3:-nosotros no tenemos problemas con los profesores!! Tenemos problemas con esa profesora.

Del diálogo anterior se interpreta que sus reclamos, por más que los coloquen en situaciones de enojo y un aparente desafío a las autoridades (del docente y de la máxima autoridad escolar) no llegan a concretarse en planteos reales por -al menos dos- razones: en primer término, no se vivencian situaciones de opresión que orienten al grupo a aglutinarse tras un motivo considerado justo o un problema nunca resuelto; en segundo término, a pesar de que existe un manejo del poder adulto arbitrario, que interfiere en las relaciones sociales escolares, esto no es percibido como una falla del sistema social que permita filtrar el reclamo y disputar por un orden distinto.

La primera situación puede vincularse con la proximidad existente entre los modelos y valores familiares y los modelos y valores que sostiene la escuela.

El disciplinamiento que realiza la escuela de acuerdo con los valores que comparte con las familias, no se percibe únicamente por el cumplimiento de preceptos de buen cristiano y la asistencia a misa, sino por el cumplimiento en el uso del uniforme, los modos de circular en los recreos, la forma del diálogo.

Los estudiantes destacan numerosos aspectos de este tipo en su vida escolar:

-acá podes dejar tranquila la cartera en el salón durante el recreo, no te va a faltar nada

-si faltás te llaman para saber qué te pasó

-si tenes un problema con un profesor vas y hablás con Teresa (la directora) 
-a veces saben tanto de nosotros que nos tenemos que ingeniar para crear secretos, para tener vida propia

Se comparte para este análisis, la postura de Tiramonti y Ziegler (2008) acerca de que en los sectores sociales medios y altos la trayectoria escolar de los padres incide sobre las elecciones de los hijos, si bien en los tiempos actuales las trayectorias resultan un poco menos predecibles debido a la vertiginosidad de los cambios sociales.

En relación a la segunda cuestión planteada, se puede considerar quela falla en el sistema social de relaciones no sería percibida como tal por la misma razón de proximidad con los valores familiares que presenta; y, a la vez, la rebeldía juvenil no estaría impulsando prácticas de resistencia o petición, en tanto no existe necesidad o deseo insatisfecho. No queda, entonces, margen para la construcción de la demanda y la institución cancela y absorbe las manifestaciones conflictivas derivadas de una subordinación que está, más bien, vinculada a una etapa formativa de los jóvenes.

\subsubsection{La demanda en ciernes: moratoria que disciplina}

Los estudiantes que participan en los espacios políticos convencionales de la escuela secundaria universitaria expresan un alto grado de compromiso con las tareas que emprenden. Esto ha sido observado de este modo en los distintos años de trabajo de campo, como se ha expuesto en los capítulos anteriores.

La agrupación Participación Colectiva Estudiantil ${ }^{213}$ en el año 2009 y 2010, tuvo una profusa exposición pública -hacia afuera de la escuela- con diferentes acciones solidarias y políticas partidarias, que se expresaban como reclamos, solicitudes, protestas. Tanto las primeras como las segundas se realizaban en el marco de las actividades que organizaba la Juventud de la CTA, filial Olavarría.

\footnotetext{
${ }^{213}$ Como se describe en el capítulo 4, esta agrupación está integrada por estudiantes de ESB y cuenta con un extenso apoyo (al momento de ganar las elecciones) de los estudiantes de este nivel de la escuela.
} 
En mayo de 2010, participan con amplia exposición en los medios de comunicación local, en la convocatoria a una marcha denominada "No al aumento del boleto", que junto a diversas organizaciones obreras, partidarias, sindicales, exigía un "NO" al aumento del boleto de transporte público local. Participaron de la convocatoria los estudiantes militantes del FPV y Juventud en CTA y pocos seguidores más.

Esta demanda "hacia afuera ${ }^{214 "}$ produjo un silencioso repudio del resto del estudiantado. Generó una profundización de la brecha que se establecía con los demás estudiantes que no compartían su militancia partidaria y fue un punto de inflexión para que luego perdieran la conducción del Centro de Estudiantes en las elecciones de setiembre-octubre de 2010.

Respecto de las acciones descriptas, se advierte en ellas una lectura sesgada -por parte de los estudiantes de la agrupación militante- del apoyo y la representación que efectivamente recibían y ejercían.

Las acciones de los jóvenes "politizados" generaron manifestaciones de preocupación por parte de los padres de varios estudiantes, que fueron presentadas a las autoridades de la escuela, quienes trasmitieron a los miembros del CE, el contenido de las charlas. En encuentros informales entre los jóvenes y un grupo de docentes y preceptores que apoyan la gestión del CE, minimizaron y desvalorizaron las expresiones de los padres.

Sin embargo, al momento de las elecciones, un grupo de estudiantes que conforman una lista (aún sin constituirse en agrupación con identidad propia), ganan las elecciones de CE 2011, sin que la agrupación perdedora pudiera explicarse lo sucedido.

En relación al tema central de este capítulo, la demanda y la construcción de subjetividad política ( $y$, por lo tanto, ciudadana) de los jóvenes, entendemos que no se produce al interior de la escuela al no poder leer (desde la agrupación que lideró el reclamo por "No al aumento del boleto") las reales necesidades y valoraciones sociales y políticas del estudiantado que decía representar. En los estudiantes que conducían el CE estaba formada una subjetividad política en relación a la política partidaria, en su tránsito por otras organizaciones coexistentes con la escuela. En la mayor parte de los miembros, se registra una trayectoria

\footnotetext{
${ }^{214}$ El reclamo tenía como destinatarios al Concejo Deliberante Municipal y a las empresas de transporte. No involucró a la modificación de ningún orden escolar y tampoco logró adhesión por fuera de los jóvenes que ya los apoyaban.
} 
familiar de participación política o político-gremial de uno (o de ambos) padres. La escuela aparece como un lugar más "para ganar", para expandir su ideología, pero después del éxito electoral inicial, pierden de vista a sus representados. Más aún, los jóvenes que habiéndolos votado les reclaman participación y reordenamiento de sus acciones, no fueron escuchados sino que se generó entre ellos una fractura que se expresó, en distintos momentos, con enfrentamientos verbales que trascendieron los ámbitos escolares.

Puede interpretarse que estos jóvenes reproducen en su accionar, prácticas propias del sistema partidario que, justamente, no es aceptado por un gran número de jóvenes de la escuela. Desconocieron que la situación de subordinación u opresión no recaía sobre el grupo que representaban formalmente $y$, por lo tanto, no lograron constituir, desde la escuela, una demanda.

El sistema social escolar -integrado mayoritariamente por los alumnos- se cerró en torno de una práctica que resultó disonante y la encapsuló. Utilizando sus propios recursos se deshizo de esa fracción, en algunos puntos amenazante, pero que no logró generar adhesiones. La situación se diluyó hasta que, al momento de elegir nuevamente a sus representantes, los estudiantes se volcaron a otra agrupación. Los jóvenes como actores institucionales cancelaron el conflicto.

Se registraron también otras situaciones en las que la estructura social escolar produce acciones de opresión sobre los jóvenes. Si bien diversas situaciones de ejercicio discrecional del poder adulto, especialmente encriptado en relaciones pedagógicas, era registrado por la investigadora, solo en un curso de segundo año fue expresado por los estudiantes:

A1: -los profesores no cumplen lo que dicen los contratos (refiriéndose a los AIC), pero a nosotros nos los hacen cumplir

Inv: -¿A quién le reclaman cuando eso pasa?

A1:- a nadie, a veces lo charlamos con los preceptores

Inv: ¿Se la bancan así nomás?¿por qué no reclaman?

A2:-por no generar enemistad con los profesores

A3: a veces se lo podés decir a Rosana (la vicedirectora) que te entiende, pero a la larga, cuando se entera el profesor, no lo toma bien, no se da cuenta de lo que estamos diciendo, siempre creen que es para zafar 
Inv: ¿ustedes creen que podrían tener otra relación no mediada por las calificaciones con los profesores?

A3: sí, con algunos las tenemos

A4: sí, pero después te caga cuando cierra el trimestre

A5: siempre es lo mismo, y si le decís a tus viejos, ellos te dicen que estudies, no entienden que hay otras cosas

Inv: ¿qué cosas?

A5: entendimiento, no sé...darte otros tiempos, entender que a nosotros también nos pasan cosas

Inv: ¿Qué cosas aprende con esto?

A2:-aprendes a que si le reclamás al profesor, perdiste

Este diálogo se propone mostrar que existe una falla en el orden escolar, al menos desde la visión de los jóvenes. No todos pueden ponerle palabras, con lo que se entiende que hay distintos procesos de maduración de la situación.

Para esta escuela, al momento de la investigación se está poniendo en marcha la ESB por primera vez en su historia y los cursos son fundacionales.

Aquí también la escuela produce un disciplinamiento en acuerdo con los valores que comparte con las familias, que no se percibe únicamente por el cumplimiento de las pautas establecidas en relación al contenido disciplinar de la enseñanza, sino por el cumplimiento de normas y costumbres que, si bien amplían a unas relaciones con mayor participación de los jóvenes, en cierta medida quedan supeditadas hasta su tránsito por el nivel superior.

\subsection{Fragmentación social que se reproduce en la escuela 0 ¿dónde está la escuela?}

Daniel Filmus (1993) ubica el inicio del deterioro de la educación en Argentina a partir del año 66, luego de "la noche de los bastones largos". Ese momento marca el detenimiento del desarrollismo en el país, posiblemente la última estrategia de consolidar el proyecto igualitarista moderno.

Jaim Echeverri (1999) explica que la tragedia educativa en Argentina, a la vez que interpela no solo al ámbito educativo sino a las esferas social, cultural, económica y política, no se 
reduce solamente a la decadencia de los indicadores de rendimiento educativo de los niños y jóvenes, sino que además es necesario pensar en cómo se ha diluido en la escuela, el tratamiento de cuestiones atinentes a la humanización, interioridad y el riesgo de la homogeneización del pensamiento con el triunfo del consumismo.

Los años noventa fueron sin dudas tiempos de profundas reformas y transformaciones en el ámbito educativo, en el que se expresan las transformaciones sociales y los cambios en la centralidad del Estado para instituir el orden social. La salida de la etapa de reducción estatal llevada a delante por el presidente Ménem (1989-1999) y su ministro de economía Domingo Cavallo, dejó como resultado no solo una sociedad más pobre, sino -y fundamentalmenteun escenario social fragmentado y desarticulado.

El mundo social de los sectores populares (Kessler et al, 2010), sufre reconfiguraciones que le imprimen nuevas particularidades. Una que se destaca para el análisis que se realiza en este apartado, se vincula con

“...la ruptura de los lazos de solidaridad: en primer lugar, en aquellos lazos interclasistas que se habían entablado entre las clases medias movilizadas y las clases populares, que encontraron su máxima expresión en los años 70; en segundo lugar, de aquellos lazos interclasistas en las clases populares, visible en la distancia operada en los trabajadores asalariados, afectados por la precarización y disciplinados por la amenaza del desempleo, y la emergencia de clases populares plebeyas, asociadas a partir de los 90, con la territorialización de la política y el mundo comunitario de los pobres urbanos, los "excluidos"”. (Kessler et al 2010: 11)

En la ciudad de Olavarría se encuentran algunas de las características mencionadas, resignificadas $^{215}$, en la Zona de Gestión Territorial 1, donde se encuentra ubicada ESB №10. La ruptura de los lazos solidarios, es un aspecto manifiesto de las relaciones sociales de los jóvenes de clases populares que componen la matrícula de ésta escuela secundaria, tanto en las relaciones interclasistas como intraclase. La primera, genera choques y conflictos en relación a los docentes, aun cuando algunos de éstos últimos eligen esta escuela por convicción ideológica, más allá de la elección de la docencia como trabajo. La segunda,

\footnotetext{
${ }^{215}$ Este tema vinculado a las transformaciones sociales que se observan en la ciudad intermedia de la Provincia de Buenos Aires es desarrollado e n el Capítulo 1, pto.
} 
lesiona las posibilidades de integración y trabajo grupal, y mucho más aún: lesiona la posibilidad de los jóvenes para pensar-se colectivamente.

En relación a las diversas formas de pobreza, nos proponemos recuperar también otra perspectiva en el análisis. Dice Tenti Fanfani (2007:18):

“...esta es cada vez más multidimensional y heterogénea. No solo es una cuestión de insuficiencia de ingresos sino que también tiene múltiples manifestaciones culturales que la diferencian de las viejas formas de pobreza, típicas del capitalismo de la segunda posguerra."

Con ello, estamos afirmando que el nuevo escenario escolar al que asisten docentes y jóvenes está atravesado por múltiples dimensiones diferentes y en oportunidades, contradictorias. Pero además, es preciso señalar una situación paradojal (Tenti Fanfani op cit): a mayor exclusión del sistema social y productivo producida en los últimos años del siglo XX, hay una mayor proporción de jóvenes en proceso de escolarización, producto de las políticas sociales que comienzan a implementarse en los `90.

En este proceso, mientras se incorporan jóvenes con matrices culturales diversas, dinámicas, con lenguajes e intereses que se reconstruyen al ritmo de los avances tecnológicos, la escuela, que permanece perpleja, atina a reproducir las prácticas que durante más de un siglo, le resultaron eficaces y eficientes en el cumplimiento de los fines propuestos por la política hegemónica. En consecuencia, “El carácter masivo de la exclusión y la escolarización genera, entre otras cosas, una crisis del sentido tradicional de la escuela" (Tenti Fanfani, 2011: 19).

\subsubsection{Una relación fragmentada y sedimentada en la cultura escolar que se construye desde la escolaridad primaria}

En la escuela ESB № 10, se observa dislocada la función educativa de la escuela secundaria $^{216}$. Dislocación, en este caso, que da cuenta de una institución que ha cambiado

${ }^{216}$ El primer objetivo general del Nivel Secundario de la Educación, establece en su Cap. V, art. 28o: “ "Garantizar la producción y adquisición de conocimientos propiciando la continuación de los estudios y 
el sentido moderno de ser escuela y donde pareciera que la organización adquiere una nueva función, en una etapa donde instituciones disciplinarias parecieran reconvertirse en organizaciones de control.

Atendiendo a la discapacidad actual que se observa en la escuela en su aspecto pedagógico (educativo) y para establecer normas y roles, el desencuentro puede explicarse apelando a comprender la orfandad de algunos docentes y funcionarios que operan en ese contexto, desprovistos del conocimiento que la situación requiere. Como expresa Tenti Fanfani (2011: 23), citando a Norbert Elías, los actores escolares "deben estar en condiciones de entender lo que pasa a su alrededor. (...) Esta comprensión requiere una dosificación adecuada de compromiso y distanciamiento". El compromiso apela a re-valorizar la tarea educativa y los valores que conlleva; el distanciamiento, apela a la racionalidad de los actos por encima de las presiones coyunturales que no permiten mirar más allá de los problemas inmediatos.

Lo cierto es que las escuelas singulares han sido lanzadas a "gestionar" su propio destino y funcionan como islas. Esto se evidencia en el discurso de los estudiantes pero también en el de los profesores:

A 1: -“... yo cuando pueda me cambio a otra escuela porque en esta, no se aprende nada. Si vas a la San Antonio $^{217}$, ahí podes seguir estudiando -yo quiero ser policía, mi tía es policía-, pero en esta no... Si los profes no vienen nunca. Ni tenemos biblioteca, nada...(alumna de 3er año ESB)

A2: mejor que no vengan, así miramos películas. Yo, cuando a mi viejo le salga una changa en el campo, me voy con él. Total, es lo mismo...si acá no aprendés nada, y a mí no me gusta estudiar. Estoy acá por el certificado para mi viejo.

asegurando la inclusión, permanencia y continuidad de los alumnos en el sistema educativo público mediante una propuesta de enseñanza específica, universal y obligatoria para todas las Modalidades y orientaciones, en todos los Ámbitos de desarrollo, que promueva el conocimiento, y la articulación con, del patrimonio cultural, científico, tecnológico, de desarrollo e innovación productiva de la provincia, el país y el mundo" (Ley Provincial de Educación № 13 688)

${ }^{217}$ San Antonio es una escuela confesional parroquial de bajo costo de matrícula que funciona a tres cuadras de la ESB 14. 
Prof. 1: “...no sé porque en esta escuela no llegan los libros, no tengo cómo incentivarlos, no hay biblioteca, nada. Parece que más pobres son y el Estado les da menos. Pero sin embargo, en la de Hinojo, que es igual que ésta, las cosas llegaron... No sé..."(profesora de Prácticas del Lenguaje) ${ }^{218}$

Prof. 2: “...cuando consiga un par de horas más, no me quedo ni un minuto en esta escuela. No puedo dar clases y además, tengo miedo. En este barrio son pesados, pesados, yo ni loca los enfrento, pero no puedo dar clases" (profesora de Inglés)

En los diálogos que se presentan se pueden observar distintos intereses que no se articulan en ningún proyecto común, pero que dejan ver con claridad una organización que no logra definir para sí sentidos asociados a la función educativa de la escuela.

La lógica que parece atravesar las relaciones sociales en la ESB suburbana pareciera basarse en el ejercicio de la fuerza para tener el control de las situaciones. Claro que la fuerza no siempre se encuentra del lado de los adultos, aunque en la mayor parte de las situaciones relevadas haya sucedido de este modo. Pero, aunque el control (y el poder) permanezca del lado de los adultos, hay momentos en que se invierte la relación, en especial con los profesores jóvenes. Un joven estudiante de segundo año de ESB, explica:

A 2: -con algunos profes es imposible llevarse bien. Vienen a bardiarte

Inv.-¿¿Y ustedes qué hacen?

A2: - a veces las hacemos llorar...¿¿se acuerda la del año pasado? (en relación a una profesora de plástica). Lloraba, hasta que se fue. Pero este año somos menos, estamos más...no sé

-¿Desorganizados? -pregunto

A2: -No, no sé, es como que no nos ponemos las pilas

Inv. -¿Con las tareas escolares?

A2: -No, con echar a los profesores (risas, aplausos). El año pasado éramos nosotros los terribles, este año son los de 5to. Yo los apoyo en todo, a mí no me importa (Emilio) si hacen quilombo, me voy con ellos...

Inv. -¿qué no te importa?

\footnotetext{
${ }^{218}$ Los libros no llegaron, la biblioteca de la ES no se puso en marcha porque la directora no sabía que ella era responsable de solicitar ese servicio. Y cabe aquí una reflexión que no es colateral, para comprender el funcionamiento de este tipo de escuela: la apertura de los nuevos "servicios educativos", requirió de concursos para la cobertura de cargos directivos porque "la estructura" necesita de éstos funcionarios (responsables civiles) del desarrollo de las actividades. Así fueron incentivados a presentarse a los concursos, docentes que nunca tuvieron en su horizonte futuro próximo ocupar esos cargos, como es el caso de la directora de esta escuela.
} 
A2: -a mí me importa echar a los profesores que nos vienen a bardiar

Inv. ¿no podrías reclamar mejor trato?

A2: no...esto ya es así desde la primaria

El diálogo resulta elocuente del sentir del joven: no ha encontrado puntos de acercamiento con los docentes, desde la escuela primaria. Las trayectorias de los jóvenes por las escuelas primarias parecen resultar un antecedente (casi una anticipación) de lo que será su trayectoria en la escuela secundaria, tal como se inscriben en su subjetividad las relaciones humanas con los docentes.

Éste joven ha internalizado la idea de que con los adultos de la escuela (a excepción de la cocinera, que es la única persona adulta con quien se relaciona en términos de igualdad y respeto), no puede establecer relaciones orientadas por el entendimiento. Permanece en estado defensivo durante la jornada escolar, si le es posible, se escapa de la escuela y de lo contrario, sus acciones se orientan a provocar a los profesores. Consigue el acompañamiento de un grupo de varones que en general, duerme durante las primeras horas de clase y no se involucra en ninguna situación de enseñanza ni de diálogo con el resto de los jóvenes del curso, o con los profesores.

\subsubsection{Una protesta espontánea y circunstancial descubre la debilidad de los lazos sociales entre los jóvenes}

Una situación de protesta colectiva se generó días antes de las vacaciones de invierno de 2011, en el momento del ingreso de los estudiantes a las aulas: la dinámica de funcionamiento que se observó durante los dos años anteriores mostró que en verano y primavera, los jóvenes llegan a la escuela y permanecen en el patio hasta que el personal directivo y los profesores presentes, salen al patio a izar la bandera y saludarlos. En el invierno, los estudiantes permanecen afuera hasta el timbre de ingreso, la directora saluda y luego ingresan a la escuela. Los profesores permanecen en el interior, rodeando el calefactor de la galería y tomando mates, "porque hace mucho frío".

Una mañana gélida, cuando los alumnos ingresan al interior del edificio, se ubican ellos (mayoritariamente estudiantes de 4ํ y 5 años que no superaban el número de 10 ) alrededor 
del calefactor, desplazando del lugar a los docentes. Cuando se les ordena ingresar a los salones, no obedecen y expresan que ellos también tienen fríoy que han decidido no ingresar al salón. Las mujeres llevan la voz cantante.

Se genera una situación de malestar; los docentes profieren amenazas (sobre calificaciones e inasistencias).La directora intenta un diálogo pero los estudiantes le reprochan su actitud de dejarlos afuera bajo la helada, "mientras los otros están calentitos" (dicen una joven) "y seguro que ellos tienen calefactor y nosotros venimos fríos desde la casa" (dice otra).

En el recreo se suman algunos otros estudiantes, pero en el transcurso de la mañana, se los observaba aburridos -y así lo expresaban-, hasta que ingresaron a sus salones.

Al día siguiente intentaron ingresar a la escuela a medida iban llegando, pero una portera, argumentando que ensuciaban la galería y desmerecían su trabajo, intentó frenar el ingreso. Como represalia las primeras chicas comenzaron a introducir gomas de borrar en el calefactor y la acción fue imitada por varios más ${ }^{219}$. El denso humo y el olor invadieron rápidamente la escuela. En ausencia de la directora, el descontrol fue en aumento hasta que alguien llamó a la directora pero también a la policía. Para el arribo de ambos se habían retirado de la escuela la mayor parte de los alumnos y el resto (profesores y jóvenes) permanecían en la vereda. En los días subsiguientes el calefactor se mantuvo apagado y al regreso de las vacaciones de invierno otros incidentes hicieron olvidar éste suceso.

En diálogo con tres de las jóvenes intervinientes en el suceso, se pretendió orientar la reflexión hacia el reclamo en base a derechos igualitarios, pero su único interés sobre el tema había girado a hostigar a la portera, a quien conocen del barrio y desde el día del incidente "se la tenemos jurada".

Profesores y directivo pretenden no volver a hablar del suceso, "para que no vuelva a repetirse", sin que nadie intente mediar con palabras y reflexión fundada sobre esas acciones. La intervención de los adultos estuvo centrada en "no perder" los poquísimos alumnos que permanecen en los años superiores.

\footnotetext{
${ }^{219}$ Relataron luego que la acción no fue acordada con anterioridad, que fue producto de la situación.
} 
¿Qué dejó la protesta en la subjetividad de los jóvenes? Sólo una pauta de acción circunstancial, situada, sin mayor trascendencia en su construcción como sujetos ni en su accionar institucional.

Retomando las ideas de Laclau y Moufe (2004) respecto de que la demanda se produce cuando hay procesos previos de opresión, éstos jóvenes han transitado una escolaridad predominantemente opresiva, descalificante, que solo en algunas situaciones ha sido alterada por relaciones bien intencionadas pedagógicamente y también compasivas.

No está en su horizonte de posibilidades disputar estratégicamente el orden escolar, exceptuando acciones coyunturales que se evaporan rápidamente. $\mathrm{Ni}$ el conocimiento del curriculum prescripto ni las prácticas del curriculum oculto acompañan la posibilidad de reflexionar sobre los sucesos que protagonizaron.

Otra ausencia significativa para la constitución de la demanda es la del lazo social. Pareciera que los jóvenes no han construido -en especial en la clase social de origen- relaciones intraclase que produzcan una solidaridad que los fortalezca.

\subsection{Reclamos que se constituyen en demanda: análisis de un caso}

La situación que se presenta a continuación corresponde a un grupo de jóvenes radicados en la zona rural del partido de Olavarría, que demandan la continuidad de la escolaridad secundaria.

Como grupo socio- económico y cultural, se ubican -al igual que el grupo anterior-en el fragmento inferior de la escala social, portadores de una cultura popular asalariada (Kessler et al 2010), que lucha por mantenerse incluido en el sistema socioproductivo y reconoce en la educación una posibilidad de ascenso social.

Se destaca que en este contexto social se mantienen ciertos aspectos de convivencia y vínculos sociales interclases, pues en los encuentros festivos participan empleados, peones, pequeños propietarios, maestras, profesores, representantes del club social y deportivo de la zona, pequeños comerciantes (compradores de producción agrícola ganadera puerta a puerta, vendedores ambulantes, propietarios de almacén de ramos generales, entre otros) y 
también políticos que ocasionalmente se hacen presentes, al igual que funcionarios municipales.

\subsection{1."Queremos seguir estudiando, que por favor nos dejen"}

Con ese titular, el día 6 de diciembre del año 2009, aparecía en el diario local "El Popular", la problemática y el reclamo de los estudiantes de la ESB de dos escuelas rurales del partido de Olavarría, que ven peligrar la continuidad de sus estudios secundarios ${ }^{220}$. El problema por el que esta comunidad rural adquiere visibilidad pública hace eclosión en el año 2009, cuando la primera cohorte de nivel secundario (inicado en 2006) debe iniciar el 4to año de la escuela secundaria superior (ESS). Es allí donde las inspectoras y el Consejo Escolar ${ }^{1}$ deciden que ante la escasa cantidad de estudiantes (3) en condiciones de iniciar la ESS y el costo que esto significa en pago de salarios docentes y traslado, es conveniente el traslado de los jóvenes a otro centro educativo. Proponen uno que funciona en la localidad de Recalde $(40 \mathrm{~km}$ de la escuela "La Moderna") o el CEPT que funciona en Espigas (es una escuela de alternancia a 60 km, con internado para los y las jóvenes).

El planteo que a través del medio de comunicación se realiza a la sociedad civil y al Estado es claro: la escuela secundaria es obligatoria por ley, pero en la práctica la ley no se cumple. Y es el Estado (o el gobierno?) quien incumple con este mandato.

Los estudiantes que asisten a la redacción del diario son 14, aunque los que se ven perjudicados con la situación son 31 en total: 23 en una escuela rural que funciona a $13 \mathrm{~km}$ de la ciudad y 8 de la otra escuela, que funciona a $80 \mathrm{~km}$ de la ciudad de Olavarría. Concurrieron al diario acompañados por la profesora Gabriela, a cargo de las materias de Historia y Construcción de Ciudadanía, en las dos escuelas rurales ${ }^{221}$.

En la nota mencionada del diario El Popular, se dice:

\footnotetext{
${ }^{220}$ Puede consultarse el Anexo Documental y Metodológico, pto VI: “Notas periodísticas en diarios locales”

${ }^{221}$ El trasfondo de esta nota periodística es que las dos escuelas rurales que se mencionan, funcionan como "anexos" de una de las escuelas secundaria de crecimiento (la ESB № 1 con asiento en la ciudad de Olavarría), que fue contactada para realizar la primera etapa de exploración. Allí tomo contacto con la profesora Gabriela quien me informa de la situación de abandono -por un lado- y la presión de las autoridades escolares sobre las comunidades rurales -por otro- para que envíen a sus hijos a la ciudad, porque no existen partidas presupuestarias para dar continuidad a los cursos obligatorios que prevé la ley 13.688/07.
} 
“P- ¿Por qué no podrían cambiar de escuela y sentarse en un banco de cualquier institución de la ciudad?

"-Porque estamos a 80 kilómetros", remarcan. "Podríamos ir a Espigas, pero igual tendríamos que separarnos de nuestras familias. Es muy complicado el tema de la distancia", dicen con naturalidad y preocupación. "Y además en Espigas vas una semana a la escuela y dos te quedás en tu casa, pero quién te explica si tenés dudas, cómo aprendés sin nadie al lado", se pregunta con absoluta lógica Telmo, mientras agrega que "necesitamos continuidad".

Los chicos conocen la ley que habla de secundaria obligatoria de seis años. Saben también sobre sus derechos y sus obligaciones, y por eso exigen. Quieren ser como cualquier adolescente que vive en su casa, con su familia, y va a la escuela todos los días, tan simple como eso".

La respuesta oficial a la escuela próxima a la ciudad fue rápida, pues los estudiantes viajaban diariamente a la ciudad en una combi subvencionada por el Consejo Escolar y articulaban directamente con la escuela secundaria de la cual es "extensión".

Los que continuaron con el reclamo fueron los más alejados de la ciudad, para quienes la opción del traslado diario no era viable y se resistían a desprenderse de su familia y de su entorno $^{222}$. Algunos no podían hacerlo aunque quisieran, no tenían familiares con quienes dejar sus hijos y "son muy chicos para instalarlos en una pensión" -argumentaron las madres-.

En los primeros meses del año, padres, estudiantes y docentes se entrevistan con el Intendente; pidieron audiencia con la inspectora regional quien les explicó que el expediente estaba iniciado, pero no había respuestas ni soluciones en el corto plazo. Al iniciarse el ciclo escolar 2010, solo un estudiante estaba en condiciones de continuar el 40 año de la educación secundaria. Como no se produjo la apertura del curso, debió quedarse con su familia en el campo, convirtiéndose, por el abandono del propio Estado que le otorga el derecho a la educación, en "desertor" que incumple con la ley, contra su voluntad.

Los jóvenes tienen conciencia de ello. En una de las entrevistas grupales han manifestado que ellos "saben" qué significa ser sujetos de derecho ${ }^{223}$.

\footnotetext{
${ }^{222}$ Con este grupo de estudiantes y con la comunidad en general, se continuó el trabajo de investigación.

${ }^{223}$ Ha quedado explícito en el Capítulo IV, punto 4.4.1.
} 
Esta situación revela por un lado, la existencia de una falla del orden social y junto con ella, la condición de posibilidad percibida como tal por un grupo de estudiantes.

Antes de avanzar en el desarrollo de los sucesos en los que se fue construyendo la demanda, nos detendremos en un análisis de otras situaciones contextuales e históricas en las que se nutre el grupo. Una, se relaciona con la historia de la comunidad y cómo construyeron la escuela; la otra, tiene que ver con la constitución de este grupo movilizado de estudiantes.

La historia de la comunidad y la escuela, ha sido desarrollada en capítulos precedentes; nos resta mencionar que existe una comunidad que "siente" la escuela como propia, que valora la educación y deposita en ellas parte del futuro de sus hijos y que aprendió a hacerse cargo de sus necesidades y a presionar desde ese lugar al Estado.

El grupo desarrolla relaciones que fortalecen la construcción de la demanda. Desde su ingreso a la ESB, los jóvenes comienzan a compartir con la profesora de Construcción de Ciudadanía un camino que no habían recorrido hasta entonces. El proceso de reflexionar, desde la mirada de las acciones de la vida cotidiana, los contenidos del espacio curricular, comenzó a hacerlos sentir vigorizados, individual y grupalmente y produjo cambios en su conducta. Así lo relataron tiempo después de su primera aparición en la vida pública ${ }^{224}$ :

J. Sí, cambiamos bastante en nuestras casas y acá. Por ejemplo acá: pedimos participar en las reuniones, organizamos nosotros almuerzos (que antes siempre lo hacían las madres y nosotros dejábamos que lo hicieran ellas), encuentros, pedimos que nos tengan al tanto sobre cosas que piden para nosotros, o administrar el uso de las computadoras, que nos avisen cuando las usen

A: ¿de qué reuniones quieren participar?

B: de las comisiones de los viajes, por ejemplo

A: qué viajes, de los que iban a...?

J: los que vamos a hacer nosotros. Antes no participábamos, y los viajes los vamos a hacer nosotros. Entonces empezamos a participar

${ }^{224}$ Poco tiempo después de la participación de los jóvenes en los talleres "Sociales en acción" -y no encontrando resistencias para el desarrollo de este trabajo- se decidió la realización de la investigación en esa escuela rural. 
Una de las propuestas que les hizo Gabriela fue comenzar a integrarse con jóvenes de otras escuelas, para compartir experiencias, puntos de vista, debatir sobre temas de mutuo interés. Así, les propone concurrir a las Jornadas "Sociales en acción" que organiza la Facultad de Ciencias Sociales para estudiantes de 3er año de ESB ${ }^{225}$. Por la tarde, participaron de un taller sobre "Los jóvenes y la ciudadanía", organizado por jóvenes del Centro de Estudiantes de la escuela universitaria y un grupo de docentes del área de Ciencias Sociales.

Allí plantearon el problema de ser denominados sujetos de derecho y a la vez, ser negados en esa misma condición. Johana, una buena oradora, capaz de encontrar las palabras que median entre el lenguaje juvenil y el lenguaje capaz de ser "tolerado" por la estructura escolar, supo plantear el problema de modo que sus compañeros se sintieron identificados en el discurso, a la vez que sumaba adhesiones de jóvenes de otras escuelas.

Las profesoras y directivos de otras escuelas presentes se reunieron con la profesora Gabriela y algunas madres que acompañaban a los jóvenes de la escuela rural, sensibilizados por la situación, con la pretensión de involucrarse en alguna acción orientada a la solución del problema ${ }^{226}$.

Nuevamente en clase de Construcción de Ciudadanía, reconstruyen con la profesora Gabriela y la preceptora (presente en el aula), los sucesos de los días previos. Los jóvenes están impactados por su propia actuación y por su incorporación a una esfera más amplia, que desconocían. Reflexionan:

Brian: -está claro que los derechos no son iguales para todos. Si nosotros no lo reclamamos, no tendríamos escuela. Pero tampoco EP, ni tercer ciclo, ni el jardín de los chiquitos.

Johana: esto te demuestra que siempre tenés que ir para adelante con tus sueños. A veces te sentís cansada, pero al otro día te pasa algo que te vuelve a cargar las pilas.

\footnotetext{
${ }^{225}$ En la Jornada, se ofrecen distintos talleres que tocan cuestiones sociales de interés para los jóvenes de esta edad.

${ }^{226}$ En este espacio surge, como primera acción, la realización de una nota en el diario (puede consultarse en el Anexo № VI)
} 
(...) con los adultos a veces te tenés que pelear, porque no entienden. Pero se alegran con nuestros logros. Ellos tienen miedos por nosotros. Y sin Gabriela, no lo hubiéramos podido hacer

Mayra: y sin Johana tampoco!! (se ríen). Ella llevaba siempre la voz cantante, nos movilizaba a todos los que teníamos un poco de miedo, de tus papás, de que va a decir la maestra...

Para los jóvenes, el contacto con jóvenes de otras escuelas fue crucial. En especial, con los organizadores, que profundizaron el discurso en torno del conflicto presentado y las posibilidades de accionar de manera conjunta. Los estudiantes de la escuela secundaria universitaria, militantes de la juventud de la CTA local, prometen activar sus contactos para que avance la solución oficial.

Cuando se inicia el año 2010 sin ninguna alternativa viable para ellos desde la política oficial, los jóvenes comienzan a delinear un plan, siempre acompañados por Gabriela.

\subsubsection{Demanda y conocimiento (o curriculum)}

Comienza un nuevo ciclo escolar, sin secundaria superior para la escuela "La Moderna". Telmo, único estudiante en condiciones de cursar 4to año, se recluye en su casa, comienza a trabajar en las tareas rurales con su familia. Una vez por semana, aproximadamente, va de visita a la escuela y se encuentra los fines de semana a jugar al futbol con sus compañeros.

Pero en la escuela el grupo continúa trabajando la idea de ejercer presión, generar conflicto, para lograr lo que por derecho, les pertenece.

Han tomado una actitud confrontativa con la Comisión Cooperadora de la escuela primaria, que pretende tener injerencia sobre decisiones que corresponden a los profesores del nivel secundario. Los jóvenes marcan esa diferencia en una reunión, solicitando que no dejen que la familiaridad avance en todos los espacios porque no podrán actuar responsablemente. Manifestarán luego "es necesario que puedan distanciarse, porque si no, todo es un chusmerío, y así no se puede llevar adelante ningún proyecto"227.

${ }^{227}$ En concreto, se trataba del manejo de fondos para la realización de un viaje de egresados del 3er ciclo. El tema de fondo, es que se trate del nivel primario o secundario, los padres son los mismos, que tienen varios hijos en distintos niveles de la escuela. Esta decisión -apoyada por Paula- repercutió también en las relaciones 
Viendo que los adultos no accionan con medidas más contundentes ${ }^{228}$, que quedaban "atrapados" -sic- en procedimientos formales "y así no se consigue nada, ya se podrían dar cuenta"-expresan-, toman dos decisiones vinculadas: conformar un Centro de Estudiantes para tener un órgano oficial de representación y para ser asesorados sobre su conformación, invitarán a los jóvenes del CE de la escuela universitaria, que recientemente había tenido elecciones y había resultado ganadora una lista integrada por los estudiantes militantes en la Juventud de la CTA.

En junio se produce la reunión, en la sede de la escuela rural. Hubo un almuerzo cordial en el que se mezclaron jóvenes y adultos, pero luego los jóvenes decidieron reunirse a solas, sin la presencia de ningún adulto. Finalizada su reunión, relatan que visualizan los procedimientos para conformar un $\mathrm{CE}$, que existen algunos puntos de la reglamentación con los que no podrán cumplir ${ }^{229}$, pero que ellos pretenden formarse en prácticas de democracia participativa, por lo cual invitarán a alumnos de los últimos años del nivel primario y a Telmo, para acordar sobre los temas que les interesan. No van a notificar a la Directora de la ESB № 1 de la cual son extensión, porque seguramente a ella no le interesa y a ellos tampoco y pedirán el asesoramiento de Gabriela.

Piden información a la preceptora y a la Directora de primaria sobre el expediente confeccionado con toda la documentación de solicitud de para la apertura del nivel Secundario Superior, porque realizar un seguimiento de ese trámite será su prioridad.

Poco tiempo después los datos del expediente en cuestión les son informados y con ello toman contacto -a través de una de las jóvenes de escuela universitaria- con un funcionario de la DGCyE -primo de la joven mencionada- que les asegura resolver la situación ${ }^{230}$.

familiares, que se vieron alteradas por la "rebeldía" de los jóvenes que pretendían decidir sobre el fin del uso del dinero.

${ }^{228}$ Los estudiantes querían ir a hacer una sentada y corte de calle a la Municipalidad y a la Secretaría de Inspección, pero no contaban con el apoyo de los padres y solos no podían llegar a la ciudad.

${ }^{229}$ Puntualmente, el número de estudiantes de ESB no resulta suficiente para conformar el CE como lo establece el reglamento vigente.

${ }^{230}$ La apertura del 4to año se concretó a principios del año 2011. Johana y Brian, no completamente seguros de las promesas recibidas, se trasladaron a vivir a la ciudad donde siguieron sus estudios secundarios. 
La demanda de los jóvenes circuló por canales no convencionales en relación a la lógica estatal y a la tradición de la comunidad que rodea a la escuela. Los jóvenes percibieron la lógica de la política actual y, aun rechazándola, la utilizaron, aunque continuaron manifestando su repudio a la política (entendida como la práctica del gobierno y del poder instalado).

\subsection{El pasaje de sujetos sociales a sujetos políticos: la potencialidad de la} demanda.

Al reflexionar, en perspectiva, sobre las acciones de reclamo o demanda que los jóvenes llevaron adelante en los contextos escolares, advertimos que esas acciones son también, para quienes participaron de ellas, portadoras de huellas en su construcción como sujetos políticos.

Las marcas de esas acciones no se medirán por lo exitosas que resultaron en término de los logros obtenidos, sino por las posibilidades de aproximación al pasaje del sujeto social al sujeto político que produzcan y, en tanto evento marcado por la significatividad en el contexto escolar, su posibilidad de transferencia a nuevas experiencias.

En los casos analizados, las situaciones de necesidad o conflicto variaron en cuanto a la intensidad lograda, pero también es preciso señalar que existieron otros factores decisivos en los modos de resolución, como son las condiciones contextuales institucionales, la intensidad de la necesidad o conflicto, la disponibilidad de conocimiento sobre el tema que permitió su elaboración y comunicación, la constitución del grupo, todas ellas coadyuvantes para el laborioso pasaje del plano individual al colectivo, del sujeto social al sujeto político. 


\section{Bibliografía:}

BOURDIEU, P. (1998). Capital cultural, escuela y espacio social. Siglo XXI. México, DF.

BOURDIEU, P. (2001). El campo político. Plural Editores. Bolivia.

FILMUS, D. (1993). ¿Para qué sirve la escuela? Tesis Norma. Buenos Aires.

GIMENO SACRISTÁN, J. (1996). La transición a la educación secundaria. Morata, Madrid.

JAIM ECHEVERRI, G. (1999). La tragedia educativa. Fondo de Cultura Económica, Buenos Aires.

KESSLER, G. (2002). La experiencia escolar fragmentada. Estudiantes y docentes en la escuela media de Buenos Aires. IIPE-Unesco- Buenos Aires

KESSLER, G., SVAMPA, M. y GONZÁLEZ BOMBAL, I. (2010). Reconfiguraciones del mundo popular. El conourbano bonaerense en la posconvertibilidad. UNGS- Prometeo, Buenos Aires.

LACLAU, E. (2000). Nuevas reflexiones sobre la revolución de nuestro tiempo. Nueva Visión, Buenos Aires.

LACLAU y MOUFE (2004). Hegemonía y estrategia socialista. Fondo de Cultura Económica, Buenos Aires.

LACLAU, E. (2005). La razón populista. Fondo de Cultura Económica, Buenos Aires.

NÚÑEZ, P. (2011). Protestas estudiantiles: interrelaciones entre escuela media y cultura política. Revista Propuesta Educativa № 35. Año 20. Junio 2011. P.7-10, Buenos Aires.

RETAMOZO, M. (2009a): Orden social, subjetividad y acción colectiva. Notas para el estudio de los movimientos sociales. Revista Athenea Digital № 16 (pag. 95 a 123). Barcelona.

RETAMOZO, M. (2009b). Las Demandas Sociales y el Estudio de los Movimientos Sociales. Cinta de Moebio 35:110-127.Santiago de Chile www.moebio.uchile.cl/35/retamozo.html SIRVENT, M. T. (2007). "La educación de jóvenes y adultos frente al desafío de los movimientos sociales emergentes en Argentina". Revista Argentina de Sociología. Vol 5 № 8, Buenos Aires. 
TENTI FANFANI, E. (2011). La escuela y la cuestión social. Ensayos de sociología de la educación. Siglo XXI, Buenos Aires.

TIRAMONTI, G. y ZIEGLER, M. (2008). La educación de las elites. Aspiraciones, estrategias y oportunidades. Paidós, Buenos Aires. 


\section{Conclusiones}

La escritura de las conclusiones aparece como una imposición del formato académico para dar un cierre, para presentar una síntesis de los desarrollos y exposiciones con que ya han sido tamizadas por la percepción de la autora, las prácticas desarrolladas por otros.

Con el propósito de, finalmente, concluir en unos aportes para seguir pensando los desafíos que la construcción de los jóvenes como sujetos políticos presenta al campo educativo, elegimos mirar y narrar las tres categorías consideradas principales para pensar en la construcción de ciudadanía de los jóvenes en la escuela secundaria, desde los ejes analíticos que señalan los elementos del curriculum escolar. Luego, remitiremos ese análisis a la dinámica de funcionamiento relacional entre los tres campos en estudio: el campo social, el campo político y el campo educativo.

Bajo esa lógica, las prácticas de convivencia, participación y demanda desarrolladas por los jóvenes podrán mostrar su complejidad, su construcción histórica y su abanico de posibilidades atendiendo a la síntesis de elementos culturales a las que remite la idea de curriculum, a la propuesta político-educativa actual, a los aspectos estructurales-formales y procesuales-prácticos que encontramos en un curriculum y a los sujetos del desarrollo curricular, o de las prácticas.

Denominaremos recapitulaciones a cada una de las presentaciones finales pues trataremos de exponer de forma resumida y ordenada, asuntos que ya han sido abordados de forma más extensa.

\subsection{Primera recapitulación: en la convivencia escolar, los jóvenes redefinen la idea de lo común, lo legítimo y lo público}

En los primeros capítulos de este trabajo hemos señalado, siguiendo a Castoriadis, la existencia de un orden social dinámico y contingente. 
Hemos diferenciado, también, la democracia formal (a la que asociamos con la ciudadanía de baja intensidad) de la democracia participativa; esto es, aquella que se construye mediante la acción del sujeto político y que requiere de ciudadanos políticos activos, participativos. Sostuvimos que la escuela y el sistema educativo están ligados, en su formato, a formas políticas vinculadas a la democracia representativa, de lo que puede inferirse que la crisis actual de la escuela para formar sujetos políticos puede rastrearse en la crisis de la democracia.

Los cambios en las funciones de las instituciones educativas impulsadas por los organismos que sostienen la hegemonía neoliberal a través de su impacto en los diseños curriculares y la red de relaciones en la que se sostiene la nueva cuestión social, adquiere, como se ha expuesto en el Capítulo IV, características diferenciales en cada escuela en relación a la forma de organizar la convivencia, la vida en común.

Los modos de convivencia que practican los jóvenes en las escuelas tienen diferentes características que apuntan a procesos de construcción de una ciudadanía que se construye como producto de las diferentes trayectorias que recorren los sujetos.

Las cinco configuraciones escolares que componen la muestra son producto de procesos socio-históricos que imprimieron sus huellas, y sobre ellas, ensayan hoy formas conservadoras, novedosas y/o alternativas de convivir en la escuela. Las lentas transformaciones de las escuelas -como configuraciones sociales- las mantienen aferradas a un discurso (moderno) que ya no las representa, que se desenhebra día tras día, pero que les continúa ofreciendo pautas de acción a la vez que, atravesadas por la realidad, van produciendo tibios indicios de la escuela porvenir.

La política educativa expresa -sin lograr imponer- una forma de convivencia escolar mediada por el entendimiento entre adultos y jóvenes que no penetra en los estilos escolares relevados. Posiblemente, las acciones formativas y contextuales para fortalecer a los docentes en una nueva perspectiva no estén orientando la acción en el sentido que se enuncia. Los adultos representantes del sistema también son sujetos sociales mediados por la lógica de estos tiempos y los jóvenes provienen de configuraciones familiares que no 
responden a la secuencia institucional que entregaba a la escuela un "alumno" dispuesto a aprender.

En la práctica procesual del curriculum escolar hemos encontrado dos tipos de situaciones escolares en relación a los ejes conceptuales seleccionados para abordar la cuestión de la convivencia y la construcción del orden social: a) escuelas donde los jóvenes son respetados como sujetos sociales -sujetos de derecho- y en consecuencia, son interpelados $y$ fortalecidos en sus prácticas; b) escuelas en las que los jóvenes son considerados sujetos en moratoria social ( $y$, por lo tanto, subordinados)(b1) o en las que directamente se los considera "parias" del sistema, en el sentido en que se refiere Bauman (2005: 16): "residuos humanos o seres humanos residuales" (b2).

En el primer tipo de situaciones (a) el conocimiento cumple papel fundamental: algunos jóvenes lo disponen desde sus posiciones sociales y en la escuela lo profundizan y amplían; otros lo "intuyen" y lo reclaman. En la escuela dependiente de la universidad y en la escuela privada, la mayoría de los jóvenes con el apoyo de su familia -que eligió las escuelas donde mandar a sus hijos- debaten y discuten posiciones frente a los conflictos, en un clima escolar que genera el espacio para el debate en un clima de confianza. En la escuela dependiente de la universidad, que es pública, el valor del conocimiento -ligado a la posición de clase que acompaña a las profesiones que detentan mayoritariamente los padres y madres- se torna aun sin pretenderlo- también elitista ${ }^{231}$.

En la escuela privada confesional los derechos reconocidos a los jóvenes se ligan -un poco más- a la condición de "clientes" de la escuela, pero ya sea por esa razón o por las inquietudes propias de su condición de jóvenes, disputan espacios sociales donde son reconocidos como sujetos de derecho para construir criterios de convivencia.

En la escuela rural, en cambio, son los propios jóvenes acompañados por algunos docentes, quienes construyen la dinámica fundante de la convivencia en la escuela secundaria. El equipo de gestión está ausente, en consecuencia, el trabajo comprometido de un grupo de

\footnotetext{
${ }^{231}$ Por reglamento, los estudiantes no pueden llevar materias "previas". Los jóvenes que ingresan con una escolaridad primaria deficitaria y con escaso acompañamiento familiar, tienen que cambiarse de escuela.
} 
profesores pone a disposición de los jóvenes conocimientos que cambian y potencian su accionar como sujetos políticos: se trata de conocimientos en torno de los derechos de los niños y jóvenes, acompañados de prácticas sobre cómo "ser usados", atendiendo al bien común.

En el segundo tipo de escuela (b) los jóvenes de la escuela secundaria centenaria (b1) pujan por hacer oír su voz y aprenden los modos de tensionar la soga sin que se corte ${ }^{232}$. Reclaman la formulación conjunta de reglas que se cumplan, porque las vigentes privilegian la acción de los docentes y las construidas en el marco de los proyectos AIC no son respetadas, precisamente, por los adultos.

En la escuela suburbana (b2) el desencuentro entre los agentes escolares y los jóvenes, como legado de las prácticas relacionales construidas durante la EGB 3, no ha sido fisurado. El mandato de inclusión "a como dé lugar" se hace equivalente al encierro, a la clausura y los jóvenes ensayan diversas formas de resistencia o preparan la huida.

El primer grupo refuerza y aprende en la escuela a forjar identidades ciudadanas que pueden disputar un orden, amparados en su posición de ciudadanos patrimonialistas (Svampa, citado en el Capítulo II) o en su posición de ciudadanos críticos, capaces de sostener tales posiciones con sus argumentos y de generar propuestas.

En el segundo grupo predomina el resentimiento y la desconfianza hacia el accionar de la escuela a través de los agentes que la representan. La fuerza de la cultura construida históricamente aferrada a estilos autoritarios (ya sea a través de una imposición consentida por las familias, como en la escuela centenaria, o por la imposición y reproducción de la desigualdad generada desde el Estado, como en la escuela suburbana), genera retracción en los jóvenes. En los sectores suburbanos pobres impera una lógica propia de la cultura barrial que la escuela no comprende. Este aspecto no es privativo de los actuales escenarios. Basta una inmersión en las historias escolares para comprender las reglas del presente.

\footnotetext{
${ }^{232}$ Referencia a la metáfora de la elasticidad de las configuraciones sociales, descripta por Elías en La sociedad cortesana, donde asimila la elasticidad de las configuraciones a los cambios con la elasticidad de la soga que sujeta un barco a un muelle)
} 
Los espacios curriculares específicos como la materia Construcción de Ciudadanía (y sus equivalentes en la escuela universitaria) siguen los estilos que impone el desarrollo curricular -mediado por la cultura escolar- en cada escuela, pero continua siendo la evaluación el mayor elemento disciplinador encontrado como modo de organizar la vida en común.

Como expresan y reclaman los jóvenes, la vida en común escolar requiere de orden y de vínculos. Esto no significa eludir los conflictos, pues su negación conduce, como ha sido expuesto, a la violencia y en esa situación, la ley que domina ese escenario, es "la ley del más fuerte". Sin ley solo encontramos en las escuelas -y en la sociedad-inseguridad y temor.

En la sociedad moderna la familia y la escuela educaron para la vida social común, donde lo social -que no era ni privado ni público- construyó al sujeto político (al ciudadano). Esto requirió de leyes que se aprendieron precisamente, en esa "zona no explícita" del curriculum escolar. Las escuelas singulares, algunas solitarias y autogestivas, no están logrando elaborar, entre adultos y jóvenes, reglas que favorezcan la convivencia.

Los jóvenes en la escuela redefinen el sentido de lo común limitándolo a los de su tipo, clase o sector social de pertenencia. Este modo restringido de reconocer al otro, ligado a la desconfianza que genera la interacción en espacios desconocidos, restringe el alcance de "lo público".

Vinculado también al espacio público y las actuaciones en él, se encuentra la cuestión del sujeto libre, del sujeto de derecho. Esta, quizá, es una de las aristas más peligrosas (por lo ambiguo y solapado del discurso dominante) que hoy presenta la perspectiva de derecho que subyace a una serie de posicionamientos tomados desde la política educativa que parecen devolver los derechos conculcados a los grupos sociales excluidos, pero que en el fondo, sin garantizar otros derechos esenciales y sin profundizar en el alcance de los mismos, corren el riesgo de afianzar un individualismo que construye ciudadanías restringidas.

El individualismo y la subjetivación (en algunos casos extrema) que caracteriza las relaciones sociales contemporáneas en la escuela secundaria, ponen en jaque a las prácticas de construcción de lo común propias del espacio público moderno. ¿Es que la disolución de lo 
social como común y referente de derechos igualitarios nos retrotrae a períodos premodernos, donde la vida privada y la vida pública -política, como ejercicio de poder-podía prescindir de la dimensión social?

Difícilmente una escuela que no logra intervenir para sostener ideales de igualdad y de justicia que regulen la convivencia social pueda contribuir al fortalecimiento de la democracia, siendo ambos ideales condiciones radicales de funcionamiento democrático, como expresamos en la Introducción.

\subsection{Segunda recapitulación: ¿participación política en la escuela o simplemente, participación social?}

Al momento de realizar un análisis de las características que asume la participación política estudiantil en la escuela secundaria, se destaca una realidad que pone de manifiesto las dificultades de las instituciones tradicionales para formar a los jóvenes como sujetos políticos.

La participación política de los jóvenes en los distintos ámbitos que establece la escuela - o que le impone la noosfera que rodea a la escuela, como en el caso de los CDE-, se produce apelando a la voluntad de los jóvenes o sin ella, del mismo modo que sucede en las prácticas políticas adultas al momento de participar de elecciones de gobernantes. Desde las escuelas -con excepción de la escuela dependiente de la universidad- no se registraron acciones formativas ante la inminencia de elecciones de $\mathrm{CE}$, ni se pretendió conmover a los demás jóvenes por parte de los integrantes de las listas que se dirimían los Centros de Estudiantes. Solo les pidieron su voto.

Una agrupación de la escuela universitaria desplegó estrategias pensadas y articuladas, persiguiendo el mismo fin instrumental y dependiendo de la tendencia que le imprimió el partido político en el que militan la mayor parte de los jóvenes, por sobre los intereses que pudieran expresar sus compañeros. Esta estrategia, eficaz para alcanzar el objetivo inicial, quedó encapsulada en la lógica instrumental y no pudo salir de ella para interpretar las expectativas de los demás jóvenes (la referencia es a los jóvenes sin militancia, no los que "perdieron" ante esa agrupación). 
Como reacción, la participación se mostró voluntaria y entusiasta cuando se trató de causas que desbordan los canales formales. Los jóvenes opositores manifestaron que son capaces de recoger voluntades al momento de decir "así-no". Pero claramente, no pudieron luego sostener las tareas específicas que la organización -la estructura- les demandó. Al poco tiempo, el CE estaba acéfalo y los "votantes" de esa causa olvidaron sus compromisos iniciales y comenzaron a efectuar reclamos a quienes integraban la comisión directiva, quienes a su vez no sentían, tampoco, vocación para ejercer de esa práctica política.

Algo similar sucedió con los jóvenes de la escuela rural. Una vez lograda la gestión del CE, la euforia inicial fue desvaneciéndose puesto que, a la vez que el objetivo que perseguían -la apertura de los años superiores de la escolaridad secundaria- se lograba, siguieron funcionando como grupo de amigos, de manera paralela a la existencia del CE que ya no les aportaban reales espacios de debate político.

En la escuela privada, luego de la primera experiencia fue necesario mucho esfuerzo desde el equipo directivo para lograr que los estudiantes participaran de una lista y se constituyera formalmente el CE que exige la reglamentación actual. Podemos suponer que los jóvenes no sentían necesidad de su existencia.

Solo en la escuela centenaria algunos jóvenes ponen en marcha prácticas participativas con intención de cambiar los circuitos de poder -aunque sea por el tiempo que a ellos les demanda su acción-, pero por fuera de los canales formales. Ese modus operandi por parte de los estudiantes se registra a lo largo de la investigación en diferentes situaciones (protagonizadas por estudiantes de los años superiores), donde el común denominador parece ser la rigidez de la cultura escolar que no parece generar espacios para incorporar la voz de los jóvenes; $y$, por otro lado, cierto aprendizaje por parte de los jóvenes sobre cómo desenvolverse en cada caso y ante los diferentes agentes del sistema escolar y social más amplio.

En dos de las tres escuelas urbanas en estudio, la expresión participativa de los jóvenes enarbolando algún reclamo que implique disputas con el orden oficial, es tratado como "susceptible de eliminar y cancelar" lo más rápidamente posible por parte de las autoridades 
o adultos intervinientes. No se visualiza el conflicto como parte constitutiva de la dinámica sociopolítica y, en ese caso, quedaría eliminada la posibilidad de construcción política.

La "desdramatización" (Reguillo Cruz, 2004) de la participación juvenil por parte de los adultos responsables en la escuela, da cuenta de las dificultades que enfrenta la democratización de las relaciones, pues en tanto se incentivan prácticas en los jóvenes (que se esperan formales y sin sobresaltos) luego se tiende a "evitar" el conflicto y, así, los adultos continúan ejerciendo el poder sin generar espacios para los jóvenes interesados en disputarlo.

Si bien la participación política de los jóvenes de la escuela centenaria es diferente a la de los estudiantes de la ESB suburbana (en tanto los primeros logran un grado de organización colectiva -aunque fugaz- persiguiendo un objetivo), las situaciones relevadas tienen en común la carencia de interlocutores adultos con quienes construir nuevas relaciones y situaciones y sus logros se reducen a obtener beneficios coyunturales.

La sociabilidad de los jóvenes que concurren a las tres escuelas que atienden sectores medios, se fortalece en la escuela como lugar en el que establecen acuerdos para actividades extraescolares que los consolidan como grupos. Esta potencia social de los jóvenes no es captada por las prácticas escolares para potenciar ciudadanías participativas, puesto que la escuela parecería no poder trascender su mandato y formato relacional tradicional.

La escuela es un ámbito social que, en la medida que reproduce la sociedad a través de mecanismos de control más o menos explícitos, habilita o coerciona los modos de emergencia de lo político. Y aunque lo social -que para la teoría posfundacional- es la base sedimentada que antecede a lo político, la sociabilidad que se produce en la escuela no genera aún prácticas políticas por parte de los jóvenes.

Uno de los supuestos es que la escuela no trabaja para des-naturalizar la realidad social, para cuestionar la estructura que preexiste al sujeto, sino que se la aborda como a una construcción de la que todos los actores sociales son parte. 
Cuestionar y problematizar la construcción social de la realidad por parte de los sujetos inmersos en ella podría conducir a un análisis y debate sobre dos planos vinculados a la democratización de la escuela secundaria: por un lado, en relación al reconocimiento de los jóvenes como sujetos de derecho; $y$, por otro, sobre la posibilidad de la democratización de la cultura de las escuelas singulares. Reconocer a los jóvenes como sujetos de derecho implicaría pasar del reconocimiento en el plano del discurso al reconocimiento práctico de las posibilidades de los jóvenes de participar, como se establece desde la política educativa vigente, del gobierno escolar.

Problematizar las posibilidades de las culturas escolares, abriría profundos debates sin los cuales, las decisiones de la política solo se "emparchan" a las prácticas existentes.

$\mathrm{Si}$ bien existen varios cuestionamientos respecto de la democratización del acceso a la educación secundaria (la asignación del presupuesto, las inversiones en infraestructura, capacitación de docentes, las condiciones de los jóvenes estudiantes, entre otras), parecería ser la tradición o la cultura escolar quienes se constituyen en los principales obstáculos para una democratización en el plano político. O bien, que los agentes del sistema descreen de los discursos de la política educativa, quizá porque los discursos del presente parecen estar montados sobre estrategias de política partidaria y no como una política de Estado.

A pesar de todo ello, los jóvenes ensayan estrategias participativas y políticas, pero las estructuras escolares parecen ser más eficaces. Mientras los jóvenes se desencantan una y otra vez, las decisiones sobre su presente y su futuro, continúan tomándose sin su participación: no por negligencia juvenil, sino porque el contexto funciona para que ocurra de esa forma.

\subsection{Tercera recapitulación: la constitución de los jóvenes como sujetos políticos}

Las tensiones entre intereses juveniles y propuestas escolares adquieren distintas expresiones en las diferentes escuelas donde se desarrolló la investigación. 
Señalamos que no todos los conflictos y reclamos que se produjeron al interior de las escuelas durante el tiempo de permanencia en el campo, se constituyeron en demandas: se registraron acciones estudiantiles que desafiaron el orden establecido y otras, que fueron reabsorbidas y/o reorientadas de distintos modos por la cultura escolar.

En el primer caso, produjeron rupturas que persisten en el tiempo, permaneciendo como una hendidura que dificulta el tránsito de algunos jóvenes por la escuela y entonces quedan atrapados en la falla del sistema social escolar, no encontrándose, desde ninguno de los dos sectores en conflicto, posibilidades de sutura.

En otras, la mediación institucional modificó sus formatos habituales a efectos de que "nada" se salga de su cauce. En la muestra, las escuelas de mayor antigüedad son capaces de desplegar estrategias que a través de la seducción, persuasión o el uso de la fuerza, disuelven los reclamos estudiantiles antes de que avancen en la constitución de demandas.

Es interesante comparar cómo, ante situaciones similares que se producen en la escuela pública centenaria, en la escuela privada confesional y en la escuela secundaria dependiente de la universidad, los jóvenes y las instituciones resuelven los conflictos.

Retomaremos uno de los aspectos centrales de la demanda, el hecho de que pone en funcionamiento situaciones subjetivas que permiten el pasaje de la subjetividad al sujeto, dado que, como se expresó en el Capítulo 6, la demanda favorece el reconocimiento de sí mismo y de los demás sujetos comprometidos, es decir, que puede permitir a los jóvenes reconocer-se como sujetos políticos ${ }^{233}$. Entonces, ¿qué impacto tienen sus prácticas políticas escolares en la constitución subjetiva como sujetos políticos?

En relación a los jóvenes de la escuela dependiente de la universidad, ésta constituye un espacio de meditado cuidado, especies de "jaulas doradas". Los jóvenes construyen una percepción de sí mismos como "especiales", en el sentido de los cuidados que reciben. Las posibilidades de comunicación directa con las autoridades, profesores, especialistas, como

\footnotetext{
${ }^{233}$ Como se ha expresa con anterioridad, no son el foco de este análisis los logros que los jóvenes instalan en el espacio público, ni en el orden que intentan cambiar, sino qué construyen interiormente ellos siendo parte activa del proceso.
} 
también el conocimiento de las reglas de juego, les producen una sensación de libertad y pertenencia institucional. Los jóvenes entrevistados no piensan en cambiar de escuela, sienten que en ella pueden desplegar sus intereses y completar una formación que les asegure un tránsito hacia la universidad sin altibajos.

La participación política por parte de los jóvenes estudiantes adquiere distintos significados que no se articulan entre sí: por un lado, están los jóvenes que expresan su militancia partidaria y pretenden ejercerla en la escuela; por otro, los jóvenes que despreciando la política partidaria, pretenden autogestionar sus necesidades, encerrando la política en el círculo de sus deseos y necesidades inmediatas.

En ninguno de los dos grupos parecieran producirse procesos reflexivos colectivos sobre sus prácticas, que trasciendan las situaciones concretas en las que se ven involucrados, que manifiesten algún tipo de perdurabilidad en el tiempo y en sus conciencias. Sí se observa, en cambio, una construcción subjetiva de autovaloración y sagacidad que les permite analizar las situaciones, medir sus deseos y planificar la acción, en el plano individual.

En la escuela privada confesional la sobreprotección ejercida desde los adultos, dificulta que se constituya en los jóvenes un reconocimiento de sí mismos como sujetos políticos: no hay necesidades ni deseos que no se puedan satisfacer. Tampoco encuentran fallas en el sistema escolar, que construye un orden interno similar al familiar. Subyace a las prácticas adultas la idea de moratoria política (asociando la política con el sentido tradicional). La dimensión política tradicional no se menciona ni se visualiza como necesaria: resuelven las situaciones conflictivas cara a cara, de manera individual.

En la escuela centenaria, si bien opera también una moratoria política para los jóvenes de ESB, la rigidez y el discurso autoritario adulto exacerban las posibilidades de emergencia de conflictos que conduzcan a demandas o rupturas en el orden social escolar. Los jóvenes acumulan una fuerza interior reprimida que -variando según las historias personalespodrán estallar o ser canalizadas por otros medios, buscando las alternativas por fuera del ámbito escolar. 
La presión que la tradición escolar y la autoridad adulta ejercen sobre los jóvenes, la rigidez de las relaciones, son generadores de pugnas y conflictos que amenazan de forma permanente el orden escolar. Aun cuando los reclamos y conflictos son cotidianos, la dinámica escolar conserva la posibilidad de cancelación o absorción de las demandas. Dos factores parecieran contribuir a esta situación: el sostenimiento familiar de las decisiones de la autoridad escolar y, por el lado de los jóvenes, el reconocimiento de la escuela pública en su calidad educativa que les garantiza el tránsito hacia los estudios terciarios o a la continuidad laboral en empresas familiares u otros puestos de trabajo. Los jóvenes discuten las normas escolares, pero no están dispuestos a producir rupturas que, finalmente, los expulsen.

En los dos últimos casos presentados, las prácticas juveniles están mediadas por los adultos: en el primero, reemplazando la figura de autoridad institucional por una figura maternal que los protege y los cuida; en el segundo, la autoridad institucional diluye las posibilidades de disputa de modo más autoritario, en la búsqueda de armonía.

La principal diferencia reside en las prácticas políticas tradicionales: por la idiosincrasia de origen de la primera escuela (la Universidad), son impulsadas por profesores y legitimadas y alentadas- también por algunos padres. Hay un margen estrecho para las demandas juveniles puesto que las necesidades no llegan a constituirse en carencias.

En las tres escuelas presentadas los jóvenes disponen de un capital cultural (Bourdieu, 1998) que les permite conocer no solo las reglas internas del juego, sino también disponer de cierto conocimiento general que favorece una eventual lectura del contexto ${ }^{234}$.

Los jóvenes de los sectores populares ubicados en la escuela suburbana y en la escuela rural, construyen subjetividades políticas diferenciales entre sí y también diferentes a las ya señaladas.

\footnotetext{
${ }^{234}$ Cabe señalar aquí que no es siempre la escuela la que produce o promueve estas lecturas, sino que es más bien la dinámica familiar la que favorece las articulaciones mentales necesarias para articular el conocimiento disciplinar con los sucesos de la realidad.
} 
En el caso de los reclamos protagonizados por los jóvenes de la escuela rural, es necesario profundizar en las condiciones socio-históricas que posibilitaron su accionar. Existe tras de ellos una historia anidada en sus trayectorias que los impulsa a la demanda y una fuerza instituyente del conocimiento del que efectivamente disponen a partir de prácticas curriculares, que se articulan para sostener la acción.

El conocimiento apropiado en los espacios educativos respecto de los Derechos de los Niños y Jóvenes, respecto de la historia reciente y de los procesos democráticos y sus interrupciones, de las leyes y reglamentos que garantizan en el discurso tales derechos, se constituyeron en herramientas clave para el accionar de los jóvenes.

La participación en las acciones relatadas, nos muestra cómo los jóvenes construyen una identidad que los fortalece, que les permite marcar una posición diferencial en la escuela (que los "fusiona") y en los contextos sociales por los que transitan.

El proceso de constitución de la demanda que llevó al menos dos años de elaboración, dejó en los jóvenes huellas significativas. Todos están finalizando su escolaridad secundaria ${ }^{235}$. Se reconoce en esta situación, la construcción de una subjetividad política que traspone, en primer término, el umbral entre la individualidad y lo colectivo. La demanda fortaleció al grupo y dejó una herencia que los trasciende, como sus antecesores.

En la escuela secundaria suburbana, las situaciones relevadas tienden a evidenciar la situación de desamparo de los sujetos individualizados (Svampa 2000; Robles, 1999) y las

\footnotetext{
${ }^{235}$ En los años subsiguientes, Johana (ESB rural) continuo el nivel secundario en una escuela pública (justamente, en la escuela centenaria que integra la muestra de esta investigación)y se desempeñó durante 4 y 5o años como delegada ante el CE de un curso de 35 estudiantes, siendo respetada y reelegida en el cargo, por sus compañeros.

Brian (ESB rural) también seguía adelante con su plan cursando la escuela secundaria en la ciudad de Bahía Blanca, donde reside gran parte de su familia.

Telmo, Mayra, Luis, Esteban (estudiantes de la ESB rural) cursan el nivel secundario en el campo, tal cual fue el proyecto original del grupo y no piensan seguir estudios superiores. Llevan adelante diferentes emprendimientos productivos, en los que incluyen a los estudiantes de primaria y a otros jóvenes egresados con anterioridad al año 2007.
} 
soluciones coyunturales y fragmentadas. El volumen de capital cultural (u otro) disponible no les facilita la lectura del contexto para poder articular con él sus tácticas y estrategias, pero pareciera ser éste el factor de mayor incidencia en el sostenimiento de la protesta.

La cuestión que aparece como la de mayor obstaculización para visualizarse como sujetos políticos (en primera instancia) y luego como sujetos sociales colectivos, es la ruptura de los lazos sociales, aquella solidaridad de clase que les permitiera a las clases populares, sus mayores conquistas (Svampa, 2005). La desconfianza entre los sujetos, pero principalmente hacia los adultos, se acrecienta en la escuela. Ellos aprenden que la escuela los "marca" en el sentido de "iniciarles causa": no se refieren a una causa judicial, pero sí a un estigma que los acompañará toda su vida.

Subjetivamente, aprendieron que la escuela es un espacio social para revelarse, que pueden interrumpir una dinámica -que les era desfavorable, en el caso relatado-, pero también pueden interrumpir otros procesos "porque sí". La protesta les dio visibilidad y reforzaron un lugar que estaban construyendo: el del otro como peligroso, no dócil ni obediente.

\section{Reflexiones finales}

Retomando la pregunta directriz y los objetivos -general y específicos- de esta investigación (Capítulo 1, p. 52), las prácticas de convivencia, participación y demanda generadas en la escuela (o posibles en la escuela) no parecen estar contribuyendo, por sí mismas, a la construcción de una ciudadanía activa y colectiva, tal como la que los tiempos actuales y la construcción de una democracia participativa, requieren.

Por el contrario, más bien pareciera que la fragmentación social que evidencian las prácticas relevadas y las marcas subjetivas que generan, conducen a delinear un escenario social y político, entre los jóvenes, cada vez más distanciado y desigual. La ciudadanía, respondería así a la condición de clase con dificultades para visualizar al otro, al diferente, como un sujeto social de derecho con capacidad de construcción colectiva, desde las diferencias. Las prácticas de distanciamiento y diferenciación atraviesan a los distintos sectores sociales que integran los jóvenes con quienes se ha trabajado. 
Las prácticas ciudadanas que dan cuenta de una intención de disputa por el poder son fugaces y restringidas a situaciones eventuales. La política en la escuela parece redefinirse hacia nuevas/otras significaciones que la alejan del sentido que remite al mundo común y al espacio público al que remiten los circuitos formales.

Los jóvenes han dado cuenta de que tienen una potencialidad política que la escuela parece encargada de abortar. Parece entonces que si los adultos formadores lograran captar esa fuerza que moviliza a los jóvenes y que motiva su participación, sería posible aún educar en ciudadanía. Pero esta actitud requiere, por parte de algunos adultos, abandonar una actitud mecánica ante la formación ciudadana y comprometerse con la construcción del futuro, en tiempo presente.

Quizá la debilidad de la formación en ciudadanía no resida en las particularidades que caracterizan a los jóvenes en los escenarios contemporáneos sino, más bien, a la ciudadanía restringida y de baja intensidad que los adultos exhibimos como modelo, en una coexistencia de "lo viejo" con "lo nuevo" que está emergiendo.

En otro plano de análisis, se considera que la nueva LEN incluye a los jóvenes en las escuelas pero no se han activado aún, en algunos casos, los mecanismos para democratizar las relaciones sociales, el acceso al conocimiento y a la formación de sujetos políticos, con lo cual se agudiza la reproducción de la fragmentación social. Todo parecería indicar que en la nueva escuela secundaria, los "recién llegados", los que no cuentan con antecedentes familiares de escolarización completa en el nivel primario o acceso al secundario, los que encuentran dificultades para permanecer bajo las condiciones escolares, es decir, sobre los que recaen con más fuerza las estructuras del sistema social, están siendo sometidos, con las mejores intenciones, a la reproducción de su propia exclusión de los bienes culturales y de su construcción como sujeto político, que puede brindar la escuela.

Si esta situación persiste sin que los responsables técnico-políticos a nivel local (país) adviertan sobre los efectos nocivos que se producen en la vida cotidiana escolar, es posible que nos encontremos ante una situación como la que describe Gentili (2000), respecto de una segregación incluyente. Esto es: 
“...atribuir un status especial a determinada clase de individuos, los cuales no son ni exterminados físicamente ni recluidos en instituciones especiales. (...) Esta forma de exclusión significa aceptar que determinados individuos están dotados de las condiciones para vivir con los incluidos, solo que en una condición inferiorizada, subalterna, desjerarquizada. Son sub-ciudadanos, los que participan de la vida social sin los derechos de aquellos que sí poseen las cualidades necesarias para una vivencia activa y plena de los asuntos de la comunidad" (Gentili 2000:23).

Como síntesis final, formularemos una nueva pregunta, que consideramos crucial para la acción desde la escuela: ¿qué relevancia tiene el conocimiento en este juego entre lo social y lo político?

Esta pregunta puede responderse considerando dos dimensiones sobre las que inciden las escuelas: una, atendiendo a la política, es decir, a la estructura de la burocracia política (Bourdieu, 2001), sobre la que se establecen unos contenidos formales y ubicados en circuitos diferenciados de las relaciones pedagógicas, donde parecieran recaer los esfuerzos del curriculum prescripto en los sectores sociales acomodados. $\mathrm{Y}$ otro, atendiendo a lo político, requiere de considerar, por un lado, que el conocimiento disciplinar resulta crucial para que los jóvenes puedan interpelar las relaciones sociales y ejercer así una acción política, privilegiando nuevamente a los sectores sociales que encuentran en la escuela una herramienta para mantener y mejorar sus expectativas de clase. En este sentido la construcción y sostenimiento de estrategias políticas por parte de los jóvenes, se han observado nutridas en la disposición de conocimiento, además de la lectura de sus posiciones en el campo social.

Atendiendo a la dinámica de los campos social, político y educativo, sostenemos que si el conocimiento (como bien social y cultural) que trasmite la escuela no es asegurado como un derecho por encima de los intereses que sobre él tiene el mercado (inscripto en el campo social), la política permanecerá sujeta (o subsumida) a los vaivenes de los intereses económicos.

Con ello estamos sosteniendo que en los actuales escenarios donde las políticas neoliberales parecen producir una apertura hacia el mejoramiento de los destinos sociales y políticos de los países a través de una política (discursiva) de derechos, ésta no logrará consolidarse 
mientras los sujetos estén subordinados a los requerimientos -y las consecuentes corrosiones del carácter y de la ética- que impone el sector económico.

Podemos concluir expresando que continúan vigentes nuestras expectativas depositadas en la escuela respecto de las posibilidades de contribuir a la conformación de sujetos políticos activos y críticos. Como hemos dicho, la sanción de la LEN es reciente (considerando los tiempos de la historia) y pueden realizarse aún reorientaciones profundas y necesarias en diferentes planos de la gestión educativa, mientras se atienden de forma conjunta y articulada los problemas económicos, sociales y políticos "de fondo" y sus implicancias pedagógicas.

Finalmente, se espera que las revelaciones en pequeña escala que esta investigación ha producido puedan convertirse en indicios para orientar nuevos debates y reflexiones sobre los riesgos de reproducción de la exclusión. 
Referencias bibliográficas utilizadas en las conclusiones:

BAUMAN, Z. (2005): Vidas desperdiciadas. La modernidad y sus parias. Paidós, Buenos Aires.

BOURDIEU, P. (2001). El campo político. Plural Editores. Bolivia.

GENTILI, P. (2000). Códigos para la ciudadanía. La formación ética como práctica dela

libertad. Santillana, Buenos Aires

REGUILLO CRUZ, R. (2004). "La performatividad de las culturas juveniles". Revista Estudios de juventud № 64/04 pp: 49-56. Guadalajara

SVAMPA, M. (2005). La sociedad excluyente. La Argentina bajo el signo del neoliberalismo. Taurus, Buenos Aires. 